
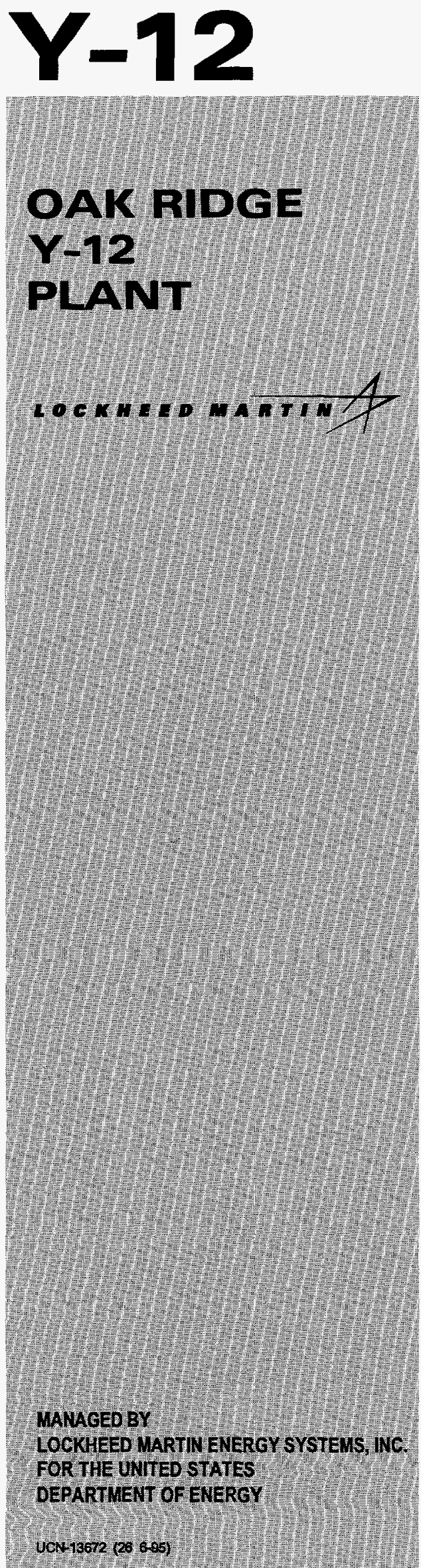

\section{RESOURCE CONSERVATION AND RECOVERY ACT (RCRA) CLOSURE SUMMARY FOR THE URANIUM TREATMENT UNIT}

May 1996

$$
\text { DEC } 20 \mathrm{WH}
$$

$$
\text { OSt }
$$

\begin{abstract}
Environmental Management Department
Health, Safety, Environment, and Accountability Organization

Enriched Uranium Operations

Organization
\end{abstract}

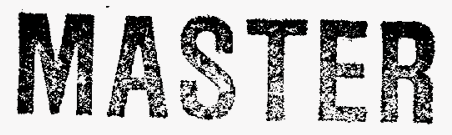

Prepared by

Oak Ridge Y-12 Plant

Oak Ridge, Tennessee 37831

Managed by

LOCKHEED MARTIN ENERGY SYSTEMS, INC. for the

U.S. DEPARTMENT OF ENERGY

UNDER CONTRACT DE0AC05-840R21400 


\section{DISCLAIMER}

This report was prepared as an account of work sponsored by an agency of the United States Government. Neither the United States Government nor any agency thereof, nor any of their employees, makes any warranty, express or implied, or assumes any legal liability or responsibility for the accuracy, completeness, or usefulness of any information, apparatus, product, or process disclosed, or represents that its use would not infringe privately owned rights. Reference herein to any specific commercial product, process, or service by trade name, trademark, manufacturer, or otherwise, does not necessarily constitute or imply its endarsement, recommendation, or favoring by the United States Government or any agency thereof. The views and opinions of authors expressed herein do not necessarily state or reflect those of the United States Government or any agency thereof. 
Y/TS-1486

\title{
RESOURCE CONSERVATION AND RECOVERY ACT (RCRA) CLOSURE SUMMARY FOR THE URANIUM TREATMENT UNIT
}

May 1996

Environmental Management Department

Health, Safety, Environment, and Accountability Organization

Enriched Uranium Operations

Organization

\author{
Prepared by \\ Oak Ridge Y-12 Plant \\ Oak Ridge, Tennessee 37831 \\ Managed by \\ LOCKHEED MARTIN ENERGY SYSTEMS, INC. \\ for the \\ U.S. DEPARTMENT OF ENERGY \\ UNDER CONTRACT DEOAC05-840R21400
}




\section{DISCLAMMER}

Portions of this document may be illegible in electronic image products. Images are produced from the best available original document. 
Y/TS-1486

\section{RESOURCE CONSERVATION AND RECOVERY ACT (RCRA) CLOSURE SUMMARY FOR THE URANIUM TREATMENT UNIT}

Environmental Management Department

Health, Safety, Environment, and Accountability Organization

Enriched Uranium Operations Organization

Date Published--May 1996

Prepared by

Oak Ridge Y-12 Plant

Oak Ridge, Tennessee 37831-8169

Managed by

LOCKHEED MARTIN ENERGY SYSTEMS, INC.

for the

U.S. DEPARTMENT OF ENERGY

under contract DE-AC05-84OR21400 



\section{CONTENTS}

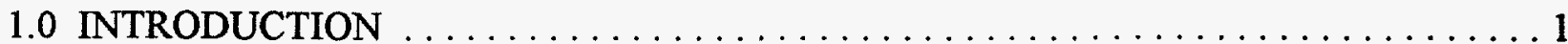

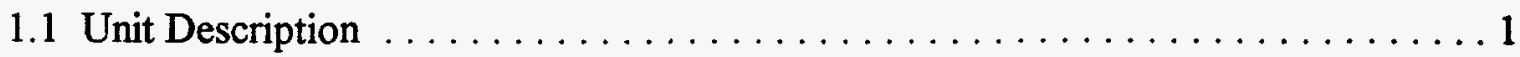

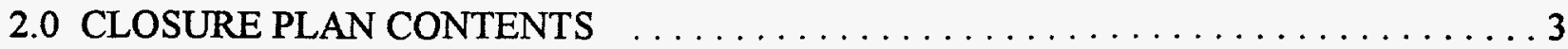

3.0 CLOSURE PERFORMANCE STANDARD $\ldots \ldots \ldots \ldots \ldots \ldots \ldots \ldots \ldots \ldots \ldots$

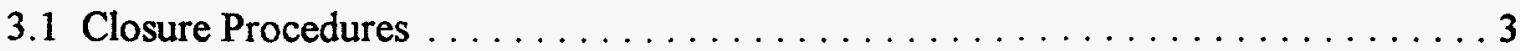

3.2 Partial Closure and Final Closure Activities $\ldots \ldots \ldots \ldots \ldots \ldots \ldots \ldots \ldots$

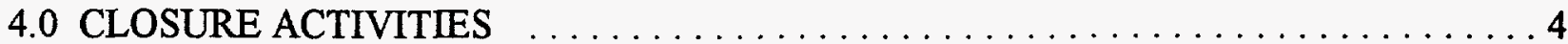

5.0 VERIFICATION OF DECONTAMINATION $\ldots \ldots \ldots \ldots \ldots \ldots \ldots \ldots \ldots$

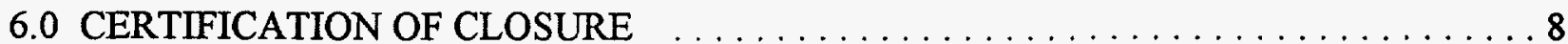

7.0 MAXIMUM WASTE INVENTORY $\ldots \ldots \ldots \ldots \ldots \ldots \ldots \ldots \ldots \ldots \ldots$

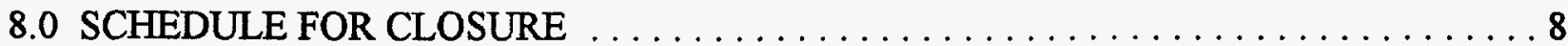

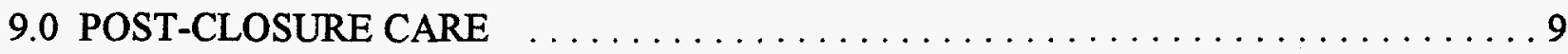

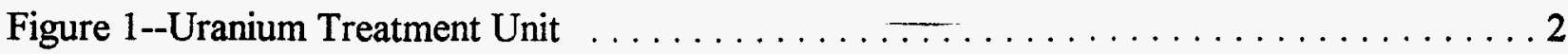

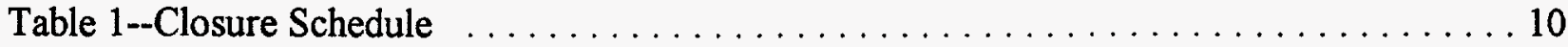

Table 2--Final Rinseate Levels $\quad \ldots \ldots \ldots \ldots \ldots \ldots$. . . . . . . . . . . . . . . . . . . . 11-20

Appendixes
A. Closure Correspondence
B. Closure Plan
C. Photographs
D. Radiological Survey/Work Permit and Industrial Hygiene Requirements
E. Site-Specific Health and Safety Plan
F. ELIMS Information
G. Decontamination Records 


\subsection{INTRODUCTION}

This closure summary has been prepared for the Uranium Treatment Unit (UTU) located at the Y-12 Plant in Oak Ridge, Tennessee (Environmental Protection Agency [EPA] Identification TN 389-009-0001). The actions required to achieve closure of the UTU area are outlined in the Closure Plan, Y/TS-1253, March 1995, submitted to and approved by the Tennessee Department of Environment and Conservation staff on March 14, 1995, and November 7, 1995, respectively (see Appendix A). See Table 1 (Closure Schedule) for details.

The UTU was used to store and treat waste materials that are regulated by the Resource Conservation and Recovery Act (RCRA). This closure summary details all steps that were performed to close the UTU in accordance with the approved plan.

\section{i.1 UNIT DESCRIPTION}

The UTU, associated equipment, and diked area were located east of Building 9206 within the boundaries of the Y-12 Plant. The UTU consisted of two 300-gal polytanks and associated structural support stands, two electrically driven agitators, and approximately $400 \mathrm{sq} \mathrm{ft}$ of ten-mil polyvinyl chloride liners. Also included in this closure are twelve 55-gal drums filled with Raschig rings which were used to collect the RCRA solutions prior to treatment at the UTU. The design treatment capacity of the UTU was $500 \mathrm{gal} /$ day, and the design storage capacity was $990 \mathrm{gal}$ or 18 drums (55-gal capacity each). A diagram of the UTU is shown in Figure 1. Photographs of the area are shown in Appendix C.

The site arrangement shown in Figure 1 represents the configuration following completion of operations on August 18, 1992. Figure 1, page 2, of the Closure Plan (Appendix B) represents the maximum number of 55-gal drums (18) allowed due to the physical arrangement. Also note that the twelfth 55-gal drum, referenced in the Closure Plan, is located in the adjacent 90-day RCRA area. This drum had been previously inspected and determined to be RCRA "empty" as is evident by the "empty" label visible in the photograph in Appendix C-2. The top surface and side wall of the loading dock adjacent to the rear of the closure site are not part of the closure.

The UTU treated organic solutions containing enriched uranium. Before these solutions can be transferred from a nuclear safe container, they must by below 400 parts per million (ppm) uranium concentration. The treatment process takes waste organic solutions containing characteristically hazardous and F001- and F002-listed (Freon 113) waste, with a uranium concentration less than $400 \mathrm{ppm}$; mixes these solutions with depleted uranyl nitrate to create a solution in which the uranium-235 concentration is less than 1 percent of the total uranium present; and then adjusts the $\mathrm{pH}$ of this solution with the addition of caustic. The resulting solutions are then removed for treatment to the West End Treatment Facility. 


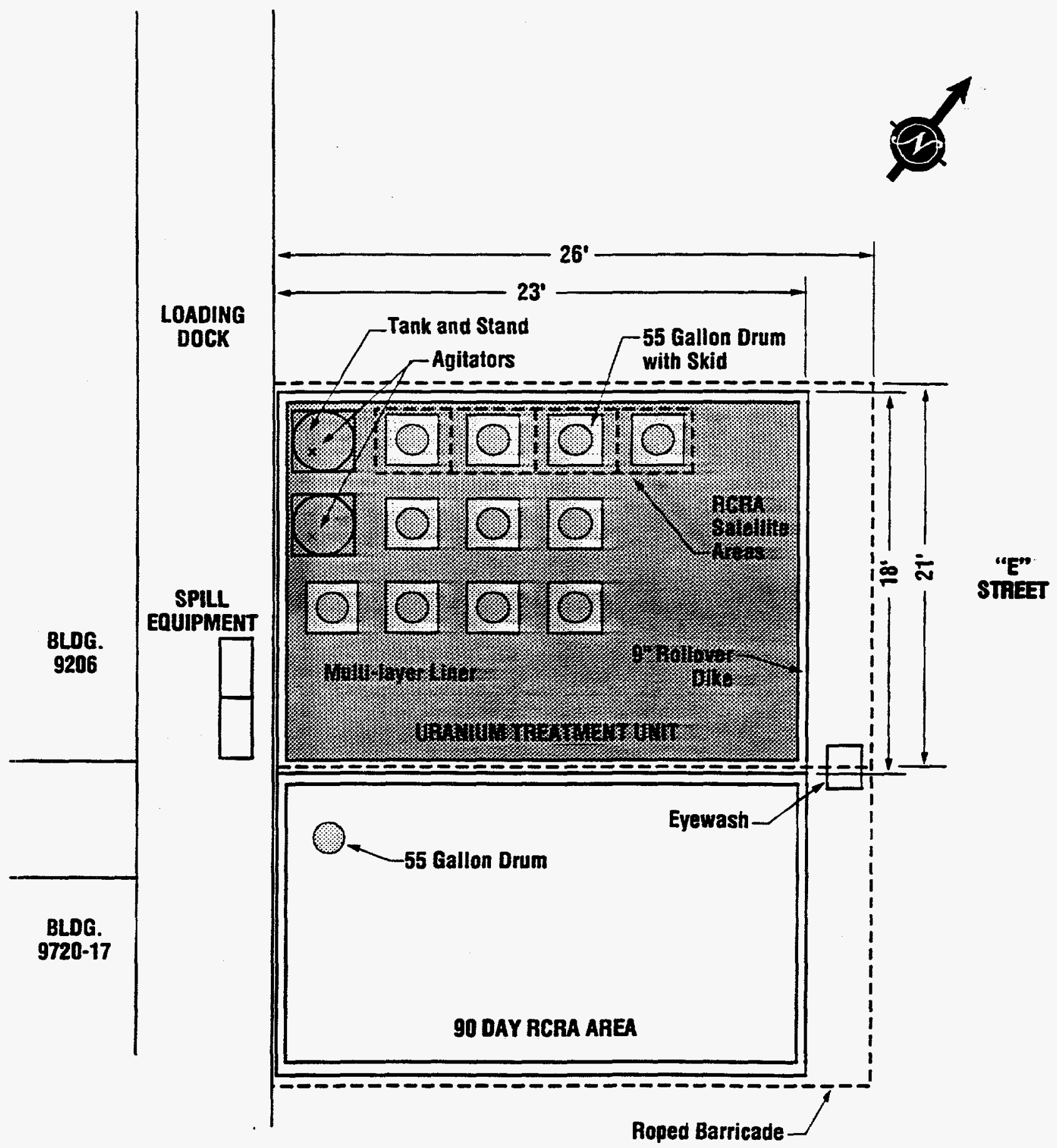

FIGURE 1. URANIUM TREATMENT UNIT 


\subsection{CLOSURE PLAN CONTENTS}

Because the UTU is part of the Y-12-Plant, which is a federal facility, no closure cost estimate, financial assurance mechanism, or liability insurance were required. This exemption from certain financial requirements is found in Title 40, Code of Federal Regulations (CFR), Part 265.140(c), and Tennessee Rule 1200-1-11-.05(8)(a).

\subsection{CLOSURE PERFORMANCE STANDARD}

Closure of the UTU minimizes the need for further maintenance, prevents the release of hazardous constituents from the unit, protects human health and the environment, and complies with all applicable closure requirements. The applicable requirements for the site are found in 40 CFR, Part 265.197, and Tennessee Rule 1200-1-11-.05(10).

Closure has been accomplished through the removal of all RCRA hazardous wastes stored in polytanks and containers at the site. The RCRA liquid wastes were transferred to the West End Treatment Facility for treatment and solid RCRA wastes (e.g., sandbags, dirt, absorbants, PPE) are in permanent storage at the Container Waste Storage Area (CWSA). To minimize residual contamination on site, the treatment area barrels, tanks, tank supports, agitators, liners, and subsurface concrete/asphalt surface were cleaned by high-pressure wash until satisfactorily decontaminated and sampled according to the sampling and analysis plan contained in the Closure Plan. Table 4 of the Closure Plan represents the required maximum contamination level of the final rinseate from each item.

\subsection{CLOSURE PROCEDURES}

Before closure activities began, the unit was surveyed by the Y-12 Radiological Control Department personnel; and a safety plan was prepared based on the site conditions. The radiological survey results, radiological work permit, and Industrial Hygiene Department recommendations for worker protection are shown in Appendix D. The closure Site-Specific Health and Safety Plan is shown in Appendix E. Closure activities were conducted in accordance with these documents.

\subsection{PARTIAL CLOSURE AND FINAL CLOSURE ACTIVITIES}

This was a final closure of the UTU, associated equipment, diking, and subsurface; there will be no partial closure activities. Final closure activities proceeded as described below. 


\subsection{CLOSURE ACTIVITIES}

The items decontaminated during closure operations included the following: two 300-gal polytanks (plus lids); two stainless-steel, electrically driven agitators used to mix solutions in the 300-gal polytanks; structural supports and catch pans for the polytanks; twelve 55-gal stainless steell drums; $90 \mathrm{cu} \mathrm{ft}$ of Raschig rings ( 7 cases per drum, 144 rings per case) used as a nuclear poison in the 55-gal drums; several layers of liner material which covered the site; and the underlying subsurface which was primarily concrete with asphalt edges.

In general, the above items (subsurface excluded) were individually removed from the UTU to a preexisting decontamination facility located about $100 \mathrm{ft}$ north. Modifications to this facility included installation of a curbed liner ( 30 mil); three rinse sinks; an acid bath tank; and assorted support equipment (e.g., high-pressure sprayer, hoses, pumps). (Reference Appendix C for photographs.) This area was formally configured and designated a 90-day RCRA area. Procedures were generated for handling of the uranium-contaminated wastes, personnel were trained, and walk-through exercises were conducted prior to actual commencement of decontamination operations. The sequence of closure was removal of waste followed by decontamination of agitators, polytanks, and lids; tank supports and catch pans; 55-gal drums; liners; Raschig rings; and site subsurface of concrete/asphalt. The final rinseate was collected and analyzed in accordance with Table 4 of the Closure Plan (see Appendix B). All rinseate items met Closure Plan requirements and are shown in Table 2 of this report. The 55-gal drums were pressure washed and determined to be "empty" in accordance with RCRA regulations. All wash/rinse water (except samples) was collected in polytanks, sampled for disposal, and sent to the West End Treatment Facility. Waste disposal and analysis records are maintained by the Enriched Uranium Operations (EUO) Environmental Officer.

\section{Removal of Waste Inventory}

Liquid wastes were stored in individual RCRA satellite areas on the north side of the UTU. (Reference Appendix C-1 and C-2, photographs.) The remainder of the 55-gal barrels contained contaminated Raschig rings. The polytanks and twelfth 55-gal barrel (in the 90-day RCRA area to the south of the UTU) were empty. Waste solutions were sampled for uranium content and decanted to waste disposal polytanks or drums following confirmation of compliance to uranium handling/transfer requirements. Each barrel had been uniquely identified as Coolant $2 \mathrm{~B}, 2 \mathrm{C}, 2 \mathrm{E}$; Extractant 1B; Oil 5A, 5B, 5C; Distillate 6A, 6B; Freon 4A, 4B; and one empty barrel. (Reference Appendix F, Raschig Ring Decontamination Tracking Logsheet.) The waste solutions were shipped to the West End Treatment Facility for disposal. (Reference Appendix G-4.)

\section{Decontamination of Stainless Steel Agitators}

The agitators were individually decontaminated using first a high-pressure detergent (reference Appendix G-5 for the Material Safety Data Sheet) wash followed by a two-step hot water rinse. For cleaning, the agitators were placed on the liner in the decontamination area; and wash/rinse water was collected at the low corner of the area. The final rinse water was collected for sampling and analysis for the constituents shown in Table 4 of the Closure Plan. The actual 
results of this analysis are shown in Table 2 of this report. Analysis was conducted according to Appendix A of the Closure Plan. The agitators were then wrapped in clean plastic and stored in the UTU until analysis showed that the closure requirements were met. Following confirmation that the final rinseate met closure requiemetns, the agitators were moved to the EUO Radioactive Material Storage Area for further radiological analysis and processing. (Reference Appendix G-4.)

\section{Decontamination of 300-Gal Polytanks and Supports}

The polytanks and lids were individually moved to the decontamination facility for cleaning using first a high-pressure detergent wash followed by a two-step hot water rinse. The items were placed on the liner, and wash/rinse water was collected at the low corner of the area. The final rinse water was collected for sampling and analysis as described above. The results are shown in Table 2. The polytanks and lids were wrapped in clean plastic and stored in the UTU until analysis showed that the closure requirements were met, at which time they were moved to the EUO Radioactive Material Storage Area.

The polytank supports and catch pans were similarly decontaminated as above, and the final rinseate was collected for analysis. The results are shown in Table 2 . These items were then wrapped in clear plastic and stored in the UTU until analysis showed that the closure requirements were met, at which time they were also moved to the EUO Radioactive Material Storage Area.

\section{Decontamination of the 55-Gal Stainless Steel Drums}

The drums containing RCRA hazardous waste were first drained as described in 1 above. Individual drums were then moved to the decontamination facility where the Raschig rings were transferred to regular 55-gal barrels lined with plastic. The identification of the rings with the drum of origin was maintained throughout decontamination and sampling of the final rinseate. As each drum was emptied of rings, it was cleaned with a high-pressure wash and inspected in accordance with 40 CFR, Part 261.7 (i.e., drums will be considered empty when all wastes have been removed that can be removed using practices commonly employed [e.g., pouring or pumping], and no more than 1 in. of residue remains on the bottom or no more than 3 percent by weight at the total capacity of the container remains in the container). All eleven drums in the UTU were cleaned of all visible residue, declared "empty, and moved to the EUO Radioactive Material Storage Area. The wash water was collected, along with any residue from the barrels and disposed of as RCRA waste at the West End Treatment Facility. The twelfth drum had already been determined to be RCRA "empty," did not receive any further decontamination, and was moved to the EUO Radioactive Material Storage Area. (Reference Appendix G-1 and G-4.)

\section{Decontamination of Liners}

Examination of the liner layers revealed two or three layers of heavy ( $\sim 30$ mil) gray-colored liners overlaying the entire site. Below these layers were two yellow-colored tarps laid side-by-side but sufficiently long to be doubled back on themselves, creating two layers. The overlapping seam between the two tarps ran north-south in orientation. Two additional white-colored tarps, similarly configured as the yellow tarps, represented the last layers of liner material. The white 
tarps were of such poor condition (i.e., numerous holes, rips, and tears) that they could not be decontaminated and were disposed of as mixed waste and placed in permitted storage at he CWSA.

It was planned that the liner layers would be carefully inspected for holes prior to being removed. If a layer did not contain holes, then decontamination of the underlying subsurface would not be necessary. This was in accordance with the Closure Plan, Appendix A, "Sampling and Analysis Plan," page A-7. However, the top gray-colored liners were inadvertently removed before any inspection could be made, and workers were unable to state if there were two or three layers. Consequently, the decision was made to proceed with decontamination of the liner material (in manageable sections--three batches) in the same process as previously used for the agitators, polytanks, etc. The results of the final rinseate analysis are shown in Table 2 (reference Customer Sample Numbers 011,012 , and 013). The decontaminated liner material was subsequently packaged and moved to the EUO Radioactive Material Storage Area.

\section{6: Decontamination of Raschig Rings}

The Raschig rings were removed from the temporary storage barrels and placed in wire baskets. The identification of each batch of rings to the drum at origin was maintained throughout decontamination and final rinseate sampling. A total of 26 batches of rings were processed (reference Table 2.) Each basket of rings was inspected and identified as very dirty, somewhat dirty, or fairly clean (reference Appendix G-3.) This identification was required by the Closure Plan. but did not have any practical use for actual decontamination. Each basket was then cleaned with a detergent, high-pressure wash; rinsed; allowed to soak in a 30-percent nitric acid solution; detergent washed a second time; and rinsed twice. Typically, 2-3 baskets of rings were cleaned in a single patch process. The final rinseate was collected for sample/analysis in accordance with Table 4 of the Closure Plan. The results of the analysis are shown in Table 2 of this report.

Each batch of rings was then placed in a plastic bag (with drum of origin identification) and temporarily stored in a clean 55-gal barrel in the decontamination area. Following confirmation that the final rinseate met the Closure Plan Table 4 requirements, the rings were moved to the EUO Radioactive Material Storage Area. Rings were typically very clean with no visible residue as evident in Appendix C-10 photograph, and all rinseate analyses met closure requirements. The batch of rings identified as Customer Sample Number 039, Sample Return Rings, consisted of rings (12 from each drum) previously selected for uranium analysis.

\section{Decontamination of Surface}

Examination of the site surface following removal of all layers of liner material revealed that the majority of the area consisted of a concrete surface with asphalt only at the edges. (Reference Appendix C-4 and C-6 photographs.)

The surface was vacuumed to remove any loose material, which was disposed of as mixed waste. Any broken sandbags or loose sand previously inside the liner area were also disposed of as mixed waste. The surface was then cleaned with a high-pressure detergent wash using a wet-vacuum system similar to that used on commercial or residential building carpets. This system prevented 
any runoff of wash or rinse water from the site. Following the detergent wash, the site was cleaned with a hot water rinse. Then a second hot water rinse was performed that was collected, sampled, and analyzed. The rinseate analysis results are shown in Table 2 (reference Customer Sample Number 40). Appendix C-4, C-11, and C-6 photographs show the site surface before, during, and after decontamination, respectively.

A second wash and rinse operation was performed several days later but 4 days before the closure schedule date of May 5, 1996. The concern was that if the first sample exceeded the requirements of the Closure Plan Table 4, there would be insufficient time for a second rinse, sample, and analyze of the surface before May 5 and, thereby, meet the closure schedule. The analysis of this sample was subsequently canceled when the first sample was shown to comply with Closure Plan Table 4 requirements.

\subsection{VERIFICATION OF DECONTAMINATION}

Rinse water samples were collected by Compliance Monitoring Services technicians who are trained and certified in regulatory-mandated methods of sample collection and handling, chain-of-custody, and EPA Test Methods for Evaluating Solid Waste SW-846. Sample analysis was also performed using SW-846 criteria. Specifically, sampling protocols were from or consistent with the "Environmental Surveillance Procedures Quality Control Program," ES/ESH/INT-14. The field notebook and chain-of-custody forms were completed in accordance with ESP-503, "Field Logs and Data Forms," August 1994, and ESP-501/500, "Chain-ofCustody," January 1990. Sample collection and analysis were conducted as required by the Closure Plan.

Final rinseate analysis of all items decontaminated (55-gal drums excepted) are shown in Table 2 of this report. Customer Sample Numbers 1, 2, 3, and 4 represent, respectively, source water, water and detergent, rinseate from the three sinks and decontamination area liner rinseate. These data represent "background" prior to conducting any closure-directed decontamination. The Customer Sample Number and description are shown at the top of Table 2 and in Appendix G.

Additional sampling was conducted other than that shown in Table 2. Duplicate samples were taken for Customer Sample Numbers 9, 17, 21, 26, 30, 35, and 38. A total of 19 samples of source water were analyzed to ensure no contamination was present. A total of 20 trip blanks were analyzed. Duplicate sample analyses were essentially identical to the original sample, and source water samples and trip blanks showed no constituents of concern. The laboratory analysis number (ELIMS) for all sampling is shown in Appendix F; however, actual results for duplicate, source water, and trip blanks are not included in this report, but are available in project or laboratory files.

All rinse water was collected by decontamination personnel, labeled for identification of source item (e.g., agitator, polytank, ring), sealed, and stored in a locked cabinet. Compliance Monitoring Services technicians made up samples for analysis from the collected rinse water, completed the necessary chain-of-custody and analysis request forms, and transported the samples 
to the laboratory. Analysis was conducted using SW-846 procedures by Analytical Services Organization personnel, and results were provided to the project team. The reported data were transcribed to the Table 2 format and double checked by two project personnel for accuracy. All analytical data reported by the laboratory staff were available, in original form, for review by the independent professional engineer; maintained in the project file in hard copy and computer disk form; and maintained in the permanent laboratory computer files.

\subsection{CERTIFICATION OF CLOSURE}

The Department of Energy/Lockheed Martin Energy Systems and independent registered professional engineer certifications of closure are included separately from this document.

Additional certification or notices are not required for this area.

\subsection{MAXIMUM WASTE INVENTORY}

The maximum treatment capacity of the UTU was $500 \mathrm{gal} /$ day, and the maximum waste inventory of the drum storage area was $990 \mathrm{gal}$ or 18 drums.

The UTU and container storage area received and treated only wastes that were characteristically hazardous or F001- and F002-listed (Freon 113) wastes. The wastes originated from processes located in either Building 9206 or Building 9212. Reference Appendix G-6 for UTU waste inventory.

\subsection{SCHEDULE FOR CLOSURE}

Closure activities were completed within 180 days of the Closure Plan being approved by TDEC personnel, as required by the Closure Plan. Table 1, Closure Schedule, of the Closure Plan as initially approved by TDEC staff reflected a 180-day duration for closure activity and preparation of closure certification documentation. A revised schedule was submitted to TDEC personnel on February 7, 1996, and approved on February 15, 1996. The revised schedule modified interim closure activity dates, authorized 60 days of documentation preparation (beyond the 180 days of closure activity) (reference $40 \mathrm{CFR}$, Part 260.115), and clarified that interim closure activities need not be executed in any specific order. Interim schedule dates were further clarified to be goals and not compliance requirements. The revised schedule showing actual completion dates is shown in Table 1 of this closure summary. Note that the April 16, 1996, date was met for all items except the Raschig rings. (Reference Appendix A for correspondence.) 


\subsection{POST-CLOSURE CARE}

Remediation activities of this closure plan removed any RCRA hazardous contaminants that may have resulted from storage or treatment operations associated with the UTU. Upon acceptance of the closure certification by the TDEC Commissioner, the UTU area will not be subject to any further requirements under 40 CFR, Part 265, Subpart G, or Tennessee Rule 1200-1-11-.05(7); and the area will be released for general use. 


\begin{tabular}{|c|c|c|c|c|}
\hline \multicolumn{5}{|c|}{ CLOSURE SCHEDULE FOR THE URANIUM TREATMENT UNIT } \\
\hline ACTION & $\begin{array}{c}\text { EXPECTED } \\
\text { COMPLETION } \\
\text { (DAYS) } \\
\end{array}$ & $\begin{array}{l}\text { APPROVED } \\
\text { SCHEDULE }\end{array}$ & $\begin{array}{c}\text { REVISED } \\
\text { SCHEDULE } \\
\text { (Days:Date) }\end{array}$ & $\begin{array}{c}\text { ACTUAL } \\
\text { SCHEDULE } \\
\text { (Days:Date) }\end{array}$ \\
\hline $\begin{array}{l}\text { Notify Tennessee Department of Health and Environment } \\
\text { staff of intent to initiate }\end{array}$ & 180 & & & \\
\hline Receive final volumes of waste; initiate closure & 0 & $11 / 7 / 95^{3}$ & $0: 11 / 7 / 95$ & $0: 11 / 7 / 95$ \\
\hline Remove inventory, load, and transfer (Step 1) & 45 & $12 / 22 / 95$ & $150: 4 / 5 / 96$ & $148: 4 / 3 / 96$ \\
\hline Decontaminate equipment (Steps 2-5) & 110 & $2 / 25 / 96$ & $159: 4 / 16 / 96$ & $166: 4 / 23 / 96^{4}$ \\
\hline Decontaminate structures and diked area (Step 6) & 115 & $3 / 1 / 96$ & $170: 4 / 25 / 96$ & $157: 4 / 12 / 96$ \\
\hline Analyze samples and results & 150 & $4 / 5 / 96$ & $178: 5 / 3 / 96$ & $178: 5 / 3 / 96$ \\
\hline $\begin{array}{l}\text { Prepare documentation for certification by an } \\
\text { independent Professional Engineer }\end{array}$ & 175 & $4 / 30 / 96$ & $209: 6 / 3 / 96$ & $209: 6 / 3 / 96$ \\
\hline Receive closure certification by DOE staff & 180 & $5 / 5 / 96$ & $239: 7 / 2 / 96$ & $\leq 239: 7 / 2 / 96$ \\
\hline \multicolumn{5}{|l|}{ or } \\
\hline Repeat decontamination and sample analysis ${ }^{1}$ & ** & & & $\mathrm{N} / \mathrm{A}$ \\
\hline $\begin{array}{l}\text { Receive independent Professional Engineer and DOE } \\
\text { staff closure certification }\end{array}$ & & & & \\
\hline
\end{tabular}

\section{Footnotes}

${ }^{1}$ If decontamination must be repeated or if closure activities cannot be completed within the allotted time, extension of the closure schedule beyond the maximum of 180 days will be requested.

${ }^{2}$ Number of days following initiation of closure.

3 TDEC Closure Plan approval date.

4 Steps 2-4 completed by required date of April 16, 1996. Only Step 5 completed on April 23, 1996. 
Table 2

\begin{tabular}{|c|c|c|c|c|c|}
\hline \multirow{2}{*}{$\begin{array}{l}\text { Uranium Treatment Unit Closure } \\
\text { TCLP Final Rinseate Levels (mg/L) }\end{array}$} & \multirow{2}{*}{\begin{tabular}{|c|} 
Required \\
By Closure
\end{tabular}} & \multicolumn{3}{|c|}{ Item Description and Customer } & \multirow[b]{3}{*}{ Decon Pad } \\
\hline & & \multicolumn{2}{|c|}{ Sample Number } & \multirow[b]{2}{*}{ Sink Rinse } & \\
\hline & Plan & Source water & Wash water & & \\
\hline ANALYTE & Level (mg/L) & 1 & 2 & 3 & 4 \\
\hline Arsenic & 5.00 & $<4$ & $<4$ & $<4$ & $<4$ \\
\hline Barium & 100.00 & 0.02 & 0.03 & 0.03 & 0.09 \\
\hline Cadmium & 1.00 & $<0.2$ & $<0.2$ & $<0.2$ & $<0.2$ \\
\hline Chromium & 5.00 & $<0.2$ & $<0.2$ & $<0.2$ & $<0.2$ \\
\hline Lead & 5.00 & $<0.5$ & $<0.5$ & $<0.5$ & $<0.5$ \\
\hline Mercury & 0.20 & $<0.02$ & $<0.02$ & $<0.02$ & $<0.02$ \\
\hline Selenium & 1.00 & $<0.5$ & $<0.5$ & $<0.5$ & $<0.5$ \\
\hline Silver & 5.00 & $<0.3$ & $<0.3$ & $<0.3$ & $<0.3$ \\
\hline o-Cresol ( or 2-methylphenol) & 200.00 & $0.01 u$ & $0.01 u$ & $0.01 u$ & $0.01 u$ \\
\hline m-Cresol & 200.00 & NA & NA & NA & NA \\
\hline$p$-Cresol (Lab reports $m$ and $p$ total) & 200.00 & $0.01 u$ & $0.01 u$ & $0.01 u$ & $0.01 u$ \\
\hline Cresol (Total of $o, m$, and p-cresol) & 200.00 & $0.02 u$ & $0.02 u$ & $0.02 u$ & $0.02 u$ \\
\hline 1,4 Dichlorobenzene & 7.50 & $.01 \mathrm{u}$ & $0.01 u$ & $0.01 u$ & $0.01 u$ \\
\hline 2,4 Dinitrotoluene & 0.13 & $0.01 \mathrm{u}$ & $0.01 u$ & $0.01 u$ & $0.01 u$ \\
\hline Hexachlorobutadiene & 0.50 & $0.01 u$ & $0.01 u$ & $0.01 u$ & $0.01 u$ \\
\hline Hexachloroethane & 3.00 & $0.01 \mathrm{u}$ & $0.01 u$ & $0.01 \mathrm{u}$ & $0.01 u$ \\
\hline Nitrobenzene & 2.00 & $0.01 u$ & $0.01 u$ & $0.01 u$ & $0.01 u$ \\
\hline Pentachlorophenol & 100.00 & $0.01 \mathrm{u}$ & $0.01 u$ & $0.01 \mathrm{u}$ & $0.01 u$ \\
\hline Pyridine & 5.00 & $0.01 \mathrm{u}$ & $0.01 u$ & $0.01 u$ & $0.01 u$ \\
\hline 2,4,5 Trichlorophenol & 400.00 & $0.01 u$ & $0.01 u$ & $0.01 u$ & $0.01 u$ \\
\hline 2,4,6 Trichlorophenol & 2.00 & $0.01 u$ & $0.01 u$ & $0.01 u$ & 0.012 \\
\hline Hexachlorobenzene & 0.13 & $0.01 u$ & $0.01 u$ & $0.01 u$ & $0.01 u$ \\
\hline Benzene & 0.50 & $0.01 u$ & $0.01 u$ & $0.01 u$ & $0.01 u$ \\
\hline Carbon Tetrachloride & 0.50 & $0.01 u$ & $0.01 u$ & $0.01 u$ & $0.01 u$ \\
\hline Chlorobenzene & 100.00 & $0.01 u$ & $0.01 u$ & $0.01 u$ & $0.01 u$ \\
\hline Chloroform & 6.00 & 0.019 & 0.016 & $0.01 u$ & $0.008 j$ \\
\hline 1,2 Dichloroethane & 0.50 & $0.01 u$ & $0.01 u$ & $0.01 \mathrm{u}$ & $0.01 u$ \\
\hline 1,1 Dichloroethylene (or -ethene) & 0.70 & $0.01 u$ & $0.01 u$ & $0.01 u$ & $0.01 u$ \\
\hline Methyl ethyl ketone (or 2-Butanone) & 200.00 & $0.01 u$ & $0.01 u$ & $0.006 j$ & $0.01 u$ \\
\hline Tetrachloroethylene (or -ethene) & 0.70 & $0.01 u$ & $0.01 u$ & $0.01 \mathrm{u}$ & $0.01 u$ \\
\hline Trichloroethylene (or -ethene) & 0.50 & $0.01 \mathrm{u}$ & $0.01 u$ & $0.01 u$ & $0.01 u$ \\
\hline Vinyl chloride & 0.20 & $0.01 u$ & $0.01 u$ & $0.01 u$ & $0.01 u$ \\
\hline Methylene Chloride & 0.02 & $0.01 u$ & $0.01 u$ & $0.01 u$ & $0.01 u$ \\
\hline 1,1,1-Trichloroethane & 0.02 & $0.01 u$ & $0.01 \mathrm{u}$ & $0.01 u$ & $0.01 u$ \\
\hline 1,1,2-Trichloro-1,2,2-trifluoroethane & 0.02 & $0.01 u$ & $0.01 u$ & $0.01 u$ & $0.01 u$ \\
\hline Trichloromonofluoromethane & 0.02 & $0.01 \mathrm{u}$ & $0.01 u$ & $0.01 u$ & $0.01 u$ \\
\hline \multicolumn{2}{|c|}{ Note: u-not present at reporting detection limit. } & & & & \\
\hline \multicolumn{2}{|c|}{ j-present at an estimated value below } & & & & \\
\hline the reporting detection limit. & & & & & \\
\hline
\end{tabular}


Table 2

\begin{tabular}{|c|c|c|c|c|c|}
\hline \multirow{3}{*}{\begin{tabular}{|l} 
Uranium Treatment Unit Closure \\
TCLP Final Rinseate Levels (mg/L) \\
\end{tabular}} & \multirow{3}{*}{\begin{tabular}{|c|} 
Required \\
By Closure \\
Plan \\
\end{tabular}} & \multicolumn{3}{|c|}{ Item Description and Customer } & \multirow[b]{3}{*}{ Poly Tank E } \\
\hline & & \multicolumn{2}{|c|}{ Sample Number } & \multirow[b]{2}{*}{ Poly Tank A } & \\
\hline & & Agitator A & Agitator B & & \\
\hline ANALYTE & Level $(\mathrm{mg} / \mathrm{L})$ & 5 & 6 & 7 & 8 \\
\hline Arsenic & 5.00 & $<4$ & $<4$ & $<4$ & $<4$ \\
\hline Barium & 100.00 & 0.05 & 0.04 & 0.05 & $<0.03$ \\
\hline Cadmium & 1.00 & $<0.2$ & $<0.2$ & $<0.2$ & $<0.2$ \\
\hline Chromium & 5.00 & $<0.2$ & $<0.2$ & $<0.2$ & $<0.2$ \\
\hline Lead & 5.00 & $<0.5$ & $<0.5$ & $<0.5$ & $<0.5$ \\
\hline Mercury & 0.20 & $<0.02$ & $<0.02$ & $<0.02$ & $<0.02$ \\
\hline Selenium & 1.00 & $<0.5$ & $<0.5$ & $<0.5$ & $<0.5$ \\
\hline Silver & 5.00 & $<0.3$ & $<0.3$ & $<0.3$ & $<0.3$ \\
\hline o-Cresol ( or 2-methylphenol) & 200.00 & $0.01 u$ & $0.01 u$ & $0.01 \mathrm{u}$ & $0.01 u$ \\
\hline m-Cresol & 200.00 & $\overline{\mathrm{NA}}$ & $\overline{N A}$ & NA & NA \\
\hline$p$-Cresol (Lab reports $m$ and $p$ total) & 200.00 & $0.01 u$ & $0.01 u$ & $0.01 u$ & $0.01 u$ \\
\hline Cresol (Total of $0, m$, and p-cresol) & 200.00 & $0.02 u$ & $0.02 u$ & $0.02 u$ & $0.02 u$ \\
\hline 1,4 Dichlorobenzene & 7.50 & $0.01 u$ & $0.01 u$ & $0.01 u$ & $0.01 u$ \\
\hline 2,4 Dinitrotoluene & 0.13 & $0.01 u$ & $0.01 u$ & $0.01 u$ & $0.01 u$ \\
\hline Hexachlorobutadiene & 0.50 & $0.01 u$ & $0.01 u$ & $0.01 u$ & $0.01 u$ \\
\hline Hexachloroethane & 3.00 & $0.01 u$ & $0.01 u$ & $0.01 u$ & $0.01 u$ \\
\hline Nitrobenzene & 2.00 & $0.01 u$ & $0.01 u$ & $0.01 u$ & $0.01 u$ \\
\hline Pentachlorophenol & 100.00 & $0.01 u$ & $0.01 u$ & $0.01 u$ & $0.01 u$ \\
\hline Pyridine & 5.00 & $0.01 u$ & $0.01 u$ & $0.01 u$ & $0.01 \mathrm{u}$ \\
\hline 2,4,5 Trichlorophenol & 400.00 & $0.01 u$ & $0.01 u$ & $0.01 u$ & $0.01 u$ \\
\hline 2,4,6 Trichlorophenol & 2.00 & $0.01 u$ & $0.01 u$ & $0.01 u$ & $0.01 u$ \\
\hline Hexachlorobenzene & 0.13 & $0.01 u$ & $0.01 u$ & $0.01 u$ & $0.01 u$ \\
\hline Benzene & 0.50 & $0.01 u$ & $0.01 u$ & $0.01 u$ & $0.01 u$ \\
\hline Carbon Tetrachloride & 0.50 & $0.01 u$ & $0.01 u$ & $0.01 u$ & $0.01 u$ \\
\hline Chlorobenzene & 100.00 & $0.01 \mathrm{u}$ & $0.01 \mathrm{u}$ & $0.01 u$ & $0.01 u$ \\
\hline Chloroform & 6.00 & $-0.01 u$ & $0.01 u$ & $0.01 u$ & $0.01 u$ \\
\hline 1,2 Dichloroethane & 0.50 & $0.01 u$ & $0.01 u$ & $0.01 u$ & $0.01 u$ \\
\hline 1,1 Dichloroethylene (or -ethene) & 0.70 & $0.01 u$ & $0.01 u$ & $0.01 \mathrm{u}$ & $0.01 u$ \\
\hline Methyl ethyl ketone (or 2-Butanone) & 200.00 & $0.01 \mathrm{u}$ & $0.01 u$ & $0.01 u$ & $0.005 j$ \\
\hline Tetrachloroethylene (or -ethene) & 0.70 & $0.01 u$ & $0.01 u$ & $0.01 u$ & $0.01 u$ \\
\hline Trichloroethylene (or -ethene) & 0.50 & $0.01 u$ & $0.01 u$ & $0.01 u$ & $0.01 u$ \\
\hline Vinyl chloride & 0.20 & $0.01 \mathrm{u}$ & $0.01 u$ & $0.01 u$ & $0.01 u$ \\
\hline Methylene Chloride & 0.02 & $0.01 u$ & $0.01 u$ & $0.01 u$ & $0.01 u$ \\
\hline 1,1,1-Trichloroethane & 0.02 & $0.01 u$ & $0.01 u$ & $0.01 u$ & $0.01 u$ \\
\hline 1,1,2-Trichloro-1,2,2-trifluoroethane & 0.02 & $0.01 u$ & $0.01 u$ & $0.01 u$ & 0.014 \\
\hline Trichloromonofluoromethane & 0.02 & $0.01 u$ & $0.01 u$ & $0.01 u$ & $0.01 u$ \\
\hline Note: $u-n$ & n limit. & & & & \\
\hline sent at an estimated val & below & & & & \\
\hline the reporting detection limit & & & & & \\
\hline
\end{tabular}


Table 2

\begin{tabular}{|c|c|c|c|c|c|}
\hline Uranium Treatment Unit Closure & Required & Item Desc & iption and & stomer & \\
\hline TCLP Final Rinseate Levels (mg/L) & By Closure & Sample N & Imber & & \\
\hline & Plan & Support B & Support A & Liner 1 & Liner 2 \\
\hline ANALYTE & Level $(\mathrm{mg} / \mathrm{L})$ & 9 & 10 & 11 & 12 \\
\hline Arsenic & 5.00 & $<4$ & $<4$ & $<4$ & $<4$ \\
\hline Barium & 100.00 & 0.06 & 0.04 & 0.06 & 0.04 \\
\hline Cadmium & 1.00 & $<0.2$ & $<0.2$ & $<0.2$ & $<0.2$ \\
\hline Chromium & 5.00 & $<0.2$ & $<0.2$ & $<0.2$ & $<0.2$ \\
\hline Lead & 5.00 & $<0.5$ & $<0.5$ & $<0.5$ & $<0.5$ \\
\hline Mercury & 0.20 & $<0.02$ & $<0.02$ & $<0.02$ & $<0.02$ \\
\hline Selenium & 1.00 & $<0.5$ & $<0.5$ & $<0.5$ & $<0.5$ \\
\hline Silver & 5.00 & $<0.3$ & $<0.3$ & $<0.3$ & $<0.3$ \\
\hline o-Cresol ( or 2-methylphenol) & 200.00 & $0.03 u$ & $0.03 u$ & $0.01 u$ & $0.03 u$ \\
\hline m-Cresol & 200.00 & NA & NA & NA & NA \\
\hline$p$-Cresol (Lab reports $m$ and $p$ total) & 200.00 & $0.03 u$ & $0.03 u$ & $0.01 u$ & $0.03 u$ \\
\hline Cresol (Total of $0, m$, and p-cresol) & 200.00 & $0.06 u$ & $0.06 u$ & $0.02 u$ & $0.06 u$ \\
\hline 1,4 Dichlorobenzene & 7.50 & $0.03 u$ & $0.03 u$ & $0.01 u$ & $0.03 u$ \\
\hline 2,4 Dinitrotoluene & 0.13 & $0.03 u$ & $0.03 u$ & $0.01 u$ & $0.03 u$ \\
\hline Hexachlorobutadiene & 0.50 & $0.03 u$ & $0.03 u$ & $0.01 u$ & $0.03 u$ \\
\hline Hexachloroethane & 3.00 & $0.03 u$ & $0.03 u$ & $0.01 u$ & $0.03 u$ \\
\hline Nitrobenzene & 2.00 & $0.03 u$ & $0.03 u$ & $0.01 u$ & $0.03 u$ \\
\hline Pentachlorophenol & 100.00 & $0.03 u$ & $0.03 u$ & $0.01 u$ & $0.03 u$ \\
\hline Pyridine & 5.00 & $0.03 u$ & $0.03 u$ & $0.01 u$ & $0.03 u$ \\
\hline 2,4,5 Trichlorophenol & 400.00 & $0.03 u$ & $0.03 u$ & $0.01 u$ & $0.03 u$ \\
\hline 2,4,6 Trichlorophenol & 2.00 & $0.03 u$ & $0.03 u$ & $0.01 \mathrm{u}$ & $0.03 u$ \\
\hline Hexachlorobenzene & 0.13 & $0.03 u$ & $0.03 u$ & $0.01 u$ & $0.03 u$ \\
\hline Benzene & 0.50 & $0.01 u$ & $0.01 u$ & $0.01 u$ & $0.01 u$ \\
\hline Carbon Tetrachloride & 0.50 & $0.01 u$ & $0.01 u$ & $0.01 u$ & 0.014 \\
\hline Chlorobenzene & 100.00 & $0.01 u$ & $0.01 u$ & $0.01 u$ & $0.01 u$ \\
\hline Chloroform & 6.00 & 0.014 & $0.01 u$ & $0.01 \mathrm{u}$ & $0.005 j$ \\
\hline 1,2 Dichloroethane & 0.50 & $0.01 u$ & $0.01 \mathrm{u}$ & $0.01 u$ & $0.01 \mathrm{u}$ \\
\hline 1,1 Dichloroethylene (or -ethene) & 0.70 & $0.01 u$ & $0.01 u$ & $0.01 u$ & $0.01 \mathrm{u}$ \\
\hline Methyl ethyl ketone (or 2-Butanone) & 200.00 & $0.01 u$ & $0.01 u$ & 0.014 & $0.01 u$ \\
\hline Tetrachloroethylene (or -ethene) & 0.70 & $0.01 u$ & $0.01 \mathrm{u}$ & $0.01 u$ & $0.01 u$ \\
\hline Trichloroethylene (or -ethene) & 0.50 & $0.01 u$ & $0.01 \mathrm{u}$ & $0.01 u$ & $0.01 u$ \\
\hline Vinvl chloride & 0.20 & $0.01 u$ & $0.01 u$ & $0.01 u$ & $0.01 u$ \\
\hline Methylene Chloride & 0.02 & $0.01 u$ & $0.01 u$ & $0.01 u$ & $0.01 u$ \\
\hline 1,1,1-Trichloroethane & 0.02 & $0.01 u$ & $0.01 u$ & $0.01 \mathrm{u}$ & $0.01 u$ \\
\hline 1,1,2-Trichloro-1,2,2-trifluoroethane & 0.02 & $0.01 u$ & $0.01 u$ & $0.01 u$ & $0.01 u$ \\
\hline Trichloromonofluoromethane & 0.02 & $0.01 u$ & $0.01 u$ & $0.01 u$ & $0.01 u$ \\
\hline & & & & & \\
\hline j-present at an estimated val & below & & & & \\
\hline the reporting detection limit. & & & & & \\
\hline
\end{tabular}


Table 2

\begin{tabular}{|c|c|c|c|c|c|}
\hline \multirow{2}{*}{$\begin{array}{l}\text { Uranium Treatment Unit Closure } \\
\text { TCLP Final Rinseate Levels (mg/L) }\end{array}$} & \multirow{2}{*}{\begin{tabular}{|c|} 
Required \\
By Closure
\end{tabular}} & \multicolumn{3}{|c|}{ Item Description and Customer } & \\
\hline & & \multicolumn{4}{|c|}{ Sample Number. * 14-39 =Raschig Rings } \\
\hline & Plan & Liner 3 & Freon $4 \mathrm{~B}^{*}$ & Freon 4B & Freon 4A \\
\hline ANALYTE & Level (mg/L) & 13 & 14 & 15 & 16 \\
\hline Arsenic & 5.00 & $<4$ & $<4$ & $<4$ & $<4$ \\
\hline Barium & 100.00 & 0.03 & 0.23 & 0.28 & 0.27 \\
\hline Cadmium & 1.00 & $<0.2$ & $<0.2$ & $<0.2$ & $<0.2$ \\
\hline Chromium & 5.00 & $<0.2$ & $<0.2$ & $<0.2$ & $<0.2$ \\
\hline Lead & 5.00 & $<0.5$ & $<0.5$ & $<0.5$ & $<0.5$ \\
\hline Mercury & 0.20 & $<0.02$ & $<0.02$ & $<0.02$ & $<0.02$ \\
\hline Selenium & 1.00 & $<0.5$ & $<0.5$ & $<0.5$ & $<0.5$ \\
\hline Silver & 5.00 & $<0.3$ & $<0.3$ & $<0.3$ & $<0.3$ \\
\hline o-Cresol ( or 2-methylphenol) & 200.00 & $0.03 u$ & $0.03 u$ & $0.05 u$ & $0.03 u$ \\
\hline m-Cresol & 200.00 & NA & NA & NA & NA \\
\hline$p$-Cresol (Lab reports $m$ and $p$ total) & 200.00 & $0.03 u$ & $0.03 u$ & $0.05 u$ & $0.03 u$ \\
\hline Cresol (Total of $o, m$, and p-cresol) & 200.00 & $0.06 u$ & $0.06 u$ & 0.1 & 0.06 \\
\hline 1,4 Dichlorobenzene & 7.50 & $0.03 u$ & $0.03 u$ & $0.05 u$ & $0.03 u$ \\
\hline 2,4 Dinitrotoluene & 0.13 & $0.03 u$ & $0.03 u$ & $0.05 u$ & $0.03 u$ \\
\hline Hexachlorobutadiene & 0.50 & $0.03 u$ & $0.03 u$ & $0.05 u$ & $0.03 u$ \\
\hline Hexachloroethane & 3.00 & $0.03 u$ & $0.03 u$ & $0.05 u$ & $0.03 u$ \\
\hline Nitrobenzene & 2.00 & $0.03 u$ & $0.03 u$ & $0.05 u$ & $0.03 u$ \\
\hline Pentachlorophenol & 100.00 & $0.03 u$ & $0.03 u$ & $0.05 u$ & $0.03 u$ \\
\hline Pyridine & 5.00 & $0.03 u$ & $0.03 u$ & $0.05 u$ & $0.03 u$ \\
\hline 2,4,5 Trichlorophenol & 400.00 & $0.03 u$ & $0.03 u$ & $0.05 u$ & $0.03 u$ \\
\hline 2,4,6 Trichlorophenol & 2.00 & $0.03 u$ & $0.03 u$ & $0.05 u$ & $0.03 u$ \\
\hline Hexachlorobenzene & 0.13 & $0.03 u$ & $0.03 u$ & $0.05 u$ & $0.03 u$ \\
\hline Benzene & 0.50 & $0.01 u$ & $0.01 \mathrm{u}$ & $0.01 u$ & $0.01 u$ \\
\hline Carbon Tetrachloride & 0.50 & $0.01 u$ & $0.01 u$ & $0.01 \mathrm{u}$ & $0.01 u$ \\
\hline Chlorobenzene & 100.00 & $0.01 u$ & $0.01 u$ & $0.01 u$ & $0.01 u$ \\
\hline Chloroform & 6.00 & $0.01 \mathrm{u}$ & $0.01 u$ & $0.01 u$ & $0.01 u$ \\
\hline 1,2 Dichloroethane & 0.50 & $0.01 u$ & $0.01 u$ & $0.01 u$ & $0.01 u$ \\
\hline 1,1 Dichloroethylene (or -ethene) & 0.70 & 0.014 & $0.01 u$ & $0.01 u$ & $0.01 u$ \\
\hline Methyl ethyl ketone (or 2-Butanone) & 200.00 & $0.006 j$ & $0.01 u$ & $0.007 j$ & $0.005 j$ \\
\hline Tetrachloroethylene (or -ethene) & 0.70 & $0.01 u$ & $0.01 u$ & $0.01 u$ & $0.01 u$ \\
\hline Trichloroethylene (or -ethene) & 0.50 & $0.01 u$ & $0.01 u$ & $0.01 u$ & $0.01 \mathrm{u}$ \\
\hline Vinyl chloride & 0.20 & $0.01 u$ & $0.01 u$ & $0.01 u$ & $0.01 u$ \\
\hline Methylene Chloride & 0.02 & $0.01 u$ & $0.01 u$ & $0.01 u$ & $0.01 \mathrm{u}$ \\
\hline 1,1,1-Trichloroethane & 0.02 & $0.01 u$ & $0.01 u$ & $0.01 u$ & $0.01 u$ \\
\hline 1,1,2-Trichloro-1,2,2-trifluoroethane & 0.02 & $0.01 u$ & 0.014 & $0.01 u$ & $0.01 u$ \\
\hline Trichloromonofluoromethane & 0.02 & $0.01 u$ & $0.01 u$ & $0.01 u$ & $0.01 u$ \\
\hline \multicolumn{2}{|c|}{ Note: u-not present at reporting detection limit. } & \multirow{2}{*}{\multicolumn{4}{|c|}{$\begin{array}{l}\text { Sample Numbers 14-39 represent Raschig } \\
\text { Rings from barrels containing freon, oil, }\end{array}$}} \\
\hline \multicolumn{2}{|c|}{ j-present at an estimated value below } & & & & \\
\hline the reporting detection limit. & & \multicolumn{4}{|l|}{ distille } \\
\hline
\end{tabular}


Table 2

\begin{tabular}{|c|c|c|c|c|c|}
\hline \multirow{3}{*}{\begin{tabular}{|l} 
Uranium Treatment Unit Closure \\
TCLP Final Rinseate Levels (mg/L)
\end{tabular}} & \multirow{2}{*}{\begin{tabular}{|c|} 
Required \\
By Closure \\
\end{tabular}} & \multicolumn{3}{|c|}{ Item Description and Customer } & \\
\hline & & \multicolumn{4}{|c|}{ Sample Number. * 14-39 =Raschig Rings } \\
\hline & Plan & Freon 4A & Dist. 6A & Dist. 6A & Dist. 6B \\
\hline ANALYTE & Level (mg/L) & 17 & 18 & 19 & 20 \\
\hline Arsenic & 5.00 & $<4$ & $<4$ & $<4$ & $<4$ \\
\hline Barium & 100.00 & 0.06 & 0.16 & 0.06 & 0.1 \\
\hline Cadmium & 1.00 & $<0.2$ & $<0.2$ & $<0.2$ & $<0.2$ \\
\hline Chromium & 5.00 & $<0.2$ & $<0.2$ & $<0.2$ & $<0.2$ \\
\hline Lead & 5.00 & $<0.5$ & $<0.5$ & $<0.5$ & $<0.5$ \\
\hline Mercury & 0.20 & $<0.02$ & $<0.02$ & $<0.02$ & $<0.02$ \\
\hline Selenium & 1.00 & $<0.5$ & $<0.5$ & $<0.5$ & $<0.5$ \\
\hline Silver & 5.00 & $<0.3$ & $<0.3$ & $<0.3$ & $<0.3$ \\
\hline o-Cresol ( or 2-methylphenol) & 200.00 & $0.03 u$ & $0.05 u$ & $0.05 u$ & $0.02 u$ \\
\hline m-Cresol & 200.00 & NA & NA & NA & NA \\
\hline$p$-Cresol (Lab reports $m$ and $p$ total) & 200.00 & $0.03 u$ & $0.05 u$ & $0.05 u$ & $0.02 u$ \\
\hline Cresol (Total of $0, m$, and p-cresol) & 200.00 & $0.06 u$ & $0.1 \mathrm{u}$ & 0.1 & $0.04 u$ \\
\hline 1,4 Dichlorobenzene & 7.50 & $0.03 u$ & $0.05 u$ & $0.05 u$ & $0.02 u$ \\
\hline 2,4 Dinitrotoluene & 0.13 & $0.03 u$ & $0.05 u$ & $0.05 u$ & $0.02 u$ \\
\hline Hexachlorobutadiene & 0.50 & $0.03 u$ & $0.05 u$ & $0.05 u$ & $0.02 u$ \\
\hline Hexachioroethane & 3.00 & $0.03 u$ & $0.05 u$ & $0.05 u$ & $0.02 u$ \\
\hline Nitrobenzene & 2.00 & $0.03 u$ & $0.05 u$ & $0.05 u$ & $0.02 u$ \\
\hline Pentachlorophenol & 100.00 & $0.03 u$ & $0.05 u$ & $0.05 u$ & $0.02 u$ \\
\hline Pyridine & 5.00 & $0.03 u$ & $0.05 u$ & $0.05 u$ & $0.02 u$ \\
\hline 2,4,5 Trichlorophenol & 400.00 & $0.03 u$ & $0.05 u$ & $0.05 u$ & $0.02 u$ \\
\hline 2,4,6 Trichlorophenol & 2.00 & $0.03 u$ & $0.05 u$ & $0.05 u$ & $0.02 u$ \\
\hline Hexachlorobenzene & 0.13 & $0.03 u$ & $0.05 u$ & $0.05 u$ & $0.02 u$ \\
\hline Benzene & 0.50 & $0.01 u$ & $0.01 u$ & $0.01 u$ & $0.01 u$ \\
\hline Carbon Tetrachloride & 0.50 & $0.01 u$ & $0.01 \mathrm{u}$ & $0.01 \mathrm{u}$ & $0.01 u$ \\
\hline Chlorobenzene & 100.00 & $0.01 u$ & $0.01 u$ & $0.01 u$ & $0.01 \mathrm{u}$ \\
\hline Chloroform & 6.00 & 0.014 & $0.01 u$ & $0.01 u$ & $0.01 u$ \\
\hline 1,2 Dichloroethane & 0.50 & $0.01 \mathrm{u}$ & $0.01 u$ & $0.01 u$ & $0.01 u$ \\
\hline 1,1 Dichloroethylene (or -ethene) & 0.70 & $0.01 u$ & $0.01 \mathrm{u}$ & $0.01 u$ & $0.01 u$ \\
\hline Methyl ethyl ketone (or 2-Butanone) & 200.00 & $0.01 u$ & $0.007 j$ & $0.006 j$ & $0.01 u$ \\
\hline Tetrachloroethylene (or -ethene) & 0.70 & $0.01 u$ & $0.01 u$ & $0.01 u$ & $0.01 u$ \\
\hline Trichloroethylene (or -ethene) & 0.50 & $0.01 u$ & $0.01 u$ & $0.01 \mathrm{u}$ & $0.01 \mathrm{u}$ \\
\hline Vinyl chloride & 0.20 & $0.01 u$ & $0.01 u$ & $0.01 u$ & $0.01 u$ \\
\hline Methylene Chloride & 0.02 & $0.01 u$ & $0.01 u$ & $0.01 u$ & $0.01 \mathrm{u}$ \\
\hline $1,1,1$-Trichloroethane & 0.02 & $0.01 u$ & $0.01 \mathrm{u}$ & $0.01 \mathrm{u}$ & $0.01 u$ \\
\hline 1,1,2-Trichloro-1,2,2-trifluoroethane & 0.02 & $0.01 u$ & $0.01 u$ & $0.01 u$ & $0.01 \mathrm{u}$ \\
\hline Trichloromonofluoromethane & 0.02 & $0.01 u$ & $0.01 u$ & $0.01 u$ & $0.01 u$ \\
\hline \multicolumn{2}{|c|}{ Note: u-not present at reporting detection limit. } & \multirow{2}{*}{\multicolumn{4}{|c|}{$\begin{array}{l}\text { Sample Numbers } 14-39 \text { represent Raschig } \\
\text { Rings from barrels containing freon, oil, }\end{array}$}} \\
\hline \multicolumn{2}{|c|}{ j-present at an estimated value below } & & & & \\
\hline the reporting detection limit. & & \multicolumn{3}{|c|}{ distillate, collant, or extract. } & \\
\hline
\end{tabular}


Table 2

\begin{tabular}{|c|c|c|c|c|c|}
\hline \multirow{2}{*}{\begin{tabular}{|l} 
Uranium Treatment Unit Closure \\
TCLP Final Rinseate Levels (mg/L)
\end{tabular}} & \multirow{2}{*}{\begin{tabular}{|c|} 
Required \\
By Closure \\
\end{tabular}} & & \\
\hline & & \multicolumn{3}{|c|}{$\begin{array}{l}\text { Item Description and Customer } \\
\text { Sample Number. }{ }^{*} 14-39=\text { Raschig Rings }\end{array}$} & \\
\hline & Plan & Dist. 6B & Dist. 6B & Oil $5 A, B, C$ & Cool. 2B \\
\hline ANALYTE & Level $(\mathrm{mg} / \mathrm{L})$ & 21 & 22 & 23 & 24 \\
\hline Arsenic & 5.00 & $<4$ & $<4$ & $<4$ & $<4$ \\
\hline Barium & 100.00 & 0.06 & 0.05 & 0.19 & 0.25 \\
\hline Cadmium & 1.00 & $<0.2$ & $<0.2$ & $<0.2$ & $<0.2$ \\
\hline Chromium & 5.00 & 0.2 & $<0.2$ & $<0.2$ & 0.1 \\
\hline Lead & 5.00 & $<0.5$ & $<0.5$ & $<0.5$ & $<0.5$ \\
\hline Mercury & 0.20 & $<0.02$ & $<0.02$ & $<0.02$ & $<0.02$ \\
\hline Selenium & 1.00 & $<0.5$ & $<0.5$ & $<0.5$ & $<0.5$ \\
\hline Silver & 5.00 & $<0.3$ & $<0.3$ & $<0.3$ & $<0.3$ \\
\hline o-Cresol ( or 2-methylphenol) & 200.00 & $0.02 u$ & $0.02 u$ & $0.02 u$ & $0.02 u$ \\
\hline m-Cresol & 200.00 & NA & NA & NA & NA \\
\hline$p$-Cresol (Lab reports $m$ and $p$ total) & 200.00 & $0.02 u$ & $0.02 u$ & $0.003 \mathrm{DJ}$ & $0.02 u$ \\
\hline Cresol (Total of $\mathrm{o}, \mathrm{m}$, and $\mathrm{p}$-cresol) & 200.00 & $0.04 u$ & $0.04 u$ & $0.023 \mathrm{DJ}$ & $0.4 \mathrm{u}$ \\
\hline 1,4 Dichlorobenzene & 7.50 & $0.02 u$ & $0.02 u$ & $0.02 u$ & $0.02 u$ \\
\hline 2,4 Dinitrotoluene & 0.13 & $0.02 u$ & $0.02 u$ & $0.02 u$ & $0.02 u$ \\
\hline Hexachlorobutadiene & 0.50 & $0.02 u$ & $0.02 u$ & $0.02 u$ & $0.02 u$ \\
\hline Hexachloroethane & 3.00 & $0.02 u$ & $0.02 u$ & $0.02 u$ & $0.02 u$ \\
\hline Nitrobenzene & 2.00 & $0.02 u$ & $0.02 u$ & $0.02 u$ & $0.02 u$ \\
\hline Pentachlorophenol & 100.00 & $0.02 u$ & $0.02 u$ & $0.02 u$ & $0.02 u$ \\
\hline Pyridine & 5.00 & $0.02 u$ & $0.02 u$ & $0.02 u$ & $0.02 u$ \\
\hline 2,4,5 Trichlorophenol & 400.00 & $0.02 u$ & $0.02 u$ & $0.02 u$ & $0.02 u$ \\
\hline 2,4,6 Trichlorophenol & 2.00 & $0.02 u$ & $0.02 u$ & $0.02 u$ & $0.02 u$ \\
\hline Hexachlorobenzene & 0.13 & $0.02 u$ & $0.02 u$ & $0.02 u$ & $0.02 u$ \\
\hline Benzene & 0.50 & $0.01 u$ & $0.01 u$ & $0.01 u$ & $0.01 u$ \\
\hline Carbon Tetrachloride & 0.50 & $0.01 u$ & $0.01 u$ & $0.01 u$ & $0.01 u$ \\
\hline Chlorobenzene & 100.00 & $0.01 u$ & $0.01 u$ & $0.01 u$ & $0.01 u$ \\
\hline Chloroform & 6.00 & $-0.01 u$ & $0.01 u$ & $0.01 u$ & $0.01 u$ \\
\hline 1,2 Dichloroethane & 0.50 & $0.01 u$ & $0.01 u$ & $0.01 u$ & $0.01 u$ \\
\hline 1,1 Dichloroethylene (or -ethene) & 0.70 & $0.01 \mathrm{u}$ & $0.01 \mathrm{u}$ & $0.01 u$ & $0.01 u$ \\
\hline Methyl ethyl ketone (or 2-Butanone) & 200.00 & $0.008 j$ & $0.006 j$ & $0.01 u$ & $0.01 u$ \\
\hline Tetrachloroethylene (or -ethene) & 0.70 & $0.01 u$ & $0.01 u$ & $0.01 u$ & $0.01 u$ \\
\hline Trichloroethylene (or -ethene) & 0.50 & $0.01 u$ & $0.01 \mathrm{u}$ & $0.01 u$ & $0.01 u$ \\
\hline Vinyl chloride & 0.20 & $0.01 u$ & $0.01 u$ & $0.01 u$ & $0.01 u$ \\
\hline Methylene Chloride & 0.02 & $0.01 u$ & $0.01 u$ & $0.01 u$ & $0.01 u$ \\
\hline 1,1,1-Trichloroethane & 0.02 & $0.01 u$ & $0.01 u$ & $0.01 u$ & $0.01 u$ \\
\hline 1,1,2-Trichloro-1,2,2-trifluoroethane & 0.02 & $0.01 \mathrm{u}$ & $0.01 u$ & $0.01 u$ & $0.01 u$ \\
\hline Trichloromonofluoromethane & 0.02 & $0.01 u$ & $0.01 u$ & $0.01 u$ & $0.01 u$ \\
\hline \multicolumn{2}{|c|}{ Note: $u$-not present at reporting detection limit. } & \multirow{2}{*}{\multicolumn{4}{|c|}{$\begin{array}{l}\text { Sample Numbers } 14-39 \text { represent Raschig } \\
\text { Rings from barrels containing freon, oil, }\end{array}$}} \\
\hline \multicolumn{2}{|c|}{ j-present at an estimated value below } & & & & \\
\hline the reporting detection limit. & & \multicolumn{4}{|c|}{ distillate, collant, or extract. } \\
\hline
\end{tabular}


Table 2

\begin{tabular}{|c|c|c|c|c|c|}
\hline \multirow{2}{*}{$\begin{array}{l}\text { Uranium Treatment Unit Closure } \\
\text { TCLP Final Rinseate Levels (mg/L) }\end{array}$} & \multirow{2}{*}{\begin{tabular}{|c|} 
Required \\
By Closure \\
\end{tabular}} & \multicolumn{3}{|c|}{ Item Description and Customer } & \\
\hline & & \multicolumn{4}{|c|}{ Sample Number. * $14-39=$ Raschig Rings } \\
\hline & Plan & Cool. 2B & Cool. 2B & Cool. 2C & Cool. 2C \\
\hline ANALYTE & Level (mg/L) & 25 & 26 & 27 & 28 \\
\hline Arsenic & 5.00 & $<4$ & $<4$ & $<4$ & $<4$ \\
\hline Barium & 100.00 & 0.04 & 0.06 & 0.05 & 0.22 \\
\hline Cadmium & 1.00 & $<0.2$ & $<0.2$ & $<0.2$ & $<0.2$ \\
\hline Chromium & 5.00 & $<0.2$ & $<0.2$ & $<0.2$ & $<0.2$ \\
\hline Lead & 5.00 & $<0.5$ & $<0.5$ & $<0.5$ & $<0.5$ \\
\hline Mercury & 0.20 & $<0.02$ & $<0.02$ & $<0.02$ & $<0.02$ \\
\hline Selenium & 1.00 & $<0.5$ & $<0.5$ & $<0.5$ & $<0.5$ \\
\hline Silver & 5.00 & $<0.3$ & $<0.3$ & $<0.3$ & $<0.3$ \\
\hline o-Cresol ( or 2-methylphenol) & 200.00 & $0.01 \mathrm{u}$ & $0.01 u$ & $0.02 u$ & $0.02 u$ \\
\hline m-Cresol & 200.00 & NA & NA & NA & NA \\
\hline$p$-Cresol (Lab reports $m$ and $p$ total) & 200.00 & $0.01 u$ & $0.01 u$ & $0.02 u$ & $0.02 u$ \\
\hline Cresol (Total of o, $\mathrm{m}$, and p-cresol) & 200.00 & $0.02 u$ & $0.02 u$ & $0.04 u$ & $0.04 u$ \\
\hline 1,4 Dichlorobenzene & 7.50 & $0.01 u$ & $0.01 u$ & $0.02 u$ & $0.02 u$ \\
\hline 2,4 Dinitrotoluene & 0.13 & $0.01 u$ & $0.01 u$ & $0.02 u$ & $0.02 u$ \\
\hline Hexachlorobutadiene & 0.50 & $0.01 u$ & $0.01 u$ & $0.02 u$ & $0.02 u$ \\
\hline Hexachloroethane & 3.00 & $0.01 u$ & $0.01 u$ & $0.02 u$ & $0.02 u$ \\
\hline Nitrobenzene & 2.00 & $0.01 \mathrm{u}$ & $0.01 u$ & $0.02 u$ & $0.02 u$ \\
\hline Pentachlorophenol & 100.00 & $0.01 u$ & $0.01 u$ & $0.02 u$ & $0.02 u$ \\
\hline Pyridine & 5.00 & $0.01 u$ & $0.01 u$ & $0.02 u$ & $0.02 u$ \\
\hline 2,4,5 Trichlorophenol & 400.00 & $0.01 u$ & $0.01 u$ & $0.02 u$ & $0.02 u$ \\
\hline 2,4,6 Trichlorophenol & 2.00 & $0.01 u$ & $0.01 u$ & $0.02 u$ & $0.02 u$ \\
\hline Hexachlorobenzene & 0.13 & $0.01 u$ & $0.01 u$ & $0.02 u$ & $0.02 u$ \\
\hline Benzene & 0.50 & $0.01 u$ & $0.01 u$ & $0.01 u$ & $0.01 u$ \\
\hline Carbon Tetrachloride & 0.50 & $0.01 u$ & $0.01 u$ & $0.01 u$ & $0.01 u$ \\
\hline Chlorobenzene & 100.00 & $0.01 u$ & $0.01 u$ & $0.01 u$ & $0.01 u$ \\
\hline Chloroform & 6.00 & $0.04 \mathrm{t}$ & $0.01 u$ & $0.01 u$ & $0.01 u$ \\
\hline 1,2 Dichloroethane & 0.50 & $0.01 u$ & $0.01 u$ & $0.01 u$ & $0.01 u$ \\
\hline 1,1 Dichloroethylene (or -ethene) & 0.70 & $0.01 u$ & $0.01 \mathrm{u}$ & $0.01 u$ & $0.01 u$ \\
\hline Methyl ethyl ketone (or 2-Butanone) & 200.00 & $0.01 \mathrm{u}$ & $0.01 u$ & $0.006 j$ & $0.005 j$ \\
\hline Tetrachloroethylene (or -ethene) & 0.70 & $0.01 u$ & $0.01 u$ & $0.01 u$ & $0.01 u$ \\
\hline Trichloroethylene (or -ethene) & 0.50 & $0.01 u$ & $0.01 u$ & $0.01 u$ & $0.01 u$ \\
\hline Vinyl chloride & 0.20 & $0.01 u$ & $0.01 u$ & $0.01 u$ & $0.01 u$ \\
\hline Methylene Chloride & 0.02 & $0.01 u$ & $0.01 u$ & $0.01 u$ & $0.01 u$ \\
\hline 1,1,1-Trichloroethane & 0.02 & $0.01 u$ & $0.01 u$ & $0.01 u$ & $0.01 u$ \\
\hline 1,1,2-Trichloro-1,2,2-trifluoroethane & 0.02 & $0.01 \mathrm{u}$ & $0.01 u$ & $0.01 u$ & $0.01 u$ \\
\hline Trichloromonofluoromethane & 0.02 & $0.01 u$ & $0.01 u$ & $0.01 u$ & $0.01 u$ \\
\hline Note: u-not present at reporting dete & tion limit. & \multirow{2}{*}{\multicolumn{4}{|c|}{\begin{tabular}{|l|} 
Sample Numbers $14-39$ represent Raschig \\
Rings from barrels containing freon, oil, \\
\end{tabular}}} \\
\hline \multicolumn{2}{|c|}{ j-present at an estimated value below } & & & & \\
\hline the reporting detection limit. & & \multicolumn{4}{|c|}{ distillate, collant, or extract. } \\
\hline
\end{tabular}


Table 2

\begin{tabular}{|c|c|c|c|c|c|}
\hline \multirow{2}{*}{\begin{tabular}{|l} 
Uranium Treatment Unit Closure \\
TCLP Final Rinseate Levels (mg/L) \\
\end{tabular}} & \multirow{2}{*}{\begin{tabular}{|c|} 
Required \\
By Closure \\
\end{tabular}} & \multicolumn{3}{|c|}{ Item Description and Customer } & \\
\hline & & \multicolumn{4}{|c|}{ Sample Number. * 14-39 =Raschig Rings } \\
\hline & Plan & Cool. 2E & Cool. 2E & Oil 5C & Oil 5C \\
\hline ANALYTE & Level (mg/L) & 29 & 30 & 31 & 32 \\
\hline Arsenic & 5.00 & $<4$ & $<4$ & $<4$ & $<4$ \\
\hline Barium & 100.00 & 0.26 & 0.6 & 0.12 & 0.11 \\
\hline Cadmium & 1.00 & $<0.2$ & $<0.2$ & $<0.2$ & $<0.2$ \\
\hline Chromium & 5.00 & $<0.2$ & $<0.2$ & $<0.2$ & $<0.2$ \\
\hline Lead & 5.00 & $<0.5$ & $<0.5$ & $<0.5$ & $<0.5$ \\
\hline Mercury & 0.20 & $<0.02$ & $<0.02$ & $<0.02$ & $<0.02$ \\
\hline Selenium & 1.00 & $<0.5$ & $<0.5$ & $<0.5$ & $<0.5$ \\
\hline Silver & 5.00 & $<0.3$ & $<0.3$ & $<0.3$ & $<0.3$ \\
\hline o-Cresol (or 2-methylphenol) & 200.00 & $0.03 u$ & $0.02 u$ & $0.02 u$ & $0.02 u$ \\
\hline m-Cresol & 200.00 & NA & NA & NA & NA \\
\hline$p$-Cresol (Lab reports $m$ and $p$ total) & 200.00 & $0.03 u$ & $0.02 u$ & $0.02 u$ & $0.02 u$ \\
\hline Cresol (Total of o, m, and p-cresol) & 200.00 & $0.06 u$ & $0.04 u$ & $0.04 u$ & $0.04 u$ \\
\hline 1,4 Dichlorobenzene & 7.50 & $0.03 u$ & $0.02 u$ & $0.02 u$ & $0.02 u$ \\
\hline 2,4 Dinitrotoluene & 0.13 & $0.03 u$ & $0.02 u$ & $0.02 u$ & $0.02 u$ \\
\hline Hexachlorobutadiene & 0.50 & $0.03 u$ & $0.02 u$ & $0.02 u$ & $0.02 u$ \\
\hline Hexachloroethane & 3.00 & $0.03 u$ & $0.02 u$ & $0.02 u$ & $0.02 u$ \\
\hline Nitrobenzene & 2.00 & $0.03 u$ & $0.02 u$ & $0.02 u$ & $0.02 u$ \\
\hline Pentachlorophenol & 100.00 & $0.03 u$ & $0.02 u$ & $0.02 u$ & $0.02 u$ \\
\hline Pyridine & 5.00 & $0.03 u$ & $0.02 u$ & $0.02 u$ & $0.02 u$ \\
\hline 2,4,5 Trichlorophenol & 400.00 & $0.03 u$ & $0.02 u$ & $0.02 u$ & $0.02 u$ \\
\hline 2,4,6 Trichlorophenol & 2.00 & $0.03 u$ & $0.02 u$ & $0.02 u$ & $0.02 u$ \\
\hline Hexachlorobenzene & 0.13 & $0.03 u$ & $0.02 u$ & $0.02 u$ & $0.02 u$ \\
\hline Benzene & 0.50 & $0.01 u$ & $0.01 u$ & $0.01 u$ & $0.01 u$ \\
\hline Carbon Tetrachloride & 0.50 & $0.01 \mathrm{u}$ & $0.01 \mathrm{u}$ & $0.01 u$ & $0.01 u$ \\
\hline Chlorobenzene & 100.00 & $0.01 u$ & $0.01 \mathrm{u}$ & $0.01 u$ & $0.01 \mathrm{u}$ \\
\hline Chloroform & 6.00 & $0.04 u$ & $0.01 u$ & $0.01 u$ & $0.01 u$ \\
\hline 1,2 Dichloroethane & 0.50 & $0.01 \mathrm{u}$ & $0.01 u$ & $0.01 u$ & $0.01 u$ \\
\hline 1,1 Dichloroethylene (or -ethene) & 0.70 & $0.01 u$ & $0.01 u$ & $0.01 \mathrm{u}$ & $0.01 u$ \\
\hline Methyl ethyl ketone (or 2-Butanone) & 200.00 & $0.005 j$ & $0.007 j$ & $0.007 j$ & 0.01 \\
\hline Tetrachloroethylene (or -ethene) & 0.70 & $0.01 u$ & $0.01 u$ & $0.01 u$ & $0.01 u$ \\
\hline Trichloroethylene (or -ethene) & 0.50 & $0.01 \mathrm{u}$ & $0.01 u$ & $0.01 u$ & $0.01 \mathrm{u}$ \\
\hline Vinyl chloride & 0.20 & $0.01 \mathrm{u}$ & $0.01 u$ & $0.01 u$ & $0.01 u$ \\
\hline Methylene Chloride & 0.02 & $0.01 u$ & $0.01 u$ & $0.01 u$ & $0.01 u$ \\
\hline 1,1,1-Trichloroethane & 0.02 & $0.01 u$ & $0.01 u$ & $0.01 u$ & $0.01 u$ \\
\hline 1,1,2-Trichloro-1,2,2-trifluoroethane & 0.02 & $0.01 u$ & $0.01 u$ & $0.01 u$ & $0.01 \mathrm{u}$ \\
\hline Trichloromonofluoromethane & 0.02 & $0.01 u$ & $0.01 u$ & $0.01 u$ & $0.01 u$ \\
\hline \multirow{2}{*}{\multicolumn{2}{|c|}{$\begin{array}{l}\text { Note: } \text { u-not present at reporting detection limit. } \\
\text { i-present at an estimated value below }\end{array}$}} & \multirow{2}{*}{\multicolumn{4}{|c|}{$\begin{array}{l}\text { Sample Numbers } 14-39 \text { represent Raschig } \\
\text { Rings from barrels containing freon, oil, } \\
\end{array}$}} \\
\hline & j-present at an estimated value below & & & & \\
\hline the reporting detection limit. & & \multicolumn{4}{|c|}{ distillate, collant, or extract. } \\
\hline
\end{tabular}




\begin{tabular}{|c|c|c|c|c|c|}
\hline \multirow{2}{*}{\begin{tabular}{|l} 
Uranium Treatment Unit Closure \\
TCLP Final Rinseate Levels (mg/L) \\
\end{tabular}} & \multirow{2}{*}{\begin{tabular}{|c|} 
Required \\
By Closure \\
\end{tabular}} & \multicolumn{3}{|c|}{ Item Description and Customer } & \\
\hline & & \multicolumn{4}{|c|}{ Sample Number. ${ }^{*} 14-39=$ Raschig Rings } \\
\hline & Plan & Ext. 1B & Ext. 1B & Oil 5A & Oil 5A \\
\hline ANALYTE & Level (mg/L) & 33 & 34 & 35 & 36 \\
\hline Arsenic & 5.00 & $<4$ & $<4$ & $<4$ & $<4$ \\
\hline Barium & 100.00 & 0.13 & 0.18 & 0.05 & 0.38 \\
\hline Cadmium & 1.00 & $<0.2$ & $<0.2$ & $<0.2$ & $<0.2$ \\
\hline Chromium & 5.00 & $<0.2$ & $<0.2$ & $<0.2$ & $<0.2$ \\
\hline Lead & 5.00 & 0.5 & 0.9 & $<0.5$ & $<0.5$ \\
\hline Mercury & 0.20 & $<0.02$ & $<0.2$ & $<0.02$ & $<0.02$ \\
\hline Selenium & 1.00 & $<0.5$ & $<0.5$ & $<0.5$ & $<0.5$ \\
\hline Silver & 5.00 & $<0.3$ & $<0.3$ & $<0.3$ & $<0.3$ \\
\hline o-Cresol ( or 2-methylphenol) & 200.00 & $0.03 u$ & $0.03 u$ & $0.02 u$ & $0.01 u$ \\
\hline m-Cresol & 200.00 & NA & NA & NA & NA \\
\hline$p$-Cresol (Lab reports $m$ and $p$ total) & 200.00 & $0.03 u$ & $0.03 u$ & $0.02 u$ & $0.01 u$ \\
\hline Cresol (Total of $o, m$, and p-cresol) & 200.00 & $0.06 u$ & $0.06 u$ & $0.04 u$ & $0.02 u$ \\
\hline 1,4 Dichlorobenzene & 7.50 & $0.03 u$ & $0.03 u$ & $0.02 u$ & $0.01 \mathrm{u}$ \\
\hline 2,4 Dinitrotoluene & 0.13 & $0.03 u$ & $0.03 u$ & $0.02 u$ & $0.01 u$ \\
\hline Hexachlorobutadiene & 0.50 & $0.03 u$ & $0.03 u$ & $0.02 u$ & $0.01 u$ \\
\hline Hexachloroethane & 3.00 & $0.03 u$ & $0.03 u$ & $0.02 u$ & $0.01 u$ \\
\hline Nitrobenzene & 2.00 & $0.03 u$ & $0.03 u$ & $0.02 \mathrm{u}$ & $0.01 u$ \\
\hline Pentachlorophenol & 100.00 & $0.03 u$ & $0.03 u$ & $0.02 u$ & $0.01 u$ \\
\hline Pyridine & 5.00 & $0.03 u$ & $0.03 u$ & $0.02 u$ & $0.01 u$ \\
\hline 2,4,5 Trichlorophenol & 400.00 & $0.03 u$ & $0.03 u$ & $0.02 u$ & $0.01 u$ \\
\hline 2,4,6 Trichlorophenol & 2.00 & $0.03 u$ & $0.03 u$ & $0.02 u$ & $0.01 u$ \\
\hline Hexachlorobenzene & 0.13 & $0.03 u$ & $0.03 u$ & $0.02 u$ & $0.01 u$ \\
\hline Benzene & 0.50 & $0.01 u$ & $0.01 \mathrm{u}$ & $0.01 u$ & $0.01 u$ \\
\hline Carbon Tetrachloride & 0.50 & $0.01 u$ & $0.01 u$ & $0.01 u$ & $0.01 u$ \\
\hline Chlorobenzene & 100.00 & $0.01 u$ & $0.01 u$ & $0.01 u$ & $0.01 u$ \\
\hline Chloroform & 6.00 & $0.04 \mathrm{u}$ & $0.01 u$ & $0.01 \mathrm{u}$ & $0.01 u$ \\
\hline 1,2 Dichloroethane & 0.50 & $0.01 u$ & $0.01 u$ & $0.01 u$ & $0.01 u$ \\
\hline 1,1 Dichloroethylene (or -ethene) & 0.70 & $0.01 u$ & $0.01 u$ & $0.01 \mathrm{u}$ & $0.01 u$ \\
\hline Methyl ethyl ketone (or 2-Butanone) & 200.00 & 0.018 & $0.009 j$ & $0.006 j$ & $0.007 j$ \\
\hline Tetrachloroethylene (or -ethene) & 0.70 & $0.01 u$ & $0.01 u$ & $0.01 u$ & $0.01 u$ \\
\hline Trichloroethylene (or -ethene) & 0.50 & $0.01 u$ & $0.01 u$ & $0.01 \mathrm{u}$ & $0.01 u$ \\
\hline Vinyl chloride & 0.20 & $0.01 u$ & $0.01 u$ & $0.01 \mathrm{u}$ & $0.01 u$ \\
\hline Methylene Chloride & 0.02 & $0.01 \mathrm{u}$ & $0.01 u$ & $0.01 u$ & $0.01 u$ \\
\hline 1,1,1-Trichloroethane & 0.02 & $0.01 u$ & $0.01 u$ & $0.01 \mathrm{u}$ & $0.01 \mathrm{u}$ \\
\hline 1,1,2-Trichloro-1,2,2-trifluoroethane & 0.02 & $0.01 u$ & $0.01 u$ & $0.01 \mathrm{u}$ & $0.01 u$ \\
\hline Trichloromonofluoromethane & 0.02 & $0.01 u$ & $0.01 u$ & $0.01 \mathrm{u}$ & $0.01 u$ \\
\hline \multicolumn{2}{|c|}{ Note: u-not present at reporting detection limit. } & \multicolumn{4}{|c|}{ Sample Numbers 14-39 represent Raschig } \\
\hline \multicolumn{2}{|c|}{ j-present at an estimated value below } & \multicolumn{4}{|c|}{ Rings from barrels containing freon, oil, } \\
\hline the reporting detection limit. & & distillate, $\mathrm{C}$ & lant, or & ract. & \\
\hline
\end{tabular}


Table 2

\begin{tabular}{|c|c|c|c|c|c|}
\hline \multirow{2}{*}{$\begin{array}{l}\text { Uranium Treatment Unit Closure } \\
\text { TCLP Final Rinseate Levels (mg/L) }\end{array}$} & \multirow{2}{*}{\begin{tabular}{|c|} 
Required \\
By Closure \\
\end{tabular}} & \multicolumn{3}{|c|}{ Item Description and Customer } & \\
\hline & & \multicolumn{4}{|c|}{ Sample Number. * $14-39=$ Raschig Rings } \\
\hline & Plan & Oil 5B & Oil 5B & Returns & Surface \\
\hline ANALYTE & Level (mg/L) & 37 & 38 & 39 & 40 \\
\hline Arsenic & 5.00 & $<4$ & $<4$ & $<4$ & $<4$ \\
\hline Barium & 100.00 & 1.03 & 0.41 & 0.12 & 0.27 \\
\hline Cadmium & 1.00 & $<0.2$ & $<0.2$ & $<0.2$ & 0.2 \\
\hline Chromium & 5.00 & 0.1 & $<0.2$ & $<0.2$ & 0.1 \\
\hline Lead & 5.00 & 0.6 & $<0.5$ & $<0.5$ & $<0.5$ \\
\hline Mercury & 0.20 & $<0.02$ & $<0.02$ & $<0.02$ & $<0.02$ \\
\hline Selenium & 1.00 & $<0.5$ & $<0.5$ & $<0.5$ & $<0.5$ \\
\hline Silver & 5.00 & $<0.3$ & $<0.3$ & $<0.3$ & $<0.3$ \\
\hline o-Cresol ( or 2-methylphenol) & 200.00 & $0.02 u$ & $0.02 u$ & $0.02 u$ & $0.1 \mathrm{u}$ \\
\hline m-Cresol & 200.00 & NA & NA & NA & NA \\
\hline$p$-Cresol (Lab reports $m$ and $p$ total) & 200.00 & $0.02 u$ & $0.02 u$ & $0.02 u$ & $0.1 \mathrm{u}$ \\
\hline Cresol (Total of $o, m$, and p-cresol) & 200.00 & $0.04 u$ & $0.04 u$ & $0.04 u$ & $0.2 \mathrm{u}$ \\
\hline 1,4 Dichlorobenzene & 7.50 & $0.02 u$ & $0.02 u$ & $0.02 u$ & $0.1 u$ \\
\hline 2,4 Dinitrotoluene & 0.13 & $0.02 u$ & $0.02 u$ & $0.02 u$ & $0.1 u$ \\
\hline Hexachlorobutadiene & 0.50 & $0.02 u$ & $0.02 u$ & $0.02 u$ & $0.1 u$ \\
\hline Hexachloroethane & 3.00 & $0.02 u$ & $0.02 u$ & $0.02 u$ & $0.1 \mathrm{u}$ \\
\hline Nitrobenzene & 2.00 & $0.02 u$ & $0.02 u$ & $0.02 u$ & $0.1 u$ \\
\hline Pentachlorophenol & 100.00 & $0.02 u$ & $0.02 u$ & $0.02 u$ & $0.1 u$ \\
\hline Pyridine & 5.00 & $0.02 u$ & $0.02 u$ & $0.02 u$ & $0.1 \mathrm{u}$ \\
\hline 2,4,5 Trichlorophenol & 400.00 & $0.02 u$ & $0.02 u$ & $0.02 u$ & $0.1 \mathrm{u}$ \\
\hline 2,4,6 Trichlorophenol & 2.00 & $0.02 u$ & $0.02 u$ & $0.02 u$ & $0.1 u$ \\
\hline Hexachlorobenzene & 0.13 & $0.02 u$ & $0.02 u$ & $0.02 u$ & $0.1 u$ \\
\hline Benzene & 0.50 & $0.01 u$ & $0.01 u$ & $0.01 u$ & $0.01 u$ \\
\hline Carbon Tetrachloride & 0.50 & $0.01 u$ & $0.01 \mathrm{u}$ & $0.01 u$ & $0.01 u$ \\
\hline Chlorobenzene & 100.00 & $0.01 u$ & $0.01 u$ & $0.01 u$ & $0.01 \mathrm{u}$ \\
\hline Chloroform & 6.00 & $0.07 u$ & $0.01 u$ & $0.01 u$ & $0.01 u$ \\
\hline 1,2 Dichloroethane & 0.50 & $0.01 u$ & $0.01 u$ & $0.01 u$ & $0.01 u$ \\
\hline 1,1 Dichloroethylene (or -ethene) & 0.70 & $0.01 u$ & $0.01 u$ & $0.01 u$ & $0.01 u$ \\
\hline Methyl ethyl ketone (or 2-Butanone) & 200.00 & 0.011 & $0.008 j$ & $0.01 u$ & $0.006 j$ \\
\hline Tetrachloroethylene (or -ethene) & 0.70 & $0.01 u$ & $0.01 \mathrm{u}$ & $0.01 u$ & $0.01 u$ \\
\hline Trichloroethylene (or -ethene) & 0.50 & $0.01 u$ & $0.01 u$ & $0.01 u$ & $0.01 u$ \\
\hline Vinyl chloride & 0.20 & $0.01 u$ & $0.01 u$ & $0.01 u$ & $0.01 u$ \\
\hline Methylene Chloride & 0.02 & $0.01 u$ & $0.01 u$ & $0.01 \mathrm{u}$ & $0.01 u$ \\
\hline 1,1,1-Trichloroethane & 0.02 & $0.01 u$ & $0.01 u$ & $0.01 u$ & $0.01 u$ \\
\hline 1,1,2-Trichloro-1,2,2-trifluoroethane & 0.02 & $0.01 u$ & 0.014 & $0.01 u$ & $0.01 u$ \\
\hline Trichloromonofluoromethane & 0.02 & $0.01 u$ & $0.01 u$ & $0.01 u$ & $0.01 u$ \\
\hline e: u-not & imit. & & $x$ & & Raschig \\
\hline j-pre & elow & gs ff & IrTels & ining & , oil, \\
\hline the reporting detection limit. & & distillate, & ant, & ract. & \\
\hline
\end{tabular}


APPENDIX A

BUILDING 9706 URANIUM TREATMENT UNIT - CORRESPONDENCE LIST

\begin{tabular}{|l|l|l|}
\hline Letter Date & Originator to Receiver & \multicolumn{1}{|c|}{ Subject } \\
\hline $04 / 04 / 95$ & Butz to Spence & Closure Plan submittal to DOE \\
\hline $04 / 14 / 95$ & Spence to Tiesler & Closure Plan submittal to TDEC \\
\hline $08 / 25 / 95$ & Tiesler to Spence & $\begin{array}{l}\text { TDEC notification of plan for public comment and } \\
\text { request for } 3 \text { additional copies }\end{array}$ \\
\hline $09 / 13 / 95$ & Spence to Tiesler & Extra copies of Closure Plan submitted \\
\hline $11 / 07 / 95$ & Tiesler to Spence & TDEC approval of Closure Plan \\
\hline $11 / 21 / 95$ & Spence to Gustavson & TDEC approval of Closure Plan \\
\hline $12 / 08 / 95$ & Hill to Jessen & Environmental Directive--Proceed with Closure \\
\hline $01 / 17 / 96$ & Butz to Spence & Schedule Change Request to DOE \\
\hline $02 / 07 / 96$ & Spence to Tiesler & Schedule Change Request to TDEC \\
\hline $02 / 15 / 96$ & Moran to Spence & TDEC approval of Schedule Change \\
\hline $02 / 16 / 96$ & Butz to Spence & Schedule Deviation Notice \\
\hline
\end{tabular}

- T. R. Butz, Plant Manager, Y-12 Plant, Lockheed Martin Energy Systems, Inc. (LMES)

- F. P. Gustavson, Vice President, Defense and Manufacturing, LMES

- C. C. Hill, Y-12 Environmental Coordinator, LMES

- N. C. Jessen Jr., Manager, EUO, LMES

- D. Moran, DOE Coordinator, DSWM, TDEC

- R. J. Spence, Y-12 Site Manager, Oak Ridge Operations Office, Department of Energy (DOE)

- T. Tiesler, Director, Division of Solid Waste Management (DSWM), Tennessee Department of Environment and Conservation (TDEC) 

April 4, 1995

Mr. R. J. Spence

Department of Energy, Oak Ridge Operations

Post Office Box 2001

Oak Ridge, Tennessee 37831

Dear Mr. Spence:

\section{Resource Conservation and Recovery Act (RCRA)}

Closure Plan for the Uranium Treatment Unit

Enciosed is a document entitled "Resource Conservation and Recovery Act (RCRA) Closure Plan for the Uranium Treatment Unit," Document Number Y/TS-1253. Submittal of this plan is required to fulfill the requirements of Title 40, Code of Federal Regulations (CFR), Part 265, Subpart G, and Tennessee Rule 1200-1-11-.05(7).

Upon your review and approval of the enclosure, please submit this closure plan to Mr. Tom Tiesler of the Tennessee Department of Environment and Conservation. The \$2,000 fee required for review of the closure plan is aiso enclosed.

I certify that this document and all enciosures were prepared under my direction or supervision in accordance with a system designed to ensure that qualified personnel properly gathered and evaluated the information submitted. Based on my inquiry of the person or persons directly responsible for gathering the information, the information submitted is, to the best of my knowledge and belief, true, accurate, and complete.

If you have any questions, contact S. E. Rathke at 574-9394.

Very truly yours,

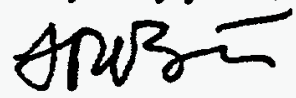

T. R. Butz

Y-12 Plant Manager

TRB:rft

Enclosures: As Stated 
Mr. R. J. Spence, DOE-ORO

Page 2

April 4, 1995

cc/encs: M. S. Burris

C. H. Fritts

J. A. Kreykes

W. G. McMillan, DOE-ORO

S. E. Rathke

L. M. Sparks, DOE-ORO

B. E Walton

Y-12 Central Files

File-EMD-RC

cc: D. J. Bostock

T. R. Butz

C. D. Goins Jr.

J. S. Guilford

C. C. Hill

R. M. Keyser/J. E. Powell

M. E. Mitchell/T. P. A. Perry

M. K. Morrow

R. K. Roosa/N. C. Jessen 


\section{Enclosure}

Letter, Butz to Spence

Dated: April 4, 1995

\section{LETTER TITLE}

Resource Conservation and Recovery Act (RCRA) Cosure Plan for the Uranium Treatment Unit 


\section{Department of Energy}

Oak Ridge Operations Office

P.O. Box 2001

Oak Ridge, Tennessee 37831-8555

$Y-12$ Site Office

April 14, 1995

Certified Mail

P 621944187

Mr. Tom Tiesler, Director

Division of Solid Waste Management

Tennessee Department of Environment

and Conservation

Fifth Floor, L \& C Tower

401 Church Street

Nashville, Tennessee. 37243-1535

Dear Mr. Tiesler:

\section{RESOURCE CONSERVATION AND RECOVERY ACT (RCRA) CLOSURE PLAN FOR THE URANIUM TREATMENT UNIT}

Enclosed is a document entitled "Resource Conservation and Recovery Act (RCRA) Closure Plan for the Uranium Treatment Unit," Document Number Y/TS-1253. This plan is being submitted for your approval to fulfill the requirements of Title 40, Code of Federal Regulations, Part 265, Subpart.G, and Tennessee Rule 1200$1-11-.55(7)$. The $\$ 2,000$ fee required for review of the closure plan is also enclosed.

If you have any questions or require additional information, please feel free to contact Larry Sparks of my staff at (615) 576-2659.

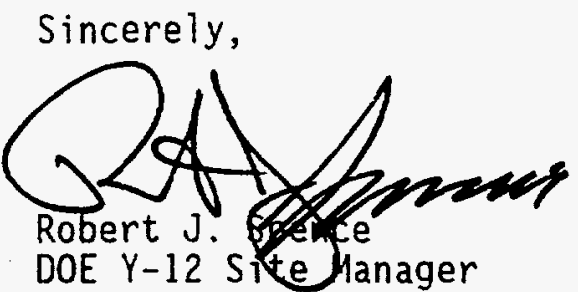

DP-813:Sparks

DOE Y-12 Site lanager

Enclosures

cc w/enclosure:

E. Lemming, TDEC, Oak Ridge

P. Gross, SE-31, ORO

cc w/o enclosure:

J. Powe 11, 9116, MS 8098, Y-12 


\section{STATE OF TENNESSEE \\ DEPARTMENT OF ENVIRONMENT AND CONSERVATION \\ Division of Solid Waste Management \\ Fifth Floor, L \& C Tower \\ 401 Church Street \\ Nashville. Tennessee $37243-1535$}

August 25, 1995

Mr. Robert Spence

Y-12 Site Manager

U.S. Department of Energy

Oak Ridge Reservation

Oak Ridge Operations Office

Post Office Box 2001

Oak Ridge, Tennessee 37831-8541
OPMONCL FOAM $99(7-\infty)$

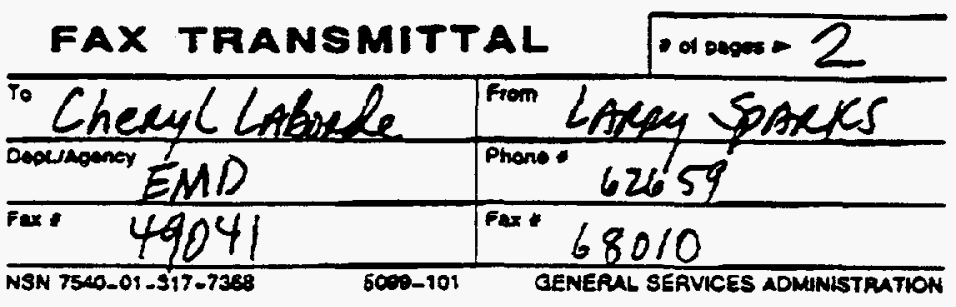

Re: Resource Conservation and Recovery Act (RCRA) Closure Plan for Building 9212 E-Wing Area

Resource Conservation and Recovery Act (RCRA) Closure Plan for the Uranium Treatment Unit

Dear Mr. Spence:

This letter is to inform you that we have completed our review of the stated plans. Based on this review, which is authorized pursuant to 40 CFR 265 Subpart G, incorporated by reference at Tennessee Rule 1200-1-11-.05 (7) (a) 1, your plans have been determined to be complete and the DSWM will be issuing a public notice. After receiving any public comments, the plans will either be approved, approved with modification or disapproved.

The plans, as presented, will be on display at the Oak Ridge Public Library, TDEC-DOE Oversite office, and the DSWM Knoxville Field Office during the public comment period. Please supply this office with three (3) additional copies of the subject plans for distribution September 5, 1995 Mr. Ed Casey, Public Information, DSWM, will be handling the specifics of the newspaper notice and distribution of copies. He may be reached in the DSWM Central Office at telephone number (615) 532-0840. 
Mr. Robert J. Spence

If you bave any questions, please contact David Moran of my staff at 615) 532-0875.

Sincerely,

Tom Tiesier, Director

Division of Solid Waste Management

c: Mr. Wayne Gregory, Manager ISS 


\section{Department of Energy}

Oak Ridge Operations Office

P.O. Box 2001

Oak Ridge, Tennessee 37831-8555

September 13, 1995

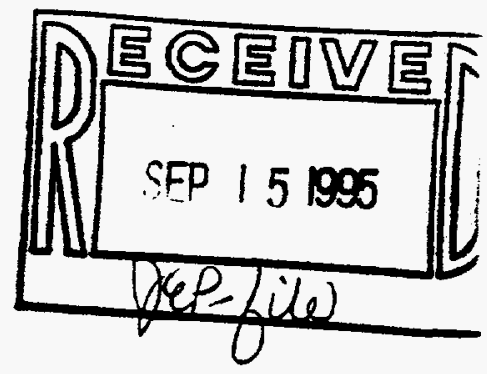

CY: $\underset{S E R}{C M L}$

Tom Tiester, Director

Division of Solid Waste Management

Tennessee Department of Environment

and Conservation

Fifth Floor, Life \& Casualty Tower

401 Church Street

Nashville, Tennessee 37243-1535

Dear Mr. Tiesler:

RESOURCE CONSERVATION AND RECOVERY ACT (RCRA) CLOSURE PLANS FOR BUILDING 9212 E-WING AREA AND THE URANIUM TREATMENT UNIT

Per your request of August $25,-1995$, please find enclosed three additional copies of each of the subject RCRA Closure Plans for units at the Department of Energy $Y-12$ Site, Oak Ridge, Tennessee.

If there are any questions on this matter, please contact Larry Sparks of my staff at (423) 576-2659.

DP-813: Sparks

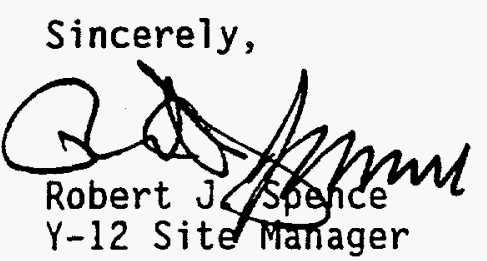

Enclosure

cc $w / 0$ enclosure

J. Powe11, 9116, MS 8098, Y-12 


\section{STATE OF TENNESSEE \\ DEPARTMENT OF ENVIRONMENT AND CONSERVATION \\ Division of Solid Waste Management \\ Fifth Floor, L \& C Tower \\ 401 Church Street \\ Nashville, Tennessee 37243 - 1535}

November 7, 1995

Mr. Robert Spence

Y-12 Site

United States Department of Energy

Oak Ridge Reservation

Oak Ridge Operations Office

Post Office Box 2001

Oak Ridge, Tennessee 37831-8541

Re: Approval of the following RCRA Closure Plans;

Resource Conservation and Recovery Act (RCRA) Closure Plan for Building 9212 E-Wing Area

Resource Conservation and Recovery Act (RCRA) Closure Plan for the Uranium Treatment Unit

Dear Mr. Spence:

The above stated closure plans have been reviewed by my staff, which is authorized pursuant to 40 CFR 265 Subpart G, incorporated by reference at Tennessee Rule 1200-1-11-.05 (7) (a) 1. Based on this review, your plans have been determined to be complete. No public comments were received during the public comment period.

The stated plans are approved. You may proceed with closure activities in accordance with the plans and Tennessee Rule 1200-1-11-.05 (7). 
Mr. Robert Spence

November 7, 1995

Page 2

If you require further service, please contact David Moran of my staff at (615) 532-0875.

Sincerely,

Tom Tiesler, Director

Division of Solid Waste Management

c: Wayne Gregory, DSWM

David Moran, DSWM

Earl Leming, DOE-O

c:cp21195 


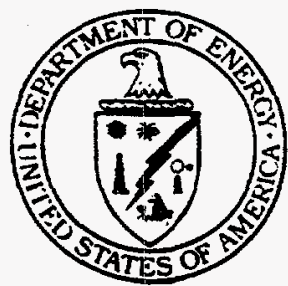

$Y-12$ Site Office
Department of Energy

Oak Ridge Operations Office

P.O. Box 2001

Oak Ridge, Tennessee 37831-8555

November 21, 1995 .

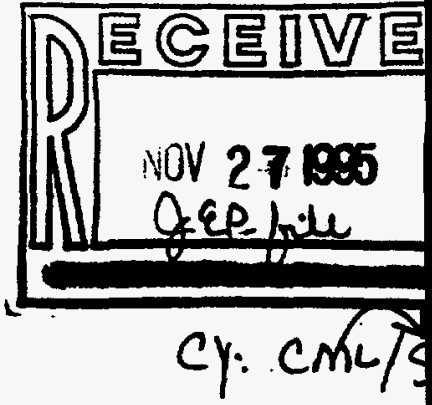

Mr. F. P. Gustavson, Vice President

Defense and Manufacturing

Lockheed Mart in Energy Systems, Inc.

Post Office Box 2009

Oak Ridge, Tennessee 37831-8010

Dear Mr. Gustavson:

APPROVAL OF RESOURCE CONSERVATION AND RECOVERY ACT (RCRA) CLOSURE PLANS

This letter provides notification that the Tennessee Department of Environment and Conservation (TDEC) has approved the RCRA closure plans for Building 9212 E-Wing Area and for the Uranium Treatment Unit. Enclosed is a copy of the letter from TDEC of November 7, 1995. Closure of these units must now proceed according to the schedules in each closure plan.

If you have any questions or need additional information, please contact Larry Sparks of my staff at 6-2659.

DP-813:Sparks

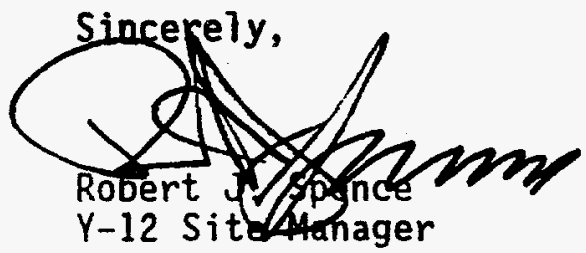

Enclosure

CC w/enclosure:

J. Powe11, 9116, MS 8098, Y-12 
Date: December 8, 1995

To: $\quad$ N. C. Jessen Jr.

cc: $\quad$ T. R. Butz, E. T. Collins, C. H. Fritts, J. M. Gilbert,

R. M. Keyser, C. M. LaBorde, M. K. Morrow, J. E. Powell,

S. E. Rathke, R. K. Roosa, File-EMD-RC

From:

C. C. Hill, Y-12 Plant Environmental Coordinator $\left(C^{2} / \mathrm{J}\right.$
Building $9116, \mathrm{US}-8098,6-7113$

Subject: Uranium Treatment Facility and E-Wing

Resource Conservation and Recovery Act (RCRA) Closures

\section{ENVIRONMENTAL DIRECTIVE}

On November 7, 1995, personnel from the Tennessee Department of Environment and Conservation (TDEC) approved the RCRA hazardous waste unit closure plans for the Uranium Treatment Unit and the RCRA Storage Unit located in E-wing of Building 9212. These closures must be performed in accordance with schedules prescribed in the approved closure plans. Personnel from the Department of Energy must certify to the state staff on or before March 6 , 1996 (for the E-wing storage area), and May 5, 1996 (for the Uranium Treatment Unit), that the closures have been completed. Completion of these closures in accordance with the approved closure plan is required to remain in compliance with the Tennessee Hazardous Waste Management Regulations.

\section{REQUIRED IMMEDIATE ACTIONS:}

Based on these facts, you are directed to provide to the Y-12 Plant Environmental Coordinator the following information by December 15, 1995:

1. A detailed project schedule that will accomplish a certified complete closure in accordance with the schedule contained in the approved closure plans.

2. Identify the individual who will have the project management responsibility and accountability.

In addition, during the project, a periodic status report that identifies any schedule slippage to the approved interim milestones must be provided to the Y-12 Plant Environmental Coordinator at least ten days prior to the approved milestone.

If you have any questions, please contact me.

$\mathrm{CCH}: \mathrm{bjs}$ 
January 17, 1996

Mr. R. J. Spence

Department of Energy, Oak Ridge Operations

Post Office Box 2001

Oak Ridge, Tennessee 37831

Dear Mr. Spence:

Resource Conservation and Recovery Act Closure Plan for the Uranium Treatment Unit-Schedule Change Request

The enclosed, revised Table 1 Closure Schedule for the Uranium Treatment Unit and belowstated addition to the closure plan are submitted for your review, approval, and forwarding to personnel at the Tennessee Department of Environment and Conservation (TDEC) (attention: Mr. Tom Tiesler). This submittal is in accordance with Title 40, Code of Federal Regulations (CFR), Parts 265.113 and 115, Subpart G, and Tennessee Rule 1200-1-11.05(7)(d).

The first interim scheduled milestone--Remove Inventory--with duration/date of $\mathbf{4 5}$ days (from TDEC personnel approval on November 7,1995 ) and resulting date of December 22, 1995, was missed. The enclosed, revised Table 1 represents a best-effort schedule to maintain completion of closure activity within 180 days (i.e., by May 5,1996 ) as required by the closure schedule approved by TDEC personnel (reference paragraph 8.0 of the closure plan). Table 1 has been revised to reflect 180 days of closure activity and 60 days for preparation of certification documentation, as allowed by 40 CFR Part 265.115. Interim milestone dates have been revised accordingly and reflect the time necessary to prepare and approve work procedures related to enriched uranium operations.

Additionally, TDEC personnel approval of the following addition to paragraph 4.0, Closure Activities, is requested in order to provide the flexibility for conducting operations. This is considered a minor, technical modification which will assist in meeting the schedule and accomplishing the same end result.

"Steps 1 through 6 may be conducted in part, in any sequence, or may overlap as deemed appropriate in order to expedite closure activities." 
Mr. R. J. Spence, DOE-ORO

Page 2

January 17, 1996

If you have any questions, please contact E T. Collins at 574-8886.

Very truly yours,<smiles>[Te][TeH]</smiles>

T. R. Butz

Y-12 Plant Manager

TRB:bjs

Enclosure: As Stated

cc/enc: C. H. Fritts

J. S. Guilford

C. C. Hill

J. A. Kreykes

S. E Rathke

R. K. Roosa/N. C. Jessen

L. M. Sparks, DOE-ORO

C. L. Stair/T. P. A. Perry

W. C. Tindal

Y.12 Central Files

File-EMD-RC

cc: T. R. Butz

F. P. Gustavson

R. M. Keyser/J. E. Powell

M. K. Morrow 
Enclosure

Letter, Butz to Spence

Dated: January 17, 1996

Letter Title

Resource Conservation and Recovery Act Closure Plan for the Uranium Treatment Unit-Schedule Change Request 


\begin{tabular}{|c|c|c|c|c|}
\hline \multicolumn{5}{|c|}{ CLOSURE SCHEDULE FOR THE URANIUM TREATMENT UNIT } \\
\hline ACTION & $\begin{array}{l}\text { EXPECTED } \\
\text { COMPLETION }^{2}\end{array}$ & $\begin{array}{l}\text { APPROVED } \\
\text { SCHEDULE }\end{array}$ & $\begin{array}{l}\text { REVISED } \\
\text { SCHEDULE } \\
\text { (Days:Date) }\end{array}$ & $\begin{array}{l}\text { ACTUAL } \\
\text { SCHEDULE } \\
\text { (Days:Date) }\end{array}$ \\
\hline $\begin{array}{l}\text { Notify Tennessee Department of Health and Environment } \\
\text { of intent to initiate }\end{array}$ & 180 days & & & \\
\hline Receive final volumes of waste; initiate closure & 0 & $11 / 7 / 95^{3}$ & $0: 11 / 7 / 95$ & $\cdot 0: 11 / 7 / 95$ \\
\hline Remove inventory, load, and transfer (Step 1) & 45 & $12 / 22 / 95$ & $150: 4 / 5 / 96$ & \\
\hline Decontaminate equipment (Steps 2-5) & 110 & $2 / 25 / 96$ & $159: 4 / 16 / 96$ & \\
\hline Decontaminate structures and diked area (Step 6) & 115 & $3 / 1 / 96$ & $170: 4 / 25 / 96$ & \\
\hline Analyze samples and results & 150 & $4 / 5 / 96$ & $178: 5 / 3 / 96$ & \\
\hline $\begin{array}{l}\text { Prepare documentation for certification by an } \\
\text { independent Professional Engineer }\end{array}$ & 175 & $4 / 30 / 96$ & 209:6/3/96 & \\
\hline Receive closure certification by DOE & 180 & $5 / 5 / 96$ & $239: 7 / 2 / 96$ & \\
\hline \multicolumn{5}{|l|}{ or } \\
\hline Repeat decontamination and sample analysis ${ }^{1}$ & ** & & & \\
\hline $\begin{array}{l}\text { Receive independent Professional Engineer and DOE } \\
\text { certify closure }\end{array}$ & & & & \\
\hline
\end{tabular}

\section{Footnotes}

1 If decontamination must be repeated or if closure activities cannot be completed within the allotted time, extension of the closure schedule beyond the maximum of 180 days will be requested.

2 Number of days following initiation of closure.

TDEC Approval: Revișed Schedule and Steps 1-6 in any sequence or overlap." 


\section{FEB $O \rightarrow 1996$}

Tom Tiester, Director

Certified Mail

Division of Solid Waste Management

Z 009191241

Tennessee Department of Environment and Conservation

Fifth Floor, Life \& Casualty Tower

401 Church Street

Nashville, Tennessee 37243-1535

Dear Mr. Tiester:

RESOURCE CONSERVATION AND RECOVERY ACT (RCRA) CLOSURE PLAN FOR THE URANIUM TREATMENT UNIT, $Y-12$ PLANT, OAK RIDGE, TN

The purpose of this letter is to document a telephone conversation between David Moran, TDEC, and Larry Sparks of my staff which took place on January 24, 1996. The purpose of the telephone conversation was to discuss progress towards completion of the subject Closure Plan. A summary of that telephone conversation follows.

The first issue discussed was the interim completion dates for the individual steps to close the Uranium Treatment Unit contained in the approved Closure Plan. Agreement was reached that the only regulatory driven completion date is the 180 day limit to complete the closure. The interim dates are viewed as goals to be used to track progress, not hard and fast deadlines. Mr. Sparks indicated that the first interim date had been missed but that efforts are being taken to ensure that al1 work is completed within 180 days from the Closure Plan approval.

The second issue discussed was the actual order in which the work will progress. In describing the work necessary to effect closure, the closure Plan breaks the work into discrete steps for ease of explanation. These steps are numbered consecutively. It was agreed that this numbering of the steps did not necessarily mean that work on each step had to be fully completed prior to the start of work on the next step. Working steps concurrently, as appropriate, with additional resources is how we plan to meet the 180 day closure requirement. 
The telephone conversation concluded with an agreement that a formal change to the approved Closure Plan was unnecessary at this time. If you disagree with this conclusion or with any of the issues discussed above, please notify us as soon as possible. If you have any questions or require further information, please feel free to contact Mr. Sparks at (423) 576-2659.

DP-813:Sparks

$$
\begin{aligned}
& \text { Sincerely, } \\
& \text { Original Signed by } \\
& R \text { J. Spence } \\
& \text { Robert J. Spence } \\
& Y-12 \text { Site Manager }
\end{aligned}
$$

cc:

E. Lemming, TDEC, Oak Ridge

J. Powe 11, 9116, MS 8098, Y-12

$960121 w p . g b$

File Code: 54912

Action: Date: 


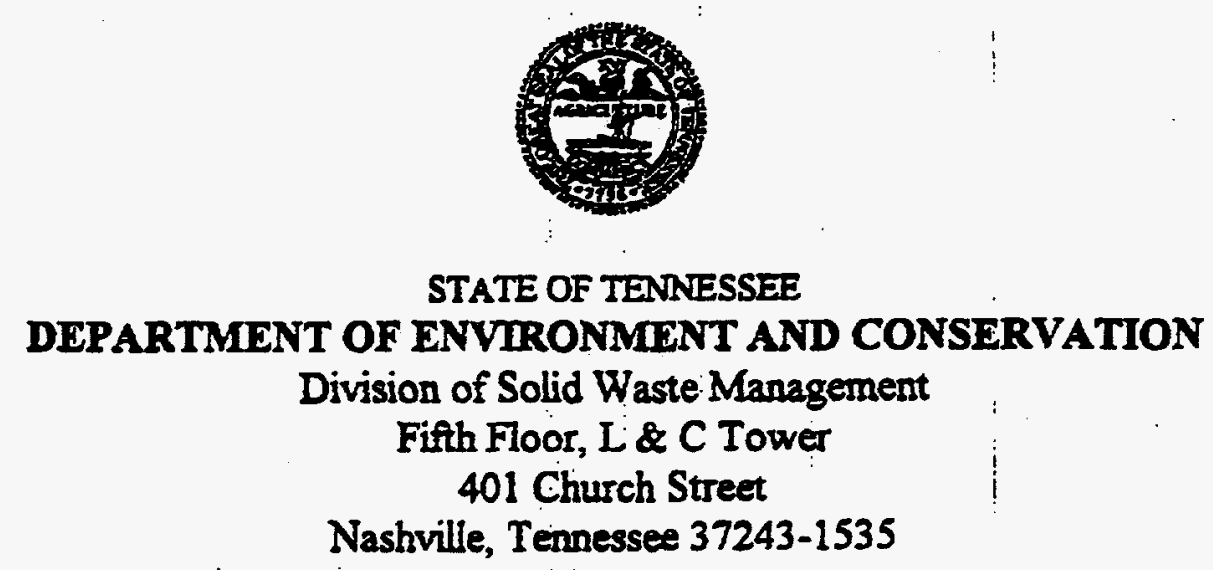

February 15, 1996

Mr. Robert J. Spence

Y-12 Site Manager

Department of Energy

Oak Ridge Operations Office

Post Office Box 2001

Oak Ridge, Tennessee 37831-8555

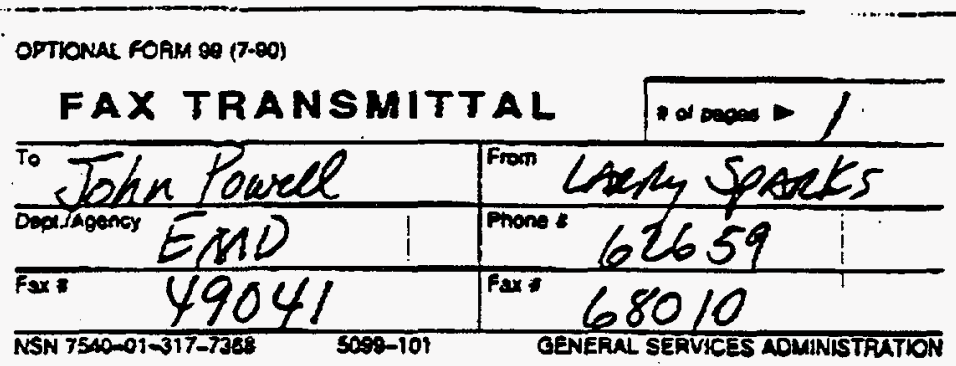

Dear Mr. Spence:

I am in receipt of your letter dated February 7, 1996, addressed to Mr. Tom Tiesler pertaining to the closure plan for the Uranium Treatment Unit at the Y-12 plant. Your understandings as put forth in the letter are correct, but be aware of the fact that this pertains solely to the Uranium Treatment Unit and no other closure.

The 180 day work completion requirement is an enforceable date and must be adhered to unless a written request for an extension is submitted to, and approved by the Division.

If you have any additional questions about this issue, please feel free to contact me at telephone number (615) 532-0875.

Sincerely,

Aaid Moran

David Moran

DOE Coordinator, DSWM

c: E. Leming, DOE-O

surang.dos

Y-12 SITE OFFIC:

LOC No. E.0448

BILE CODE 
February 16, 1996

Mr. R. J. Spence

Department of Energy, Oak Ridge Operations

Post Office Box 2001

Oak Ridge, Tennessee 37831

Dear Mr. Spence:

\section{Contract DE-AC05-84OR21400, Resource Conservation and Recovery Act (RCRA) Closure Plan for the Uranium Treatment Unit--Schedule Deviation}

This is to advise you that the Tennessee Department of Environment and Conservation (TDEC) staff-approved interim closure schedule dates of February 25, 1996, (decontaminate equipment) and March 1, 1996, (decontaminate structures and diked areas) will not be met. The closure activity is progressing in accordance with the revised schedule which was submitted for your approval and forwarding to personnel at the TDEC. We are requesting that Mr. David Moran of the TDEC be advised of this information.

Per discussions with Larry Sparks, of your staff, the revised schedule was discussed with Mr. Moran on January 24, 1996, and deemed acceptable. Written TDEC staff approval of the revised schedule is anticipated in due course. However, notification of missed, approved closure schedule dates will continue until the TDEC staff approval of the revised schedule is in hand.

If you have any questions, please contact $\mathrm{E}$. T. Collins at 574-8886.

Very truly yours,<smiles>CCC(C)C1CCCC12CCCC2</smiles>

T. R. Butz

Y-12 Plant Manager

TRB:Ift
cc: T. R. Butz
E. T. Collins
C. H. Fritts
C. D. Goins Jr.
J. S. Guilford
F. P. Gustavson
C. C. Hill

R. M. Keyser/J. E. Powell

M. K. Morrow/N. C. Jessen

S. E. Rathke

L. M. Sparks, DOE-ORO

C. L. Stair/T. P. A. Perry

Y-12 Central Files

File-EMD-RC 
APPENDIX B

Uranium Treatment Unit--Closure Plan 



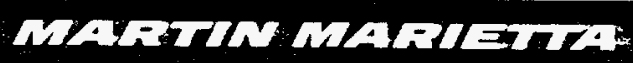

\title{
RESOURCE CONSERVATION AND RECOVERY ACT (RCRA) CLOSURE PLAN FOR THE URANIUM TREATMENT UNIT
}

Environmental Management Department

Health, Safety, Environment, and Accountability Organization

Enriched Uranium Operations Organization

\author{
Prepared by \\ Oak Ridge Y-12 Plant \\ Oak Ridge, Tennessee 37831 \\ Managed by \\ MARTIN MARIETTA ENERGY SYSTEMS, INC. \\ for the \\ U.S. DEPARTMENT OF ENERGY \\ under contract DE-AC05-84OR21400
}

MANAGED BY

MARTIN MARIETTA ENERGY SYSTEMS, INC.

FOR THE UNITED STATES

DEPARTMENT OF ENERGY 



\section{RESOURCE CONSERVATION AND RECOVERY ACT (RCRA) CLOSURE PLAN FOR THE URANIUM TREATMENT UNIT}

Environmental Management Department

Health, Safety, Environment, and Accountability Organization

Enriched Uranium Operations Organization

Date Published--March 1995

Prepared by

Oak Ridge Y-12 Plant

Oak Ridge, Tennessee 37831-8169

Managed by

MARTIN MARIETTA ENERGY SYSTEMS, INC.

for the

U.S. DEPARTMENT OF ENERGY

under contract DE-AC05-84OR21400 

TABLE OF CONTENTS

Page No.

1.0 INTRODUCTION $\ldots \ldots \ldots \ldots \ldots \ldots \ldots \ldots \ldots \ldots \ldots \ldots \ldots \ldots \ldots \ldots \ldots \ldots \ldots \ldots$

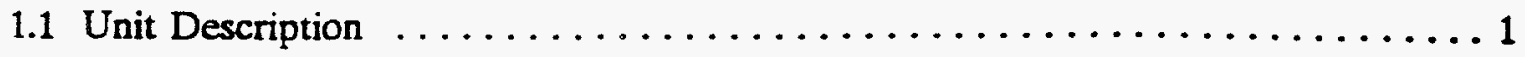

2.0 CLOSURE PLAN CONTENTS $\ldots \ldots \ldots \ldots \ldots \ldots \ldots \ldots \ldots \ldots \ldots \ldots \ldots \ldots \ldots \ldots \ldots \ldots \ldots \ldots$

3.0 CLOSURE PLAN PERFORMANCE STANDARD $\ldots \ldots \ldots \ldots \ldots \ldots \ldots \ldots \ldots$

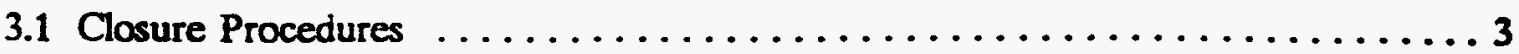

3.2 Partial Closure and Final Closure Activities $\ldots \ldots \ldots \ldots \ldots \ldots \ldots \ldots \ldots$

4.0 CLOSURE ACTTVITIES $\ldots \ldots \ldots \ldots \ldots \ldots \ldots \ldots \ldots \ldots \ldots \ldots \ldots \ldots \ldots \ldots \ldots \ldots$

5.0 VERIFICATION OF DECONTAMINATION $\ldots \ldots \ldots \ldots \ldots \ldots \ldots \ldots \ldots \ldots$

6.0 CERTIFICATION OF CLOSURE $\ldots \ldots \ldots \ldots \ldots \ldots \ldots \ldots \ldots \ldots \ldots \ldots \ldots \ldots \ldots \ldots \ldots \ldots$

7.0 MAXIMUM WASTE INVENTORY $\ldots \ldots \ldots \ldots \ldots \ldots \ldots \ldots \ldots \ldots \ldots \ldots \ldots \ldots \ldots \ldots$

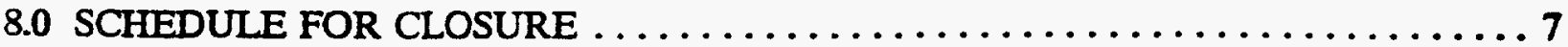

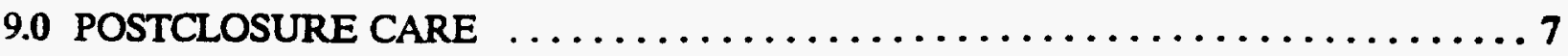

APPENDIX: SAMPLING AND ANALYSIS PLAN 


\section{ACRONYMS}

CFR

DOE

Energy Systems

EPA

ppm

pve

RCRA

TDEC
Code of Federal Reguiations

U.S. Department of Energy

Martin Marietta Energy Systems, Inc.

U.S. Environmental Protection Agency

Parts Per Million

Polyvinyl Chloride

Resource Conservation and Recovery Act

Tennessee Department of Environment and Conservation 


\subsection{INTRODUCTION}

This closure plan has been prepared for the Uranium Treatment Unit located at the Y-12 Plant in Oak Ridge, Tennessee (Environmental Protection Agency [EPA] Identification TN 389-009-0001). The actions required to achieve closure of the Uranium Treatment Unit are outlined in this plan, which is being submitted in accordance with Tennessee Rule 1200-1-11-.05(7) and Title 40, Code of Federal Regulations (CFR), Part 265, Subpart G.

The Uranium Treatment Unit is used to store and treat waste materials that are regulated by the Resource Conservation and Recovery Act (RCRA). A diagram of the Uranium Treatment Unit is shown in Figure 1. This plan details all steps that are to be performed to close the Uranium Treatment Unit at the end of its operation.

The Oak Ridge Y-12 Plant was built by the U.S. Army Corps of Engineers in 1943 as part of the Manhattan Project. The U.S. Department of Energy (DOE) owns and operates the Y-12 Plant. Personnel from Martin Marietta Energy Systems, Inc. (Energy Systems), co-operate and manage the Y-12 Plant under a prime contract with DOE. The contract is administered by personnel at the DOE, Oak Ridge Operations Office.

The Y-12 Plant occupies approximately 800 acres in Anderson County, Tennessee, and is located southwest of the city of Oak Ridge. Approximately 4,000 people are employed at the Y-12 Plant, including employees of the Oak Ridge National Laboratory who are assigned to the plant. Two surface streams, East Fork Poplar Creek and Bear Creek, border the facility on the south, east, and southwest sides of the plant. Access to the Y-12 Plant is controlled on Bear Creek Road on the north side of the facility; indirect access is available from Scarboro Road on the east side and Bethel Valley Road on the south side of the facility. A controlled access road from Bethel Valley Road by way of Mt. Vernon Road is located on the southwest side of the site.

The mission of Y-12 Plant personnel is to provide a key manufacturing technology center for the development and demonstration of unique materiais, components, and services of importance to DOE and the nation. This mission is accomplished through reclaiming and storing nuclear materiak, manufacturing nuclear materiais, manufacturing components for the defense capabilities of the nation, supporting national security programs, and providing services to other customers as approved by DOE personnel.

\subsection{Unit Description}

The Uranium Treatment Unit, associated equipment, and diked areas are located east of Building 9206 within the boundaries of the Y-12 Plant. The Uranium Treatment Unit consists of two 300-gallon polytanks and associated structural support stands, two electrically driven agitators, and approximately 400 square feet of ten-mil polyvinyl chloride (PVC) liners. Also included in this closure plan are twelve 55-gallon drums filled with Raschig rings which were used to collect the RCRA solutions prior to treatment at the Uranium Treatment Unit. The design treatment capacity of the Uranium Treatment Unit is $\mathbf{5 0 0}$ gallons per day, and the design storage capacity of the drum storage area is 990 gallons. 


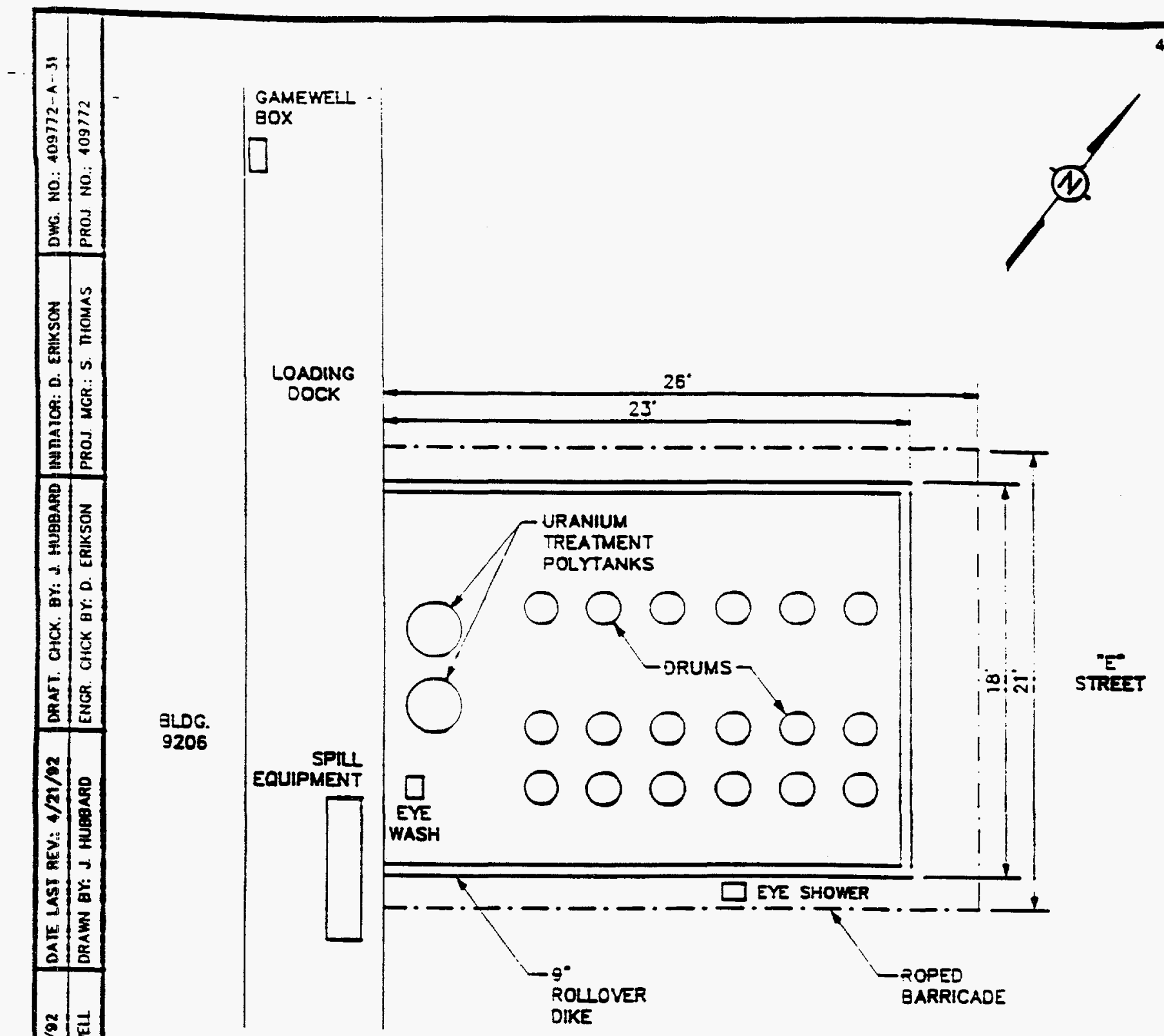

SCALE:

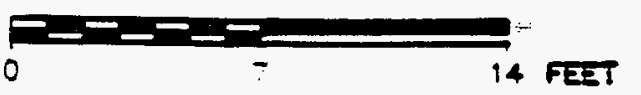

FGURE D-8. URANIUM TREATMENT UNT AND DRUM STORAGE AREA 
The Uranium Treatment Unit treats organic solutions containing enriched uranium. Before these solutions can be transferred from a nuclear safe container, they must be below $\mathbf{4 0 0}$ parts per million (ppm) uranium concentration. The treatment unit takes waste organic solutions containing characteristically hazardous and FOO1 and FO02 listed (Freon 113) waste with a uranium concentration less than $400 \mathrm{ppm}$, mixes this solution with depleted uranyl nitrate to create a solution in which the $\mathrm{U}-235$ concentration is less than 1 percent, and then adjusts the $\mathrm{pH}$ of this solution with the addition of caustic.

\section{CLOSURE PLAN CONTENTS}

This plan has been prepared in accordance with the requirements of 40 CFR Part 265, Subpart G, and Tennessee Rule 1200-1-11-.05(7)(a). The steps that are to be performed to close the Uranium Treatment Unit are detailed herein.

Because the Uranium Treatment Unit is part of the Y-12 Plant, which is a federal facility, no closure cost estimate, financial assurance mechanism, or liability insurance is required. This exemption from certain financial requirements is found in 40 CFR Part 265.140(c) and Tennessee Rule 1200-1-11-.05(8)(a).

\subsection{CLOSURE PLAN PERFORMANCE STANDARD}

Closure of the Uranium Treatment Unit minimizes the need for further maintenance, prevents the release of hazardous constituents from the unit. protects human heaith and the environment, and complies with all applicable closure requirements. The applicable requirements for the site are found in 40 CFR Part 265.197 and Tennessee Rule 1200-1-11-.05(10).

This standard will be accompiished through the removal of all RCRA hazardous wastes stored in polytanks and containers at the unit. The RCRA wastes will be transferred to an appropriately permitted facility for storage, treatment, or disposal. To minimize residual contamination on site, the treatment area, containers, tanks, and equipment located there will be cleaned until satisfactority decontaminated and sampled according to the attached sampling and anaiysis plan, if applicable.

\subsection{Closure Procedures}

Before closure activities begin, the unit will be surveyed by the $Y-12$ Radiological Control (Rad Con) Department personnel and a safety plan will be prepared based on the site conditions. The plan will identify radiological and chemical hazards as well as controls to reduce worker risk.

\section{Partial Closure and Final Closure Activities}

This is a final closure of the Uranium Treatment Unit, associated equipment, and diking; there will be no partial closure activities. Final closure activities will proceed as described below. 


\subsection{CLOSURE ACTIVITTES}

The equipment that is utilized during operations includes two 300-gallon polytanks: two stainless-steel, electrically driven agitators used to mix solutions in the 300-gailon polytaniks: tweive 55-gallon stainless steel drums; and 90 cubic feet ( 7 cases/drum; 144 ringsicase) of Raschig rings used as a nuciear poison in the 55-gallon drums. Facility-related items requiring decontamination inchude structural supports for the 300-gailon polytanks and the two-layer PVC 10-mil liners (approximately 400 square feet) for the diked area.

\section{Step 1: Removal of Waste Inventory}

All hazardous waste will be transferred to an approved facility for storage, treatmeat, or disposal. Equipment to be used will be, but is not limited to, forklift truck, hand pallet jact, and/or hand dolly. Material will be removed from the polytanks or drums using pumps or other means as necessary. Sludges, if present, will be removed using pumps or removed by shovels or scoops. All material removed will be transferred to an approved facility for storage, treatment, and/or disposal in drums, polytanks, or tank trucks.

Step 2: Decontamination of Stainiess-Steel Agitators

The two stainiess steel agitators will be deenergized and processed through a two-stage cleaning process. The initial cleaning will be with a detergent applied using a high presure washer. The second stage will be a two-step rinsing with hot water applied with a high pressure washer. All solution generated will be collected, containerized, property characterized, and stored at an approved on-site storage facility awaiting treatment or dispoal The containerized solution will be marked, stored, and treated based upon the appropriate RCRA listings and applicable RCRA characteristics. The solution generated during the final cleaning pass will be collected separately and sampled for RCRA constituents to document that decontamination criteria listed in Table 4 in the attached sampling and analysis plan are met (see Appendix A). The agitators will not be disposed of, but will be considered clean reusable equipment.

\section{Step 3: Decontamination of 300-gailon Polytaniks}

The polytanks will be drained of RCRA hazardous wastes. The taniks will be decontaminated using a two step approach. The initial cleaning will be with a detergent applied using a high pressure washer. The second stage will be a two-step rinsing with hot water applied with a high pressure washer. All solution generated will be collected, containerized, property characterized, and stored at an approved on-site storage facility awaiting treatment or disposal The containerized solution will be marked, stored, and treated based upon the appropriate RCRA listings and appiicable RCRA characteristics. The solution generated during the final cleaning pass will be collected separately and sampled for RCRA constituents to document that decontamination criteria listed in Table 4 in the attached sampling and analysis plan are met. The polytanks will then be disposed of as nonhazardous waste or reused for nonhazardous purposes.

Step 4: Decontamination of Raschig Rings

The RCRA decontamination of the Raschig rings will be attempted using a four-stage process. The Raschig rings will be removed from the 55-gallon drums and segregated based upon the 
RCRA constituents that have been in contact with the rings. In addition, the rings will be segregated based upon the buildup of material on the rings (i.e., very dirty, somewhat dirty, fairiy clean). Segregating the rings in this manner will minimize the hazardous waste that is generated. The segregated rings will be placed inside a stainiess steel mesh basket (or similar device) and cleaned with a detergent applied using a high pressure washer. The rings will then be rinsed with water and allowed to soak in a 30 percent nitric acid solution. The rings will then be cleaned with a detergent applied with a high pressure washer. The final stage will consist of a thorough rinsing with hot water applied with a high pressure washer. All solution generated will be collected, containerized, and stored at an approved on-site storage facility. The containerized solution will be marked, stored. and treated based upon the appropriate RCRA listings and applicable RCRA characteristics. The solution generated during the final cleaning pass will be collected separately and sampled for RCRA constituents to document that the decontamination criteria listed in Table 4 in the attached sampling and anabysis plan are met.

If RCRA decontamination of the Raschig rings is unsuccessful, the rings will be packaged into 55-gailon drums and placed into long-term storage as mixed hazardous waste.

Step 5: Decontamination of 55-gailon Stainiess Steel Drums

The drums will be drained of RCRA hazardous wastes. The drums will be considered empty under 40 CFR Part 261.7 if:

- All wastes have been removed that can be removed using the practices commonly employed to remove materiais from similar containers (e.g., pouring or pumping), and

- No more than one inch of residue remains on the bottom of the container or inner liner, or

- No more than 3 percent by weight of the total capacity of the container remains in the container or inner liner.

All materiai removed from the containers will be collected, containerized, property characterized, and stored at an approved on-site storage facility awaiting treatment or disposal. The drums will then be disposed of as nonhazardous waste or reused for other purposes.

Step 6: Decontamination of Plastic Liner and Structural Support for 300-gallon Polytanks

The structural supports and the plastic liner will be decontaminated using a two-step process. Initial cleaning will be with a detergent applied using a high pressure washer. This will be followed by a two-stage high pressure rinsing. All solution generated will be collected, containerized, and stored at an approved on-site storage facility. The containerized solution will be marked, stored, and treated based upon the appropriate RCRA listings and applicable RCRA characteristics. The solution generated during the final cleaning pass will be collected separately and sampled for RCRA constituents to document that decontamination criteria listed in Table 4 in the attached sampling and analysis plan are met. 
If RCRA decontamination of the liner is unsuccessful. the liner will be packaged into 55-gailon drums and placed into long-term storage as mixed hazardous waste.

Step 7: Decontamination of Asphait Surface under the Plastic Liner

A thorough inspection of the integrity of each layer of the plastic liner will be made during the above described decontamination effort. If there is no indication that the liner has been breached, this will be documented and no decontamination will be performed on the asphait. If the liner has been breached, then the asphait surface, beneath the breached area of the liner, will be cleaned using a two stage process. The surface will initiaily be cleaned with a detergent. This will be followed by a hot water rinse. The excess solution generated will be collected, containerized, and stored at an approved on-site storage facility pending the analyais from samples taken from the solution. Based on the analytical results, the containerized solution will be disposed of in an appropriate manner. The excess solution generated during the final cleaning pass will be collected separately and sampied for RCRA constituents to document that decontamination criteria listed in Table 4 in the attached sampling and analysis plan are met.

\subsection{VERIFICATION OF DECONTAMINATION}

Rinse water samples will be analyzed for the hazardous constituents formerly stored in the container storage and treatment areas as an indicator of decontamination verification. Decontamination will be considered complete if the concentration of these constituents in the water are less than the decontamination criteria listed in Table 4 in the attached sampling and analysis plan. The sample will be analyzed by EPA method ("Test Methods for Evaluating Solid Waste," SW-846, November 1990 as amended). Sampiing and analytical quality assurance/quality control will be conducted as specified in SW-846. Further water and surfactant/water rinses will be used if decontamination of an item is not complete. These rinses will be repeated until the decontamination criteria listed in Table 4 in the attached sampling and analysis plan are met.

\subsection{CERTIFICATION OF CLOSURE}

Documentation for certification by an independent Professional Engineer will be prepared. Finai certification of closure by DOE and Energy Systems personnel will be performed. The certification, along with the closure report, will then be submitted to the Commissioner of the Tennessce Department of Environment and Conservation (TDEC) staff for closure approval.

\subsection{MAXIMUM WASTE INVENTORY}

The maximum treatment capacity of the Uranium Treatment Unit is $\mathbf{5 0 0}$ gallons per day, and the maximum waste inventory of the drum storage area is 990 gallons or 18 drums.

The Uranium Treatment Unit and container storage area receive and treat only wastes that are characteristicaily hazardous or F001 and F002 listed (Freon 113) wastes. The wastes originate from processes located in either Building 9206 or Building 9212. 


\subsection{SCHEDULE FOR CLOSURE}

Closure activities will be completed within 180 days from the closure plan being approved by personnel from the state. The actual times for each step of the closure activities are shown in Table 1. It is not anticipated that an extension of time for closure activities will be required. However, if closure cannot be completed within the specified time, a request for an extension of closure time will be submitted to the TDEC Commissioner in accordance with Tennessee Rule 1200-1-11-.06(7)(d).

\subsection{POSTCLOSURE CARE}

Remediation activities of this closure plan are intended to clean up any RCRA hazardous contaminants that may have resulted from storage and/or treatment activities associated the Uranium Treatment Unit. Upon successful completion of cleanup activities and certification/approval of the TDEC Commissioner, this site will be returned to plant activities and not subject to any further requirements under 40 CFR Part 265. Subpart G, or Tennessee Rule 1200-1-11-.05(7). 


\begin{tabular}{||l|c|}
\hline \multicolumn{2}{|c|}{ CLOSURE SCHEDULE FOR THE URANIUM TREATMENT UNTT* } \\
\hline \multicolumn{1}{|c|}{ ACTION } & EXPECTED COMPLETION** \\
\hline $\begin{array}{l}\text { Notify Tennessee Department of Health and } \\
\text { Environment of intent to initiate }\end{array}$ & -180 days \\
\hline $\begin{array}{l}\text { Receive final volumes of waste; initiate } \\
\text { closure }\end{array}$ & 0 \\
\hline Remove inventory, load and transfer & 45 \\
\hline Decontaminate equipment & 110 \\
\hline Decontaminate structures and diked area & 115 \\
\hline Analyze samples and resuits & 150 \\
\hline $\begin{array}{l}\text { Prepare documentation for certification by an } \\
\text { independent Professional Engineer }\end{array}$ & 175 \\
\hline Receive closure certification by DOE & 180 \\
\hline or & \\
\hline Repeat decontamination and sample analysis & $* *$ \\
\hline $\begin{array}{l}\text { Receive independent Professional Engineer } \\
\text { and DOE certify closure }\end{array}$ & \\
\hline
\end{tabular}

* If decontamination must be repeated or if closure activities cannot be completed within the allotted time, extension of the closure schedule beyond the maximum of 180 days will be requested.

** Number of days following initiation of closure. 
APPENDIX A

\section{RESOURCE CONSERVATION AND RECOVERY ACT (RCRA)} CLOSURE PLAN FOR THE URANIUM TREATMENT UNIT

SAMPLING AND ANALYSIS PLAN 


\section{TABLE OF CONTENTS}

1.0 PROJECT OVERVIEW $\ldots \ldots \ldots \ldots \ldots \ldots \ldots \ldots \ldots \ldots \ldots \ldots \ldots \ldots \ldots \ldots \ldots \ldots \ldots \ldots \ldots$

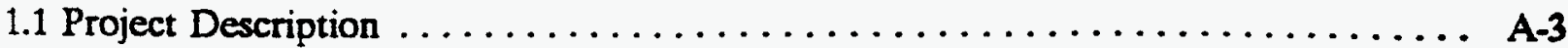

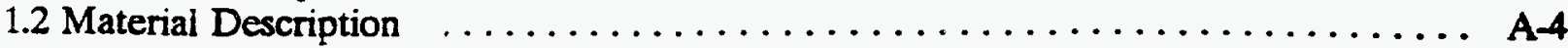

2.0 DESIGN AND PROCEDURES FOR SAMPLE COLLECTION $\ldots \ldots \ldots \ldots \ldots \ldots$ A.5

2.1 Sampling Procedures $\ldots \ldots \ldots \ldots \ldots \ldots \ldots \ldots \ldots \ldots \ldots \ldots \ldots \ldots \ldots \ldots$

2.1 .1 Water Sampling $\ldots \ldots \ldots \ldots \ldots \ldots \ldots \ldots \ldots \ldots \ldots \ldots \ldots \ldots \ldots \ldots \ldots$, A\&

2.2 Sampling Quality Assurance $(\mathrm{QA}) \ldots \ldots \ldots \ldots \ldots \ldots \ldots \ldots \ldots \ldots \ldots \ldots \ldots \ldots$

2.3 Sampie Preservation, Containers, and Holding Times $\ldots \ldots \ldots \ldots \ldots \ldots \ldots$ A 8

3.0 SAMPLE CUSTODY AND DOCUMENTATION $\ldots \ldots \ldots \ldots \ldots \ldots \ldots \ldots$ A.9

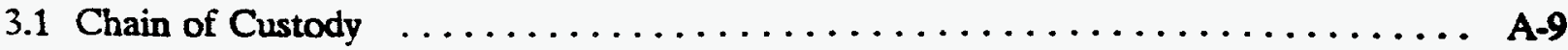

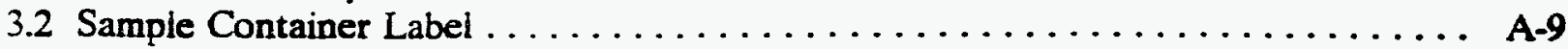

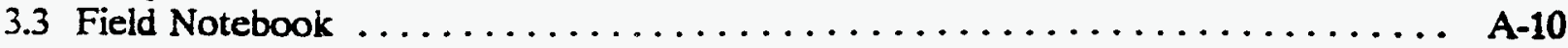

3.4 Laboratory Notebooks $\ldots \ldots \ldots \ldots \ldots \ldots \ldots \ldots \ldots \ldots \ldots \ldots \ldots \ldots$ A-10

4.0 ANALYTICAL PROCEDURES $\ldots \ldots \ldots \ldots \ldots \ldots \ldots \ldots \ldots \ldots \ldots \ldots \ldots \ldots \ldots \ldots \ldots \ldots \ldots$

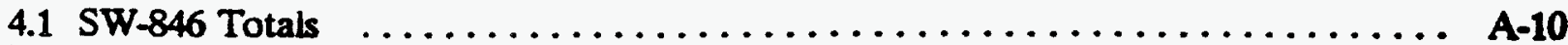



4.3 Laboratory $\mathrm{QA}$ and $\mathrm{QC} \ldots \ldots \ldots \ldots \ldots \ldots \ldots \ldots \ldots \ldots \ldots \ldots \ldots \ldots \ldots \ldots \ldots \ldots$

5.0 DATA REDUCTION, VERIFICATION, REPORTING, AND ASSESSMENT ..... A-11

5.1 Data Reduction/Verification $\ldots \ldots \ldots \ldots \ldots \ldots \ldots \ldots \ldots \ldots \ldots \ldots \ldots \ldots \ldots \ldots \ldots \ldots$ A-11

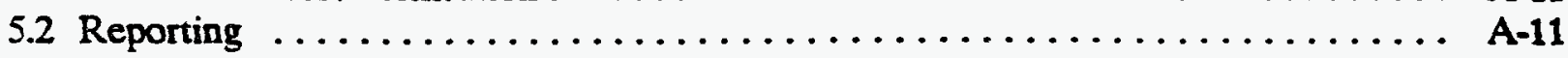




\section{ACRONYMS}

$\begin{array}{ll}\text { CFR } & \text { Code of Federal Regulations } \\ \text { DDU } & \text { Destructive Distillation Unit } \\ \text { Energy Systems } & \text { Martin Marietta Energy Systems. Inc. } \\ \text { ICP } & \text { Inductively Coupled Plasma } \\ \text { PVC } & \text { Polyvinyi Chloride } \\ \text { PCB } & \text { Polychlorinated Biphenyl } \\ \text { QA } & \text { Quality Assurance } \\ \text { QC } & \text { Quality Control } \\ \text { RCRA } & \text { Resource Conservation and Recovery Act } \\ \text { SOP } & \text { Standard Operating Procedure } \\ \text { SVOA } & \text { Semivolatile Organic Analysis } \\ \text { VOA } & \text { Volatile Organic Analysis }\end{array}$




\subsection{PROJECT OVERVIEW}

This document defines the sampling and analytical procedures needed to assure that the decontamination of materiais needed for closure of the Uranium Treatment Unit is achieved.

The Uranium Treatment Unit consists of the treatment area, poiytanks, and associated equipment located east of Building 9206 at the Y-12 Plant. The Uranium Treatment Unit has been used to store and treat waste materiais that are regulated by the Resource Conservation and Recovery Act (RCRA). The Closure Plan for the Uranium Treatment Unit (Y/TS-1253) details the steps to be performed to close this unit in accordance with the requirements of Title 40, Code of Federal Regulations (CFR), Part 265, Subpart G, and Tennessee Rule 1200-1-11-.05(7)(a).

\subsection{Project Description}

The Uranium Treatment Unit has in the past received. stored. and treated waste solutions that contained organic material contaminated with low concentrations of uranium. The equipment covered by this closure plan includes:

* Two 300-gallon polytanks.

* Two stainiess-steel, electrically driven agitators,

* Twelve 55-gallon stainiess-steel drums,

* Raschig rings (each 55-gailon drum contains 7 cases [144 rings/case] of Raschig rings),

* Structural supports for the two 300 -galion polytaniks,

* Approximately $\mathbf{4 0 0}$ square feet of 10-mil polyvinyl chloride (PVC) liner, and

* Asphait surface under the plastic liner (ONLY if the integrity of the two layers of the plastic liner has been breached).

Analyses of rinse waters will be performed to determine if any RCRA-hazardous materiais are remaining after material has undergone decontamination. Process knowledge indicates that the Toxicity Characteristic Leaching Procedure analytes listed in Table 4 could be present. Random testing of the area has confirmed that no polychlorinated biphenyl (PCB) contamination of the area took place. Presence of radiological contamination is known, but is not of concern from the standpoint of this sampiing and analysis activity.

The drums will not require decontamination because they will be drained of RCRA hazardous wastes and declared empty under 40 CFR Part 261.7. The applicable criterion for RCRA-empty is as follows:

* All wastes have been removed that can be removed using the practices commonly employed to remove materials from similar containers (e.g., pouring or pumping), and

* No more than one inch of residue remain on the bottom of the container or inner liner, or

* No more than 3 percent by weight of the total capacity of the container remains in the container or inner liner. 


\section{Material Description}

The Uranium Treatment Unit has the capacity of treating $\mathbf{5 0 0}$ gallons of waste per day and storing up to 900 gallons. The waste received at the treatment facility originates from the following different streams (C. H. Fritts, interoffice memorandum, 5/10/94):

a. Distillate from the ventilation system of Building 9212 Destructive Distillation Unit (DDU). Potentially applicable waste codes inciude:

D002: exhibits the characteristics of corrosivity, D004: containing Arsenic (CAS\# 7440-38-2), DO05: containing Barium (CAS\#7440-39-3), D006: containing Cadmium (CAS\# 7440-43-9), D007: containing Chromium (CSA\# 7440-47-3), D008: containing Lead (CAS\# 7439-92-1), D009: containing Mercury (CAS\# 7439-97-6), D010: containing Selenium (CAS\# 7782-49-2), D011: containing Silver (CAS\# 7440-22-4), D018: containing Benzene (CAS\# 71-43-2), D019: containing Carbon Tetrachloride (CAS\# 56-23-5), D021: containing Chlorobenzene (CAS\# 108-90-7), D022: containing Chloroform (CAS\# 67-66-3), D023: containing o-Cresol (CAS\# 95-48-7), D024: containing m-Cresol (CAS\# 108-39-4), D025: containing p-Cresol (CAS\# 106-44-5), D026: containing Cresol, D027: containing 1,4-Dichlorobenzene (CAS\# 106-46-7), D028: containing 1,2-Dichloroethane (CAS\# 107-06-2), D029: containing 1,1-Dichloroethylene (CAS\# 75-35-4), D030: containing 2,4-Dinitrotoluene (CAS\# 121-14-2), D032: containing Hexachlorobenzene (CAS\# 118-74-1), D033: containing Hexachlorobutadiene (CAS\# 87-68-3), D034: containing Hexachloroethane (CAS\# 67-72-1), D035: containing Methyl Ethyl Ketone (CAS\# 78-93-3), D036: containing Nitrobenzene (CAS\# 98-95-3), D037: containing Pentachlorophenol (CAS\# 87-86-5), D038: containing Pyridine (CAS\# 110-86-1), D039: containing Tetrachloroethylene (CAS\# 127-18-4), D040: containing Trichloroethylene (CAS\# 79-01-6), D041: containing 2,4,5-Trichlorophenol (CAS\# 95-95-4), D042: containing 2,4,6-Trichlorophenol (CAS\# 88-06-2), D043: containing Vinyl Chloride (CAS\# 75-01-4) 
b. Waste extraction solutions from the primary and secondary column extractors in the enriched uranium recovery process. Potential contaminants include:

D002: exhibits the characteristics of corrosivity,

D004: containing Arsenic (CAS\# 7440-38-2),

D005: containing Barium (CAS\#7440-39-3),

D006: containing Cadmium (CAS\# 7440-43-9),

D007: containing Chromium (CSA\# 7440-47-3),

D008: containing Lead (CAS\# 7439-92-1),

D009: containing Mercury (CAS\# 7439-97-6)

c. Waste Freon F001 and F002 resulting from the use as a water displacement chemical during the handling and storage of uranium materiais at the Y-12 Plant.

d. Non-PCB oil resulting from the plant operation. The oil itself is not a listed RCRA waste. Potentiai applicable waste codes include D018: (containing Benzene [CAS \#71-43-2]) and D035 (containing Methyl Ethyl Ketone [CAS\# 78-93-3]).

e. Propylene Glycol from the cooling process of uranium metal machining. Propylene Glycol is a non-RCRA material. Potential applicable waste codes are D007: (containing Chromium [CAS\# 7440-47-3]) and D008 (containing lead [CAS\# 7439-92-1]).

These waste streams are handled and stored in the 300-gailon polytanks and in twelve 55-gallon drums. All drums contain Raschig rings.

\section{DESIGN AND PROCEDURES FOR SAMPLE COLLECTION}

In accordance with the RCRA closure pian. rinse water samples will be collected. Before samples are collected, all RCRA hazardous waste previously stored in containers and polytanks at the unit will have been removed. The decontamination process will consist of a detergent wash followed by rinse steps. The final rinse material for the plastic liner, Raschig rings, structural supports, poiytaniks, and agitators will be sampied and analyzed for the RCRA constituents listed in Table 4 to document that decontamination criteria have been met. All other solutions generated through the decontamination process will be collected, containerized, and stored at an approved on-site storage facility for future treatment or disposal.

The anatytical samples to be collected are shown in Table 1. Details of sample collection are discussed in the sections that follow. 
Table 1. Anticipated number of anatytical samples

\begin{tabular}{lc|}
\hline Sample & Minimum Number of Samples \\
\hline Liner rinse water (1 each) & 2 \\
Raschig ring rinse water & 12 \\
Structural support rinse water (2 replicates) & 2 \\
Agitator rinse water (2 each) & 4 \\
Polytanks (2 each) & 4 \\
Quality Control (QC) Samples & \\
$\quad$ Trip blanks & 1 per cooler with volatile \\
Source water blanks & organic analyses (VOAs) \\
Replicates & 1 per source water \\
\hline \hline
\end{tabular}

Decontamination of Stainiess-Steel Agitators

The two stainiess steel agitators will be deenergized and processed through a two-stage cleaning process. The initial cleaning will consist of a detergent applied using a high pressure washer. The second stage will be a two-step rinsing with hot water applied with a high pressure washer. All solution generated will be collected, containerized, property characterized, and stored at an approved on-site storage facility awaiting treatment or disposal. The containerized solution will be marked, stored, and treated based upon the appropriate RCRA listings and applicable RCRA characteristics. The solution generated during the final cleaning pass will be collected separately and sampled for RCRA constituents to document that decontamination criteria listed in Table 4 are met. The agitators will not be disposed of, but will be considered clean reusable equipment.

\section{Decontamination of 300 -gallon Polytanks}

The polytanks will be drained of RCRA hazardous wastes. The tanks will be decontaminated using a two-step approach. The initial cleaning will consist of a detergent applied using a high pressure washer. The second stage will be a two-step rinsing with hot water applied with a high pressure washer. All solution generated will be collected, containerized, property characterized, and stored at an approved on-site storage facility awaiting treatment or disposal. The containerized solution will be marked, stored, and treated based upon the appropriate RCRA listings and applicable RCRA characteristics. The solution generated during the final cleaning pass will be collected separately and sampled for RCRA constituents to document that decontamination criteria listed in Table 4 are met: The polytanks will then be disposed of as non-hazardous waste or reused for nonhazardous purposes.

\section{Decontamination of Raschig Rings}

The RCRA decontamination of the Raschig rings will be attempted using a four-stage process. The Raschig rings will be removed from the 55-gallon drums and will be 
segregated based upon the RCRA constituents that have been in contact with the rings. In addition. the rings will be segregated based upon the buildup of material on the rings (i.e., very dirty, somewhat dirty, fairiy clean). The segregated rings will be placed inside a stainiess steel mesh basket (or similar device) and cleaned with a detergent applied using a high pressure washer. The rings will then be rinsed with water and then allowed to soak in a $\mathbf{3 0}$ percent nitric acid solution. The rings will then be cleaned with a detergent applied with a high pressure washer. The final stage will consist of a thorough rinsing with hot water applied with a high pressure washer. All solution generated will be collected, containerized. and stored at an approved on-site storage facility. The containerized solution will be marked, stored, and treated based upon the appropriate RCRA listings and applicable RCRA characteristics. The solution generated during the finai cleaning pass will be collected separately and sampled for RCRA constituents to document that the decontamination criteria listed in Table 4 are met.

If RCRA decontamination of the Raschig rings is unsuccessful, the rings will be packaged into 55-gailon drums and placed into long-term storage as mixed hazardous waste.

Decontamination of Plastic Liner and Structural Support for 300-gallon Polytanks

The structural supports and the plastic liner will be decontaminated using a two-step process. Initial cleaning will be with a detergent applied using a high pressure washer. This will be followed by a two-stage high pressure rinsing. All solution generated will be collected, containerized. and stored at an approved on-site storage facility. The containerized solution will be marked, stored, and treated based upon the appropriate RCRA listings and applicable RCRA characteristics. The solution generated during the final cleaning pass will be collected separately and sampled for RCRA constituents to document that decontamination criteria listed in Table 4 are met.

If RCRA decontamination of the liner is unsuccessful, the liner will be packaged into 55-gailon drums and placed into long-term storage as mixed hazardous waste.

\section{Decontamination of Asphait Surface under the Plastic Liner}

A thorough inspection of the integrity of each layer of the plastic liner will be made during the above described decontamination effort. If there is no indication that the liner has been breached, this will be documented and no decontamination will be performed on the asphalt. If the liner has been breached, then the asphalt surface will be cleaned using a two-stage process. The surface will initially be cleaned with a detergent appilied with a high pressure washer. This will be followed by a high pressure hot-water rinse. All solution generated will be collected, containerized, and stored at an approved on-site storage facility pending the analysis from samples taken from the solution. Based on the anaiytical results, the containerized solution will be disposed of in an appropriate manner. The solution generated during the final cleaning pass will be collected separately and sampled for RCRA constituents to document that decontamination criteria listed in Table 4 are met. 


\section{Sampling Procedures}

Sample sizes, preservatives, and holding times are given in Table 2.

Samples listed in Table 1 will be collected by Martin Marietta Energy Systems, Inc. (Energy Systems), sampling personnel. Samples will be preserved in the field, scanned by Y-12 Radiological Control personnel, and delivered to the Energy Systems analytical laboratory at the end of each sampling day or no later than 24 hours after the samples are collected. Samples are stored in coolers at $4{ }^{\circ} \mathrm{C}$ (metais samples may be stored uncooled) in the field and during transport to the laboratory.

\subsection{Water Sampling}

Protocols from or consistent with the Environmental Surveillance Procedures Quality Control Program. ES/ESH/INT-14, are to be used when possible. The following activities take place once the decontamination is completed. Sampies for volatile organic determinations will be collected as soon as possible.

As indicated in Table 1, an additional volume of water will sometimes be needed to provide sufficient sample for laboratory QC. Each sample will be placed in its container as soon as it has been obtained. The samples are preserved in accordance with practices given in Table 2 . The field notebook and chain-of-custody forms will be completed in accordance with ESP-503, Field Logbooks and Data Forms (August 1994), and -501/500 Chain-of-Custody (January 1990).

\section{Sampling Quality Assurance (QA)}

Field sampling personnel must perform operations according to the closure plan, this sampling and analysis plan (SAP), and the procedures specified.

The quality of the sampling is monitored by the analysis of field duplicate samples. Collection of replicate samples serves two uses. Every other replicate collected is designated as a field duplicate; these are ideally collocated with the original associated sample.

Field blanks (source water blanks) will be submitted at a rate of one sample per water type (e.g., steam cleaning water and decontamination water) per sampling event (time sampling personnel arrive at the site until the time they leave for more than 24 hours).

To ensure that cross-contamination does not occur, most sampling equipment will be utilized only one time. However, if equipment is reused, decontamination will be performed as described in ES/ESH/INT-14.

\section{Sample Preservation, Containers, and Holding Times}

The primary means of sample preservation will be cooling to $4^{\circ} \pm 2^{\circ} \mathrm{C}$. For water samples, chemical preservation will be conducted according to requirements of Environmental Protection Agency (EPA) SW-846 Test Methods for Evaluating Solid Waste, November 1990, as amended (see Table 2).

Sample containers will be selected as appropriate for the applicable anaiysis. Choosing the correct container is a matter of making sure that the sample and container are nonreactive to 
Table 2 Preservation, bolding times, and containers by sample type and anatysis

\begin{tabular}{|c|c|c|c|c|}
\hline $\begin{array}{c}\text { Sample } \\
\text { Type }\end{array}$ & $\begin{array}{c}\text { Anatysis } \\
\text { (SW-846) }\end{array}$ & $\begin{array}{l}\text { Preser- } \\
\text { vation }\end{array}$ & Holding time & Containes \\
\hline \multirow[t]{4}{*}{ Waters } & VOAs & & 7 days to anatyze. & $\begin{array}{l}2-40 \mathrm{~mL} \\
\text { amber vial } \\
\text { with Tefloa- } \\
\text { lined aps }\end{array}$ \\
\hline & SVOAs' & $4^{\circ} \mathrm{C}$ & 14 days to extraction, plus 40 days to anatysis & $\begin{array}{l}\text { 2-L amber } \\
\text { glass jar with } \\
\text { Teflon liner }\end{array}$ \\
\hline & Metals & $\begin{array}{l}\mathrm{HNO}_{3} \text { to } \\
\mathrm{pH}<2\end{array}$ & 180 days & $\begin{array}{l}\text { 1-L glase or } \\
\text { pohyethylene } \\
\text { jar }\end{array}$ \\
\hline & Mercury & $\begin{array}{l}\mathrm{HNO}_{3} \text { to } \\
\mathrm{pH}<2\end{array}$ & 13 days in potyertyylene, 38 days in glass & $\begin{array}{l}250-m L \\
\text { potycthylene } \\
\text { or glass jar } \\
\text { (Note change } \\
\text { in } 1992 \text { SW- } \\
846 \text { update) }\end{array}$ \\
\hline
\end{tabular}

Herbicides and Pesticides will not be required tor this ciosure.

*SVOAs = Semivotatile Organic Analyses

each other. If possible, containers will be kept full to help retard air oxidation. Volatile samples must be collected with zero headspace.

Holding times will follow the guidance provided in EPA/SW-846. Holding times start at the time of collection of the sample in the field.

\subsection{SAMPLE CUSTODY AND DOCUMENTATION}

\subsection{Chain of Custody}

The ability to trace samples from the time of collection is accomplished through the process known as chain of custody. This record is filled out during the sampling event and accompanies every sample from the time it is taken until the sampie is relinquished to the laboratory. Samples taken under chain-of-custody for this project will follow the specific guidance provided in ESP-501/500 or Analytical Service Organization Standard Operating Procedure (SOP) 9094, Sampie Chain of Custody (February 1982).

\section{Sample Container Labed}

Samples will be physically identified by a label placed on the sampie bottle in a manner that is clear and easily recognizable. Samplers will fill out the labels on each container before collection, if possible, to minimize handling errors. Labels will be attached to the sample container and discarded when analysis is complete. 


\subsection{Field Notebook}

The field sampling event will be recorded in the field notebook. The field notebook is bound with consecutively numbered pages. All pertinent information necessary to interpret the analytical data will be recorded in the field notebook in black ink. The entries should provide a chronological record of the sampling team's activities, enabling reconstruction of the sampling event at a later date. The field notebooks are to be maintained as project records.

\subsection{Laboratory Notebooks}

Laboratory logbools provide a record of events surrounding the analysis of the samples. The recorded data entered into the notebook each day must be reviewed and signed by the user and a qualified second reviewer (e.g., peer reviewer, supervisor, team leader). All entries are made in ink. Data must be sufficient to enable a person to reconstruct sample preparation and analysis and to perform any calculations. The notebook is also used to record the source of all standard materials, sample preparations, sample preservations, and unusual conditions. Guidance on laboratory notebooks can be found in Y-12 Plant SOP 9069, Issue, Use, and Accountability of Laboratory Logbooks in the Analytical Services Organization.

\subsection{ANALYTICAL PROCEDURES}

The following sections provide a brief description of the analytical methods to be used in this characterization study. Table 3 lists the analytical methods. The number of samples expected to be analyzed are given in Table 1 , and the determinations to be performed for each sample and matrix are given in Table 2

Quality control practices suggested or recommended by the analytical method will be considered required for this project uniess the laboratory obtains permission from the project otherwise prior to initiation of analysis.

\subsection{SW-846 Totals}

Water samples will be analyzed by current SW-846 protocois as indicated in Table 3 .

\section{Calibration}

All laboratory equipment must be calibrated according to manufacturer's instructions, analytical protocois, and applicable Y-12 Plant SOPs such as 9071, Calibration of Analytical Equipment, and 9086, Calibration of Mechanical and Electronic Pipettes.

\subsection{Laboratory QA and QC}

Laboratory QA systems must be in place, documented, and implemented.

The goal of a QA program is to monitor the activities within the laboratory to ensure that all data generated are suitable for their intended use. The QA activities will be under the direction of a person that reports directly to the laboratory director or other independent QA organizations. 
Table 3. Analytical methods"

\begin{tabular}{l|l}
\hline \multicolumn{1}{c||}{ Anatyes } & $\begin{array}{l}\text { Method of anatysis } \\
\text { (SOPs) }\end{array}$ \\
ICP metals & 6010 \\
Mercury & 7470 \\
Semivolatiles & 8270 \\
Volatiles & 8240 or 8260 \\
\hline
\end{tabular}

- All samptes will undergo further preparation and possibly cleanup according to approved SW-846 methods prior to anatysic.

The laboratory responsible for the analysis will subject a minimum of 5 percent of all samples to spiking for the purpose of QC. The laboratory also will analyze 5 percent of the samples as laboratory duplicates.

Additional material will be supplied and identified for these QC samples from the field replicates. The results will serve as tools to evaluate the quality of data being furnished by the laboratory. Procedures for analyzing QC samples and utilizing the results must be in place. At a minimum, the QC program must meet the criteria specified within the required methods.

\subsection{DATA REDUCTION, VERIFICATION, REPORTING, AND ASSESSMENT}

\subsection{Data Reduction/Verification}

Field data and observations are verified by another sample team member at the time of collection and are reported without further manipulation or reduction to the Project Manager. Data generated in the laboratory will be reduced and verified in accordance with the specific procedures and the internal QA program of that laboratory. Applicable Y-12 Plant SOPs include 9122. Internal Data Verification; 9114, Statistical Determination of Precision, Bias, Significant Digits, and Detection Limits; and Data Management Procedures associated with different Y-12 Plant analytical centers.

All data generated on controls and samples shall be maintained at the laboratory. The QA data generated by the laboratory will be part of the deliverables for this project.

\section{Reporting}

Hard-copy results will be the formal transfer method for reporting results to the Project Manager. In addition to hard-copy resuits, results and $Q C$ data will be submitted electronically. Electronic data should be in ASCII file format or similar standard format. 
Table 4. TCLP reguiatory levels

\begin{tabular}{|c|c|}
\hline ANALYTE & Level (mg/L) \\
\hline Arsenic & 5.0 \\
\hline Barium & 100.0 \\
\hline Cadmium & 1.0 \\
\hline Chromium & 5.0 \\
\hline Lead & 5.0 \\
\hline Mercury & 0.2 \\
\hline Selenium & 1.0 \\
\hline Silver & 5.0 \\
\hline o-Cresol & 200.0 \\
\hline m-Cresol & 200.0 \\
\hline p-Cresol & 200.0 \\
\hline Cresol & 200.0 \\
\hline 1,4 Dictlorobemene & 7.5 \\
\hline 2,4 Dinitrotoluene & 0.13 \\
\hline Hecachlorobutadiene & 0.5 \\
\hline Hecachloroethane & 3.0 \\
\hline Nitrobenzene & 2.0 \\
\hline Pentachiorophenol & 100.0 \\
\hline Pyridine & 5.0 \\
\hline 2,4,5 Trichioropbenol & 400.0 \\
\hline 2,4,6 Trichlorophenol & 2.0 \\
\hline Herachlorobenzene & 0.13 \\
\hline Benrene & 0.5 \\
\hline Carbon tetrachloride & 0.5 \\
\hline Chlorobenzene & 100.0 \\
\hline Chloroform & 6.0 \\
\hline 1,2 Dichloroethane & 0.5 \\
\hline 1,1 Dichloroetnylene & 0.7 \\
\hline Methyl etbyt ketone & 200.0 \\
\hline Tetractiloroethylene & 0.7 \\
\hline Trichloroethylene & 0.5 \\
\hline Vinyl chloride & 0.2 \\
\hline Methylene Chloride & 0.02 \\
\hline 1,1,1-Trichloroethane & 0.02 \\
\hline 1,1,2-Trichloro-1,2,2-trifluoroethane & 0.02 \\
\hline Trichloromonofluoromethane & 0.02 \\
\hline
\end{tabular}


Distribution:

M. S. Burris

C. H. Fritts

J. A. Kreykes

A. K Lee/DOE-OSTI (2)

W. G. McMillan, DOE-ORO

S. E Rathke

L. M. Sparks

B. E. Walton

Y-12 Central Files

File-EMD-RC 


\section{Appendix C}

Building 9706 Uranium Treatment Unit - Photographs

\begin{tabular}{|l|l|l|}
\hline Reference Number & Photograph Number & \multicolumn{1}{c|}{ Subject } \\
\hline C-1 & 319542 & UTU Prior to Closure \\
\hline C-2 & 319543 & UTU Prior to Closure \\
\hline C-3 & 320712 & Site Surface Prior to Decontamination \\
\hline C-4 & 320713 & Site Surface Prior to Decontamination \\
\hline C-5 & 320887 & Equipment, Drum, Liners Removed \\
\hline C-6 & 321042 & Site Surface After Decontamination \\
\hline C-7 & 321025 & Decontamination Facility \\
\hline C-8 & 321044 & Loading Raschig Ring for Decontamination \\
\hline C-9 & 321028 & Decontaminating Raschig Rings \\
\hline C-10 & 32103 & Decontaminated Raschig Rings \\
\hline C-11 & 321190 & Decontamination of Subsurface \\
\hline
\end{tabular}



5


Wn

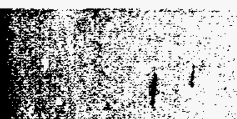

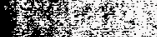

(1) 13

(3)

, W Whet

of

2

5.,

Sor

48

药4

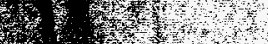

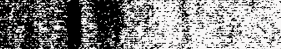

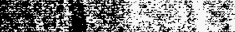

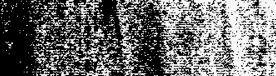

14

通

定

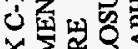





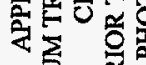

费高望

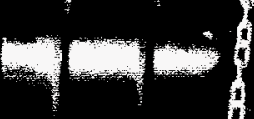

5

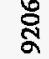
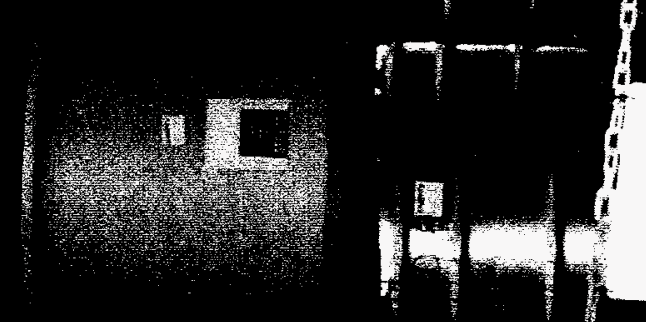

17

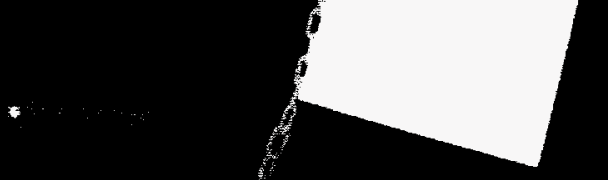

tan
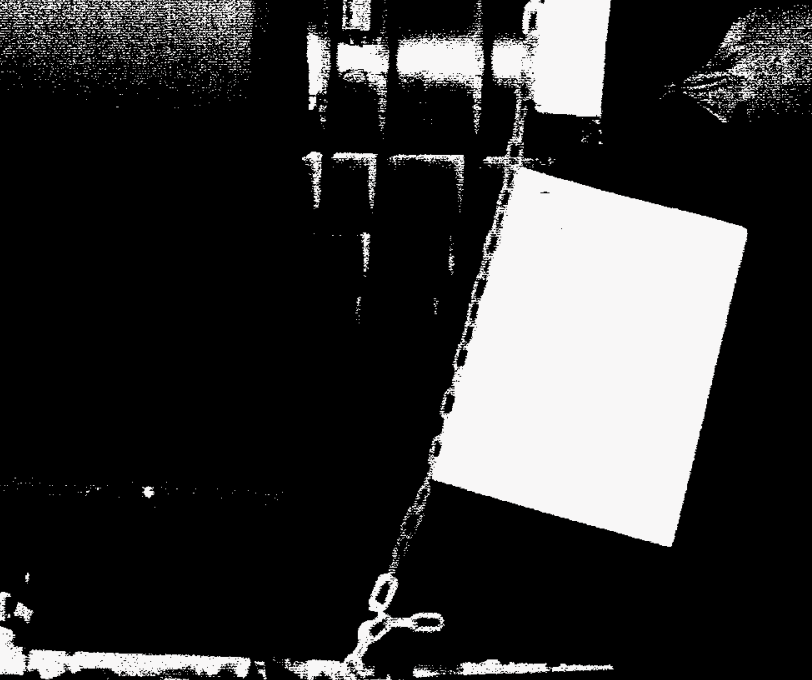

\%
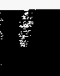



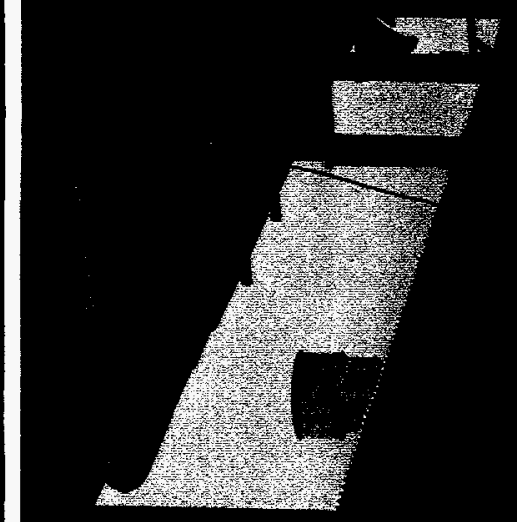

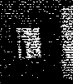
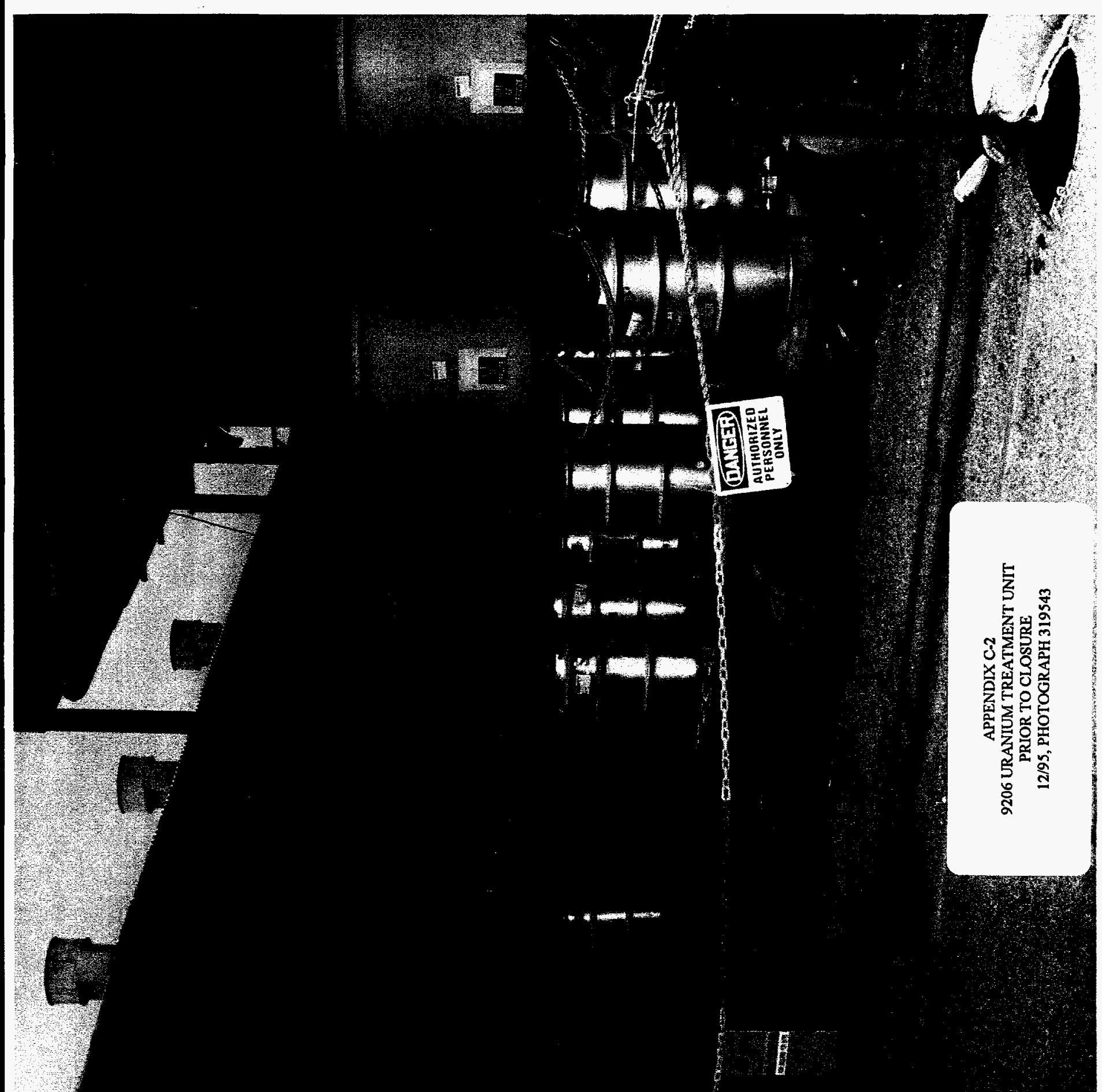


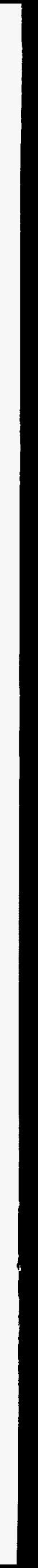



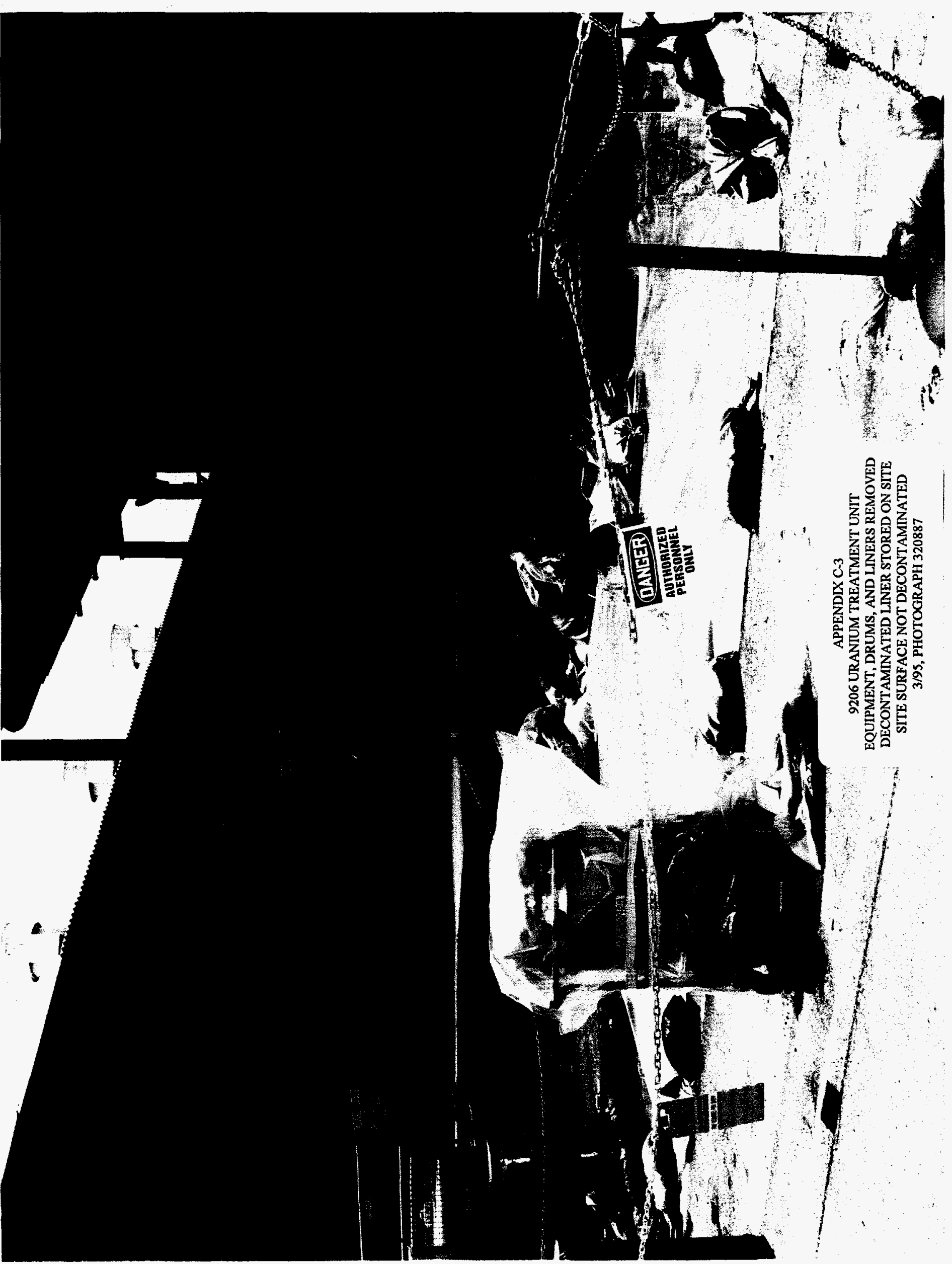


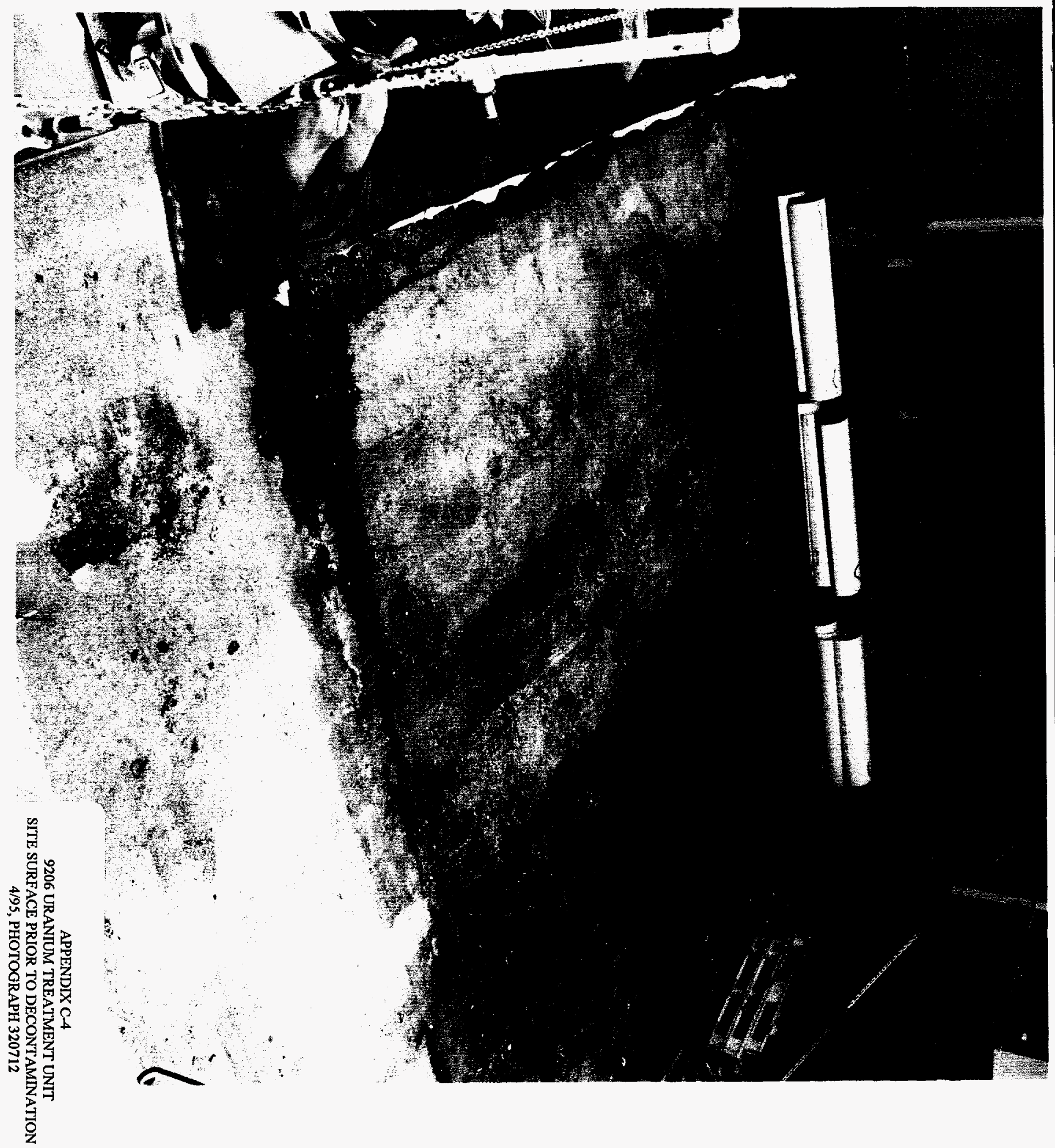




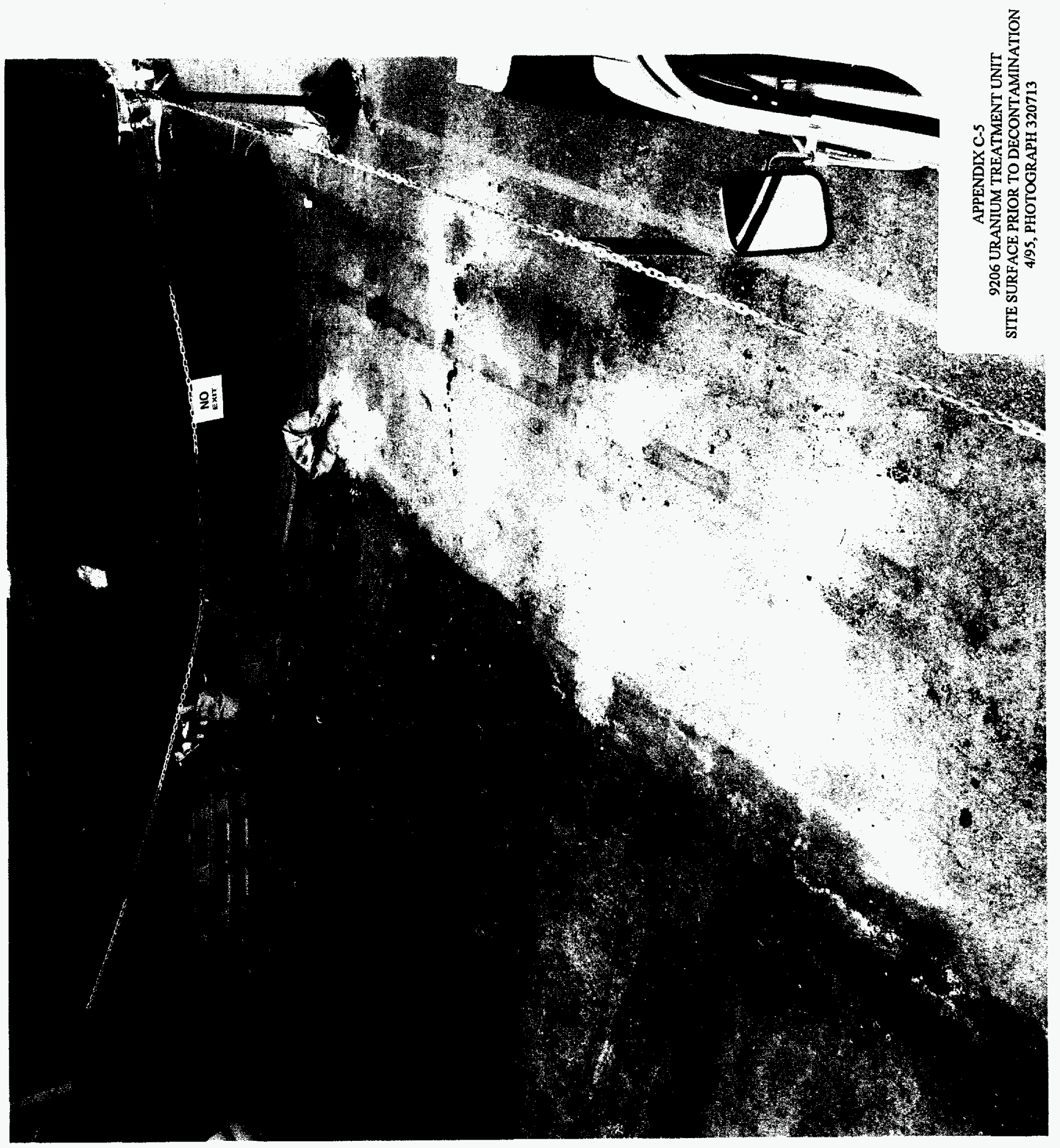



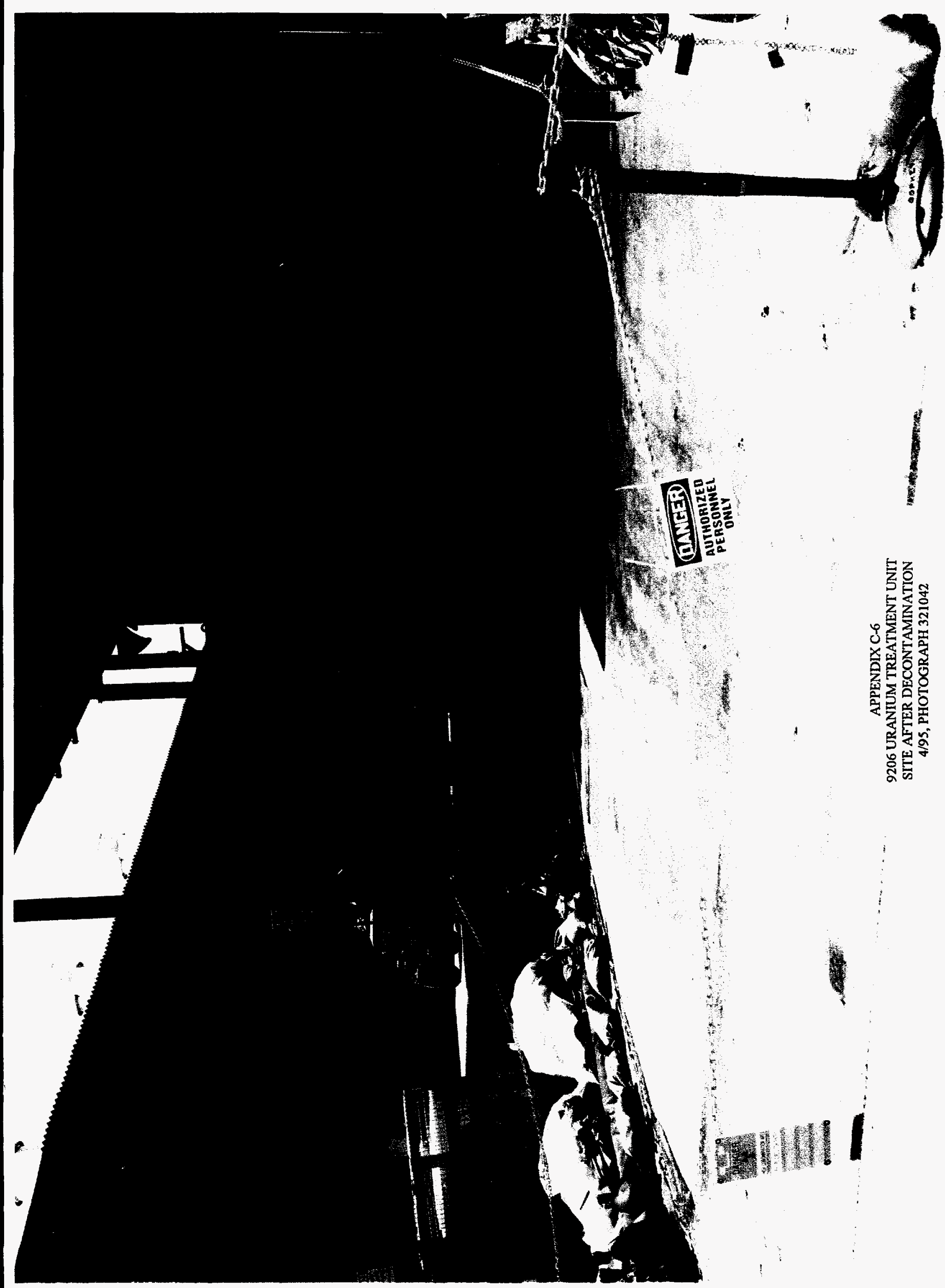


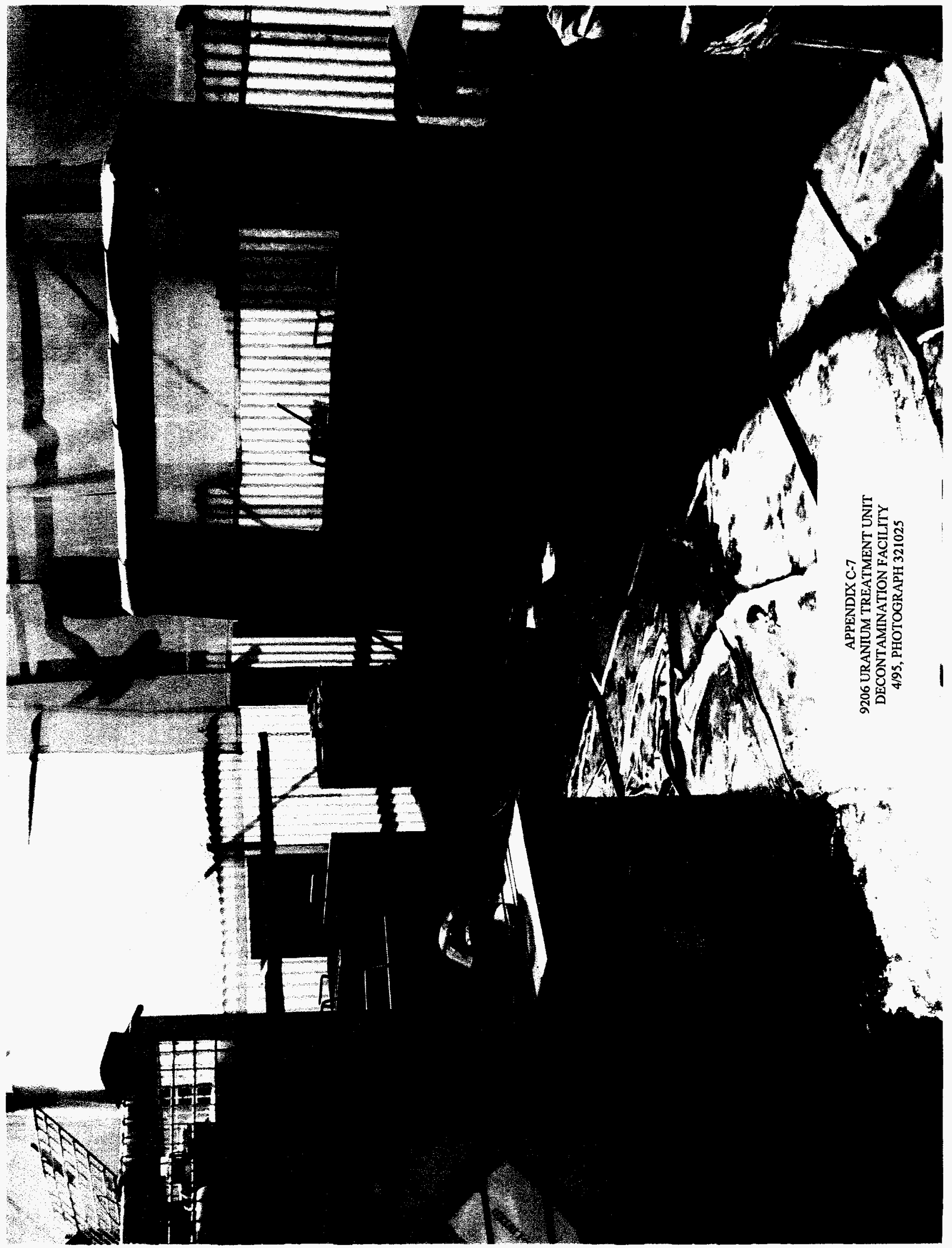




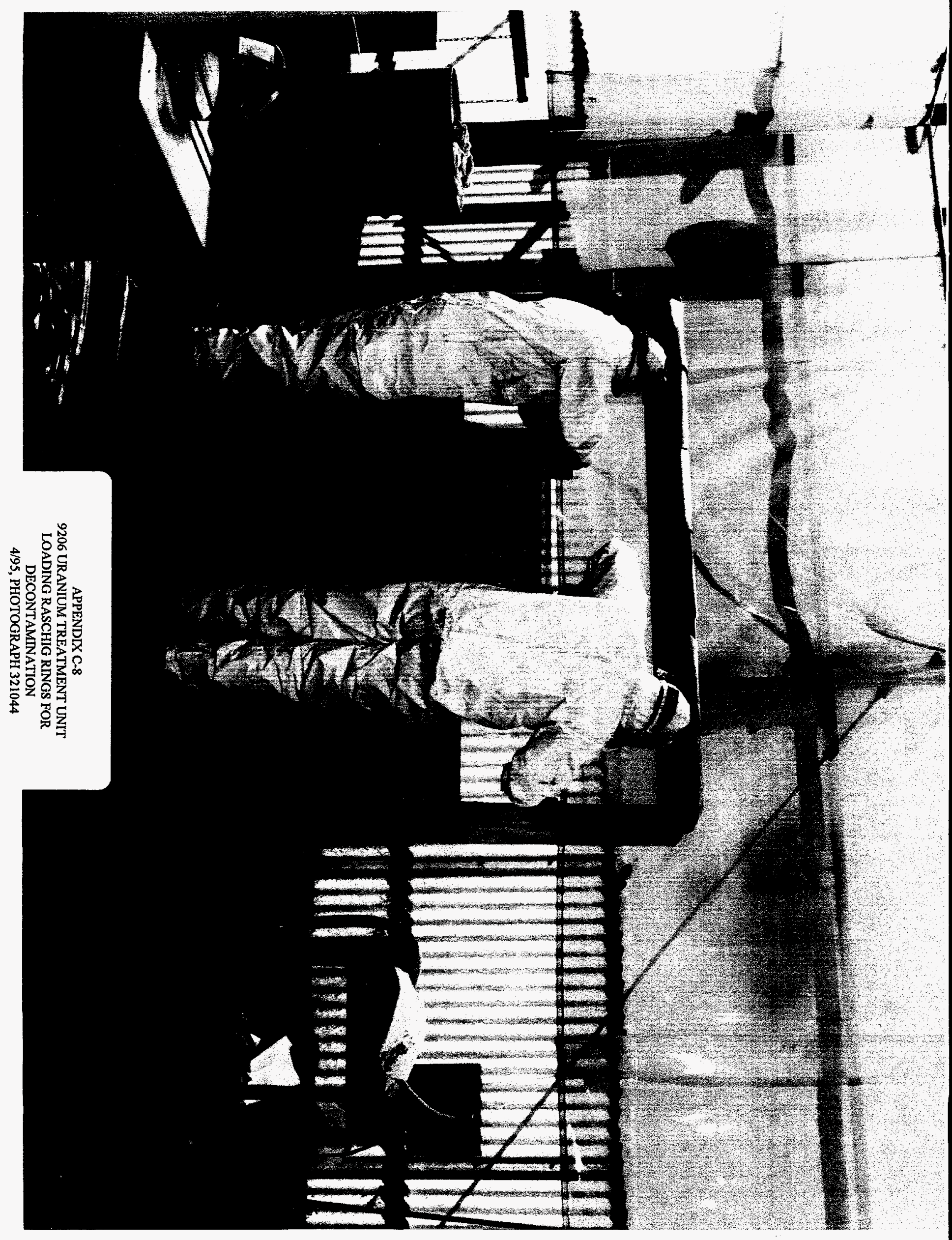




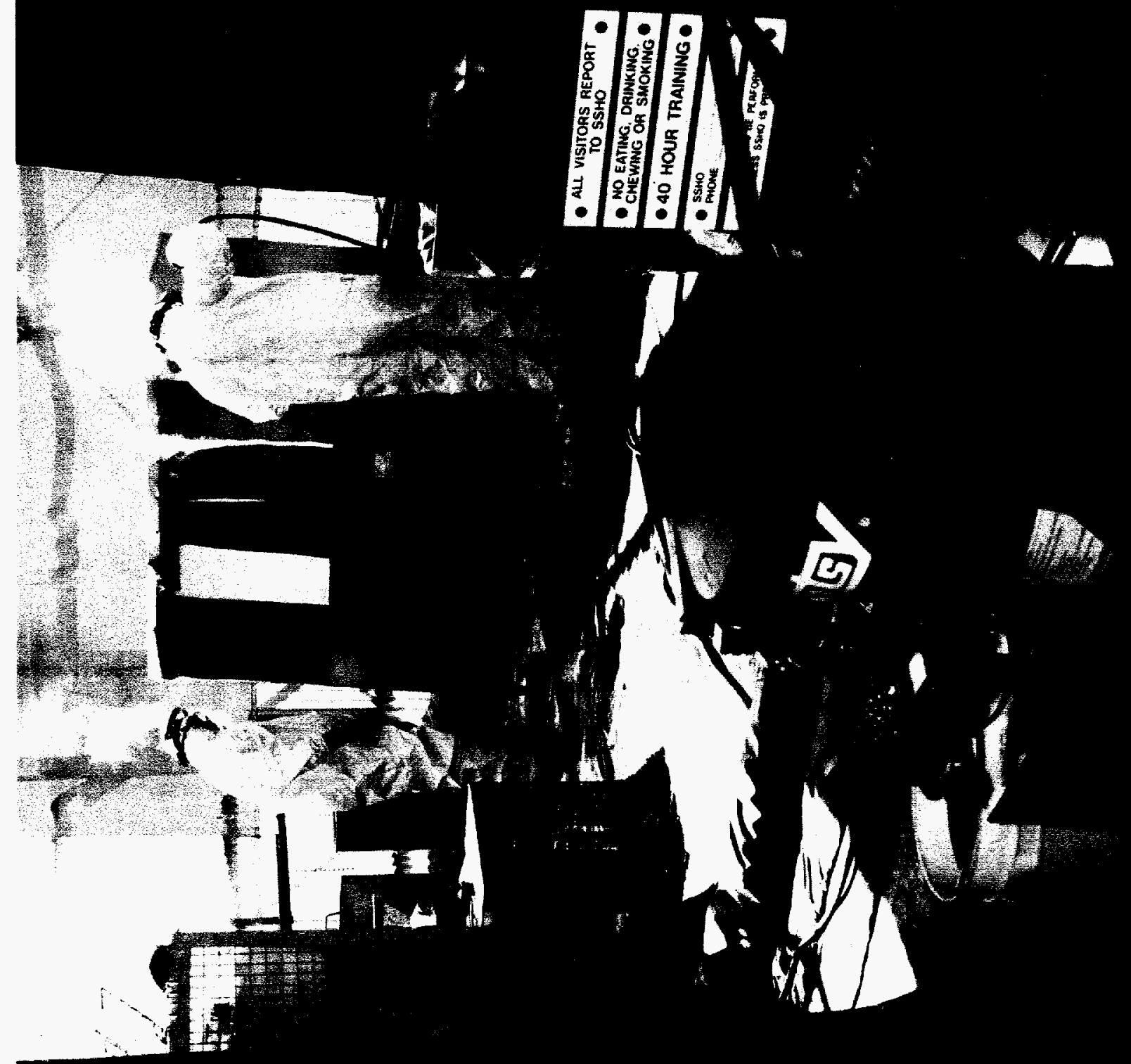





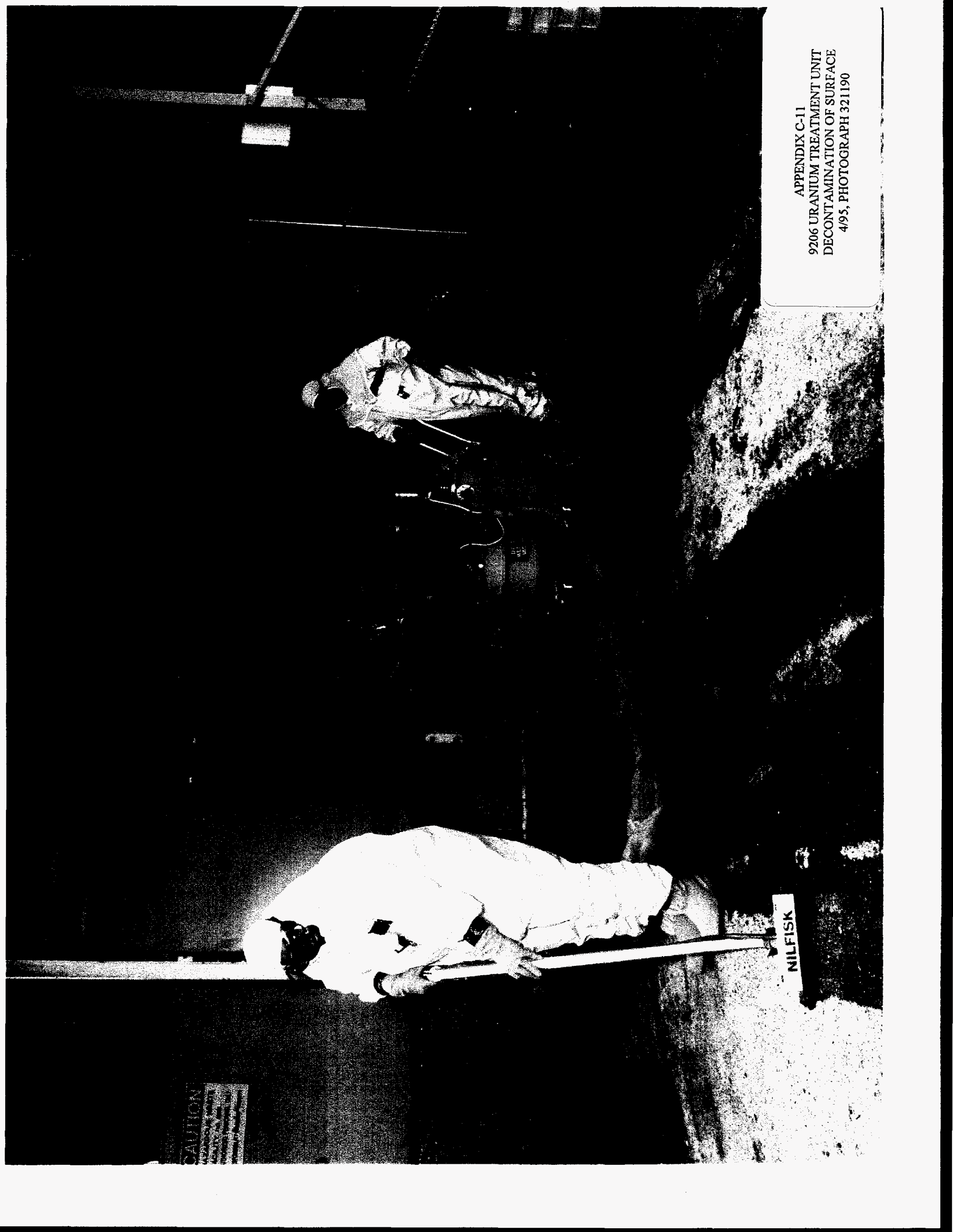




\begin{abstract}
APPENDIX D
Uranium Treatment Unit--

Radiological Survey/Work Permit and Industrial Hygiene Requirements
\end{abstract}



MONITORING AND SURVEY RESULTS

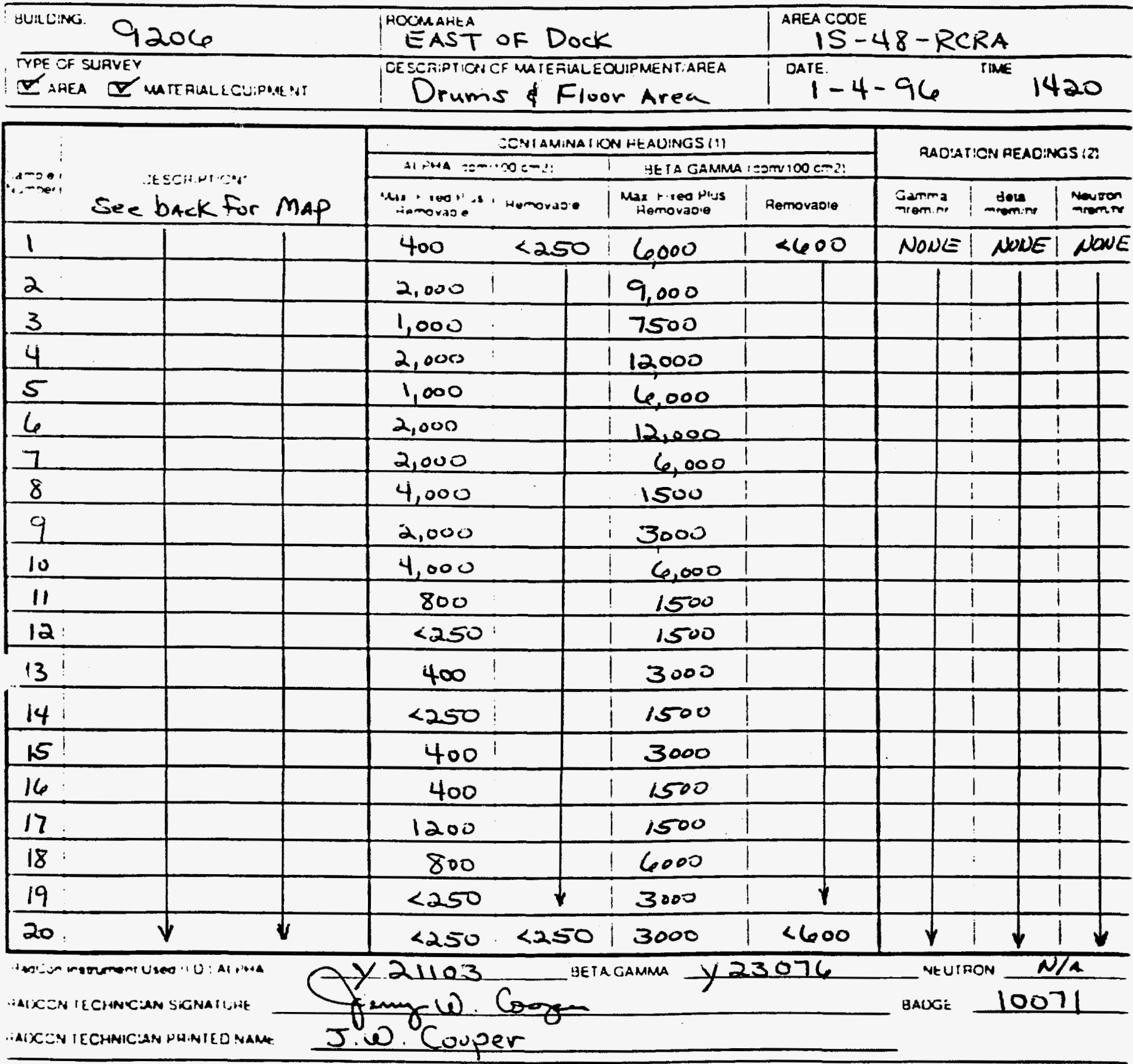

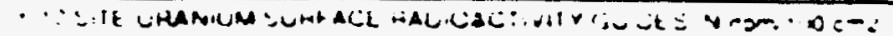
Alinsa

inmoras

Mur ren

Dins Homorade

$24+2: 19002$

\begin{tabular}{|c|c|c|c|}
\hline$\$ 5000$ & $\because: \infty$ & $=2000$ & : ass eo as wrcoriaminated \\
\hline .5000 & $\because 500$ & - j & as cortam naied \\
\hline
\end{tabular}

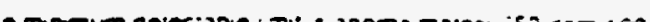

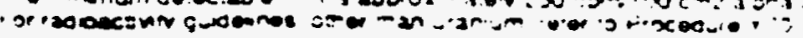

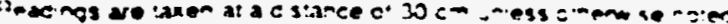

ASTHIHUIKCN

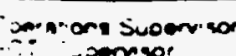

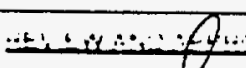

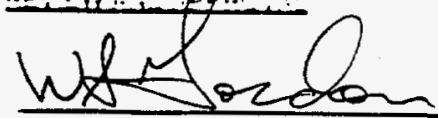

$1 / 4 / 96$
-SEE MAP ON REVERS SIDE FOR SURVEY LOCATIONS 
RADIOLOGICAL CONTROL ORGANIZATION MONITORING AND SURVEY RESULTS

\begin{tabular}{|c|c|c|}
\hline Burong. 9206 & ROOMAHEA & AREA COOE -48 RCRA \\
\hline $\begin{array}{l}\text { TPE OF SUAVEY } \\
\text { DAREA MATERULEOUIPMENT }\end{array}$ & $\begin{array}{l}\text { OESCAIPTIONCF MATEALALEOUIPMENTIAAEA: } \\
\text { Drums \& Floor Area }\end{array}$ & DATE. $1-4-96$ \\
\hline
\end{tabular}



Aeción menmom Ueea II O I AL ma Y21103 getagamma y23076 HaUcON IECTENCUN SICRATUHE $f \ln w \cos$ NEUIRON N/A

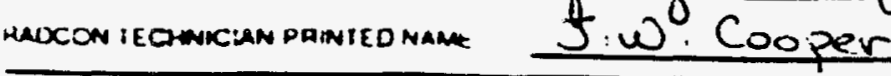

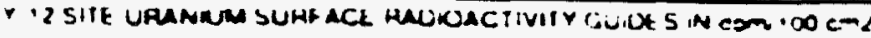
Alese HET I Tizena

\begin{tabular}{|c|c|c|c|c|}
\hline Memovare & $\begin{array}{l}\text { Wur ried } \\
\text { Pnus Hemovenos }\end{array}$ & Hemoraoe & 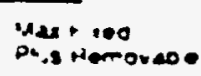 & \\
\hline$\$+\infty$ & $\$ 5.000$ & $\leq \infty$ & 35000 & _ 2wito as urcontaminateo \\
\hline .1000 & .5000 & .1000 & .5000 & 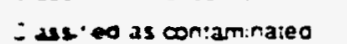 \\
\hline
\end{tabular}

'SEE MAP ON REVE: SIDE FOR SURVEY LOCATIONS

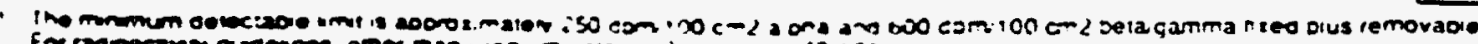

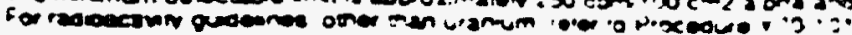

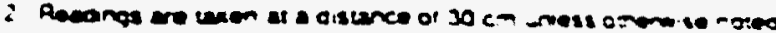

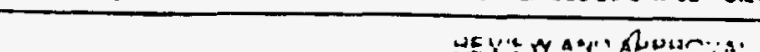

ist hautron

dow anone sucemeo

HiC? "uoenneor

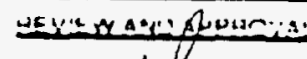

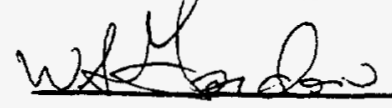

. AC: - .sen so

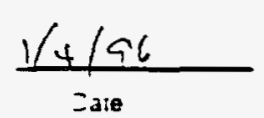

Pererence

70.10

175.11 : 
Use the space below to draw a general floor plan using equipment, stairs, walls, rooms. etc , in the area as landmarks Place numbers corresponding with survey localions inside the appropriate symbol and list specific survey location descriptions on the attached HPAM form Use either a HPAM-5 or a HPAM-111



\begin{tabular}{|c|c|c|c|}
\hline \multicolumn{2}{|r|}{ ART } & \multicolumn{2}{|c|}{. دNATIONS } \\
\hline ARA & Airborne Radic. & RA & Radialion Area \\
\hline IICA & Hign Contamination Area & RMA & Radiological Material Area \\
\hline IIRA & High Radiation Area & & \\
\hline
\end{tabular}

MAP SYMBOLS

O Smear Location

Q ...eed + Removable

Large Area Wipo

\& Radiation Readino

III Sier iff Pad 


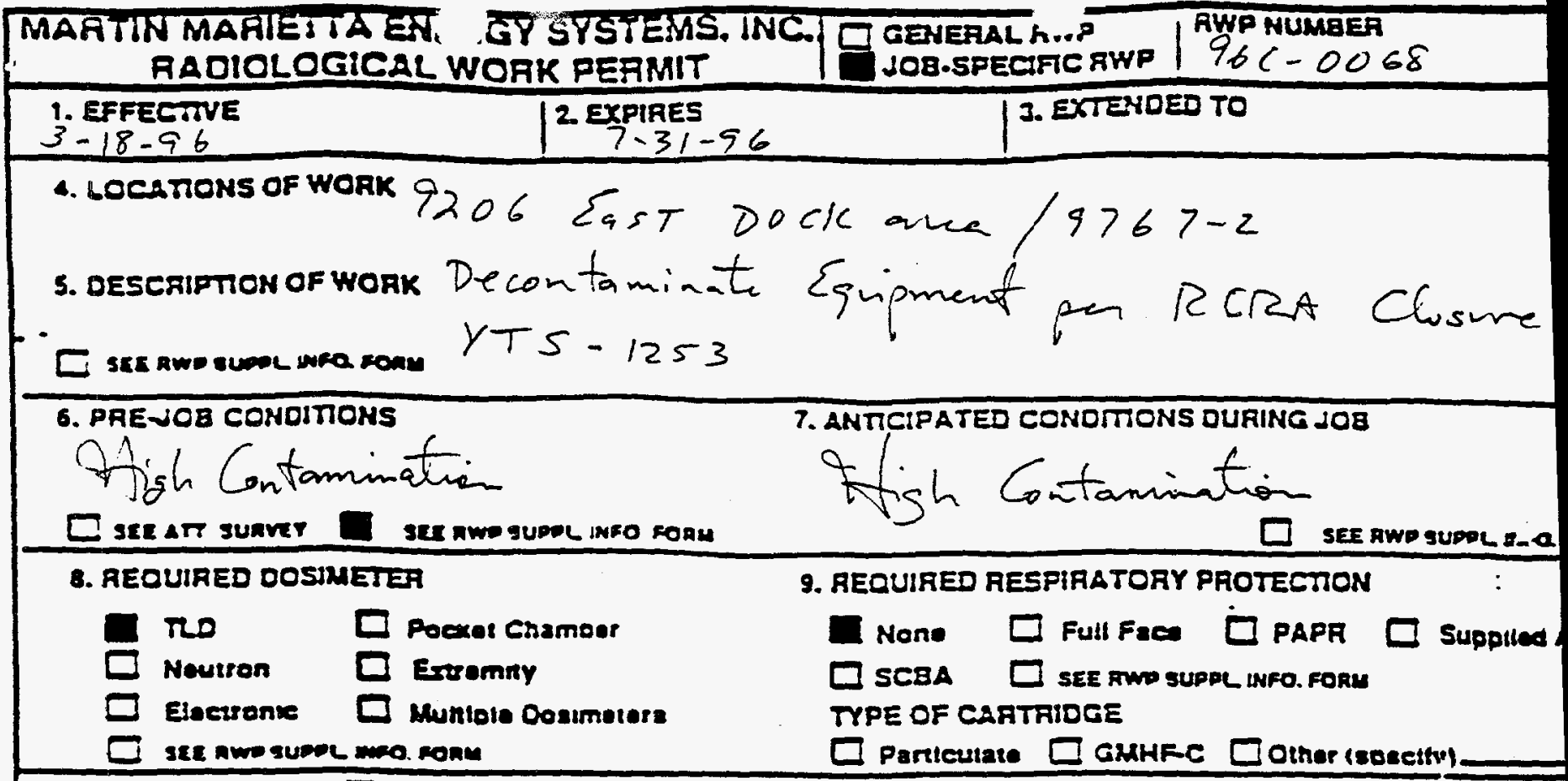

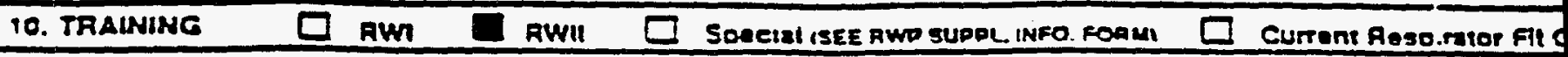

11. REOUIRED ANTI-C CLOTHING (NO. OR DAIAS WOKCATEO W PAAERTMESES?
COVERALIS GLOVES
SHOE COVERS

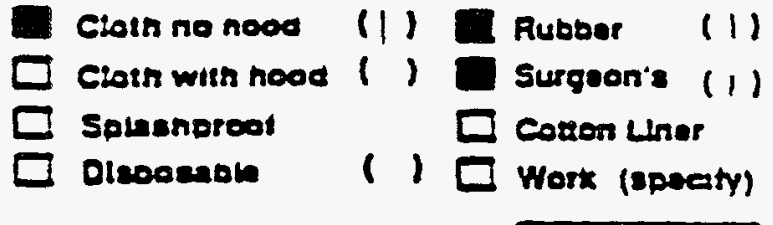
Ecotias
Rubbar, tow top (1)
$\square$ Rubber, hight top
$\square$ Disposabio
OTHER

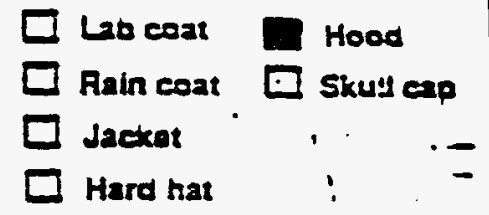

12 SPECAL ANTI-C LLOTHING MSTAUCTONS

SEE RWP SUPAL ive

13. PAE.JOQ BAIEFTNG AEDUIRED? D NO $\square$ YES $\square$ SEE AWD SUPAL INFO. FORM

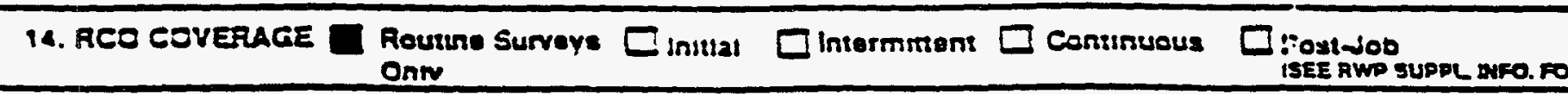

15. SPECAL INSTRUCTONS

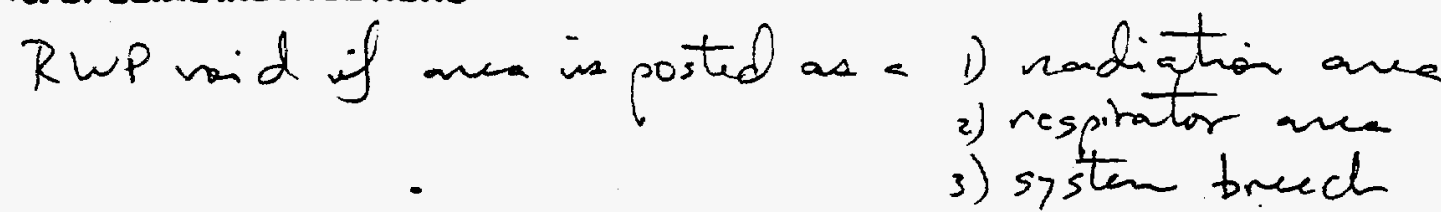

Ser nwo supe woo. ronk

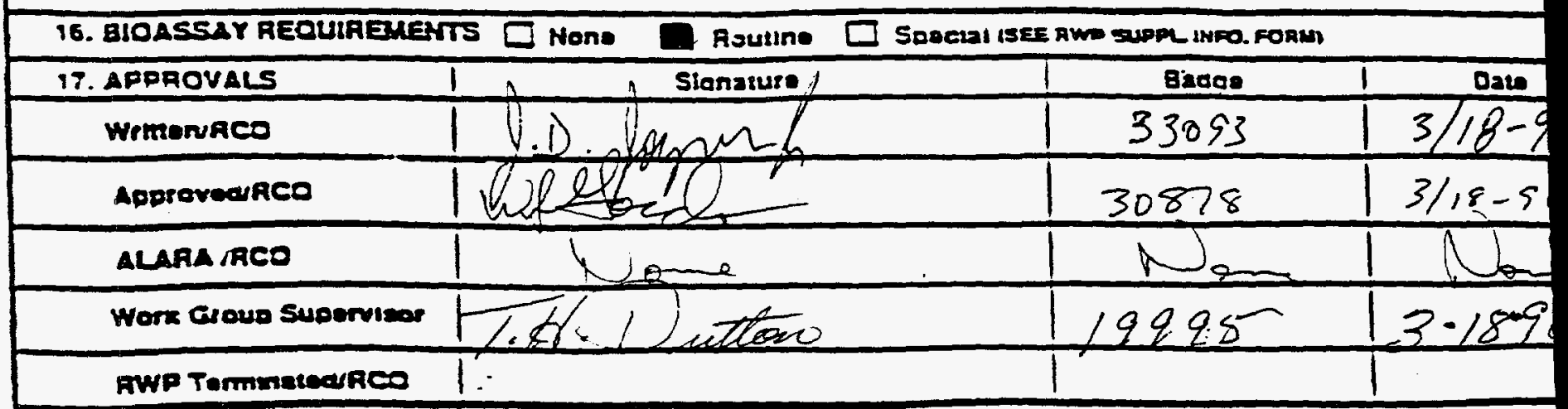

Distrigution:

RCO-FC

Work Group Supervisor

vestro18 $\cdot 23$ 305) 


\begin{tabular}{|c|c}
\hline $\begin{array}{c}\text { MARTIN MARIETTA ENERGY SYSTEMS. INC. } \\
\text { RADIOLOGICAL WORK PERMIT }\end{array}$ & SUPPLEMENTARY INFORMATION \\
\hline & TWP NUMBER $96 \mathrm{C}-0068$ \\
\hline
\end{tabular}

c) See routine surrey results before entering nee.

12) Saranex suits on PET (trek) suits may

be substituted for cloth antic's if necessary. A plastic shield man be utilized for face protection by operations personnel unite met decontamination is in progress. See site specific Health and Salter plur for IH specifies an dotting options.

15) This Rep is valid for una type decontamination activities pen Decor.

UCN-20118 (1203 3-95) 
I N T E R O F F I C E M E M O R A N D U M

$\begin{array}{ll}\text { Date: } & 22-\text { Feb-1996 12:51pm EST } \\ \text { From: } & \text { P D Calkin } \\ & \text { CALKINPD@A1@OCU1 } \\ \text { Dept: } & 2066 \\ \text { Tel No: } & \end{array}$

TO: TINDALWC

CC : LOMAXBA

MCINTYRERF POLSONJE

Subject: Fwd: ORGANIC ASSAY NEUTRALIZATION PPE

File: CLOSURE 001296

Bill,

After conferring with the RADCON Department, the Industrial Hygiene Department (IHD) recommends that Polyethylene Tyvek (PET) may be utilized for personal protective equipment (PPE) during each task of the Organic Assay Neutralization Operation. While performing (task one) sampling, personnel mal utilize the PET instead of the chemical protective sleeves.

While performing (task two) neutralization and (task three) caustic mixing, personnel may utilize PET instead of Saranex protective suits. Operators should be made aware that PET has not been tested against many of the constituents that are potentially contained in the Distillate drums. Therefore, if the PET is utilized while performing tasks associated with the Distillate drums, spills or splashes of volumes greater than $100 \mathrm{ml}$ will necessitate an immediate change. Spills less than $100 \mathrm{ml}$ will necessitate an inspection of the PET by the operators to ensure no degradation or permeation has occurred.

Please feel free to contact me if I can be of further assistance.

Pete Calkin

Industrial Hygiene Department 


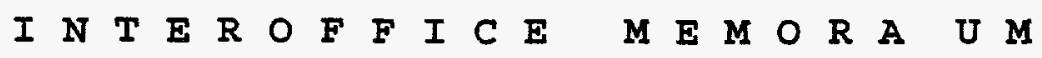
Date: $\quad 01-M a r-1996$ 09:03am EST
From: $\quad$ P D Calkin
Dept: $\quad 2066$

Tel No:

O: TINDALWC

$c:$ LOMAXBA

ubject: Fwd(2): ORGANIC ASSAY NEUTRALIZATION PPE

ile: READ

001392

As we discussed Wednesday, additional Industrial Hygiene Department ecommendations include the following:

Rubber booties will be utilized during all three tasks.

For Task Three (Caustic Mixing), the requirement for utilizing a fan to rect potential airborne hazards away from the operators' breathing zone or he utilization of a half-face respirator with GMCH cartridge is now optional.

Please feel free to contact me if I can be of further assistance.

te Calkin

dustrial Hygiene Department 
Date: $\quad$ 15-Feb-1996 09:40am EST

$\begin{array}{ll}\text { From: } & \text { P D Calkin } \\ & \text { CALKINPD@A1@OCUI } \\ \text { Dept: } & 2066 \\ \text { Tel No: } & \end{array}$

TO: LOMAXBA

TINDALWC

CC: GREENEJS

Subject: ORGANIC ASSAY NEUTRALIZATION PPE

Bill,

The Industrial Hygiene Department (IHD) recommends the following protection with regard to the tasks that will be performed during the organic Assay Neutralization Operation located at the Uranium Treatment Unit RCRA Facility.

Task One (Uranium Sampling) - Personal Protective Equipment (PPE) shall include company clothing and shoes, goggles, chemical resistant sleeves, and Trionic or Latex gloves. The use of a fan to direct potential airborne hazards away from the operators' breathing zone is required when sampling the distillate $\operatorname{drum}(\mathbf{s})$.

Task Two (Drum Neutralization) - PPE shall include Saranex suit, Trionic or Latex gloves, company shoes, safety glasses, and face shield (hard hat required if Saranex suit has no hood). The use of a fan to direct potential airborne hazards away from the operators' breathing zone is required when neutralization of the distillate drums is performed. At minimum, half-face respirator with GMCH cartridge is required. The task of pouring the caustic solution into the drum(s) shall be performed very slowly and cautiously and is to be performed at times when weather conditions will not present additional concerns.

Task Three (Caustic Mixing) - PPE shall include Trionic and Latex gloves, safety goggles, face shield, Saranex suit (hard hat required if Saranex suit has no hood), and company shoes. Mixing is required to be performed with the use of a fan to direct potential airborne hazards away from the operators' breathing zone or a half-face respirator with GMCH cartridge. The task of mixing the caustic flake is to be performed at times when weather conditions will not present additional concerns. 


\section{APPENDIX E}

Uranium Treatment Unit--Site-Specific Health and Safety Plan 


\section{BITE-8PECIFIC HEALTH AND BAFETY PLAN}

FOR

Site Name:_Uranium Treatment Unit (UTUC)

Prepared by:

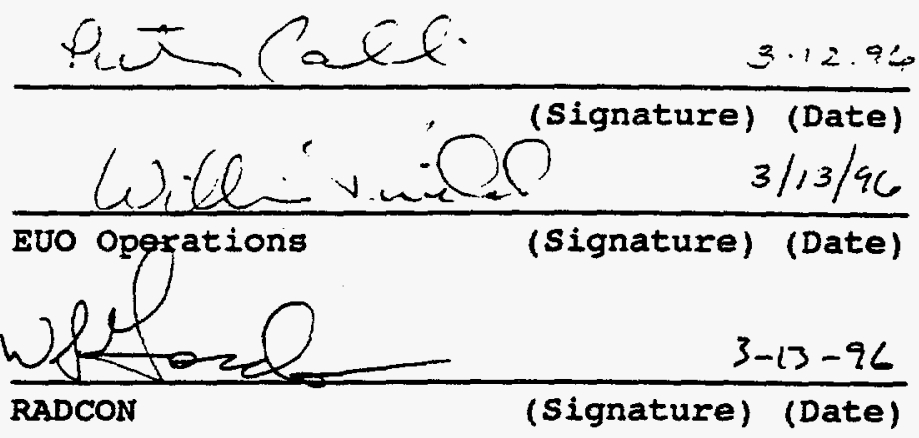

Reviewed by:

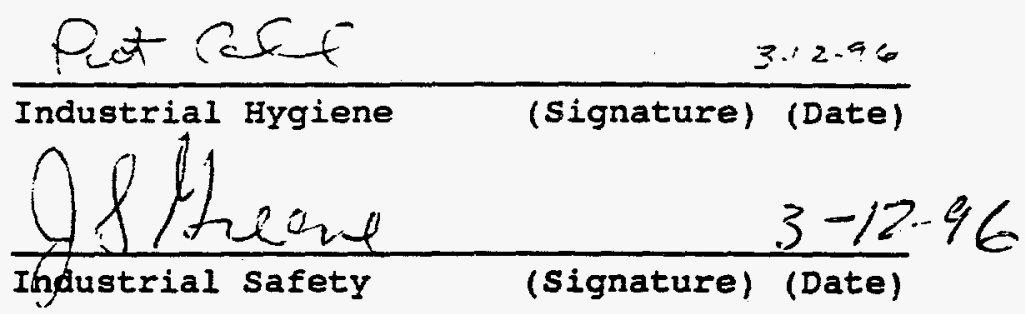

Approved by:

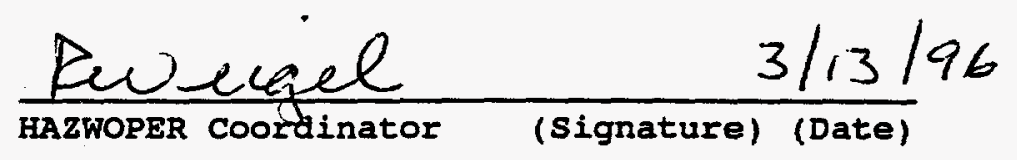


Page 2 of 16

Revision No.: 1

Revision Date: $3 / 12 / 96$

\subsection{SITE DESCRIPTION}

The UTUC Site is located at the western exclusion area of Y-12.

The UTUC Site is near the (roads, other landmarks) located between First street and " $\mathrm{g}$ " street.

\subsection{SITE HISTORY}

(Brief description of site history and use. Include all site activities that may contribute to current site conditions.) The Uranium Treatment Unit is used to store and teat waste materials that are regulated by the Resource Conservation and Recovery Act (RCRA).

The Oak Ridge Y-12 Plant was built by the U.S. Army Corps of Engineers in 1943 as part of the Manhattan Project. The U.S. Department of Energy (DOE) Owns and operates the Y-12 Plant. Personnel from Lockheed Martin Energy Systems, Inc. (Energy Systems), co-operate and manage the Y-12 Plant under a prime contract with DOE. The contract is administered by personnel at the DOE, Oak Ridge Operations office.

The Y-12 Plant occupies approximately 800 acres in Anderson County, Tennessee, and is located southwest of the city of Oak Ridge. Approximately 4000 people are employed at the Y-12 plant including employees of the Oak Ridge National Laboratory who are assigned to the plant. Two surface streams, East Fork Poplar Creek and Bear Creek, border the facility on the south, east, and southwest sides of the plant. Access to the $Y-12$ Plant is controlled on Bear Creek Road on the north gide of the facility; indirect access i available from Scarboro road on the east side and Bethel valley Road by way of Mt. Vernon road is located on the southwest side of the site.

The mission of $Y-12$ Plant personnel is to provide a key manufacturing components for the defense capabilities of the nation supporting national security programs, and providing services to other customers as approved by DOE personnel.

The Uranium Treatment Unit (UTUC), associated equipment, and diked areas are located east of Building 9206 within the boundaries of the $Y-12$ Plant. The UTUC consists of two 300 -gallon polytanks and associated structural support stands, tow electrically driven agitators, and approximately 400 square feet of $10 \mathrm{mil}$ polyvinyl chloride (PVC) liners. Also included in this closure plan are twelve 55-galion drums filled with Raschig rings which were used to collect the RCRA solutions prior to treatment at the UTUC. The design treatment capacity of the UTUC is 500 gallons per day, and the design storage capacity of the drum storage area is 900 gallons.

\subsection{HEALTH AND SAFEIY HAZARD EVATUATION}

[Place an $X$ in each $($ ) to indicate presence of hazard]

3.1 Physical Hazards

( $\mathrm{X}$ ) Heat Stress

( ) Confined Space

( $x$ ) Cold stress

() Enclosed space 
Page 3 of 16

Revision No.: 1

Revision Date: $3 / 12 / 96$

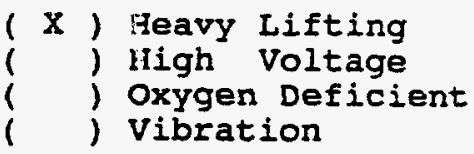

3.2 Construction Hazards

( ) Trenching

( ) Demolition

( X ) Ladders

3.3 Chemical Hazardg

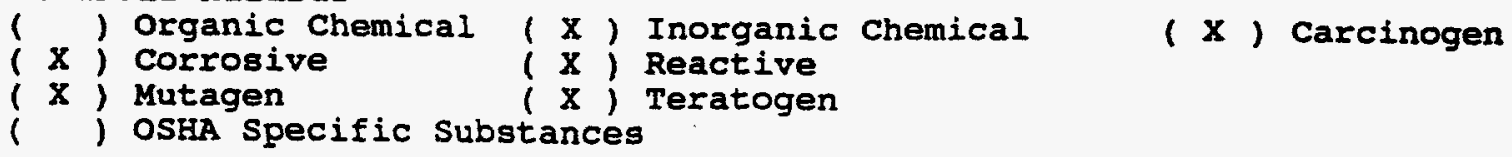

x ) Tripping/Falling

( $X$ ) High Pressure Water

( $x$ ) Explosive/Elammable

$(x)$ Noise

avating

) High Work

x ) Heavy Equipment

) Welding/Cutting

3.4 Ionizing Radiological Hazards

( $\mathrm{X}$ ) Internal Exposure $(\mathrm{x})$ External Exposure

3.5 Non-Ionizing Radiological hazards

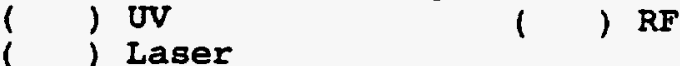

) Laser

3.6 Biological/Vector Hazards

( ) Wildife

Bacterial

) Plants

Parasites

( ) Microwave

( ) Medical Waste 
Page 4 of 16

Revision No.: 1

Revision Date: $3 / 12 / 96$

\subsection{PRAVIOUS SAMPLIMG RESULTS}

Contaminant Source (Water, Sediment, Sludge Soil, Air, etc...)

Quantity or Concentration

Propylene glycol

Distillate

Dibutyl Carbitol

Tributyl Phosphate

Oil

Freon

35 gallons ( 3 drums)
35 gallons ( 2 drum)
35 gallons ( 1 drum)
35 gallons ( 3 drums)
35 gallons ( 2 drums)

\section{5 .0 CONTAMTNANTS}

5.1 Chemical: Nitric Acid
PEL/TLV : 2 ppm
STEL: none
IDLH: $100 \mathrm{ppm}$

Action Level: Ippm

Route of Exposure: Inhalation, Ingestion

Monitoring Equipment: Silica Gel

Symptoms/Effects of Exposure: Irritation to mucous membranes and eyes; skin irritation; delayed pulmonary bronchitis.

Special Medical Monitoring: none

5.2 Chemical: Uranium Metal
PEL/TLV : $0.2 \mathrm{mg} / \mathrm{m3}$
STEL: $0.6 \mathrm{mg} / \mathrm{m} 3$
IDLH: $\quad 30 \mathrm{mg} / \mathrm{m} 3$

Action Level: $0.1 \mathrm{mg} / \mathrm{m} 3$

Route of Exposure: Inhalation, Ingestion

Monitoring Equipment: Direct reading; $37 \mathrm{~mm}$ cellulose esther

Symptoms/Effects of Exposure: Radiation hazard exists from inhalation

of fine particles of approximately one micron. Acute swallowing of

uranium produces low toxicity because of poor absorption. Uranium

compounds may cause damage to liver and kidneys, with possible

albuminuria and hematuria.

Special Medical Monitoring: RADCON monitoring program

(Provide detailed description, controls, and requirements, for each task to be performed, i.e., drilling, sampling, etc.)

6.1 Description: Decontamination of 300-Gallon Polytank

Level of Personal

Protective Equipment:

Primary Level D Modified

Engineering Controls:

None

Administrative controls:

1) 50 Series Procedures

(required permits, training)

2) 70 Series plant Procedures.

3) 40 Hour OSHA training with 8-Hour refresher

4) Radiological worker training

5) Respirator training 
Page 5 of 16

Revision No.: 1

Revision Date: $3 / 12 / 96$

6) Medically qualified

Personal Protective Equipment:

(Specify Type)
a)
Respiratory Protection:
P: See Applicable Radiological Work Permit (RWP)
b) Protective clothing:
P: Company issue clothing /Radiological required clothing
c) Head Protection:
P: See radiological requirements
d) Eye Protection:
P: Company issue safety goggles
e) Foot protection:
P: Company issue safety shoes
f) Hand Protection:
P: Leather palm gloves and/or rubber gloves
g) Hearing Protection:
P: Industrial Hygiene Department will make determination
h) Tape-up Required:
P: See radiological requirements

6.2 Description: Decontamination of Stainless Steel Agitator

Level of Personal

Protective Equipment:

Primary Level D Modified

Engineering Controls:

None

Administrative Controls (required permits, training)
1) 50 Series Procedures
2) 70 Series Plant Procedures.
3) 40 Hour OSHA training with 8- Hour refregher
4) Radiological worker training
5) Respirator training
6) Medically qualified

Personal Protective Equipment: (Specify Type)
a)
Respiratory Protection:
P: See applicable Radiological Work Permit (RWP)
b) Protective clothing:
P: Company issue clothing/Radiological required clothing
c) Head Protection:
P: See radiological requirements
d) Eye Protection:
P: Company issue safety goggles
e) Foot Protection:
P: Company issue safety shoes 
Page 6 of 16

Revision No.: 1

Revision Date: 3/12/96

f) Hand Protection:

g) Hearing Protection:

h) Tape-up Required:
P: Leather palm gloves and/or rubber gloves

P: Industrial Hygiene Department will determine

P: See radiological requirements

6.3 Description: Transfer of Raschig Rings from Drum to Poly Liner

Level of Personal

Protective Equipment:

Primary

Level D Modified

Engineering Controls:

None

Administrative Controls (required permits, training)

1) 50 Series procedures

2) 70 Serieg plant Procedures.

3) 40 Hour OSHA training with 8Hour refresher

4) Radiological worker training

5) Respirator training

6) Medically qualified

Personal Protective Equipment: (Specify Type)
a) Respiratory Protection:
P: See applicable Radiological Work Permit (RWP)
b) Protective clothing:
P: Company issue clothing/radiological required clothing
c) Head Protection:
P: See radiological requirements
d) Eye Protection:
P: Company issue safety goggles
e) Foot Protection:
p: Company issue safety shoes
f) Hand Protection:
P: Rubber latex gloves
g) Hearing Protection:
P: None
h) Tape-up Required:
P: See radiological requirements

6.4 Description: Transfer of Raschig Rings from Poly Liner to Baskets

Level of Personal

Protective Equipment:

Primary

Level Modified D

Engineering Controls:

None

Administrative Controls (required permits, training)

1) 50 Series Procedures

2) 70 Series Plant Procedures. 
Page 7 of 16

Revision No.: 1

Revision Date: $3 / 12 / 96$
3) 40 Hour OsHA training with 8- Hour refresher
4) Radiological worker training
5) Respirator training
6) Medically qualified

Personal Protective Equipment: (Specify Type)
a)
Reapiratory Protection:
P: See applicable Radiological Work Permit (RWP)
b) Protective clothing:
P: Company issue clothing/radiological clothing requirements
c) Head Protection:
P: See radiological requirements
d) Eye Protection:
P: Company issue safety glasses
e) Foot Protection:
P: Company isgue safety shoes
f) Hand Protection:
P: Leather palm gloves and rubber gloves
g) Hearing Protection:
P: None
h) Tape-up Required:
P: See radiological requirements

6.5 Description: Decontamination of Raschig Rings in Baskets

Level of Personal

Protective Equipment

Primary

Level Modified D

Engineering Controls:

None

Administrative Controls (required permits, training)
1) 50 Series Procedures
2) 70 Series Plant Procedures.
3) 40 Hour OsHA training with 8- Hour refresher
4) Radiological worker training
5) Respirator training
6) Medically qualified

Personal Protective Equipment: (Specify Type)
a)
Respiratory Protection:
P: See Radiological Work Permit
b) Protective clothing:
P: Company issue clothing/radiological work requirements/acid protective sleeves/chemical resistant apron
c) Head Protection:
P: See radiological requirements 
Page 8 of 16

Revision No.: 1

Revision Date: $3 / 12 / 96$

d) Eye Protection:

e) Foot Protection:

f) Hand Protection:

g) Hearing Protection:

h) Tape-up Required:
P: Company issue safety gogglea/face shield

p: Company issue safety shoes

P: Leather palm gloves and rubber gloves (Trionic)

P: Industrial Hygiene Department will determine

P: See radiological requirements

The Industrial hygiene Department has been requested to perform area Nitric Acid measurements to determine airborne concentrations. The MDA-TLD 1 will be utilized in order to determine immediate concentrations in the air.

6.6 Description: Decontamination of 55-Galion stainless steel Drum

Level of Personal

Protective Equipment:

Primary

Level D Modified

Engineering Controls:

Administrative Controls (required permits, training)
None
1) 50 Series Procedures
2) 70 Series plant Procedures.
3) 40 Hour OSHA training with 8- Hour refregher
4) Radiological worker training
5) Respirator training
6) Medically qualified

Personal Protective Equipment: (Specify Type)
a) Respiratory protection:
P: See applicable Radiological Work Permit (RWP)
b) Protective clothing:
P: Company issue clothing/radiological clothing requirements
c) Head Protection:
P: See radiological requirements
d) Eye Protection:
P: Company issue safety goggles
e) Foot Protection:
P: Company issue safety shoes
f) Hand Protection:
P: Leather palm gloves and rubber gloves
g) Hearing Protection:
P: Industrial Hygiene Department will determine
h) Tape-up Required:
P: See radiological requirements 
Page 9 of 16

Reviaion No.: 1

Revision Date: $3 / 12 / 96$

6.7 Description: Decontamination of Structural Support for 300-Gallon Polytank

Level of Personal

Protective Equipment: Primary Level D Modified

Engineering Controls: None

Administrative Controls

(required permits, training) 1) 50 series Procedures

2) 70 Series Plant Procedures.

3) 40 Hour OSHA training with 8Bour refresher

4) Radiological worker training

5) Respirator training

6) Medically qualified

Personal Protective Equipment: (Specify Type)
a) Respiratory Protection:
P: See applicable Radiological Work Permit (RWP)
b) Protective Clothing:
P: Company issue clothing/radiological clothing requirements
c) Head Protection:
P: See radiological requirements
d) Eye Protection:
P: Company issue safety goggles
e) Foot Protection:
P: Company issue safety shoes
f) Hand Protection:
P: Leather palm gloves and rubber gloves
g) Hearing Protection:
P: Industrial Hygiene Department will determine
h) Tape-up Required:
P: See radiological requirementa

\subsection{Description: Decontamination of Plastic Liner Layer}

Level of Personal

Protective Equipment:

Primary

Level D Modified

Engineering Controls:

None

Administrative Controls (required permits, training)
1) 50 Series Procedure日
2) 70 Series Plant Procedures.
3) 40 Hour OSHA training with 8- Hour refresher
4) Radiological worker training
5) Respirator training
6) Medically qualified 
Page 10 of 16

Revision No.: 1

Revision Date: $3 / 12 / 96$

Personal Protective Equipment:

(Specify Type)
a) Respiratory Protection:
P: See applicable Radiological Work Permit (RWP)
b) Protective clothing:
P: Company issue clothing/radiological work clothing
c) Head Protection:
P: See radiological requirements
d) Eye Protection:
P: Company issue safety goggles
e) Foot Protection:
P: Company issue safety shoes
f) Hand Protection:
P: Leather palm gloveg and rubber gloves
g) Hearing Protection:
P: Industrial Hygiene Department will determine
h) Tape-up Required:
P: See radiological requirements

7.0 MONITORING REQUIREMENTS

Instrument

7.1 Direct Reading Instruments

LEL Meter

$\mathrm{O}_{2}$ Neter

Colorimetric Indicator Tube Photoionization Detector

Flame Ionization Detector

Alpha Meter

Beta/Gamma Meter

Area Radiation Monitors

Perimeter Radiation Monitor

Noise Meter

Wibget

MDA-TLD 1

7.2 Personnel Monitoring

Whole-body Dosimetry

Extremity Dosimetry

Whole-body count

Urinalysis/Bioassay

Chemical Air Sampling

Radiological Air Sampling

\section{Tagk(g)}

Monitoring

Erequency

Constant

Constant

AlI

None

None

None

None

None

All

None

$6.1,6.2,6.5,6.6,6.7,6.8$

Al1

6.5

Initial
Action

Guidelines 
Page 11 of 16

Revision No.: 1

Revision Date: $3 / 12 / 96$

\subsection{GAZARD MNATYSIS \\ 8.1 Chemicals and Residues}

Specific labeling requirements of site-generated waste: Labelled as RCRA wastes with completed 2114A tags.

Chemical-specific disposal requirements: Initiation of Form 2109, "Request for Transfer, Storage, or Disposal of Wastes," any time wastes enter area.

RCRA wastes do not accumulate more than 75 days.

\subsection{Fire/Explosion}

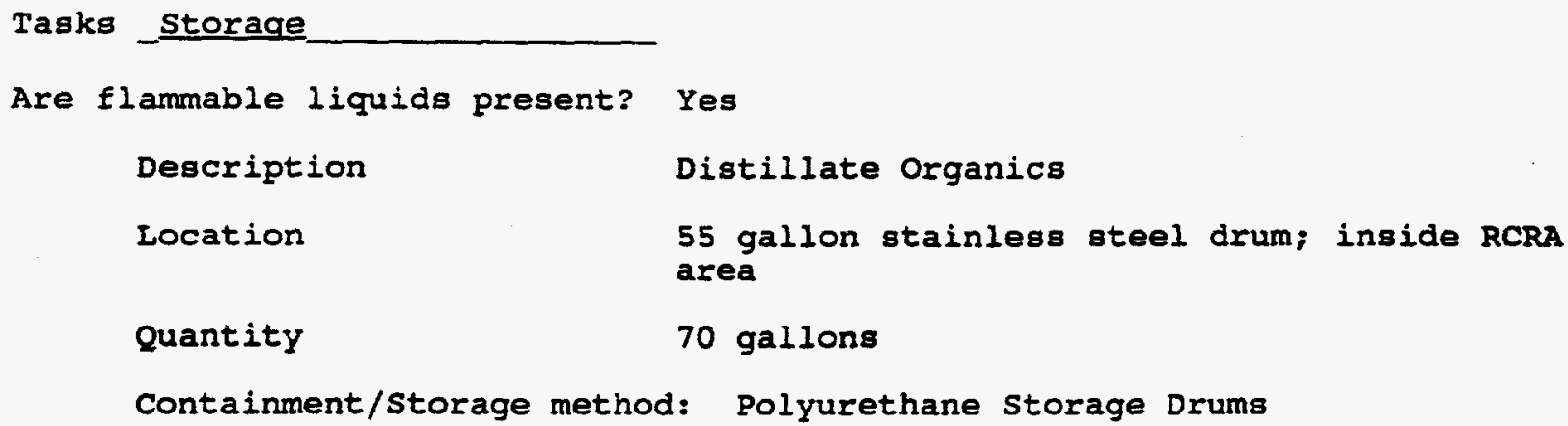

For welding, cutting, or brazing is a welding Permit required? No 8.3 Confined/Enclosed Spaces

Confined/enclosed space entry required (Low/High Risk)? No

Operations Safety Work Permit required? No

standard Operating Procedure required? Yes

\subsection{Ionizing Radiation}

Tasks All

Applicable detailed checklist? Radiological Work Permit (RWP)

Primary contaminating isotope(s) Uranium

Location on site UTUC

Containment/storage method stainlegs steel storage containers

Radiation type Alpha/Beta/Gamma 
Page 12 of 16

Revision No.: 1

Revision Date: 3/12/96

Dose rate (maximum)

(average)

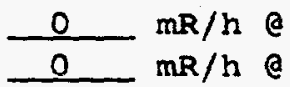

a

5000

Worker dose limit

(whole body)

contamination level

\begin{tabular}{ll} 
& \multicolumn{2}{c}{ Alpha } \\
(fixed) & $\leq 20000 \mathrm{dpm} / 100 \mathrm{~cm}^{2}$ \\
(removable) & $\underline{250} \mathrm{dpm} / 100 \mathrm{~cm}^{2}$
\end{tabular}

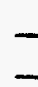

meter (s)

ft \& direct

$\mathrm{mR} / \mathrm{yr}$

Airborne contamination concentration 0.0

$\mathrm{d} / \mathrm{m} / \mathrm{m}^{3}$
Beta/Gamma $\leq 30000 \mathrm{dpm} / 100^{2}$ $\leq 600 \mathrm{dpm} / 100^{2}$

Water contamination potential? No

Unrestricted airborne contamination release potential? No

Radiation work permit required? Yes

RADCON coverage? Conditional

Special task operation requirements?

YES/CON Welding/cutting/brazing YES/CON Grinding/chipping

YES/CON Hydraulic/air hammer operation YES/CON Dusty conditions (sweeping, vacuuming, etc.)

YES/CON Equipment decontamination/free release 
Page 13 of 16

Revision No.: 1

Revision Date: 3/12/96

8.5 Electrical Hazards

Tasks $6.1,6.2,6.5,6.6,6.7,6.8$

Electrical shock hazard? Yes

110 voltage

AC Current

Location of hazard: Hotsy High Pressure Compressor and associated portable lighting placed inside of the RCRA Area.

8.6 Temperature Extremes

Tasks AlI

Temperature extremes (Hot/Cold)? Yes Average daily high temperature (during work shift) ${ }^{\circ} \mathrm{F} /{ }^{\circ} \mathrm{C}$

Average daily low temperature (during work shift) ${ }^{\circ} \mathrm{F} /{ }^{\circ} \mathrm{C}$
Average wind speed MPH Temperature WBGT ${ }^{\circ} \mathrm{C}$

Work load: Light Moderate

Work/Rest regimen:

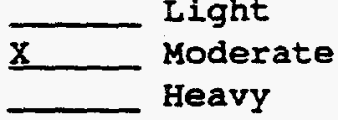

o work

8 rest

Threshold Limit Value:

Precautions (specify): Temperature extreme conditions will be determined by the Industrial Hygiene Department

Cooling/heating equipment needed: Temperature Dependant

\subsection{Noise}

Tasks $6.1,6.2,6.5,6.6,6.7,6.8$

Noise extremes?

Yes

Sound level

$>85 \mathrm{~dB}(\mathrm{~A})$

Noise source(s): Hotsy High Pressure Carbon Dioxide Compressor

Noise above $85 \mathrm{~dB}(\mathrm{~A})$ (hearing protection required) Yes

Precautions (specify): Hearing Protection Devices required when utilizing the Hotsy High Pressure Carbon Dioxide for decontamination. 
Page 14 of 16

Revision No.: 1

Revision Date: 3/12/96

8.9 Safety Hazards

Site posted information/notification required? Yes

Site posting required? Yes

Site guard required? No

Access control required? Yes

Entry/exit logs required? Yes

Escape routing/posting required (include site map)? No

Compressed gas cylinders? No Location:

Storage:

* OSHA, NIOSH, or ACGIH Standard, whichever is most restrictive 
Page 15 of 16

Revision No.: 1

Revision Date: $3 / 12 / 96$

\subsection{EMERGENCY PREPAREDNESS}

Evacuation route: The evacuation route for the UTUC are to the assembly points are number 4 , next to the cafe.

EMERGENCY CONTACTS: All emergenCy services at the UTUC _ site are to be contacted by first calling the Plant shift superintendent (PSS) at -

4-7172 - In the event that the pSs is not available, emergency services may be reached at the telephone numbers ghown below.

\begin{tabular}{lc} 
Facility Pergonnel & Phone \\
\hline PSS & $4-7172$ \\
Program Health/Safety Coordinator & $1-2486$ \\
Industrial Hygiene/Cathy Groover & $6-3976$ \\
Bill Sliski & $1-2486$ \\
Walter Porter & $6-6698$ \\
Pete Calkin & $6-7183$ \\
Industrial Safety/John Greene & $4-1560$ \\
RADcoN/Dave Gass & $4-8070$ \\
Bill Gordon & $6-5055$ \\
& \\
Emergency Assistance Service & phone \\
Police & 911 \\
Ambulance & 911 \\
Fire & 911 \\
Hospital & $4-1580$ \\
Doctor & $4-1580$ \\
Health Information Services & $4-1580$
\end{tabular}


Page 16 of 16

Revision No.: 1

Revision Date: 3/12/96

\subsection{RECORD KEEPING REQUIREMENTS}

(Mark with an $X$ as appropriate)

Hazardous Chemicals

Area monitoring

Personnel monitoring

Oxygen Level Measurements

Flammability Measurements

Ionizing Radiation

Worker dose

Contamination levels

Airborne contamination level

Radiological work permit (RWP)

Non-Ionizing Radiation

uv level measurements

Microwave level measurements

Laser power level measurements

Biological

Personnel exposure monitoring

Electrical

Tag-out records

Temperature extremes

WBGT measurements

Daily temperature/wind speed

Noise

Area monitoring

Personnel monitoring

Personnel Medical Monitoring

Safety/Emergency Response

OSHA accident records

Accident/incident reports

Personal Protective Equipment

Inspection of: clothing

Respirators

Gloves

Boots

Waste Disposal Manifests

Spill Incident Reports

Training of Employees

Required

$\underline{x}$

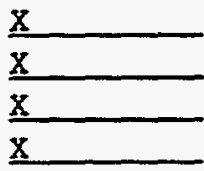

$\underline{x}$

X.

$\underline{X}$

$\underline{x}$

$\underline{x}$

$\underline{X}$

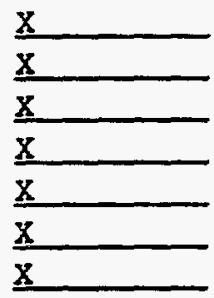




\section{APPENDIX F}

\section{Uranium Treatment Unit}

1. Customer Sample Number and Laboratory Report (ELIMS) Number

2. Source Water ELIMS Number

3. Trip Blank ELIMS Number

4. Customer Sample Number Description

5. Chromium Analysis Explanation 



\section{RCRA CLOSURE}

\begin{tabular}{|c|c|c|c|c|c|c|}
\hline ELIMS NO. & CUSTOMER SAMPLE NO. & COC\# & SAMPLE DATE & TIME & TECH. BADGE NO. & COMMENTS \\
\hline E960650017 & 001 & 18753 & $3 / 12 / 96$ & $09: 15$ & 13303 & \\
\hline E960650018 & 002 & 18753 & $3 / 12 / 96$ & $09: 30$ & 13303 & \\
\hline E960650020 & 003 & 18753 & $3 / 12 / 96$ & $09: 45$ & 13303 & \\
\hline E960650022 & 004 & 18753 & $3 / 12 / 96$ & $10: 00$ & 13303 & \\
\hline E960650023 & 005 & 18754 & $3 / 19 / 96$ & $14: 15$ & $13303 / 25966$ & \\
\hline E960650024 & 006 & 18755 & $3 / 22 / 96$ & $14: 10$ & $13303 / 32216$ & \\
\hline E960650025 & 007 & 18756 & $3 / 25 / 96$ & $14: 20$ & $13303 / 32216$ & DIRTY WATER \\
\hline E960650026 & 008 & 18757 & $3 / 26 / 96$ & $16: 31$ & $32216 / 24480$ & DIRTY WATER \\
\hline E960650027 & 009 & 18757 & $3 / 28 / 96$ & $13: 51$ & 11368 & \\
\hline E960650028 & 009 & 18758 & $3 / 28 / 96$ & $13: 59$ & 11368 & DUPLICATE \\
\hline E960650029 & 010 & 18759 & $3 / 29 / 96$ & $14: 28$ & $13303 / 32216$ & \\
\hline E960650030 & 011 & 18760 & $4 / 9 / 96$ & $15: 00$ & $13303 / 11368$ & MILDLY SOAPY \\
\hline E960650031 & 012 & 18761 & $4 / 11 / 96$ & $14: 40$ & $13303 / 28962$ & \\
\hline E960650032 & 013 & 18762 & $4 / 12 / 96$ & $14: 30$ & $13303 / 11368$ & \\
\hline$E 960650033$ & 014 & 18763 & $4 / 17 / 96$ & $08: 30$ & $13303 / 11368$ & \\
\hline$E 960650034$ & 015 & 18763 & $4 / 17 / 96$ & $08: 40$ & $13303 / 11368$ & \\
\hline$E 960650035$ & 016 & 18763 & $4 / 17 / 96$ & $08: 45$ & $13303 / 11368$ & \\
\hline$E 960650036$ & 017 & 18764 & $4 / 17 / 96$ & $15: 00$ & $32216 / 30096$ & \\
\hline$E 960650037$ & 017 & 18764 & $4 / 17 / 96$ & $15: 00$ & $32216 / 30096$ & DUPLICATE \\
\hline$E 960650038$ & 018 & 18765 & $4 / 18 / 96$ & $14: 40$ & $30096 / 26888$ & \\
\hline$E 960650039$ & 019 & 18765 & $4 / 18 / 96$ & $14: 45$ & $30096 / 26888$ & \\
\hline$E 960650040$ & 020 & 18765 & $4 / 18 / 96$ & $14: 50$ & $30096 / 26888$ & \\
\hline$E 960650041$ & 021 & 18766 & $4 / 19 / 96$ & $08: 55$ & $32216 / 28962$ & \\
\hline & & & & & & \\
\hline
\end{tabular}

ENTRIES MUST BE IN WATERPROOF BLACK INK.

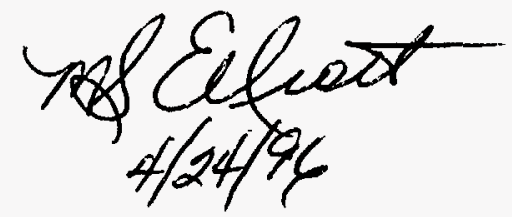




\section{RCRA CLOSURE}

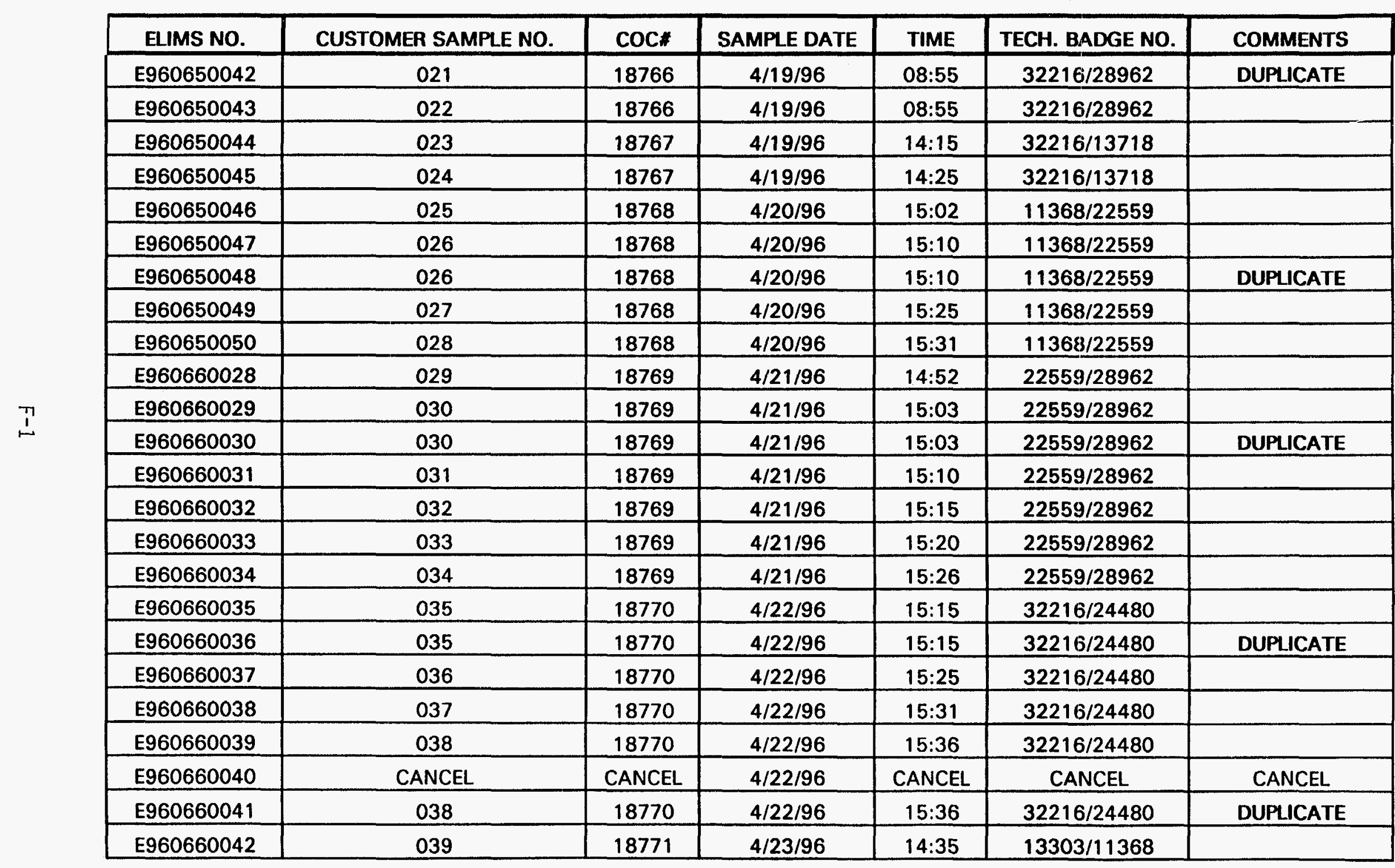

ENTRIES MUST BE IN WATERPROOF BLACK INK. 


\section{RCRA CLOSURE}

\begin{tabular}{|c|c|c|c|c|c|c|}
\hline ELIMS NO. & CUSTOMER SAMPLE NO. & COC\# & SAMPLE DATE & TIME & TECH. BADGE NO. & COMMENTS \\
\hline$E 960660043$ & 040 & 18772 & $4 / 24 / 96$ & $14: 00$ & $13303 / 32216$ & \\
\hline E960660045 & & & & & & DUPLICATE \\
\hline E960660046 & & & & & & \\
\hline \multicolumn{7}{|l|}{$E 960660047$} \\
\hline \multicolumn{7}{|l|}{ E960660048 } \\
\hline \multicolumn{7}{|l|}{$E 960660144$} \\
\hline E960660145 & & & & & & DUPLICATE \\
\hline \multicolumn{7}{|l|}{ E960660146 } \\
\hline \multicolumn{7}{|l|}{ E960660147 } \\
\hline \multicolumn{7}{|l|}{ E960660148 } \\
\hline \multicolumn{7}{|l|}{ E960660149 } \\
\hline E960660150 & & & & & & DUPLICATE \\
\hline & & & & & & \\
\hline & & & & & & \\
\hline & & & & & & \\
\hline & & & & & & \\
\hline & & & & & & \\
\hline & & & & & & \\
\hline & & & & & & \\
\hline & & & & & & \\
\hline & & & & & & \\
\hline & & & & & & \\
\hline & & & & & & \\
\hline & & & & & & \\
\hline
\end{tabular}

ENTRIES MUST BE IN WATERPROOF BLACK INK. 


\section{RCRA CLOSURE}

TRIP BLANK

\begin{tabular}{|c|c|c|c|c|c|c|}
\hline ELIMS NO. & CUSTOMER SAMPLE NO. & COCF & SAMPLE DATE & TIME & TECH. BADGE NO. & COMMENTS \\
\hline$E 960650021$ & TRIP BLANK & 18753 & $3 / 12 / 96$ & 08:30 & 13303 & ASTM\#1 \\
\hline$E 960670001$ & TRIP BLANK & 18754 & $3 / 19 / 96$ & $13: 45$ & 11368 & ASTM\#1 \\
\hline$E 960670002$ & TRIP BLANK & 18755 & $3 / 22 / 96$ & $13: 30$ & 13303 & ASTM\#1 \\
\hline E960670003 & TRIP BLANK & 18756 & $3 / 25 / 96$ & $13: 05$ & 13303 & ASTM\#1 \\
\hline E960670004 & TRIP BLANK & 18757 & $3 / 26 / 96$ & $16: 05$ & 32216 & ASTM\#1 \\
\hline E960670006 & TRIP BLANK & 18758 & $3 / 28 / 96$ & $12: 36$ & 11368 & ASTM\#1 \\
\hline E960670007 & TRIP BLANK & 18759 & $3 / 29 / 96$ & $13: 50$ & 13303 & ASTM\#1 \\
\hline E960670008 & TRIP BLANK & 18760 & $4 / 9 / 96$ & $14: 10$ & 13303 & ASTM\#1 \\
\hline E960670009 & TRIP BLANK & 18761 & $4 / 11 / 96$ & $14: 00$ & 13303 & ASTM\#1 \\
\hline E960670010 & TRIP BLANK & 18762 & $4 / 12 / 96$ & $14: 00$ & 13303 & ASTM\#1 \\
\hline E960670011 & TRIP BLANK & 18763 & $4 / 17 / 96$ & $07: 45$ & 11368 & ASTM\#1 \\
\hline E960670012 & TRIP BLANK & 18764 & 4/17/96 & $15: 00$ & 32216 & ASTM\#1 \\
\hline E960670013 & TRIP BLANK & 18765 & 4/18/96 & $06: 30$ & 30096 & ASTM\#1 \\
\hline E960670014 & TRIP BLANK & 18766 & $4 / 19 / 96$ & $08: 15$ & 32216 & ASTM\#1 \\
\hline E960670015 & TRIP BLANK & 18767 & $4 / 19 / 96$ & $13: 10$ & 32216 & ASTM\#1 \\
\hline E960670016 & TRIP BLANK & 18768 & $4 / 20 / 96$ & $13: 40$ & 11368 & ASTM\#1 \\
\hline E960670017 & TRIP BLANK & 18769 & $4 / 21 / 96$ & $14: 00$ & 11368 & ASTM\#1 \\
\hline E960670018 & TRIP BLANK & 18770 & $4 / 22 / 96$ & $13: 55$ & 11368 & ASTM\#1 \\
\hline E960670019 & TRIP BLANK & 18771 & $4 / 23 / 96$ & $14: 00$ & 13303 & ASTM\#1 \\
\hline E960670020 & TRIP BLANK & 18772 & $4 / 24 / 96$ & $13: 00$ & 13303 & ASTM\#1 \\
\hline E960670021 & TRIP BLANK & 18773 & $5 / 2 / 96$ & $13: 30$ & 13303 & ASTM\#1 \\
\hline E960670022 & TRIP BLANK & & & & & \\
\hline E960670023 & TRIP BLANK & & & & & \\
\hline E960670024 & TRIP BLANK & & & & & \\
\hline
\end{tabular}

ENTRIES MUST BE IN WATERPROOF BLACK INK. 


\section{RCRA CLOSURE}

SOURCE BLANK

\begin{tabular}{|c|c|c|c|c|c|c|}
\hline ELIMS NO. & CUSTOMER SAMPLE NO. & $\operatorname{coc} \#$ & SAMPLE DATE & TIME & TECH. BADGE NO. & COMMENTS \\
\hline E960660151 & SOURCE/SPIGOT/HOSE & 18754 & $3 / 19 / 96$ & $14: 10$ & $13303 / 25966$ & \\
\hline E960660152 & SOURCE/SPIGOT/HOSE & 18755 & $3 / 22 / 96$ & $14: 00$ & $13303 / 32216$ & \\
\hline E960660153 & SOURCE/SPIGOT/HOSE & 18756 & $3 / 25 / 96$ & $14: 25$ & $13303 / 32216$ & \\
\hline E960660154 & SOURCE/SPIGOT/HOSE & 18757 & $3 / 26 / 96$ & $16: 23$ & $32216 / 24480$ & \\
\hline$E 60660155$ & SOURCE/SPIGOT/HOSE & 18758 & 3/28/96 & 13:36 & 11368 & \\
\hline E960660156 & SOURCE/SPIGOT/HOSE & 18759 & $3 / 29 / 96$ & $14: 30$ & $13303 / 32216$ & \\
\hline E960660157 & SOURCE/SPIGOT/HOSE & 18760 & 4/9/96 & $14: 50$ & $13303 / 11368$ & \\
\hline E960660158 & SOURCE/SPIGOT/HOSE & 18761 & $4 / 11 / 96$ & $14: 30$ & $13303 / 11368$ & \\
\hline E960660159 & SOURCE/SPIGOT/HOSE & 18762 & $4 / 12 / 96$ & $14: 20$ & $13303 / 11368$ & \\
\hline E960660160 & SOURCE/SPIGOT/HOSE & 18763 & $4 / 13 / 96$ & $08: 20$ & $13303 / 11368$ & NEW HOSE \\
\hline E960660161 & SOURCE/SPIGOT/HOSE & 18764 & $4 / 17 / 96$ & $15: 00$ & $32216 / 30096$ & \\
\hline$E 960660162$ & SOURCE/SPIGOT/HOSE & 18765 & $4 / 18 / 96$ & $14: 30$ & $30096 / 25966$ & \\
\hline E960660163 & SOURCE/SPIGOT/HOSE & 18766 & $4 / 19 / 96$ & $08: 55$ & $32216 / 28962$ & \\
\hline E960660164 & SOURCE/SPIGOT/HOSE & 18767 & 4/19/96 & $14: 10$ & $32216 / 13718$ & \\
\hline E960660165 & SOURCE/SPIGOT/HOSE & 18768 & $4 / 20 / 96$ & $14: 55$ & $11368 / 22559$ & \\
\hline E960660166 & SOURCE/SPIGOT/MOSE & 18769 & $4 / 21 / 96$ & $14: 46$ & $22559 / 28962$ & \\
\hline$E 960660167$ & SOURCE/SPIGOT/HOSE & 18770 & $4 / 22 / 96$ & $15: 05$ & $32216 / 24480$ & \\
\hline E960660168 & SOURCE/SPIGOT/HOSE & 18771 & 4/23/96 & $14: 30$ & $13303 / 11368$ & \\
\hline E960680035 & SOURCE/SPIGOT/HOSE & 18772 & $4 / 24 / 96$ & $13: 55$ & $13303 / 32216$ & \\
\hline$E 960680036$ & SOURCE/SPIGOT/HOSE & & & & & \\
\hline$E 960680037$ & SOURCE/SPIGOT/HOSE & & & & & \\
\hline$E 960680038$ & SOURCE/SPIGOT/HOSE & & & & & \\
\hline E960680039 & SOURCE/SPIGOT/HOSE & & & & & \\
\hline E960680040 & SOURCE/SPIGOT/HOSE & & & & & \\
\hline$E 960680041$ & SOURCE/SPIGOT/HOSE & & & & & \\
\hline
\end{tabular}

ENTRIES MUST BE IN WATERPROOF BLACK INK. 


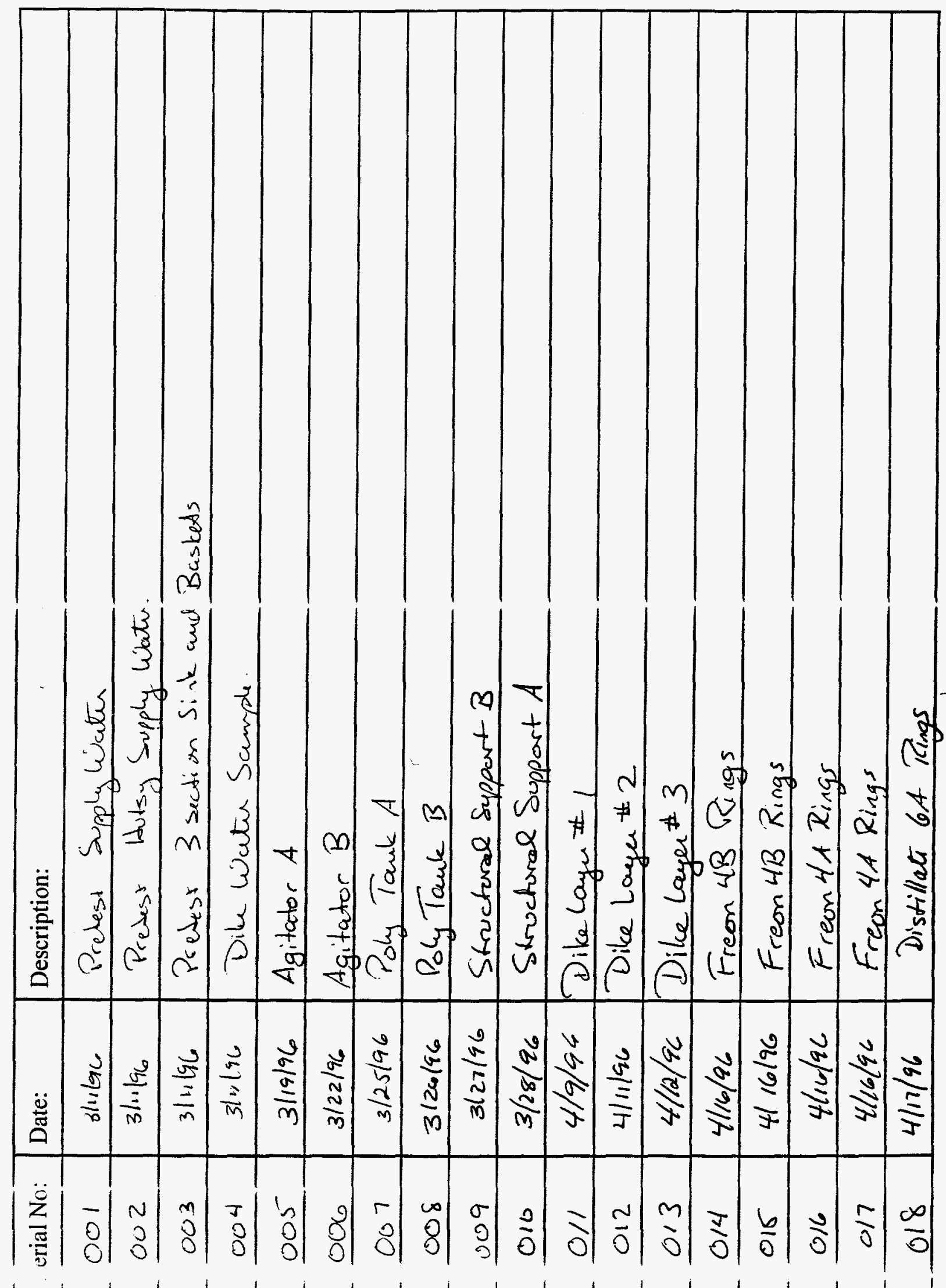




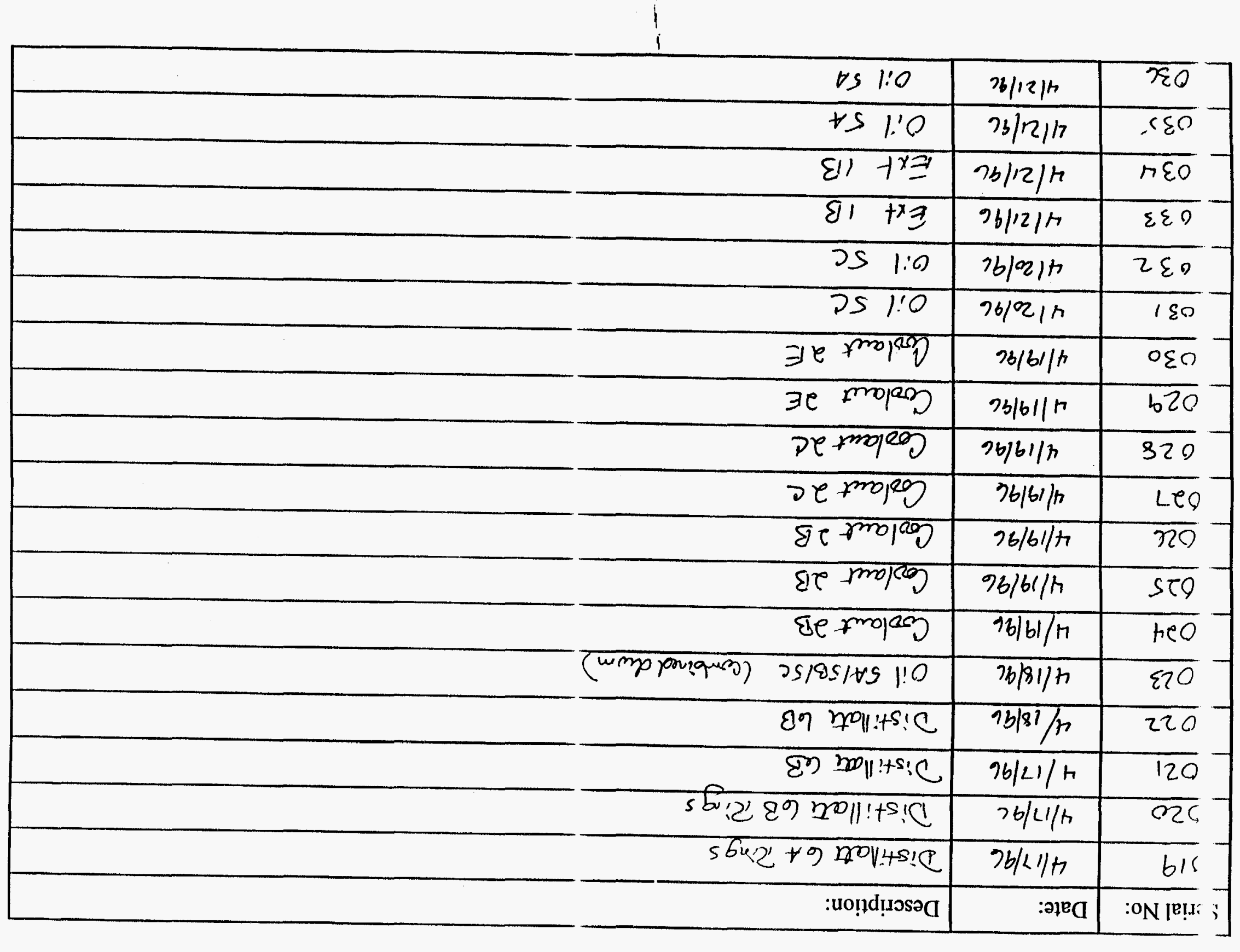




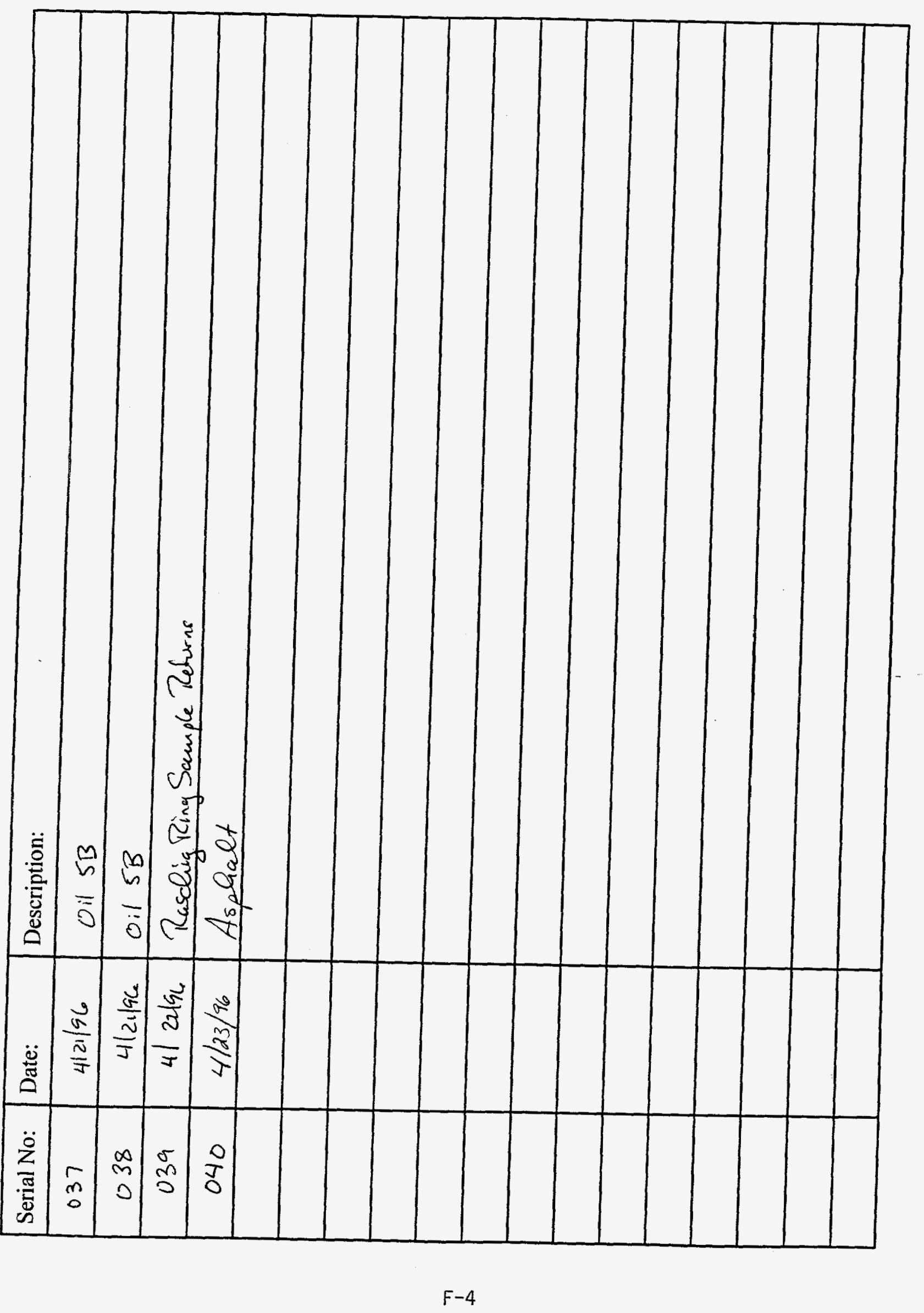




\section{N T E R O}

$\begin{array}{ll}\text { Date: } & \text { 22-May-1996 12:37pm EDT } \\ \text { From: } & \text { Debbie Garrett Ailey } \\ & \text { AILEYDG1eA1eOCU1 } \\ \text { Dept: } & 7222 \\ \text { Tel No: } & 1-2385\end{array}$

TO: COLLINSET

CC: BUDDINNPIII KEEBLERDT MCCOYR WILKESRM

subject: Re: UTU-Analysis>>THANKS

File: READ

025114

Tom,

The reason that you received three answers below the $0.2 \mathrm{mg} / \mathrm{L}$ reporting limit for chromium has to do with the way our software programs handle significant figures and rounding when the final report is generated. The reporting limit for chromium within the software (after the sample dilution factor is applied is $0.111 \mathrm{mg} / \mathrm{L}$. A determination of whether a result is below the reporting limit is done before any rounding and significant digits rules are inacted. After the QC data in the analysis has been evaluated the sample results are rounded for reporting. In the case of chromium all results and the reporting limit are rounded to the first decimal, which is the precision limit for chromium. The reporting limit is rounded up to $0.2 \mathrm{mg} / \mathrm{L}$ since 0.111 is greate than $0.1 \mathrm{mg} / \mathrm{L}$. The three samples in question, E960650045, E960660038, E960660043 had chromium results of $0.14,0.12$ and $0.11 \mathrm{mg} / \mathrm{L}$ chromium, respectively, and were noted as having reportable amounts of chromium before the rounding of the results took place.

We are reviewing whether rounding can be done prior to determining whether a result is below the reporting limit. This approach also has limitations. If you wish we will be glad to edit the ICP results for these three samples to reflect that they are $<0.2 \mathrm{mg} / \mathrm{L}$ like the majority of your samples. Please let us know. Sorry for the inconvenience and delay.

Debbie 



\section{APPENDIX G \\ Uranium Treatment Unit--Decontamination Records}

G-1 "Empty" Drum Sign-off Sheet

G-2 Item Decontamination Sign-off Sheet

G-3 Raschig Ring Decontamination Tracking Logsheet

Note: The "207X" number is the basket number.

G-4 Waste Disposal

G-5 Detergent--Material Safety Data Sheet

G-6 Waste Inventory 



\section{Drum Verification Sign-Off Sheet



\section{Acceptance Criteria:}

(from Y/TS-1253, RCRA Closure Plan for the Uranium Treatment Unit)

The drums will be drained of RCRA hazardous wastes. The drums will be considered empty under 40 CFR Part 261.7 if

- All wastes have been removed that can be removed using the practices commonly employed to remove materials from similar containers, AND

- No more than one inch of residue remains on the bottom of the container or inner liner, $O R$

- No more than 3 percent by weight of the total capacity of the container remains in the container or the inner liner.

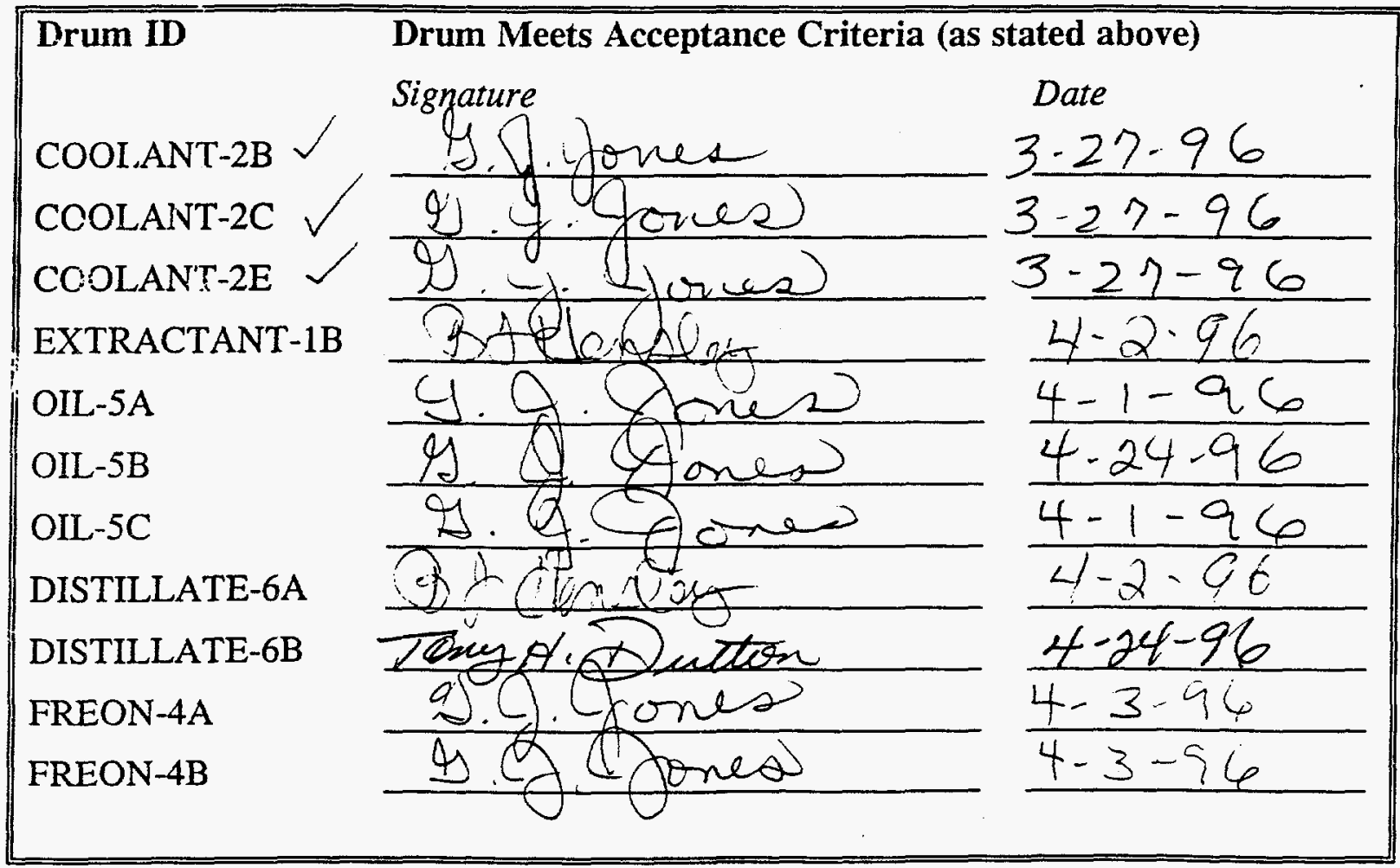

Reviewed by:

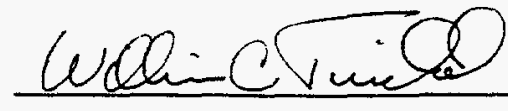

Project Manager
' $\frac{4 / 25 / 96}{\text { Date }}$ 


\section{Decontamination Sign-Off-Sheet}

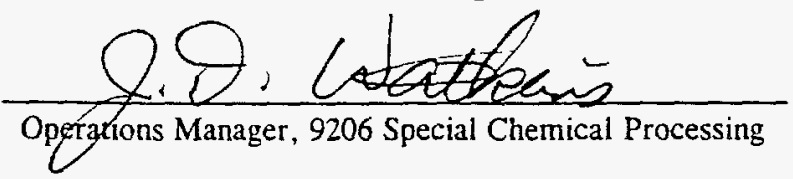

Equipment Description: Pretest Supply Wates Serial Number:

001

\begin{tabular}{|c|l|l|}
\hline Action & Activity & $\begin{array}{l}\text { Signature } \\
\text { N/A }\end{array}$ \\
\hline 2 & High-pressure detergent wash & $\frac{\text { DPSD Supervisor }}{\text { Signature }}$ \\
\hline 3 & High-pressure hot water rinse & $\frac{N / A}{\text { DPSD Supervisor }}$ \\
\hline & & $\frac{N / A}{\text { Signature }}$ \\
\hline
\end{tabular}

\begin{tabular}{|c|l|l|}
\hline 6 & $\begin{array}{l}\text { Sample results indicate that equipmen is } \\
\text { free of RCRA contamination. }\end{array}$ & $\begin{array}{l}\text { Signature } \\
\frac{6 \sqrt{\text { inOS }} 4 / 2 / 96}{\text { Project Manager }}\end{array}$ \\
\hline 7 & $\begin{array}{l}\text { Material is to be dispositioned as } \\
N / A\end{array}$ & $\frac{N / A}{\text { Project Manager }}$ \\
\hline
\end{tabular}

\begin{tabular}{|l|l|}
\hline Comments: & \\
\hline Sampe No. $960650017 \quad$ Wrise $4 / 2 / 96$ \\
\hline \\
\hline \\
\hline
\end{tabular}




\section{Decontamination Sign-Off-Sheet}

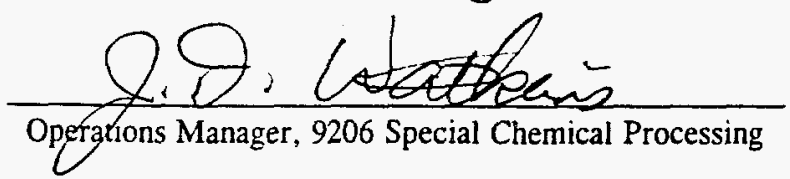

Equipment Description: Pretest totsy Suppyleatu Serial Number:

002

\begin{tabular}{|c|l|l|}
\hline Action & Activity & $\begin{array}{l}\text { Signature } \\
\frac{N}{A}\end{array}$ \\
\hline 1 & High-pressure detergent wash & DPSD Supervisor \\
\hline 2 & High-pressure hot water rinse & $\frac{N / A}{\text { Signature }}$ \\
\hline 3 & Second high-pressure hot water rinse & $\frac{N / A}{\text { SPSD Supervisor }}$ \\
\hline
\end{tabular}

\begin{tabular}{|c|c|c|}
\hline$\overline{\overline{6}}$ & $\begin{array}{l}\text { Sample results indicate that equipment is is } \\
\text { free of RCRA contamination. }\end{array}$ & Wignature $_{\text {Project Manager }} 4 / 2 / 96$ \\
\hline 7 & Material is to be dispositioned as & $\begin{array}{l}\text { Signature } \\
N \mid A\end{array}$ \\
\hline
\end{tabular}

\begin{tabular}{|l|l|}
\hline Comments: \\
\hline Sample number $9606500 / 8.6 \sqrt{\text { inos }} 4 / 2 / 96$ \\
\hline \\
\hline \\
\hline \\
\hline
\end{tabular}




\section{Decontamination Sign-Off-Sheet}

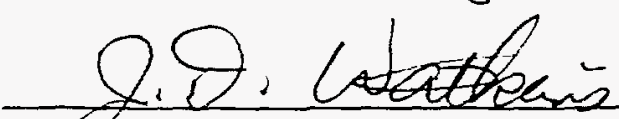

Operations Manager, 9206 Special Chemical Processing

Equipment Description: Rretest 3 scetin Sinctiastats Serial Number:

03

\begin{tabular}{|c|l|l|}
\hline Action & Activity & $\begin{array}{l}\text { Signature } \\
\frac{N}{A}\end{array}$ \\
\hline 1 & High-pressure detergent wash & DPSD Supervisor \\
\hline 2 & High-pressure hot water rinse & $\begin{array}{l}\text { Signature } \\
\text { DPSD Supervisor }\end{array}$ \\
\hline 3 & Second high-pressure hot water rinse & Signature \\
& & $\frac{N / A}{\text { DPSD Supervisor }}$ \\
\hline
\end{tabular}

\begin{tabular}{|c|l|l||}
\hline 6 & $\begin{array}{l}\text { Sample results indicate that equipment (1S)/ is } \\
\text { free of RCRA contamination. }\end{array}$ & $\begin{array}{l}\text { Signature } \\
\frac{6}{\text { Project Manager }}\end{array}$ \\
\hline 7 & $\begin{array}{l}\text { Material is to be dispositioned as } \\
N / A\end{array}$ & $\frac{N / A}{\text { Project Manager }}$ \\
\hline
\end{tabular}

\begin{tabular}{|l|l|}
\hline Comments: \\
\hline \\
\hline \\
\hline \\
\hline
\end{tabular}




\section{Decontamination Sign-Off-Sheet}

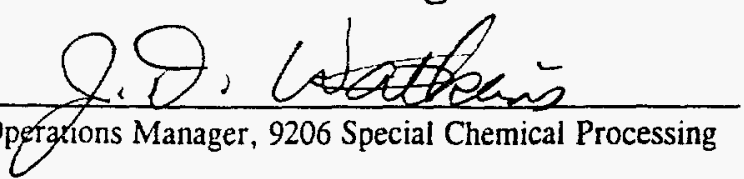

Equipment Description: Dike WatuSamph Serial Number:

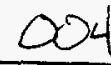

\begin{tabular}{|c|l|l|}
\hline Action & Activity & $\begin{array}{l}\text { Signature } \\
N / A\end{array}$ \\
\hline 1 & High-pressure detergent wash & DPSD Supervisor \\
\hline 2 & High-pressure hot water rinse & $\begin{array}{l}\text { Signature } \\
N / A\end{array}$ \\
& Second high-pressure hot water rinse & $\begin{array}{l}\text { SPSD Supervisor } \\
N / A\end{array}$ \\
\hline 3 & & $\frac{N \text { DPSD Supervisor }}{}$ \\
\hline
\end{tabular}

\begin{tabular}{|c|l|l|}
\hline 6 & $\begin{array}{l}\text { Sample results indicate that equipment } \\
\text { free of RCRA contamination. }\end{array}$ & $\begin{array}{l}\text { Signature } \\
\frac{\text { Sroject Manager }}{4 / 2 / 96}\end{array}$ \\
\hline 7 & $\begin{array}{l}\text { Material is to be dispositioned as } \\
N / A\end{array}$ & $\frac{N / A}{\text { Project Manager }}$ \\
\hline
\end{tabular}

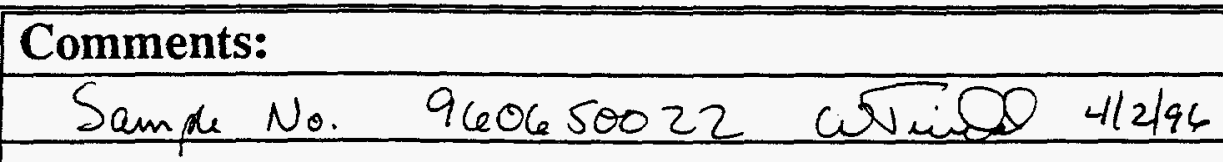




\section{Decontamination Sign-Off-Sheet}

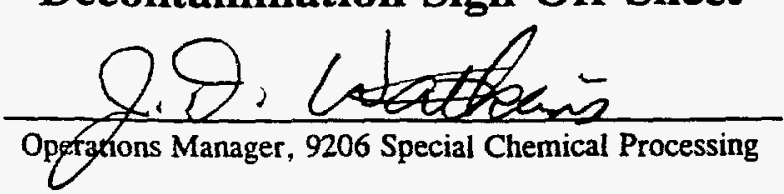

Equipment Description: A-AgitATOR Serial Number: 005

\begin{tabular}{|c|c|c|}
\hline Action & \multicolumn{2}{|l|}{ Activity } \\
\hline \multirow[t]{2}{*}{1} & High-pressure detergent wash & Signature \\
\hline & & $\frac{\text { Louy of Lutter }}{\text { DPSDStupervisor }}$ \\
\hline \multirow[t]{2}{*}{2} & High-pressure hot water rinse & Signature \\
\hline & & 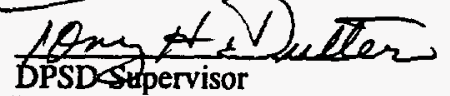 \\
\hline \multirow[t]{2}{*}{3} & Second high-pressure hot water rinse & Signature \\
\hline & & $\operatorname{LOny}_{\mathrm{DPSD} \text { supervisor }}$ \\
\hline
\end{tabular}

\begin{tabular}{|c|l|l|}
\hline 6 & $\begin{array}{l}\text { Sample results indicate that equipmen (is } y \text { is nor } \\
\text { free of RCRA contamination. }\end{array}$ & $\begin{array}{l}\text { Signature } \\
\text { Project Manager }\end{array}$ \\
\hline 7 & $\begin{array}{l}\text { Material is to be dispositioned as } \\
\text { Cenres tricted use }\end{array}$ & $\frac{\text { Signature }}{\text { Project Manager }}$ \\
\hline
\end{tabular}

\section{Comments:}

Sample No. $960650023 \quad$ WTige $4 / 3 / 96$




\section{Decontamination Sign-Off-Sheet}

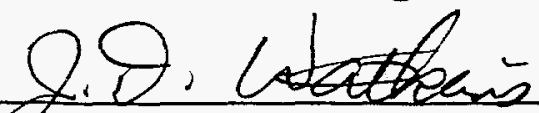

Opertarions Manager, 9206 Special Chemical Processing

Equipment Description: $\beta \quad A g i t A T 0 R$ Serial Number: 1906

\begin{tabular}{|c|l|l|}
\hline Action & Activity & Signature \\
\hline 1 & High-pressure detergent wash & DPSDSupervisor \\
\hline 2 & High-pressure hot water rinse & Signature \\
\hline 3 & Second high-pressure hot water rinse & Signdure \\
\hline
\end{tabular}

\begin{tabular}{|c|l|l|}
\hline 6 & $\begin{array}{l}\text { Sample results indicate that equipment } \\
\text { free of RCRA contamination. }\end{array}$ & $\begin{array}{l}\text { Signature } \\
\text { Project Manager }\end{array}$ \\
\hline 7 & $\begin{array}{l}\text { Material is to be dispositioned as } \\
\text { Un restricted Use }\end{array}$ & $\begin{array}{l}\text { Signature } \\
\text { Project Manager }\end{array}$ \\
\hline
\end{tabular}

\begin{tabular}{|ll|}
\hline Comments: & \\
\hline Sample No. 960650024 & Wruida $4 / 3 / 96$ \\
\hline & \\
\hline \\
\hline
\end{tabular}




\section{Decontamination Sign-Off-Sheet}

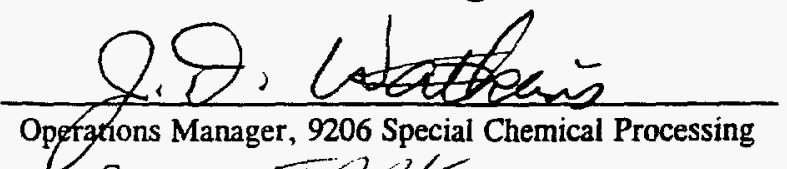

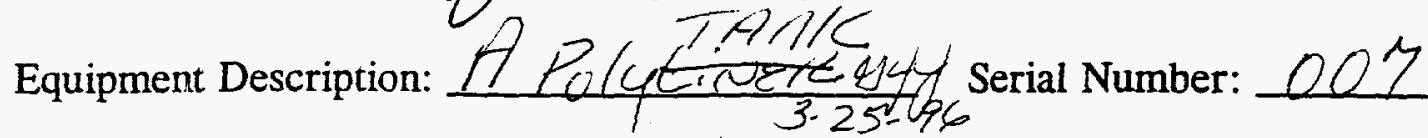

\begin{tabular}{|c|c|c|}
\hline Action & Activity & \\
\hline 1 & High-pressure detergent wash & $\frac{\text { Signature }}{\text { D. A. Coned }}$ \\
\hline 2 & High-pressure hot water rinse & $\frac{g .9 .9 \text { ones } 3-2}{\text { DPSDS Supetisor }}$ \\
\hline 3 & Second high-pressure hot water rinse & 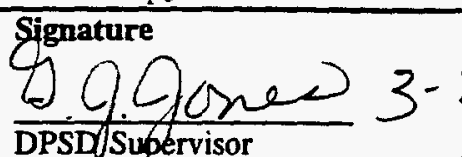 \\
\hline
\end{tabular}

\begin{tabular}{|c|c|c|}
\hline$\overline{6}$ & $\begin{array}{l}\text { Sample results indicate that equipment } 1 / 2 / \text { is } \\
\text { free of RCRA contamination. }\end{array}$ & 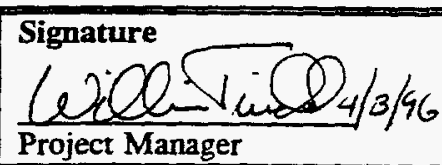 \\
\hline 7 & $\begin{array}{l}\text { Material is to be dispositioned as } \\
\text { Storage in } 92062 \mu 4 \neq 3\end{array}$ & $\frac{6 \sqrt{\text { Sigot }}}{\text { Project Manager }}$ 4/10/ac \\
\hline
\end{tabular}

\section{Comments:}

Sample No. 960650025 Wride $4 / 3 / 96$ 


\section{Decontamination Sign-Off-Sheet}

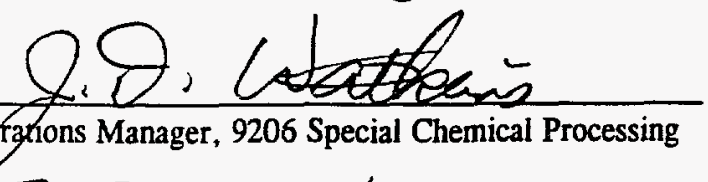

Equipment Description: B Poly TAN/C Serial Number: 008

\begin{tabular}{|c|c|c|}
\hline Action & Activity & \\
\hline 1 & High-pressure detergent wash & $\frac{9 \text { Signature }}{\text { DPSD Stopervisor }}$ \\
\hline 2 & High-pressure hot water rinse & $\begin{array}{l}\text { Signature } \\
\frac{9.9 .9 \text { ones }}{3-26} \\
\text { DPSD Supervisor }\end{array}$ \\
\hline 3 & Second high-pressure hot water rinse & 919 DPSDSuperyisor \\
\hline
\end{tabular}

\begin{tabular}{|c|c|c|}
\hline$\overline{6}$ & $\begin{array}{l}\text { Sample results indicate that equipment (is) } \\
\text { free of RCRA contamination. }\end{array}$ & Project Manager \\
\hline 7 & $\begin{array}{l}\text { Material is to be dispositioned as } \\
\text { Sterage in } 92 \tau_{0} R_{\mu A} \pm 3\end{array}$ & 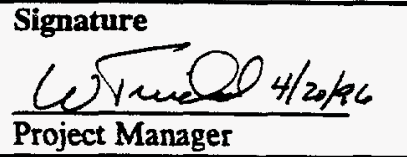 \\
\hline
\end{tabular}

\begin{tabular}{|lll|}
\hline Comments: & & \\
\hline Sample io. 960650026 & wine & $413 / 96$ \\
\hline & \\
\hline & \\
\hline \\
\hline
\end{tabular}




\section{Decontamination Sign-Off-Sheet}
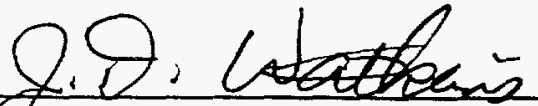

Operzuons Manager, 9206 Special Chemical Processing

Equipment Description: Strue tuRAl. Support Serial Number:

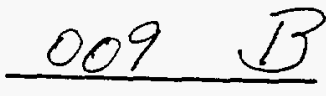

\begin{tabular}{|c|c|c|}
\hline Action & Activity & \\
\hline 1 & High-pressure detergent wash & $\begin{array}{l}\text { Signature } \\
\text { 9.8. Aonee, 3-27- } \\
\text { DPs Supervisor }\end{array}$ \\
\hline 2 & High-pressure hot water rinse & Signature \\
\hline 3 & Second high-pressure hot water rinse & 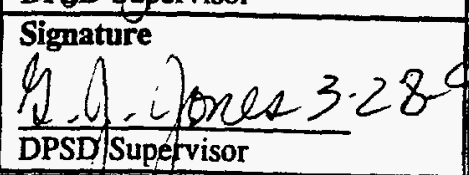 \\
\hline
\end{tabular}

\begin{tabular}{|c|c|c|}
\hline$\overline{6}$ & $\begin{array}{l}\text { Sample results indicate that equipment (1S) is not } \\
\text { free of RCRA contamination. }\end{array}$ & 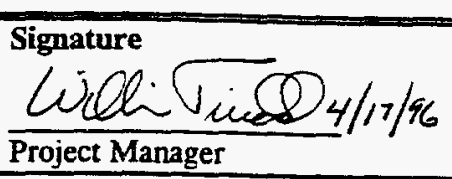 \\
\hline 7 & $\begin{array}{l}\text { Material is to be dispositioned as } \\
\text { Starage in } 92 \alpha_{6} \mathrm{RMA}_{3}\end{array}$ & $\frac{\text { Wignature }}{\text { Project Manager }} 4 / 20 / 96$ \\
\hline
\end{tabular}

\section{Comments:}

Sample No. 960650027 Wriso 4/3/96

Sample No 960650028 is a duplicate of 009 . Whind 4 /irlac 


\section{Decontamination Sign-Off-Sheet}

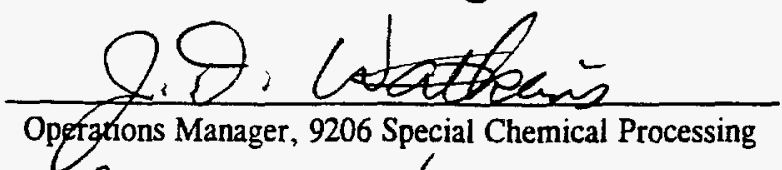

Equipment Description: A structural Fefthid Serial Number: 010

\begin{tabular}{|c|c|c|}
\hline Action & Activity & \\
\hline$\overline{1}$ & $\begin{array}{l}\text { High-pressure detergent wash } \\
\text { a }\end{array}$ & $\frac{9.9 . G_{\text {ones }}}{3-28}$ \\
\hline$\overline{2}$ & High-pressure hot water rinse & 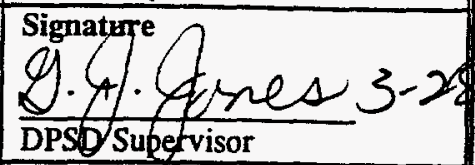 \\
\hline 3 & Second high-pressure hot water rinse & 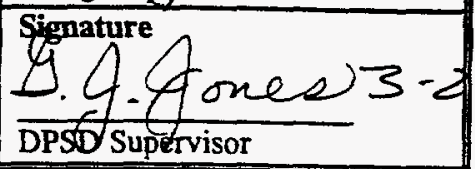 \\
\hline
\end{tabular}

\begin{tabular}{|c|c|c|}
\hline 6 & $\begin{array}{l}\text { Sample results indicate that equipment is is Ior } \\
\text { free of RCRA contamination. }\end{array}$ & Gignature \\
\hline 7 & $\begin{array}{l}\text { Material is to be dispositioned as } \\
\text { Starage in } 9200\end{array}$ & Signature \\
\hline
\end{tabular}

\section{Comments:}

Sample No. 960650029 Wrioge 4/3/96




\section{Decontamination Sign-Off-Sheet}

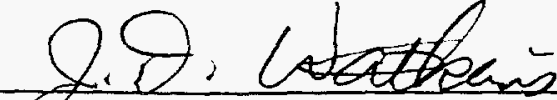

Operzxions Manager, 9206 Special Chemical Processing

Equipment Description: Dike Layer \# 1_ Serial Number

011

\begin{tabular}{|c|l|l|}
\hline Action & Activity & \\
\hline 1 & High-pressure detergent wash & DPSD Supervisor \\
\hline 2 & High-pressure hot water rinse & Signature \\
\hline 3 & Second high-pressure hot water rinse & DPSD Supervisor \\
\hline & & Signature \\
\hline
\end{tabular}

\begin{tabular}{|c|l|l|}
\hline 6 & $\begin{array}{l}\text { Sample results indicate that equipmen is / ignature } \\
\text { free of RCRA contamination. }\end{array}$ & $\begin{array}{l}\text { Signallous } \\
\text { Project Manager }\end{array}$ \\
\hline 7 & $\begin{array}{l}\text { Material is to be dispositioned as } \\
\text { Rad Waste }\end{array}$ & $\begin{array}{l}\text { Signature } \\
\text { Project Manager }\end{array}$ \\
\hline
\end{tabular}

\begin{tabular}{|l|l|}
\hline Comments: & \\
\hline & \\
\hline & \\
\hline & \\
\hline & \\
\hline & \\
\hline
\end{tabular}




\section{Decontamination Sign-Off-Sheet}

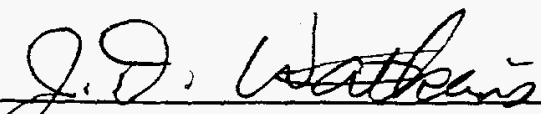

Operarions Manager, 9206 Special Chemical Processing

$$
4-n-96
$$

Equipment Descriptionc Dike Layer $\$ 2$ Serial Number:

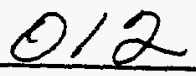

\begin{tabular}{|c|c|c|}
\hline Action & Activity & \\
\hline 1 & High-pressure detergent wash & $\frac{\text { Signature }}{\text { DPSD Supervisor }}$ \\
\hline$\overline{2}$ & High-pressure hot water rinse & Bignature \\
\hline $\begin{array}{c}3 \\
4 \cdot 11 \cdot 96\end{array}$ & Second high-pressure hot water rinse & 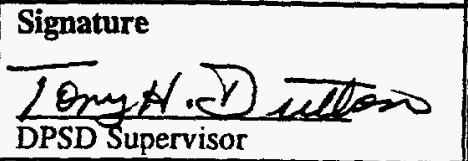 \\
\hline
\end{tabular}

\begin{tabular}{|c|l|l|}
\hline 6 & $\begin{array}{l}\text { Sample results indicate that equipment is ) is nor } \\
\text { free of RCRA contamination. }\end{array}$ & $\begin{array}{l}\text { Signature } \\
\text { Project Manager }\end{array}$ \\
\hline 7 & $\begin{array}{l}\text { Material is to be dispositioned as } \\
\text { Rad Waste }\end{array}$ & $\begin{array}{l}\text { Signature } \\
\text { Project Manager }\end{array}$ \\
\hline
\end{tabular}

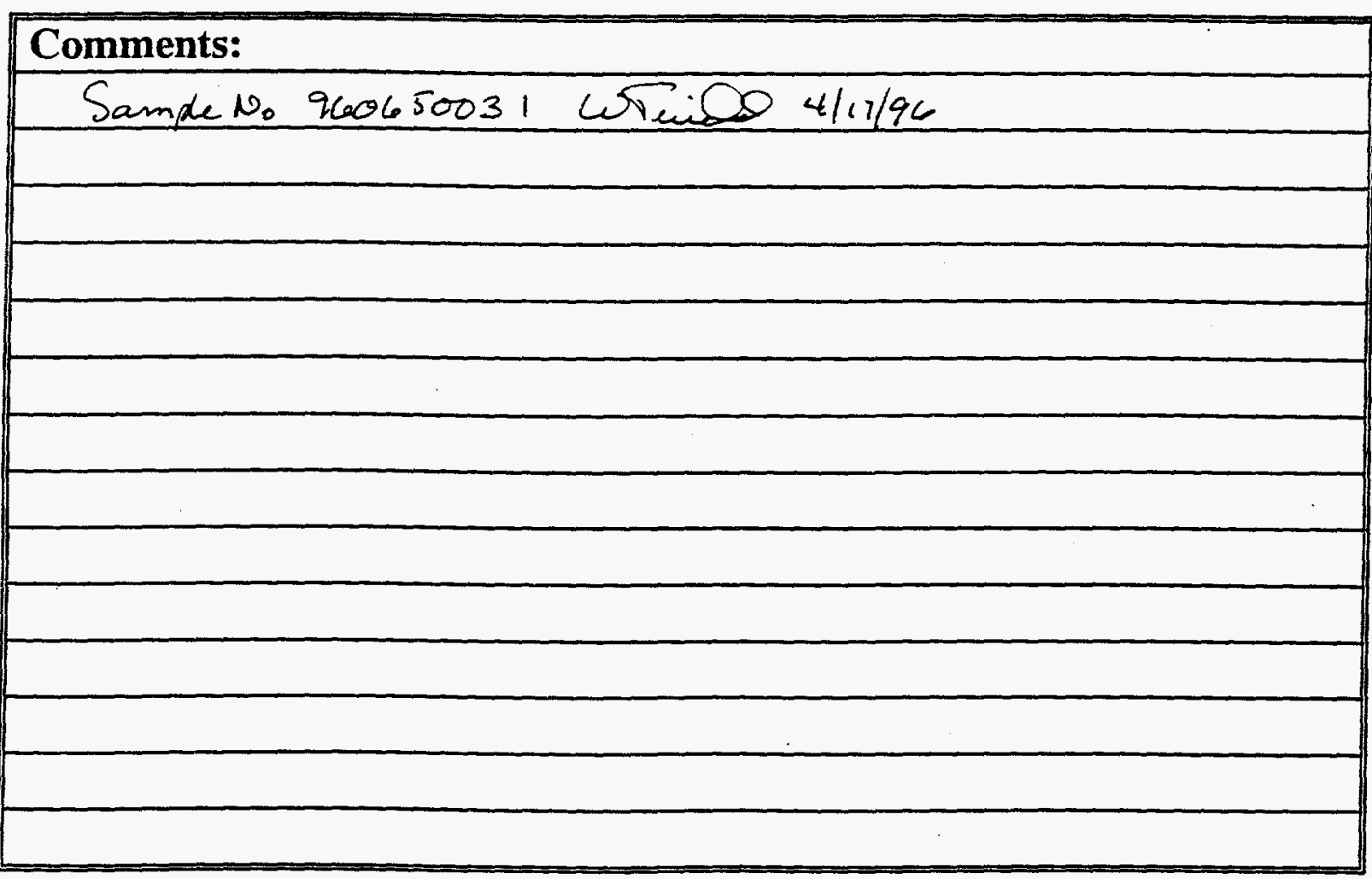




\section{Decontamination Sign-Off-Sheet}

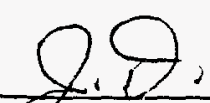

Operations Manager, 9206 Special Chemical Processing

Equipment Description: Diks LaysR\#3 Serial Number: 013

\begin{tabular}{|c|c|c|}
\hline Action & Activity & \\
\hline 1 & High-pressure detergent wash & ${ }_{\text {SPSD Supervisor }}^{\text {Signature }}$ \\
\hline 2 & High-pressure hot water rinse & $\frac{\text { 9. } 4 . \text { Aoned } 4.12 .96}{\text { DPSD Supervisor }}$ \\
\hline 3 & Second high-pressure hot water rinse & \& 9.4 onee 41 \\
\hline$\overline{6}$ & $\begin{array}{l}\text { Sample results indicate that equipment } \operatorname{sis} / \text { is not } \\
\text { free of } R C R A \text { contamination. }\end{array}$ & $\frac{6 Q 0 \cdot V_{\text {in }}\left(D_{4 / 29} / \mathrm{c}\right.}{\text { Pignature }}$ \\
\hline 7 & $\begin{array}{l}\text { Material is to be dispositioned as } \\
\text { Rad Waste }\end{array}$ & 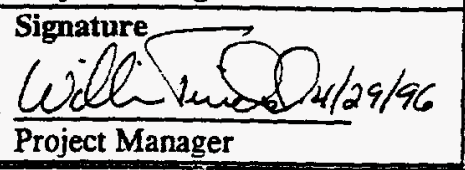 \\
\hline
\end{tabular}

\section{Comments:}

Sangle No. 960650032 . Ceviule 4/29/26 


\section{Raschig Ring Decontamination Sign-Off Sheet}

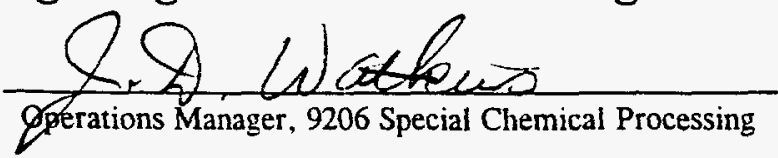

Drum Designation: FReON $\mathrm{O}$ Serial Number:

Basket Designation: $2079 / 2072 / 2078 / 2077 / 2074 / 2073$ 48g

Date of Transfer: $\quad 4-15 \cdot 96$

\begin{tabular}{|c|c|c|}
\hline Action & Activity & \\
\hline 1 & High-pressure detergent wash. & D997 $4-15.96$ \\
\hline 2 & High-pressure hot water rinse & DPSD Supervisor \\
\hline 3 & One hour nitric acid soak. & 4994.15 .96 \\
\hline 4 & High-pressure detergent wash. & $\frac{\pi H D}{\text { Signature }} 4-16-96$ \\
\hline 5 & High-pressure hot water rinse. & DPSD Supdrvisor $4-16$ \\
\hline
\end{tabular}

\begin{tabular}{|c|l|l|}
\hline 6 & $\begin{array}{l}\text { Sample results indicate that rings ares/are free } \\
\text { of RCRA contaminaion. }\end{array}$ & $\begin{array}{l}\text { Signature } \\
\text { Project Manager }\end{array}$ \\
\hline 7 & $\begin{array}{l}\text { Material is to be dispositioned as } \\
\text { Rad Waste }\end{array}$ & $\begin{array}{l}\text { Cignature } \\
\text { Project Manager }\end{array}$ \\
\hline
\end{tabular}

\section{Comments:}

Sample No. 960650033 Wring $35981 \% / 29 / 26$ 


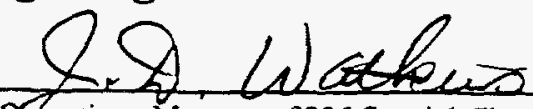

Qperations Manager, 9206 Special Chemical Processing

Drum Designation: FReoN 43

Basket Designation: $2077 / 2074 / 2073$

Serial Number:

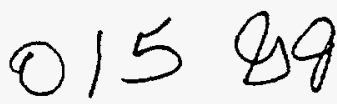

Date of Transfer: $4-15-96$

\begin{tabular}{|c|c|c|}
\hline Action & Activity & \\
\hline 1 & High-pressure detergent wash. & 915.96 \\
\hline 2 & High-pressure hot water rinse & की $4-15-9$ \\
\hline 3 & One hour nitric acid soak. & Signature $4-15-9$ \\
\hline 4 & High-pressure detergent wash. & 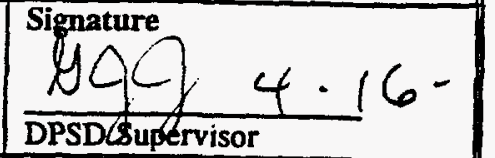 \\
\hline 5 & High-pressure hot water rinse. & Signature $4-16$ \\
\hline
\end{tabular}

\begin{tabular}{|c|c|c|}
\hline 6 & $\begin{array}{l}\text { Sample results indicate that rings arei/ free } \\
\text { of RCRA contaminaion. }\end{array}$ & 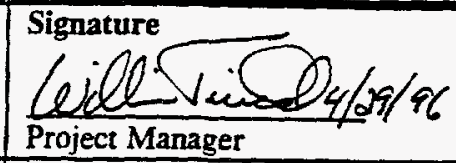 \\
\hline 7 & $\begin{array}{l}\text { Material is to be dispositioned as } \\
\text { Rad was te }\end{array}$ & $\frac{\mathrm{Cetll} \mathrm{Vew}_{4 / 2} \mathrm{O} / \mathrm{q}}{\text { Project Manager }}$ \\
\hline
\end{tabular}

\section{Comments:}

Sample No. 960650034 Whine 4/29/96 


\section{Raschig Ring Decontamination Sign-Off Sheet}

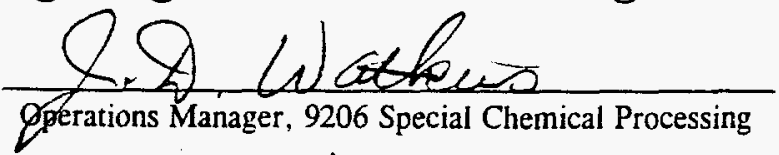
Drum Designation:
FREON $4 A$
Serial Number:
016

Basket Designation: 2072/2079/2078

Date of Transfer:

$4146 / 94$

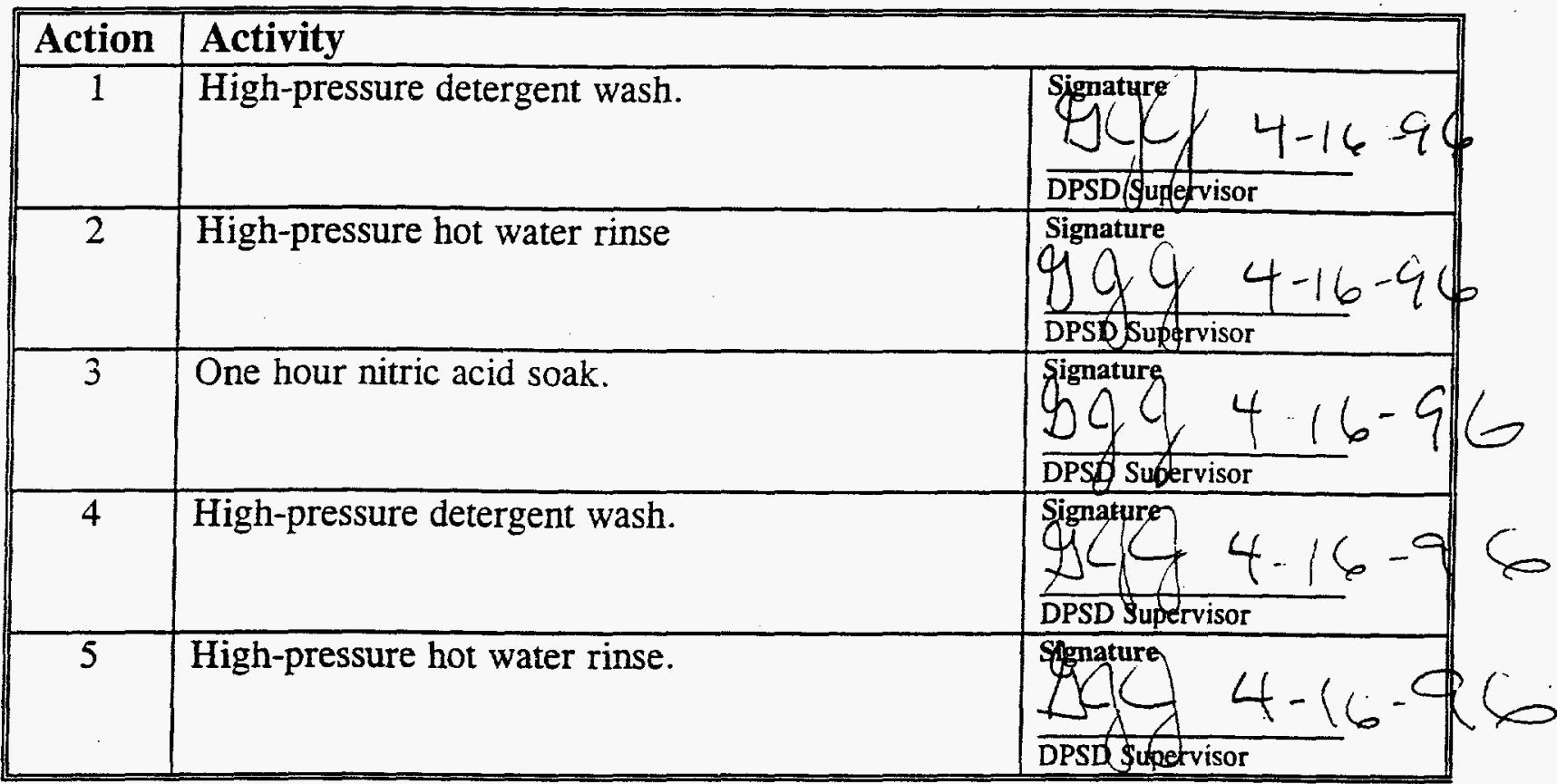

\begin{tabular}{|c|l|l|}
\hline 6 & $\begin{array}{l}\text { Sample results indicate that rings are/4ree free } \\
\text { of RCRA contaminaion. }\end{array}$ & $\begin{array}{l}\text { Signature } \\
\text { Project Manager }\end{array}$ \\
\hline 7 & $\begin{array}{l}\text { Material is to be dispositioned as } \\
\text { Rad Waste }\end{array}$ & $\begin{array}{l}\text { Signature } \\
\text { Project Manager }\end{array}$ \\
\hline
\end{tabular}

\section{Comments: \\ Sample No. 960650035 W vivel 4/29/96}




\section{Raschig Ring Decontamination Sign-Off Sheet}

Gerations Manager, 9206 Special Chemical Processing

Drum Designation: FreON $4 \mathrm{~A}$ Serial Number:

017

Basket Designation: $-2076 / 2080 / 2075$

Date of Transfer: $4-16-96$

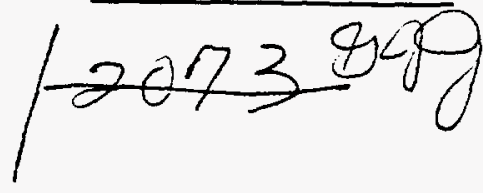

\begin{tabular}{|c|c|c|}
\hline$\overline{\text { Action }}$ & Activity & \\
\hline 1 & High-pressure detergent wash. & DPSD Supervisor \\
\hline$\overline{2}$ & High-pressure hot water rinse & 9) Signature $4-16-96$ \\
\hline 3 & One hour nitric acid soak. & DPSD Supervisor \\
\hline 4 & High-pressure detergent wash. & 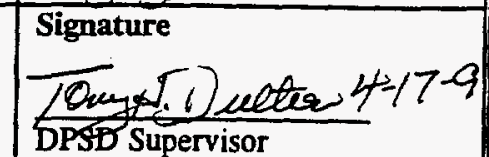 \\
\hline 5 & High-pressure hot water rinse. & Dorm Hignature \\
\hline
\end{tabular}

\begin{tabular}{|c|c|c|}
\hline 6 & $\begin{array}{l}\text { Sample results indicate that rings are / aree } \\
\text { of RCRA contaminaion. }\end{array}$ & 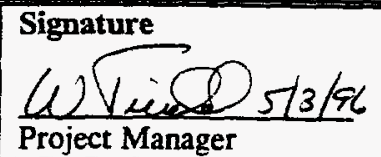 \\
\hline 7 & $\begin{array}{l}\text { Material is to be dispositioned as } \\
\text { Rad Waste }\end{array}$ & $\frac{G \sqrt{1 \text { und }} 5 / 3 / 9 C}{\text { Project Manager }}$ \\
\hline
\end{tabular}

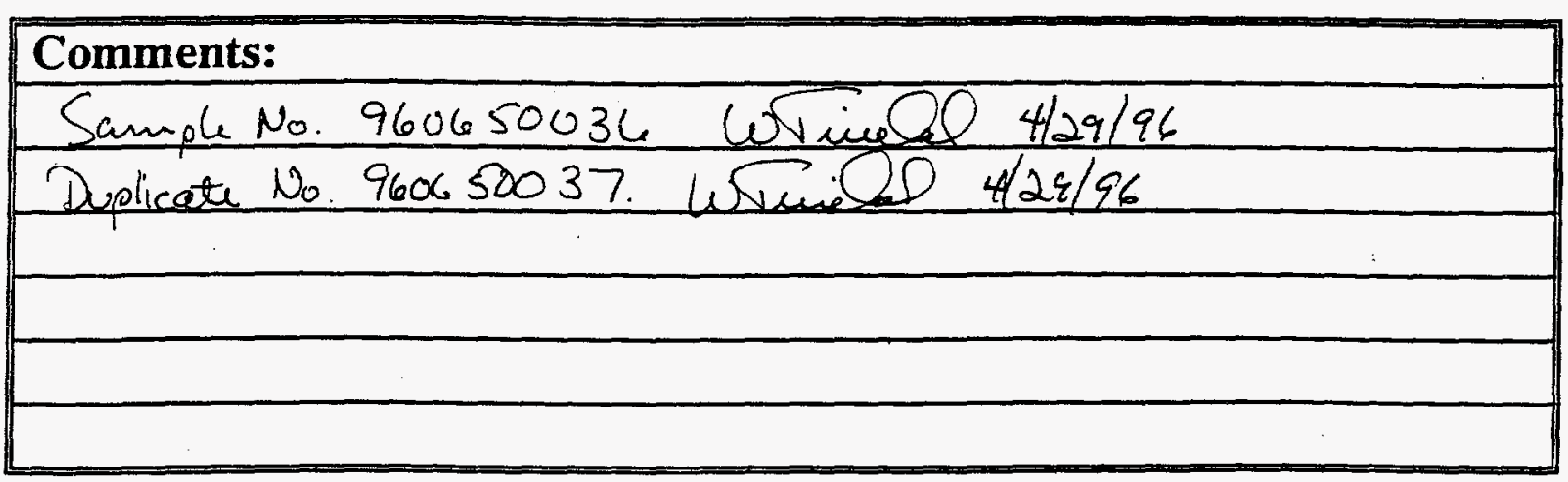




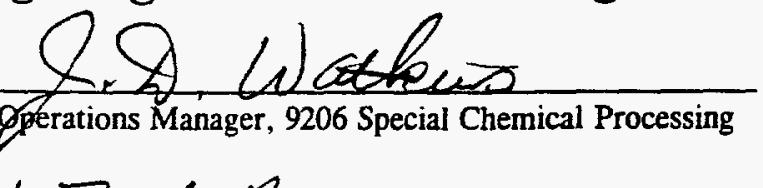

Drum Designation. Dis $6 月$ Serial Number:



Baskei Designation: $2072 / 2080 / 2078$

Date of Transfer: $\not b-12-96$

\begin{tabular}{|c|c|c|}
\hline Action & Activity & \\
\hline 1 & High-pressure detergent wash. & 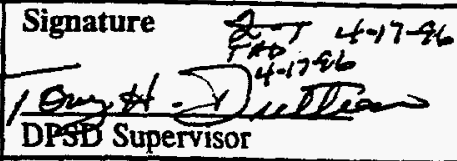 \\
\hline 2 & High-pressure hot water rinse & \begin{tabular}{|l} 
Signature $4.17-96$ \\
DPSD Supervisor
\end{tabular} \\
\hline 3 & One hour nitric acid soak. & \begin{tabular}{|l} 
Signature $4-n-96$ \\
DPST Supervisor \\
\end{tabular} \\
\hline 4 & High-pressure detergent wash. & DPSD Stpetvisor $4-17-96$ \\
\hline 5 & High-pressure hot water rinse. & $\frac{4}{\text { Signature }} 4-17-96$ \\
\hline
\end{tabular}

\begin{tabular}{|c|l|l|}
\hline 6 & $\begin{array}{l}\text { Sample results indicate that rings are are not free } \\
\text { of RCRA contaminaion. }\end{array}$ & $\begin{array}{l}\text { Signature } \\
\text { Project Manager }\end{array}$ \\
\hline 7 & $\begin{array}{l}\text { Material is to be dispositioned as } \\
\text { Rad waste }\end{array}$ & Signature \\
\hline
\end{tabular}

\section{Comments:}

Sample No 960650038 LSuido 4/29/96




\section{Raschig Ring Decontamination Sign-Off Sheet}
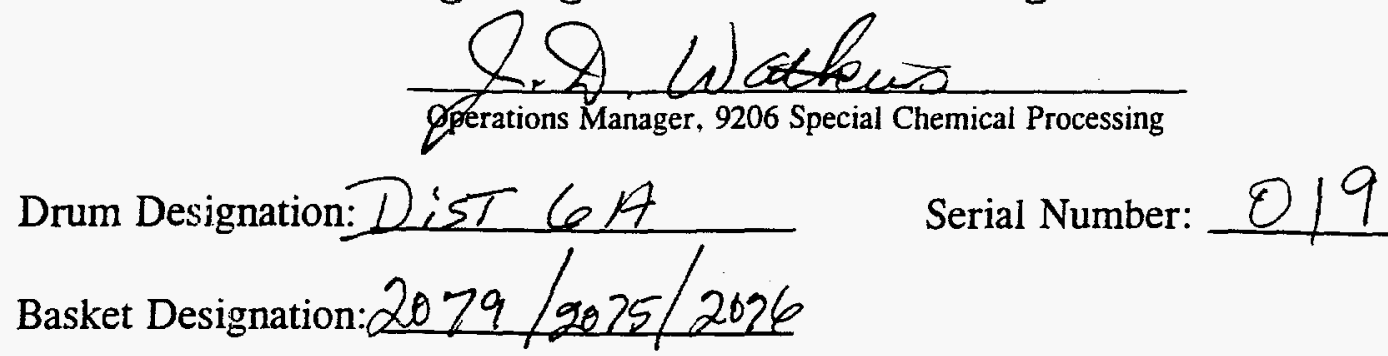

Date of Transfer: $4-17-96$

\begin{tabular}{|c|c|c|}
\hline Action & Activity & \\
\hline 1 & High-pressure detergent wash. & PSAC $4-17-96$ \\
\hline 2 & High-pressure hot water rinse & DPSD Spervisor \\
\hline 3 & One hour nitric acid soak. & $9944 \cdot 17-96$ \\
\hline 4 & High-pressure detergent wash. & S9: $4-17-9$ \\
\hline 5 & High-pressure hot water rinse. & Signatury $4-17-9$ \\
\hline
\end{tabular}

\begin{tabular}{|c|l|l||}
\hline 6 & $\begin{array}{l}\text { Sample results indicate that rings are } \gamma \\
\text { of RCRA contaminaion. }\end{array}$ & $\begin{array}{l}\text { Signature } \\
\frac{1}{\text { Project Manager }}\end{array}$ \\
\hline 7 & $\begin{array}{l}\text { Material is to be dispositioned as } \\
\text { Rad Wasta }\end{array}$ & $\begin{array}{l}\text { Signature } \\
\text { Project Manager }\end{array}$ \\
\hline
\end{tabular}

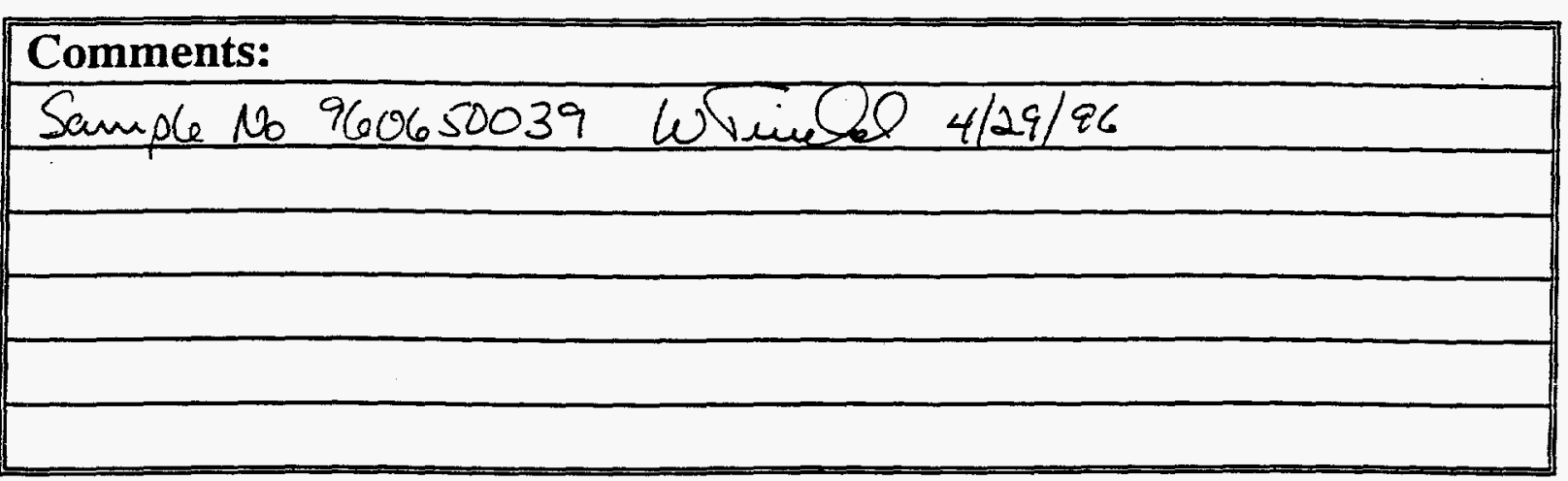




\section{Raschig Ring Decontamination Sign-Off Sheet}

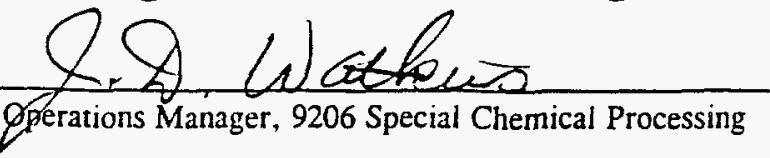

Drum Designation: (Dist) 63 Serial Number: 120

Basket Designation: $2073 / 2074 / 207 \%$

Date of Transfer: $4-17-96$

\begin{tabular}{|c|c|c|}
\hline Action & Activity & \\
\hline 1 & High-pressure detergent wash. & Signature $494-17-96$ \\
\hline 2 & High-pressure hot water rinse & $9004-96$ \\
\hline 3 & One hour nitric acid soak. & 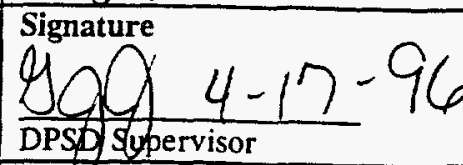 \\
\hline 4 & High-pressure detergent wash. &  \\
\hline 5 & High-pressure hot water rinse. & 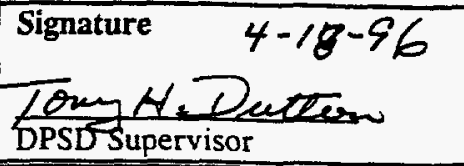 \\
\hline
\end{tabular}

\begin{tabular}{|c|l|l|}
\hline 6 & $\begin{array}{l}\text { Sample results indicate that rings fre } \\
\text { of RCRA contaminaion. }\end{array}$ & $\begin{array}{l}\text { Signature } \\
\text { Project Manager }\end{array}$ \\
\hline 7 & $\begin{array}{l}\text { Material is to be dispositioned as } \\
\text { Rad Waste }\end{array}$ & $\frac{1}{\text { Project Manager }}$ \\
\hline
\end{tabular}

\section{Comments:}

Sample No. 960650040 Wridel $4 / 24 / 96$ 


\section{Raschig Ring Decontamination Sign-Off Sheet}

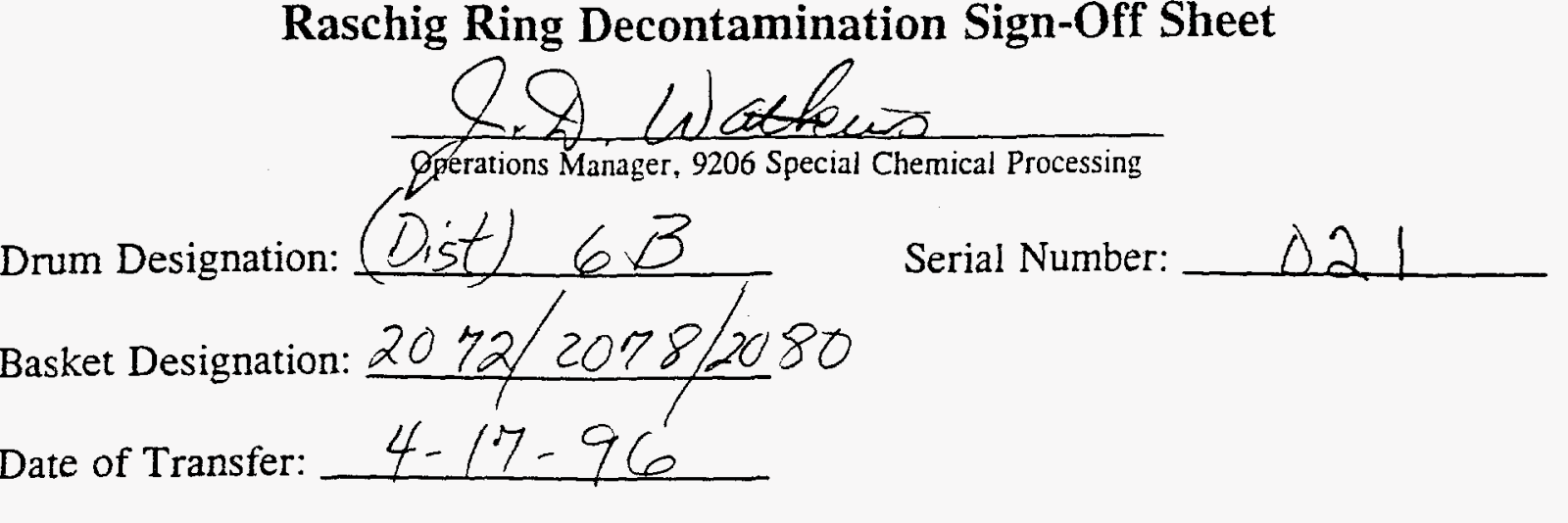

\begin{tabular}{|c|c|c|}
\hline Action & Activity & \\
\hline 1 & High-pressure detergent wash. & 404 Signaturg 4796 \\
\hline 2 & High-pressure hot water rinse & $90 \bigcirc 96$ \\
\hline 3 & One hour nitric acid soak. & SG \\
\hline 4 & High-pressure detergent wash. & $\begin{array}{l}\text { Signature } 4-18-96 \\
\text { TRuy } 1 \text { acteas } \\
\text { DPSU Supervisor }\end{array}$ \\
\hline 5 & High-pressure hot water rinse. & $2 / 4-18-96$ \\
\hline
\end{tabular}

\begin{tabular}{|c|l|l|}
\hline 6 & $\begin{array}{l}\text { Sample results indicate that rings arey are not free } \\
\text { of RCRA contaminaion. }\end{array}$ & $\begin{array}{l}\text { Signature } \\
\text { Raderial is to be dispositioned as } \\
\text { Rasle }\end{array}$ \\
\hline 7 & $\begin{array}{l}\text { Matect Manager } \\
\text { Ragnature }\end{array}$ \\
\hline
\end{tabular}

\begin{tabular}{|llll|}
\hline Comments: & & & \\
\hline Sample No & 960650041 & Wveres & $4 / 28 / 96$ \\
\hline Duplicate No & 960650042 & wVencol & $4 / 29 / 96$ \\
\hline & & \\
\hline
\end{tabular}




\section{Raschig Ring Decontamination Sign-Off Sheet}

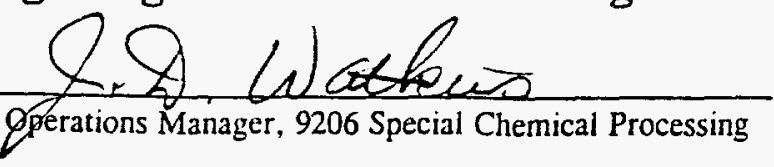

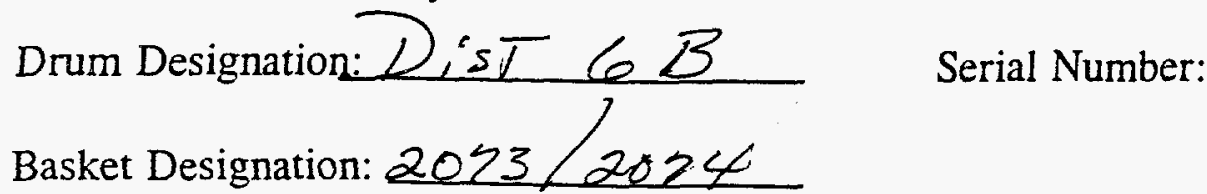

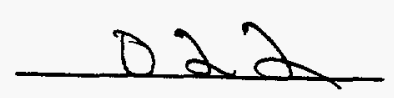

Date of Transfer: $\not-\angle 8-96$

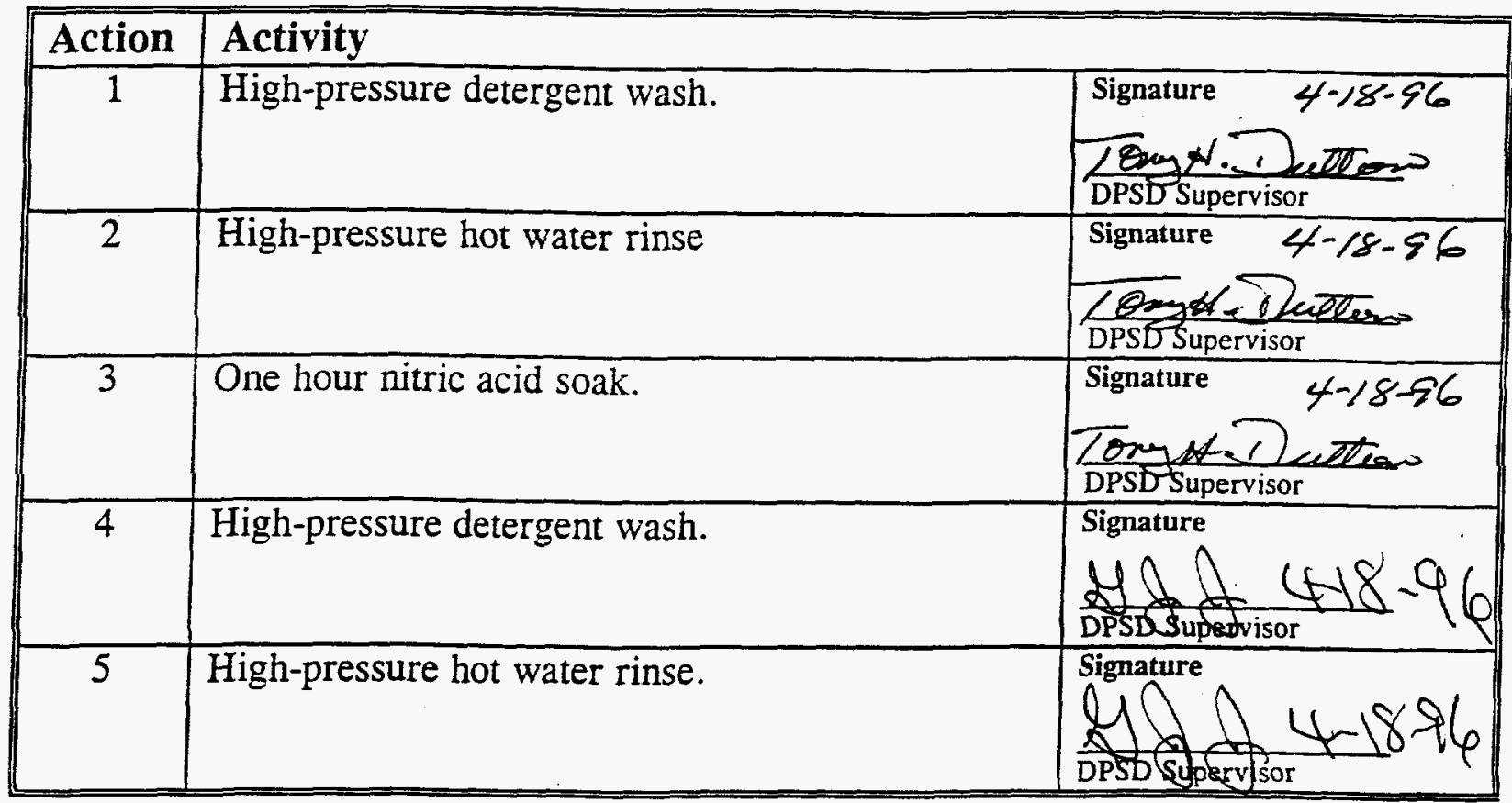

\begin{tabular}{|c|c|c|}
\hline 6 & $\begin{array}{l}\text { Sample results indicate that rings are / are not free } \\
\text { of RCRA contaminaion. }\end{array}$ & $\frac{6 \sqrt{\text { Signature }} 5 / 2 / 9}{\text { Project Manager }}$ \\
\hline 7 & $\begin{array}{l}\text { Material is to be dispositioned as } \\
\text { Rad Was te }\end{array}$ & $\frac{\text { Signature }}{\text { Project Manager }}$ \\
\hline
\end{tabular}

\section{Comments:}

Sample No. 960650043 Wrided 4/29/96 


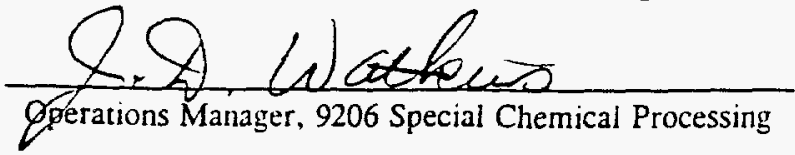

Drum Designation: li 5 A , SB, $5 \mathrm{C}$ Serial Number: 023

Basket Designation: $2072 / 2078 / 2080$

Date of Transfer: $4-18-96$

\begin{tabular}{|c|c|c|}
\hline Action & Activity & \\
\hline 1 & High-pressure detergent wash. & $\int_{D P B}$ Signature $4-18-96$ \\
\hline 2 & High-pressure hot water rinse & $\int_{\text {DesD Subervitor }}^{4}+18-96$ \\
\hline$\overline{3}$ & One hour nitric acid soak. & $\frac{210}{D P S D} \frac{4}{\text { Signature }}+18-96$ \\
\hline 4 & High-pressure detergent wash. & 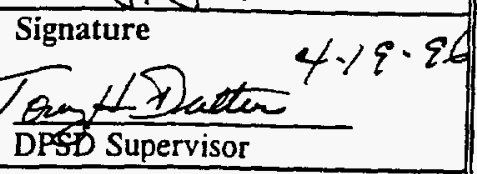 \\
\hline 5 & High-pressure hot water rinse. & $\begin{array}{l}\text { Signature } 4 \cdot 19 \cdot 96 \\
\text { Tong } 1 \text { Dutan } \\
\text { DPSO Supervisor }\end{array}$ \\
\hline
\end{tabular}

\begin{tabular}{|c|l|l|}
\hline 6 & $\begin{array}{l}\text { Sample results indicate that ring are' } \\
\text { of RCRA contaminaion. }\end{array}$ & $\begin{array}{l}\text { Signature } \\
\frac{1}{\text { Project Manager }}\end{array}$ \\
\hline 7 & $\begin{array}{l}\text { Material is to be dispositioned as } \\
\text { Rad Waste }\end{array}$ & $\begin{array}{l}\text { Signature } \\
\text { Project Manager }\end{array}$ \\
\hline
\end{tabular}

\section{Comments:}

Sample No. 960650044 Wrese 4/29/96 


\section{Raschig Ring Decontamination Sign-Off Sheet

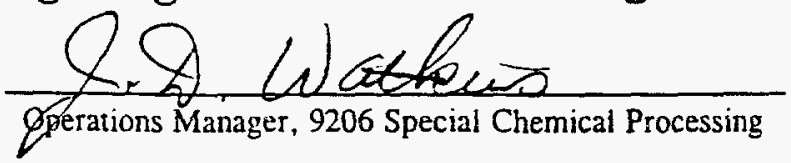

Drum Designation:Coolant 23 Serial Number:



Basket Designation:2073/2074/2076

Date of Transfer: $4-19-96$

\begin{tabular}{|c|c|c|}
\hline Action & Activity & \\
\hline 1 & High-pressure detergent wash. & $\begin{array}{l}\text { Signature } 4-19-96 \\
\text { Toxy H. Yulteres } \\
\text { DPSD Supervisor }\end{array}$ \\
\hline 2 & High-pressure hot water rinse & 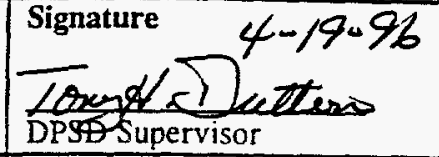 \\
\hline 3 & One hour nitric acid soak. & 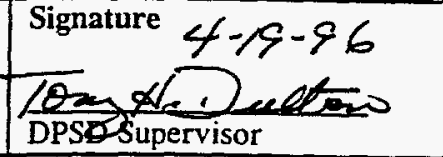 \\
\hline 4 & High-pressure detergent wash. & 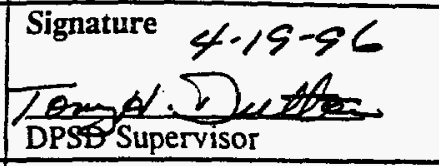 \\
\hline 5 & High-pressure hot water rinse. & 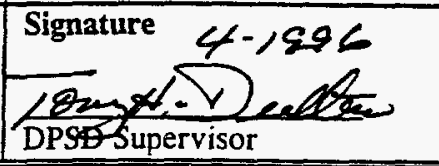 \\
\hline
\end{tabular}

\begin{tabular}{|c|l|l||}
\hline 6 & $\begin{array}{l}\text { Sample results indicate that rings gre } \\
\text { of RCRA contaminaion. }\end{array}$ & $\begin{array}{l}\text { Signature } \\
\text { Project Manager }\end{array}$ \\
\hline 7 & $\begin{array}{l}\text { Material is to be dispositioned as } \\
\text { Rad Coaste }\end{array}$ & $\begin{array}{l}\text { Signature } \\
\text { Project Manager }\end{array}$ \\
\hline
\end{tabular}

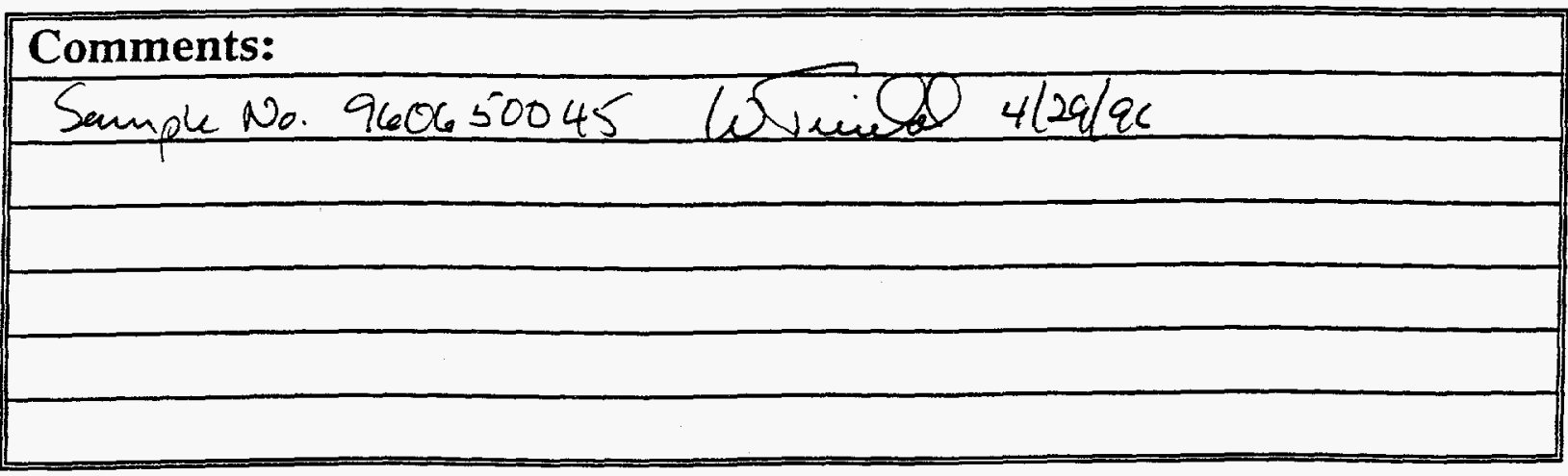




\section{Raschig Ring Decontamination Sign-Off Sheet}

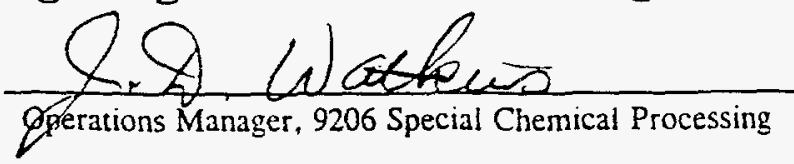

Drum Designation: Cooktow 2.3

Serial Number:



Basket Designation: $2072 / 2078 / 2075$

Date of Transfer: $\angle-2 q-96$

\begin{tabular}{|c|c|c|}
\hline Action & \multicolumn{2}{|l|}{ Activity } \\
\hline 1 & High-pressure detergent wash. & Signature $\quad 4 / 9.96$ \\
\hline & & $\frac{\text { Qxed. Dectles }}{\text { DPSESupervisor }}$ \\
\hline 2 & High-pressure hot water rinse & $\begin{array}{l}\text { Signature } 4.19-96 \\
\text { ony } 4 \text { \% Dutton } \\
\text { DPSESupervisor }\end{array}$ \\
\hline 3 & One hour nitric acid soak. & $\begin{array}{l}\text { Signature } 4-19-96 \\
18 \text { and } 12 u+t \operatorname{ton} \\
\text { DPSESupervisor }\end{array}$ \\
\hline 4 & High-pressure detergent wash. & Signature \\
\hline 5 & High-pressure hot water rinse. & Signature \\
\hline
\end{tabular}

\begin{tabular}{|c|l|l||}
\hline 6 & $\begin{array}{l}\text { Sample results indicate that rings are/ are not free } \\
\text { of RCRA contaminaion. }\end{array}$ & $\begin{array}{l}\text { Signature } \\
\text { Project Manager }\end{array}$ \\
\hline 7 & $\begin{array}{l}\text { Material is to be dispositioned as } \\
\text { Cad coges Le }\end{array}$ & Signature \\
\hline
\end{tabular}

\begin{tabular}{|lll|}
\hline Comments: & \\
\hline Sample No. 960650046 & Wricos & \\
\hline & \\
\hline & \\
\hline
\end{tabular}




\section{Raschig Ring Decontamination Sign-Off Sheet}

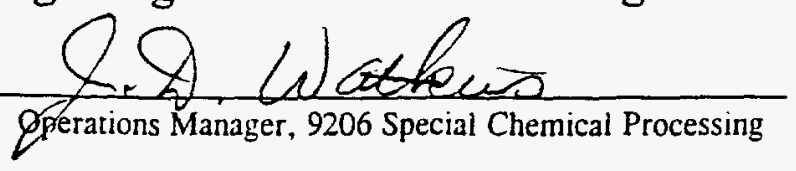

Drum Designation: $00 \operatorname{LAn} 23$
Basket Designation: $2080 / 2029$

Serial Number:

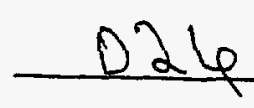

Date of Transfer: $4-19-96$

\begin{tabular}{|c|c|c|}
\hline Action & \multicolumn{2}{|l|}{ Activity } \\
\hline \multirow[t]{2}{*}{1} & High-pressure detergent wash. & Signature $4-19.96$ \\
\hline & & 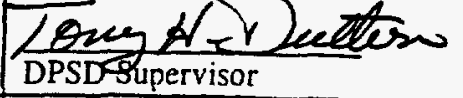 \\
\hline 2 & High-pressure hot water rinse & Signature $4-19-96$ \\
\hline & & $\begin{array}{l}\text { Tonat rataro } \\
\text { DPSDSupervisor }\end{array}$ \\
\hline 3 & One hour nitric acid soak. & 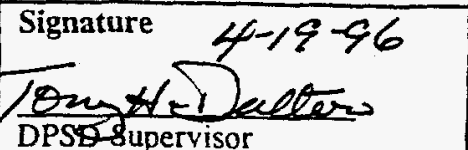 \\
\hline 4 & High-pressure detergent wash. & DPSD Sa teatisor $4-19-96$ \\
\hline 5 & High-pressure hot water rinse. & $\int_{\text {DPSE }}^{\text {Signature }}+19.96$ \\
\hline
\end{tabular}

\begin{tabular}{|c|c|c|}
\hline$\overline{6}$ & $\begin{array}{l}\text { Sample results indicate that ring are / are not free } \\
\text { of RCRA contaminaion. }\end{array}$ & $\frac{6 \sqrt{\text { Signature }}}{\text { Project Manager }} 50 / 3 / 96$ \\
\hline 7 & $\begin{array}{l}\text { Material is to be dispositioned as } \\
\text { Rad luaste }\end{array}$ & $\frac{6 Q_{\mu w} O_{5 / 3 / 96}}{\text { Project Manager }}$ \\
\hline
\end{tabular}

\section{Comments:}

Sample No 960650047 . Drplicate 960650048 


\section{Raschig Ring Decontamination Sign-Off Sheet}

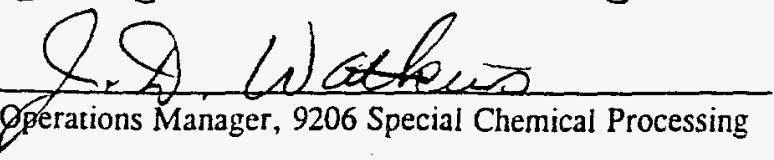

Drum Designation: Crelant IC

Basket Designation: 2073/2074/2076

Date of Transfer: $4-19-96$

\begin{tabular}{|c|c|c|}
\hline Action & Activity & \\
\hline 1 & High-pressure detergent wash. & Signature \\
\hline 2 & High-pressure hot water rinse & $\begin{array}{l}\text { Signature } \\
\text { DPSD Supetvisor }\end{array}$ \\
\hline 3 & One hour nitric acid soak. & Signature \\
\hline 4 & High-pressure detergent wash. & $\frac{\text { Y0 }}{\text { DPS vedurgervisor }}-19-96$ \\
\hline 5 & High-pressure hot water rinse. & DO 4.19 .96 \\
\hline
\end{tabular}

\begin{tabular}{|c|c|c|}
\hline 6 & $\begin{array}{l}\text { Sample results indicate that rings fre ll are nor free } \\
\text { of RCRA contaminaion. }\end{array}$ & 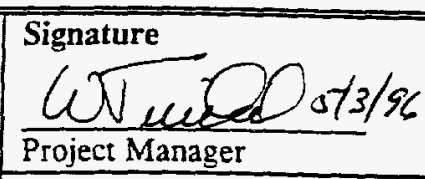 \\
\hline 7 & $\begin{array}{l}\text { Material is to be dispositioned as } \\
\text { Rad Casle }\end{array}$ & $\frac{\text { Quverod } 5 / 3 / 96}{\text { Project Manager }}$ \\
\hline
\end{tabular}

\section{Comments:}

Sample No. 960650049 Win $4 / 30 / 96$ 


\section{Raschig Ring Decontamination Sign-Off Sheet}



Drum Designation: Coelant $2 C$ Serial Number:

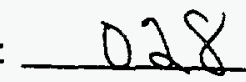

Basket Designation: $207512078 / 2077^{888} 4-20.96$

Date of Transfer: $4-19-96$

\begin{tabular}{|c|c|c|}
\hline Action & Activity & \\
\hline 1 & High-pressure detergent wash. & 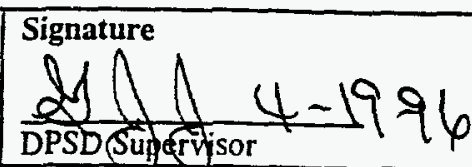 \\
\hline 2 & High-pressure hot water rinse & $\frac{40}{\text { DPSD Supervisor }} 4=19$ \\
\hline 3 & One hour nitric acid soak. & $\frac{M}{\text { DPSD Supervisor }} 4-19-96$ \\
\hline 4 & High-pressure detergent wash. & $\frac{5 \lambda}{\text { DPSD Sypetyisor }} 4.9 .96$ \\
\hline 5 & High-pressure hot water rinse. & Signature $14-19 \cdot 96$ \\
\hline
\end{tabular}

\begin{tabular}{|c|l|l||}
\hline 6 & $\begin{array}{l}\text { Sample results indicate that rings bre free } \\
\text { of RCRA contaminaion. }\end{array}$ & $\begin{array}{l}\text { Signature } \\
\frac{1}{\text { Project Manager }}\end{array}$ \\
\hline 7 & $\begin{array}{l}\text { Material is to be dispositioned as } \\
\text { Red Claste }\end{array}$ & $\begin{array}{l}\text { Signature } \\
\text { Project Manager }\end{array}$ \\
\hline
\end{tabular}

\section{Comments:}

Sampe No. 960650050 Wriod 4/30/x 


\section{Raschig Ring Decontamination Sign-Off Sheet

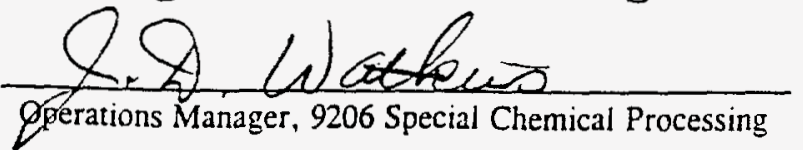
Drum Designation:
Solout $2 E$
Serial Number
Basket Designation: 2029/2072/2080
Date of Transfer: $4 \sim 19 \sim 96$

129

\begin{tabular}{|c|c|c|}
\hline Action & Activity & \\
\hline 1 & High-pressure detergent wash. & Signature \\
\hline 2 & High-pressure hot water rinse & Signature 4196 \\
\hline 3 & One hour nitric acid soak. & Signature \\
\hline$\overline{4}$ & High-pressure detergent wash. & $\frac{T H D}{\text { Signature }} 4-20-96$ \\
\hline 5 & High-pressure hot water rinse. & Signature 4 - \\
\hline
\end{tabular}

\begin{tabular}{|c|c|c|}
\hline 6 & $\begin{array}{l}\text { Sample results indicate that rings are / are not free } \\
\text { of RCRA contaminaion. }\end{array}$ & $\frac{6 \sqrt{\text { Sucad }} 5 / 3 / 96}{\text { Project Manager }}$ \\
\hline 7 & Material is to be dispositioned as & $\frac{\text { W V eus } 5 / 3 / x}{\text { Project Manager }}$ \\
\hline
\end{tabular}

\section{Comments:}

Sample No. 960660028 Lrimon 4/30/46 


\section{Raschig Ring Decontamination Sign-Off Sheet}



Drum Designation: Colant $2 E$ Serial Number:

Basket Designation: $2076 / 2074$

Date of Transfer: $4-19-96$

\begin{tabular}{|c|c|c|}
\hline Action & Activity & \\
\hline 1 & High-pressure detergent wash. & $\frac{\text { IHD }}{\text { DPSD Supervisor }} 4-20-96$ \\
\hline 2 & High-pressure hot water rinse & $\frac{7}{\text { DPSD Supervisor }} 4-20-96$ \\
\hline 3 & One hour nitric acid soak. & $9044-20-96$ \\
\hline 4 & High-pressure detergent wash. & $9444-20-96$ \\
\hline 5 & High-pressure hot water rinse. & Signature 4.20 .94 \\
\hline
\end{tabular}

\begin{tabular}{|c|c|c|}
\hline$\overline{\overline{6}}$ & $\begin{array}{l}\text { Sample results indicate that rings (are) / are not free } \\
\text { of RCRA contaminaion. }\end{array}$ & $\frac{6 \sqrt{\min }}{\text { Project Manager }} 5 / 3 / 96$ \\
\hline 7 & $\begin{array}{l}\text { Material is to be dispositioned as } \\
\text { Red Waste }\end{array}$ & 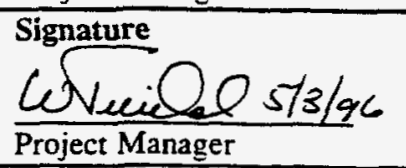 \\
\hline
\end{tabular}

\section{Comments:}

Sample vo. 960660029,960660030 (D.p.) Wrised $4 / 30 / 96$ 


\section{Raschig Ring Decontamination Sign-Off Sheet}

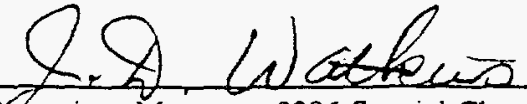

Gperations Manager, 9206 Special Chemical Processing

Drum Designation: $0,25 \mathrm{C}$ Serial Number:

031

Basket Designation: $2076 / 2074 / 2080$

Date of Transfer: 4 - $20-96$

\begin{tabular}{|c|c|c|}
\hline Action & Activity & \\
\hline 1 & High-pressure detergent wash. & $\oiiint_{\text {DPSD|Sugervisor }}^{\text {Signature }} 4.20-95$ \\
\hline 2 & High-pressure hot water rinse & $\$ 994 \quad 4.20 .96$ \\
\hline 3 & One hour nitric acid soak. & $9994-20.94$ \\
\hline 4 & High-pressure detergent wash. & $\frac{\text { fignature } 4.20=0}{\text { DPSD Supervisor }}$ \\
\hline 5 & High-pressure hot water rinse. & 29 Signature $4-20-9$ \\
\hline
\end{tabular}

\begin{tabular}{|c|l|l|}
\hline 6 & $\begin{array}{l}\text { Sample results indicate that rings are } 7 \text { are not free } \\
\text { of RCRA contaminaion. }\end{array}$ & $\begin{array}{l}\text { Signature } \\
\frac{6 \text { Nenos } 5 / 3 / 96}{\text { Project Manager }}\end{array}$ \\
\hline 7 & $\begin{array}{l}\text { Material is to be dispositioned as } \\
\text { Rad Wa L Le }\end{array}$ & $\begin{array}{l}\text { Signature } \\
\text { Project Manager }\end{array}$ \\
\hline
\end{tabular}

\section{Comments:}

Sample No.960660031 WVuise 4/30/94 


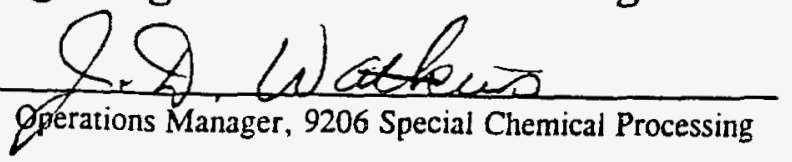

Drum Designation: Qil $5 \mathrm{C}$

Basket Designation: 2012/2029

Date of Transfer: $4-20-96$

\begin{tabular}{|c|c|c|}
\hline Action & Activity & \\
\hline 1 & High-pressure detergent wash. & Dignature \\
\hline 2 & High-pressure hot water rinse & $90 \int_{\text {DPSO Supervisor }}^{\text {Signature }}$ \\
\hline 3 & One hour nitric acid soak. & Signature 4.26 \\
\hline$\overline{4}$ & High-pressure detergent wash. & 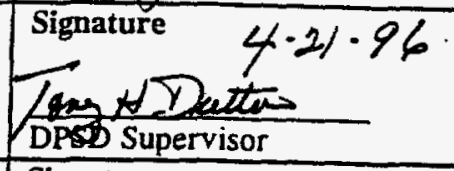 \\
\hline 5 & High-pressure hot water rinse. & 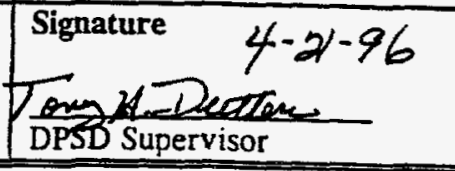 \\
\hline
\end{tabular}

\begin{tabular}{|c|l|l|}
\hline 6 & $\begin{array}{l}\text { Sample results indicate that rings are } \\
\text { of RCRA contaminaion. }\end{array}$ & $\begin{array}{l}\text { Signature } \\
\text { Raderial is to be dispositioned as } \\
\text { Raste }\end{array}$ \\
\hline 7 & $\begin{array}{l}\text { Signature } \\
\text { Project Manager }\end{array}$ \\
\hline
\end{tabular}

\section{Comments:}

Sample No. 960660032 wVmso $4 / 30 / 96$



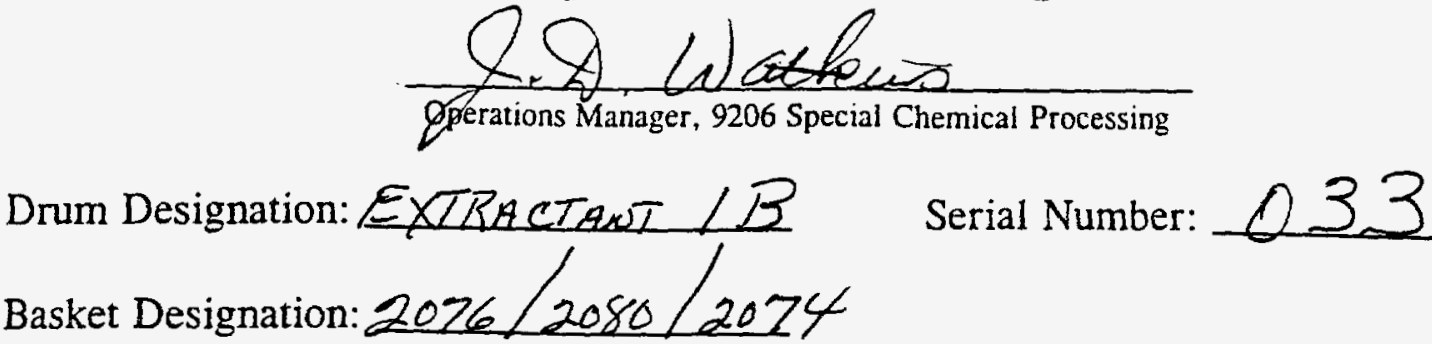

Date of Transfer: $4-21-96$

\begin{tabular}{|c|c|c|}
\hline Action & Activity & \\
\hline 1 & High-pressure detergent wash. & $\begin{array}{l}\text { Signature } 4 \cdot 21-96 \\
\text { Fons } 1 \text { Dettens } \\
\text { DPSB Supervisor }\end{array}$ \\
\hline 2 & High-pressure hot water rinse & \begin{tabular}{|l} 
Signature $4-21-96$ \\
Tong \& Dutteres \\
DPSO Supervisor \\
\end{tabular} \\
\hline$\overline{3}$ & One hour nitric acid soak. & 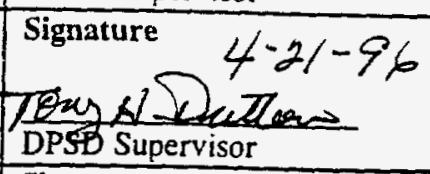 \\
\hline$\overline{4}$ & High-pressure detergent wash. & $\begin{array}{l}\text { Signature } 4 \cdot 2196 \\
\text { TEm } 12 \text { atten } \\
\text { DPSD Supervisor }\end{array}$ \\
\hline 5 & High-pressure hot water rinse. & 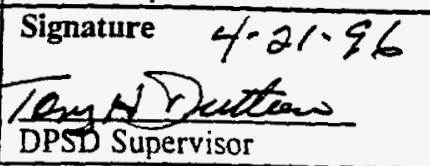 \\
\hline
\end{tabular}

\begin{tabular}{|c|l|l|}
\hline 6 & $\begin{array}{l}\text { Sample results indicate that rings are } \\
\text { of RCRA contaminaion. }\end{array}$ & $\begin{array}{l}\text { Signature } \\
\text { Project Manager }\end{array}$ \\
\hline 7 & $\begin{array}{l}\text { Material is to be dispositioned as } \\
\text { Rod Claste }\end{array}$ & Signature \\
\hline
\end{tabular}

\section{Comments:}

Sample No 960660033 wriado 4/30/96 


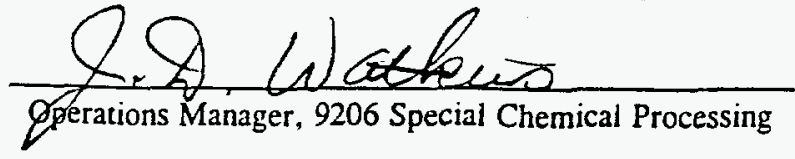

Drum Designation:EXTRACTEN / 3

Serial Number:

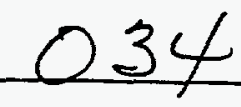

Basket Designation:2075/2072/2078

Date of Transfer: $4-21-96$

\begin{tabular}{|c|c|c|}
\hline Action & Activity & \\
\hline 1 & High-pressure detergent wash. & 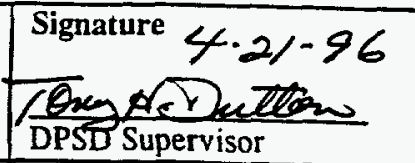 \\
\hline 2 & High-pressure hot water rinse & 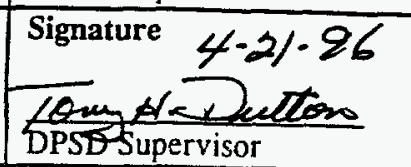 \\
\hline 3 & One hour nitric acid soak. & \begin{tabular}{|l|} 
Signature $4-21-96$ \\
10 yatervisor \\
DPSOSuper \\
\end{tabular} \\
\hline 4 & High-pressure detergent wash. & 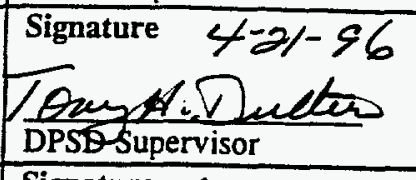 \\
\hline 5 & High-pressure hot water rinse. & $\begin{array}{l}\text { Signature } 4-21-96 \\
\text { Towy di: Duttow } \\
\text { DPSO Supervisor }\end{array}$ \\
\hline
\end{tabular}

\begin{tabular}{|c|l|l|}
\hline 6 & $\begin{array}{l}\text { Sample results indicate that rings are / are free } \\
\text { of RCRA contaminaion. }\end{array}$ & $\begin{array}{l}\text { Signature } \\
\frac{6 \sqrt{\text { PeuS }} 5 / 3 / 96}{\text { Project Manager }}\end{array}$ \\
\hline 7 & $\begin{array}{l}\text { Material is to be dispositioned as } \\
\text { Rad Waste }\end{array}$ & $\begin{array}{l}\text { Signature } \\
\text { Project Manager }\end{array}$ \\
\hline
\end{tabular}

\section{Comments:}

Sample No 960660034 coving $4 / 3 \% / 96$ 


\section{Raschig Ring Decontamination Sign-Off Sheet}

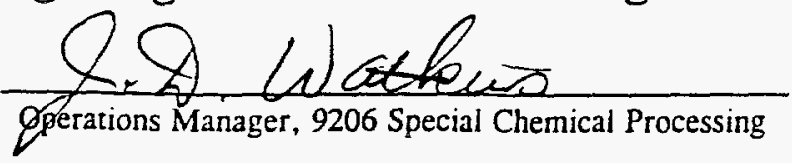

Drum Designation: 0 i SA Serial Number:

Basket Designation:2029/2077/2074

Date of Transfer: $4-2 /-96$

\begin{tabular}{|c|c|c|}
\hline Action & Activity & \\
\hline 1 & High-pressure detergent wash. & $\frac{Y}{\text { DPSD }} 4-21-96$ \\
\hline 2 & High-pressure hot water rinse & $\frac{4}{\text { DPSD Bupgervisor }} 4-21+96$ \\
\hline 3 & One hour nitric acid soak. & 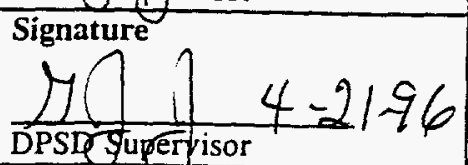 \\
\hline 4 & High-pressure detergent wash. & $\frac{-1]}{\text { DPSD Supervisor }}+21.96$ \\
\hline 5 & High-pressure hot water rinse. & DPSD Stupervisor $4-21-96$ \\
\hline
\end{tabular}

\begin{tabular}{|c|c|c|}
\hline$\overline{\overline{6}}$ & $\begin{array}{l}\text { Sample results indicate that rings are } \\
\text { of RCRA contaminaion. }\end{array}$ & $\frac{6 \sqrt{\text { signature }}}{\text { Project Manager }}$ \\
\hline 7 & Material is to be dispositioned as & 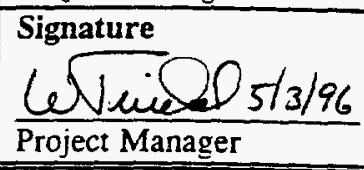 \\
\hline
\end{tabular}

\section{Comments:}

Sample No. 960660035 , Duplicale 960660036 WVirdo 4/30/a6 


\section{Raschig Ring Decontamination Sign-Off Sheet}

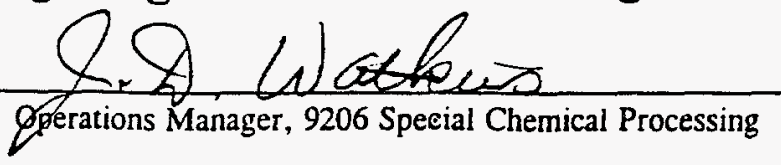
Drum Designation
lil $5 \mathrm{~A}$
Serial Number:
036

Basket Designation: $2078 / 2073 / 2080$

Date of Transfer: $4 \sim 21.96$

\begin{tabular}{|c|c|c|}
\hline Action & Activity & \\
\hline 1 & High-pressure detergent wash. & $\frac{y}{\text { DPSDSSuRetvisor }} 4-21-96$ \\
\hline 2 & High-pressure hot water rinse &  \\
\hline 3 & One hour nitric acid soak. & 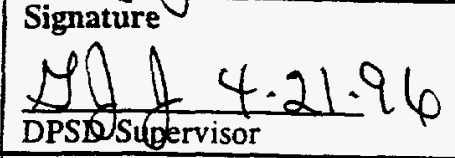 \\
\hline 4 & High-pressure detergent wash. & DPA 4.21 .96 \\
\hline 5 & High-pressure hot water rinse. & $\int_{\text {DPSB Sucetvisor }}^{\text {Signature }} 4.216$ \\
\hline
\end{tabular}

\begin{tabular}{|c|c|c|}
\hline 6 & $\begin{array}{l}\text { Sample results indicate that rings are / are free } \\
\text { of RCRA contaminaion. }\end{array}$ & $\frac{\omega \sqrt{\text { Signature }}}{\text { Project Manager }} 5 / 3 / 96$ \\
\hline 7 & $\begin{array}{l}\text { Material is to be dispositioned as } \\
\text { Rad Waste }\end{array}$ & $\frac{W \sqrt{\text { niv } 20} 5 / 3 / x}{\text { Project Manager }}$ \\
\hline
\end{tabular}

\begin{tabular}{|ll|}
\hline Comments: & \\
\hline Sample No 960660037 & WVinch $4 / 30 / 96$ \\
\hline & \\
\hline
\end{tabular}




\section{Raschig Ring Decontamination Sign-Off Sheet}

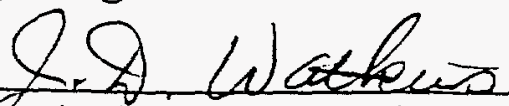

Eperations Manager, 9206 Special Chemical Processing

Drum Designation: Qil $5 \mathrm{~B}$ Serial Number: 037

Basket Designation: $2072 / 2075 / 2078$

Date of Transfer:

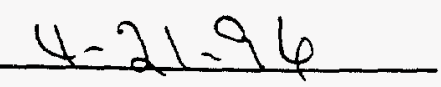

\begin{tabular}{|c|c|c|}
\hline Action & Activity & \\
\hline 1 & High-pressure detergent wash. & DPSDGudervisor 4126 \\
\hline 2 & High-pressure hot water rinse & $\frac{21}{\text { DPSDD Soretvisor }}+21.96$ \\
\hline$\overline{3}$ & One hour nitric acid soak. & $\left.\frac{M A}{D P S D} 4-2\right\rfloor-96$ \\
\hline 4 & High-pressure detergent wash. & 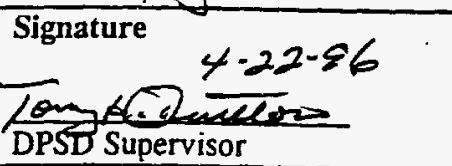 \\
\hline 5 & High-pressure hot water rinse. & 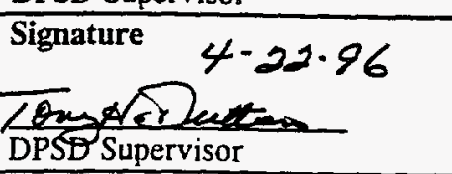 \\
\hline
\end{tabular}

\begin{tabular}{|c|l|l|}
\hline 6 & $\begin{array}{l}\text { Sample results indicate that rings are / are not free } \\
\text { of RCRA contaminaion. }\end{array}$ & $\begin{array}{l}\text { Signature } \\
\frac{1}{\text { Project Manager }} \mathrm{s} / 3 / 96\end{array}$ \\
\hline 7 & $\begin{array}{l}\text { Material is to be dispositioned as } \\
\text { Rad Waste }\end{array}$ & $\begin{array}{l}\text { Signature } \\
\text { Project Manager }\end{array}$ \\
\hline
\end{tabular}

\begin{tabular}{|l|}
\hline Comments: \\
\hline Sample No. 9606600038 coster \\
\hline \\
\hline
\end{tabular}




\section{Raschig Ring Decontamination Sign-Off Sheet}

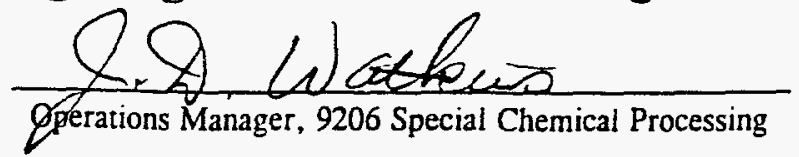

Drum Designation: $\mathbb{Q}^{\prime} \leq \mathrm{B}$ Serial Number:

Basket Designation: $2074 / 2077 / 2079$

Date of Transfer: 4.21 .96

\begin{tabular}{|c|c|c|}
\hline Action & Activity & \\
\hline 1 & High-pressure detergent wash. & 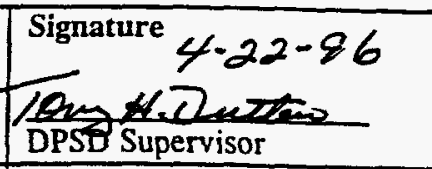 \\
\hline 2 & High-pressure hot water rinse & \begin{tabular}{|l|} 
Signature $4 \cdot 22-96$ \\
Tongor Cuttow \\
DPSD Supervisor
\end{tabular} \\
\hline 3 & One hour nitric acid soak. & 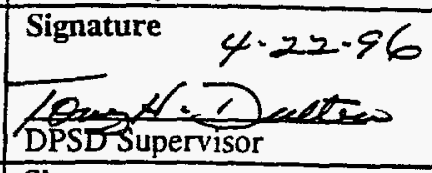 \\
\hline 4 & High-pressure detergent wash. & 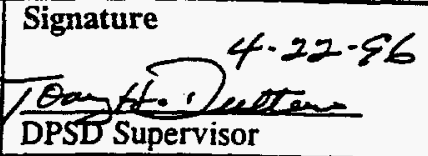 \\
\hline 5 & High-pressure hot water rinse. & \begin{tabular}{|l} 
Signature \\
Toxy \\
DPSOSupervisor \\
\end{tabular} \\
\hline
\end{tabular}

\begin{tabular}{|c|c|c|}
\hline 6 & $\begin{array}{l}\text { Sample results indicate that rings are } / \text { are free } \\
\text { of RCRA contaminaion. }\end{array}$ & $\frac{6 \sqrt{\text { vid }}}{\text { Project Manager }}$ \\
\hline 7 & $\begin{array}{l}\text { Material is to be dispositioned as } \\
\text { Rad Waste }\end{array}$ & Signature \\
\hline
\end{tabular}

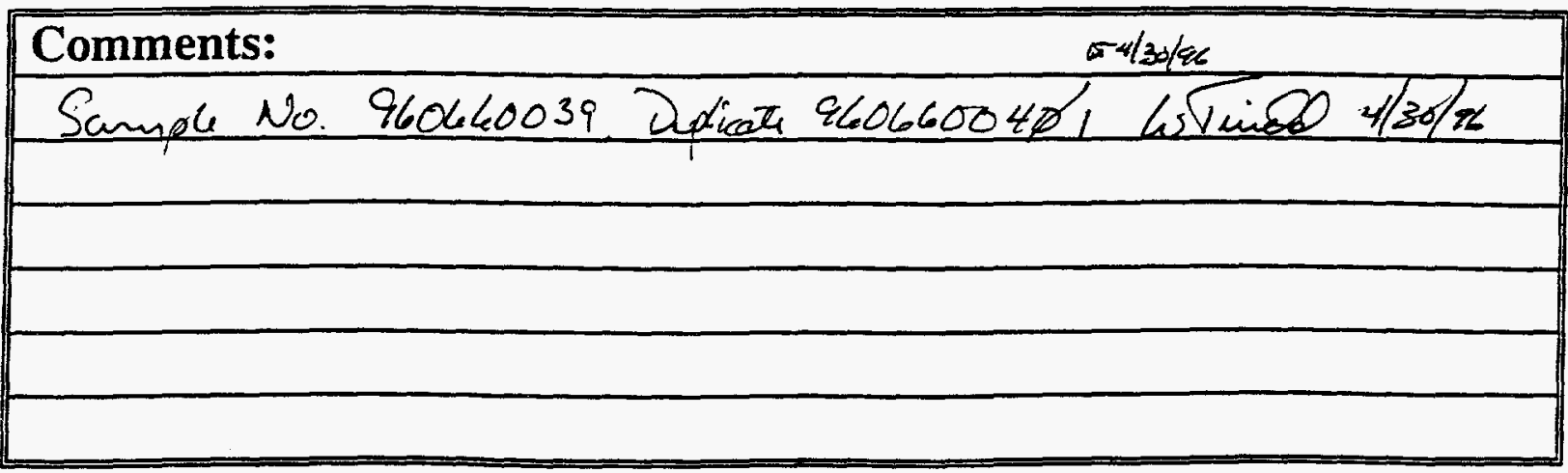




\section{Raschig Ring Decontamination Sign-Off Sheet}

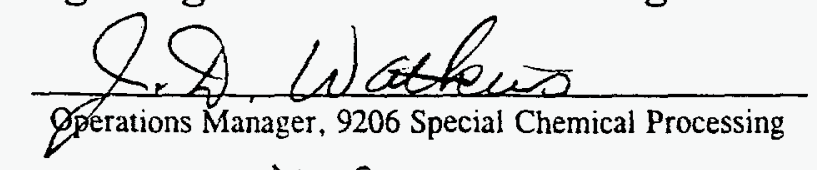

Drum Designation: Raschig Ring Samples Serial Number:



Basket Designation: 2074

Date of Transfer: $4-22-96$

\begin{tabular}{|c|c|c|}
\hline Action & Activity & \\
\hline 1 & High-pressure detergent wash. & 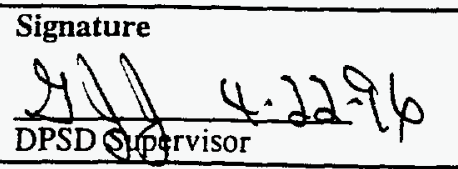 \\
\hline 2 & High-pressure hot water rinse & $\frac{211}{\text { DPSD Superfyisor }} 4229$ \\
\hline 3 & One hour nitric acid soak. & $\sum_{\text {DPSD Sukervisor }}^{\text {Signature }} 4.229$ \\
\hline 4 & High-pressure detergent wash. & $\frac{y}{\text { DPSD Sup }} 4.227 x$ \\
\hline 5 & High-pressure hot water rinse. & DPSDSlipectisor \\
\hline
\end{tabular}

\begin{tabular}{|c|l|l|}
\hline 6 & $\begin{array}{l}\text { Sample results indicate that rings free } \\
\text { of RCRA contaminaion. }\end{array}$ & $\begin{array}{l}\text { Signature } \\
\frac{1}{\text { Project Manager }}\end{array}$ \\
\hline 7 & $\begin{array}{l}\text { Material is to be dispositioned as } \\
\text { Rad Waste }\end{array}$ & $\frac{1}{\text { Signature }}$ \\
\hline
\end{tabular}

\section{Comments:}

Sample No. 960660042 GVinges 4/30/96 


\section{Decontamination Sign-Off-Sheet}
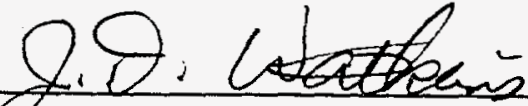

Operarions Manager, 9206 Special Chemical Processing

Equipment Description: Lorth RCRARDiKe serial Number: $\frac{040}{\text { Asphat }}$

\begin{tabular}{|c|c|c|}
\hline Action & Activity & \\
\hline 1 & High-pressure detergent wash & DPSD Supervisor $4-23-9$ \\
\hline 2 & High-pressure hot water rinse & $490 \bigcirc-23-9$ \\
\hline 3 & Second high-pressure hot water rinse & DPSQ Supervisor \\
\hline
\end{tabular}

6 Sample results indicate that equipment(is $\chi$ is free of RCRA contamination.

7 Material is to be dispositioned as

Signature

w00 Vuions/3/96 Project Manager

Signature

Unrestricted use

\section{Comments: \\ Sample No 960660043 LVkios $4 / 30 / 26$}




\section{Decontamination Sign-Off-Sheet}

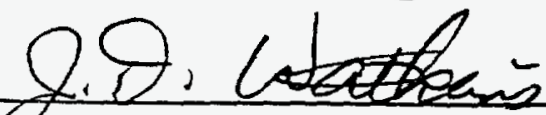

Operations Manager, 9206 Special Chernical Processing

Equipment Description: $\frac{I}{4} \cdot 48$ PAV POD AREA Serial Number: 041

\begin{tabular}{|c|c|c|}
\hline Action & Activity & \\
\hline 1 & High-pressure detergent wash $5,2-96$ & Signature \\
\hline 2 & High-pressure hot water rinse $5-2-96$ & Signature \\
\hline 3 & Second high-pressure hot water rinse $5-2-96$ & 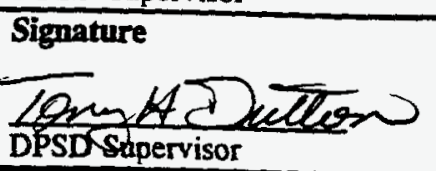 \\
\hline
\end{tabular}

\begin{tabular}{|c|c|c|}
\hline 6 & $\begin{array}{l}\text { Sample results indicate that equipment is / is not } \\
\text { free of RCRA contamination. }\end{array}$ & $\begin{array}{l}\text { Signature } \\
N / / 4 \text { ct } 5 / 3 / 9 c \\
\frac{\text { Project Manager }}{2}\end{array}$ \\
\hline 7 & Material is to be dispositioned as & $\begin{array}{l}\text { Signature } \\
N / A \text { WT } 5 / 3 / 96 \\
\text { Project Manager }\end{array}$ \\
\hline
\end{tabular}

\begin{tabular}{|l|}
\hline Comments: \\
\hline \\
\hline \\
\hline \\
\hline
\end{tabular}




\section{Raschig Ring Decontamination Tracking Logsheet}

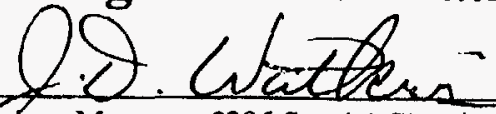

Operations Manager, 9206 Special Chemical Processing

\begin{tabular}{|c|c|c|c|c|c|c|c|c|c|c|}
\hline $\begin{array}{l}\text { Original } \\
\text { Drum }\end{array}$ & $\begin{array}{l}\text { Basket } \\
\text { Number }\end{array}$ & $\begin{array}{l}\text { Basket } \\
\text { Number }\end{array}$ & $\begin{array}{l}\text { Basket } \\
\text { Number }\end{array}$ & $\begin{array}{l}\text { Basket } \\
\text { Number }\end{array}$ & $\begin{array}{l}\text { Basket } \\
\text { Number }\end{array}$ & $\begin{array}{l}\text { Basket } \\
\text { Number }\end{array}$ & $\begin{array}{l}\text { Basket } \\
\text { Number }\end{array}$ & $\begin{array}{l}\text { Basket } \\
\text { Number }\end{array}$ & $\begin{array}{l}\text { Basket } \\
\text { Number }\end{array}$ & $\begin{array}{c}\text { Rinse } \\
\text { (Initial when } \\
\text { complete) }\end{array}$ \\
\hline $\begin{array}{c}\text { COOLANT } \\
2 \mathrm{~B} \\
\end{array}$ & $\begin{array}{c}1 0 \longdiv { 3 } \\
2073\end{array}$ & $\begin{array}{r}1023 \\
2074\end{array}$ & $\begin{array}{r}1 2 \longdiv { 3 } \\
2076\end{array}$ & $\begin{array}{r}12 \sqrt{3} \\
2072\end{array}$ & $\begin{array}{c}1 2 \longdiv { 3 } \\
2078 \\
\end{array}$ & $\begin{array}{c}1(2 \longdiv { 3 } \\
2875\end{array}$ & $\begin{array}{l}1053 \\
2080 \\
\end{array}$ & $\begin{array}{l}1(2) 3 \\
2079\end{array}$ & 123 & N/A \\
\hline $\begin{array}{c}\text { COOLANT } \\
2 \mathrm{C}\end{array}$ & $\begin{array}{r}123 \\
2073 \\
\end{array}$ & $\begin{array}{r}123 \\
2074\end{array}$ & $\begin{array}{l}1(2) 3 \\
2076\end{array}$ & $\begin{array}{r}1(2) 3 \\
2025\end{array}$ & $\begin{array}{r}1 2 \longdiv { 3 } \\
2028\end{array}$ & 23 & 123 & 123 & 123 & $N / A$ \\
\hline $\begin{array}{c}\text { COOLANT } \\
2 \mathrm{E}\end{array}$ & $\begin{array}{r}1123 \\
2079 \\
\end{array}$ & $\begin{array}{r}1(2) 3 \\
2072\end{array}$ & $\begin{array}{l}128 \\
2080\end{array}$ & $\begin{array}{r}1313 \\
2077\end{array}$ & $\begin{array}{r}153 \\
2026\end{array}$ & $\begin{array}{l}1(2) 3 \\
2074\end{array}$ & 123 & 123 & 123 & $N / A$ \\
\hline $\begin{array}{l}\text { EXTRACTANT } \\
\text { 1B } 4^{-4 x}\end{array}$ & $\begin{array}{r}1(2) 3 \\
2076 \\
\end{array}$ & $\begin{array}{r}1(2) 3 \\
2080 \\
\end{array}$ & $\begin{array}{c}123 \\
2074 \\
\end{array}$ & $\begin{array}{r}103 \\
2075\end{array}$ & $\begin{array}{r}103 \\
2072\end{array}$ & $\begin{array}{l}183 \\
078\end{array}$ & 123 & 123 & 123 & N/A \\
\hline $\begin{array}{c}\text { OIL } \\
5 \mathrm{~A}\end{array}$ & $\begin{array}{l}\text { 1023 } \\
2029\end{array}$ & $\begin{array}{l}1023 \\
2072\end{array}$ & $\begin{array}{l}1123 \\
2024\end{array}$ & $\begin{array}{c}1123 \\
2078\end{array}$ & & 2080 & 123 & 123 & 123 & $N / A$ \\
\hline $\begin{array}{c}\text { OIL } \\
\text { 5B }\end{array}$ & $\begin{array}{r}1123 \\
2072 \\
\end{array}$ & $\begin{array}{r}1123 \\
2078 \\
\end{array}$ & 2075 & $\begin{array}{r}11) 23 \\
2079\end{array}$ & & $\begin{array}{l}(1) 3 \\
2077\end{array}$ & 123 & 123 & 123 & $N / A$ \\
\hline $\begin{array}{l}\text { OIL } \\
5 \mathrm{C}\end{array}$ & $\begin{array}{l}1123 \\
2076\end{array}$ & $\begin{array}{l}\text { (1) } 23 \\
2074\end{array}$ & $\begin{array}{l}1123 \\
2080\end{array}$ & (1) 23 & (1) 23 & (1) 3 & 123 & 23 & 123 & $N / A$ \\
\hline $\begin{array}{l}\text { DISTILLATE } \\
6 \mathrm{~A}\end{array}$ & $\begin{array}{r}023 \\
2072 \\
\end{array}$ & $\begin{array}{l}1123 \\
2080 \\
\end{array}$ & $\begin{array}{l}0.23 \\
2078\end{array}$ & $\begin{array}{l}1123 \\
2079\end{array}$ & $\begin{array}{l}1123 \\
2075\end{array}$ & $\begin{array}{l}1023 \\
2076\end{array}$ & 123 & 123 & 123 & $N / A$ \\
\hline $\begin{array}{l}\text { DISTILLATE } \\
\text { 6x 6B } \\
\text { Extremely Dirty }\end{array}$ & $\begin{array}{l}1123 \\
2073\end{array}$ & $\begin{array}{l}213 \\
2074\end{array}$ & $\begin{array}{l}1123 \\
2077\end{array}$ & $\begin{array}{l}2123 \\
20 \% 2\end{array}$ & $\begin{array}{l}\text { 1) } 23 \\
2078\end{array}$ & $\begin{array}{l}123 \\
7080\end{array}$ & $\begin{array}{l}023 \\
2-2 y\end{array}$ & $\begin{array}{l}1 \longdiv { 2 } 3 \\
2073\end{array}$ & 123 & $N / A$ \\
\hline $\begin{array}{c}\text { FREON } \\
4 \mathrm{~A}\end{array}$ & $\begin{array}{l}(1)^{23} \\
02072\end{array}$ & $\begin{array}{l}1123 \\
2079\end{array}$ & $\begin{array}{l}1233 \\
2078\end{array}$ & $\begin{array}{l}7123 \\
2076\end{array}$ & $\begin{array}{l}1123 \\
2080\end{array}$ & $\begin{array}{l}4 \sqrt{23} \\
2075\end{array}$ & 123 & 123 & 123 & $N / A$ \\
\hline $\begin{array}{l}\text { FREON } \\
\text { 4B }\end{array}$ & 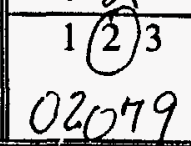 & $\begin{array}{r}1 2 \longdiv { 3 } \\
02072 \\
\end{array}$ & $\begin{array}{c}1 2 \longdiv { 3 } \\
02048\end{array}$ & $\begin{array}{c}1(2) 3 \\
02077\end{array}$ & $\begin{array}{c}12 / 3 \\
02074\end{array}$ & $\begin{array}{c}123 \\
02073\end{array}$ & 123 & 123 & 123 & $N / A$ \\
\hline
\end{tabular}

Q.',

Circle one to indicate condition of the rings: $1=$ Very Dirty

2 = Somewhat Dirty

3 = Fairly Clean

$5-C-5=5 B-5 B-D i r y$. 
Date:

From:

Dept:

Tel No:
16-May-1996 09:33am EDT Charles $H$ Fritts FRITTSCH 2637

576-7052 / PAGER 873-7407

TO: COLLINSET

CC: DUNCANAL

FRITTSCH

subject: Re: Closure costs File: READ

025042

Tom,

A separate account was set for closure activities associated with the UTU which Bill should be able to supply you, but no special account was set up for the E-Wing Closure. Since the E-Wing closure didn't involve the amount of work and time that UTU did, we didn't keep track of the amount of time it took to search for the needed information.

Items that were deconed will be stored within an EUO Radioactive Material storage Area (RMA) according to plant procedures. These items will remain in these areas until a percent $U 235$ and a total $U$ can be determined for these items. Energy system Waste Management organization (ESWMO) cannot receive and store these items within their areas without this analysis. (This includes the drums packed with the rings that were deconed.)

The wash/rinse will be disposed of by ESWMO at the West End Treatment Facility (WETF), the drums that are F-Listed will be stored by ESWMO at CWSA (Dolly Parton Tents), and the other drums (characteristic) will be stored by ESWMO at OD-8. AIl of these waste are presently being stored at AA-13 (drums), located at Building 9206, and AA-19 (Tuff-Tanks), located at Building 9818, while undergoing waste certification. All of these waste will be moved to the designated permitted facility before the ninety-day time ends which is July 30, 1996. By this date all waste generated by the closure activities will be properly stored in a ESWMO permitted facility.

Chuck Fritts 


\section{MATERIAL SAFETY DATA SHEET}

PRODUCT MAME: R I P P $\mathrm{B}$ R I

Pege 1 of 2

BRCTION I

Manufacturere Hane: The Hotgy Corporation, Detergert Division Addrege: 2621 7 th.Avanue South Phone Number: 712-362-7797 City. State Z1p: Estherville. Iowa S1334

FOR MEDICAT EMrRGHCY : Rocky Hountein Foian Control Centar $303-623-5716$.

FOR CHEMICAL EHEROEHCY: Sp 111, Leak, Fira, Expogure or Aceident CBI1 CHEMTREC - 1-800-424-9300. Outside U.S. call 202-483-7616

Peraon Roeponaible for Preparation: Dean $F$. Femholz Revieion Date : September 15, 1994 Superbedes : June 1, 1993

D.D. Fit. Shipping Clabe: Cleantng Compound, Clage 55

$\begin{array}{clc}\text { Health Hazarda } & \text { :Health } & {[2]} \\ 0>4 & \text { :Flammablilty } & {[0]} \\ \text { Kone- Extrome } & \text { :Regetivity } & {[0]}\end{array}$

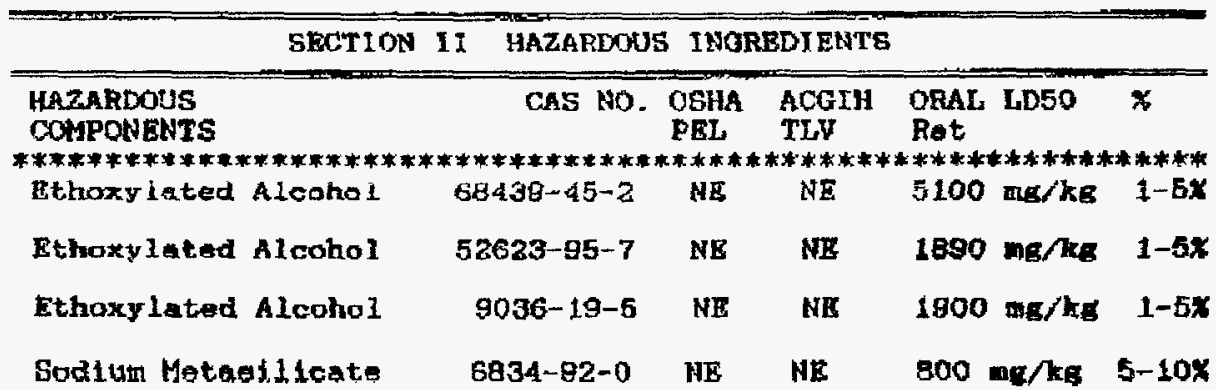

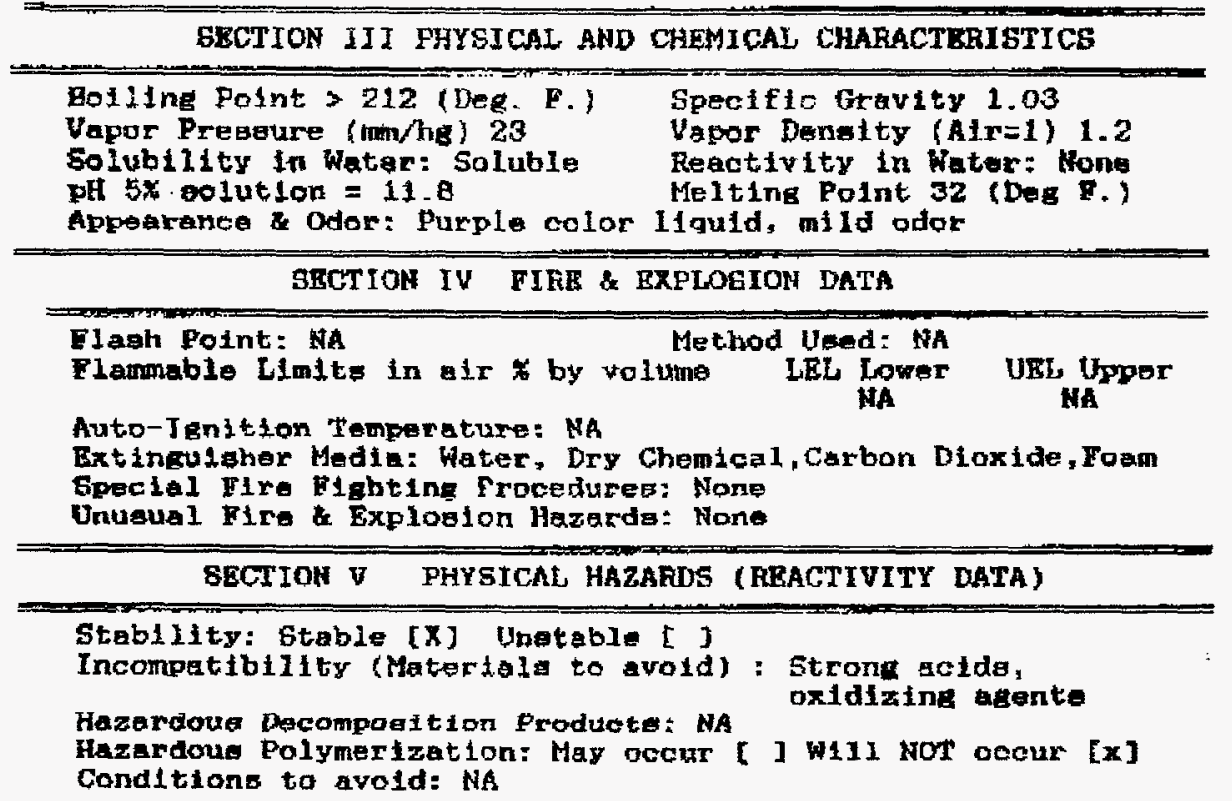






$$
\text { NA = Not epplicable } N A=\text { None eatablighed }
$$

While the information and recomendations at forth herein are belleved to be necurate as of the date hereof, THE HOTSY

CORPORATION, DETERGENT DIVIBION, MAKES NO WARRANTY WITH RISSPECT THERETO AND DIGCLAIHS ALL LIABILITY FROM RELIANCB THEREDH. 


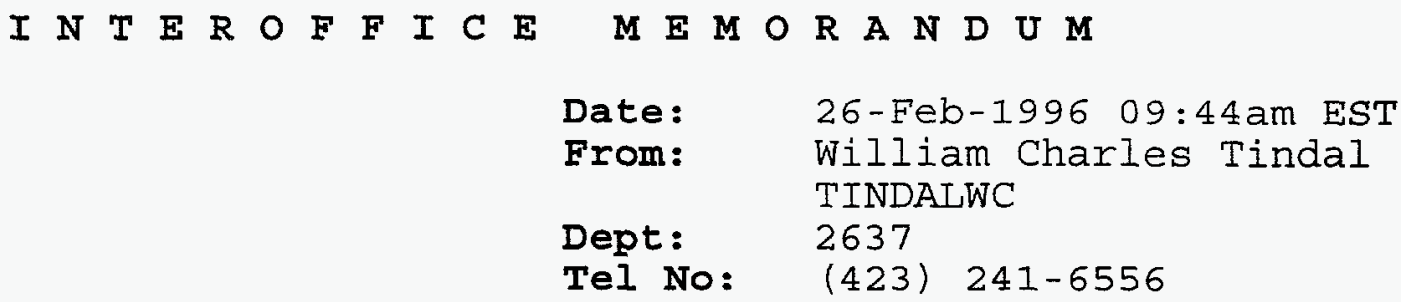

s you requested earlier in this project, the following is an inventory of the aste and equipment in the Uranium Treatment Unit:

aste Extractant

aste Coolant

aste Distillate

aste Freon

aste Oil

wo 300 gal. Poly Tanks

wo Agitators

wo Stuctural Supports

leven Drums of Raschig Rings

he Mixing Drum

pproximately 10 layers of PVC diking material

ill Tindal

$$
\begin{aligned}
& 26 \mathrm{~kg} \\
& 23 \mathrm{~kg} \\
& 45 \mathrm{~kg} \\
& 36 \mathrm{~kg} \\
& 82 \mathrm{~kg}
\end{aligned}
$$

\section{ill Tindal}




\section{Distribution:}

E. T. Collins

C. H. Fritts

N. C. Jessen

A. K. Lee/DOE-OSTI, 9731, MS-8175 (2)

J. E. Powell

S. E. Rathke

R. K. Roosa

L. M. Sparks, DOE-ORO

W. C. Tindal

File-EMD-RC

Y-12 Central Files 